\title{
Microvascular effects of aldosterone and salt in health, obesity and hypertension
}

Citation for published version (APA):

Schütten, M. T. J. (2019). Microvascular effects of aldosterone and salt in health, obesity and hypertension: consequences for blood pressure and insulin sensitivity. [Doctoral Thesis, Maastricht University]. Ipskamp Printing BV. https://doi.org/10.26481/dis.20190620ms

Document status and date:

Published: 01/01/2019

DOI:

10.26481/dis.20190620ms

Document Version:

Publisher's PDF, also known as Version of record

\section{Please check the document version of this publication:}

- A submitted manuscript is the version of the article upon submission and before peer-review. There can be important differences between the submitted version and the official published version of record. People interested in the research are advised to contact the author for the final version of the publication, or visit the DOI to the publisher's website.

- The final author version and the galley proof are versions of the publication after peer review.

- The final published version features the final layout of the paper including the volume, issue and page numbers.

Link to publication

\footnotetext{
General rights rights.

- You may freely distribute the URL identifying the publication in the public portal. please follow below link for the End User Agreement:

www.umlib.nl/taverne-license

Take down policy

If you believe that this document breaches copyright please contact us at:

repository@maastrichtuniversity.nl

providing details and we will investigate your claim.
}

Copyright and moral rights for the publications made accessible in the public portal are retained by the authors and/or other copyright owners and it is a condition of accessing publications that users recognise and abide by the legal requirements associated with these

- Users may download and print one copy of any publication from the public portal for the purpose of private study or research.

- You may not further distribute the material or use it for any profit-making activity or commercial gain

If the publication is distributed under the terms of Article $25 \mathrm{fa}$ of the Dutch Copyright Act, indicated by the "Taverne" license above, 


\section{MICROVASCULAR EFFECTS OF ALDOSTERONE AND}

\section{SALT IN HEALTH, OBESITY AND HYPERTENSION}

CONSEQUENCES FOR BLOOD PRESSURE AND INSULIN SENSITIVITY 
(c) Monica Schütten, Maastricht 2019, All rights reserved

Cover design: Jean Scheijen | vierdrie.nl Layout: Tiny Wouters Lenssen

Production: IPSKAMP Printing, Enschede

ISBN: 978-94-028-1539-9 


\section{MICROVASCULAR EFFECTS OF ALDOSTERONE AND SALT IN HEALTH, OBESITY AND HYPERTENSION \\ CONSEQUENCES FOR BLOOD PRESSURE AND INSULIN SENSITIVITY}

\section{PROEFSCHRIFT}

Ter verkrijging van de graad van doctor aan de Universiteit Maastricht, op gezag van de Rector Magnificus, Prof.dr. Rianne M. Letschert volgens het besluit van het College van Decanen, in het openbaar te verdedigen

op

donderdag 20 juni 2019 om 14.00 uur

door

Monica Theresia Jozefina Schütten 


\section{Promotores}

Prof. dr. C.D.A. Stehouwer

Prof. dr. P.W. de Leeuw

\section{Copromotor}

Dr. A.J.H.M. Houben

\section{Beoordelingscommissie}

Prof. dr. N.C. Schaper (voorzitter)

Prof. dr. E.E. Blaak

Prof. dr. H. ten Cate

Dr. J. Deinum (Radboud UMC Nijmegen)

Dr. E. Eringa (Amsterdam UMC)

The research presented in this thesis was conducted at the CARIM School for Cardiovascular Diseases, Maastricht University, Maastricht, the Netherlands.

Financial support by the Dutch Heart Foundation and Maastricht University for the publication of this thesis is gratefully acknowledged. 


\section{Contents}

Chapter 1 General introduction and outline of the thesis 7

Chapter 2 The link between adipose tissue renin-angiotensinaldosterone system (RAAS) signaling and obesity-associated hypertension

Chapter 3 Aldosterone-renin ratio and side-selective renal perfusion in essential hypertension

Chapter 4 Aldosterone is not associated with metabolic and microvascular insulin sensitivity in lean and abdominally obese men

Chapter 5 Differential effects of high and low salt intake on muscle microvascular recruitment, blood pressure and insulin-mediated whole-body glucose disposal in lean and abdominally obese individuals

Chapter 6 Associations of aldosterone with blood pressure, metabolic and microvascular insulin sensitivity in lean and abdominally obese individuals: interactions with salt intake and obesity

Chapter 7 Summary and general discussion

Chapter $8 \quad$ Nederlandse samenvatting

Chapter 9 Valorisation addendum

Chapter 10 Dankwoord

Chapter 11 Curriculum vitae 



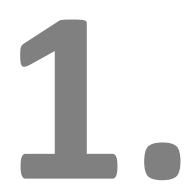

GENERAL INTRODUCTION AND

OUTLINE OF THE THESIS 



\section{Introduction}

Cardiovascular disease, including coronary artery disease, heart failure and stroke, is a leading cause of death worldwide ${ }^{1}$. Obesity, especially that of the visceral type, increases risk of cardiovascular disease and premature death ${ }^{2,3}$, and this is partly mediated by its association with insulin resistance, raised blood pressure, and lipid spectrum abnormalities ${ }^{1}$, commonly referred to as the metabolic syndrome ${ }^{3}$. Moreover, obese individuals are more susceptible to the hypertensive effects of salt ${ }^{4}$. 'Salt-sensitivity' interacts with insulin sensitivity', and is linked to increased premature mortality, even independent of blood pressure status ${ }^{6}$. Obesity is also a risk factor for microvascular dysfunction ${ }^{7}$, which impairs insulin-mediated glucose disposal by reducing the supply of insulin and glucose to target tissues, raises blood pressure by increasing peripheral vascular resistance ${ }^{7-11}$, and links insulin resistance and saltsensitivity of blood pressure in both the normotensive and hypertensive range ${ }^{12}$. The exact pathophysiological mechanisms of obesity-associated microvascular dysfunction and consequently, insulin resistance and hypertension, whether or not salt-sensitive, have been insufficiently elucidated. In the light of the current obesity epidemic and its devastating consequences, more insight is of utmost importance, which may contribute to early intervention or even prevention.

\section{Microvascular function as a link between insulin resistance and (salt-sensitive) hypertension}

\section{Insulin resistance}

Insulin resistance is classically defined as the inability of insulin to stimulate GLUT4 translocation to the cell surface through activation of $I R(S) / P I 3-K$ signalling pathways, resulting in impaired insulin-mediated glucose uptake in insulin-responsive tissues ${ }^{10}$. Under normal circumstances, insulin also increases NO synthesis in vascular endothelial cells via comparable $\mathrm{PI} 3-\mathrm{K}$ cascades, which causes relaxation of precapillary terminal arterioles and redirects blood flow from non-nutritive to nutritive microvessels, socalled capillary recruitment. These microvascular actions of insulin promote its own delivery and that of glucose to skeletal muscle cells, thereby increasing insulinmediated glucose disposal ${ }^{8,10,11,13,14}$. This is illustrated by direct correlations of basal capillary density in skeletal muscle, as well as post-occlusive and insulin-stimulated capillary recruitment in skin and skeletal muscle, with insulin sensitivity in lean, obese and hypertensive individuals ${ }^{15-21}$. Insulin is also capable of inducing vasoconstriction by 
increasing ET-1 production via stimulation of MAPK-ERK1/2 signalling pathways, but in health, the balance between insulin-mediated vasodilatation and-vasoconstriction is either neutral or shifted towards vasodilatation. In insulin-resistant states such as obesity, however, insulin-induced vasodilatation is impaired and vasoconstriction predominates, which results in reduced insulin-mediated glucose uptake $e^{8,10,13,14}$. Indeed, in obese, compared to lean Zuckers rats and humans, insulin-mediated capillary recruitment in both skin and skeletal muscle is hampered, which is paralleled by decreased insulin-induced glucose uptake ${ }^{15,17,22,23}$. In summary, a reduced ability of insulin to dilate and recruit microvessels impairs its metabolic actions and is partially responsible for the insulin-resistant state commonly observed in obesity.

\section{Hypertension}

Blood pressure is the resultant of cardiac output and total peripheral vascular resistance ${ }^{24}$. It logically follows that the increase of one factor, without compensation by the other, can lead to hypertension. In most individuals with essential hypertension, peripheral resistance is raised ${ }^{24}$, likely due to defects at the microvascular level ${ }^{25}$. Microvascular abnormalities observed in hypertension include remodelling of small arteries and arterioles, which is characterized by increased wall-to-lumen ratio and thought to displace the initial vasoconstriction occurring in response to increased pressure $^{26}$, and rarefaction, i.e. a reduction in the number or length of arterioles and capillaries $^{27}$. The rarefaction that is often demonstrated in clinical and experimental hypertension can be either functional or structural. Functional rarefaction is defined as a reduction in the number of perfused vessels, resulting from enhanced activity of, or increased sensitivity to vasoconstrictor stimuli, and/or a decrease in either vasodilatory mediators or response, including loss of NO-induced vasodilatation ${ }^{26,27}$. The latter also involves an impaired vasodilator response to insulin ${ }^{28}$, which might participate in basal NO release ${ }^{29}$. Prolonged vessel closure or nonperfusion can ultimately lead to the disappearance of microvessels, termed structural rarefaction ${ }^{30}$. Over the years, evidence has accumulated that the aforementioned microvascular abnormalities, including hampered insulin-mediated microvascular dilatation, may also occur before and contribute to elevations in blood pressure ${ }^{8,10,31,32}$. In normotensive individuals, both retinal arteriolar narrowing and venular widening were independently associated with an increased risk of hypertension ${ }^{33}$, and in untreated hypertensive individuals, low muscle capillary density predicted a rise in mean arterial pressure during 20 years of follow-up ${ }^{34}$. Moreover, a decreased vasodilator response to insulin was observed before the development of hypertension in young, spontaneously hypertensive rats ${ }^{35}$. 
Both animal and human studies suggest that impairment of (insulin-mediated) microvascular function may underlie obesity-related hypertension as well: in obese Zucker rats, reduced skeletal muscle microvascular density preceded increases in blood pressure $^{36}$, whereas acetylcholine-mediated vasodilatation and post-occlusive skin capillary recruitment were diminished in obese, compared to lean women and correlated negatively with blood pressure in both the normotensive and the hypertensive range ${ }^{17}$. In addition, skin insulin-mediated microvascular dilatation was inversely associated with peripheral resistance in overweight individuals ${ }^{37}$. Another characteristic of obesity-related hypertension closely related to microvascular functioning is salt-sensitivity, which is defined as the tendency of blood pressure to rise following an increase in salt intake, and to fall in response to a reduction in salt intake ${ }^{38}$. A salt-induced elevation of blood pressure is eventually the result of increased peripheral resistance ${ }^{39,40}$, which suggests that the defect must be sought in the microvasculature. This could involve either failure of microvessels to dilate in response to increased cardiac output, or detrimental microvascular effects of salt ${ }^{39,41}$. Indeed, Dahl salt-sensitive rats displayed a moderate elevation in peripheral resistance when fed a normal salt diet, which was exacerbated after high salt feeding ${ }^{42}$. In humans, forearm vascular resistance was increased, and conjunctival capillary density decreased, in salt-sensitive, compared to salt-resistant individuals ${ }^{43}$; and salt-sensitivity of blood pressure was inversely associated with skin post-occlusive capillary recruitment and endothelium-dependent vasodilatation in normotensive and hypertensive individuals ${ }^{12}$. Moreover, salt loading has been shown to impede skin postocclusive reactive hyperaemia in healthy women ${ }^{44}$, whereas reducing salt intake increased basal and maximal skin capillary density, and bulbar conjunctival arteriolar density in essential hypertensive individuals ${ }^{45,46}$. Interestingly, salt-sensitivity is often paralleled by insulin resistance as well, which has been demonstrated in both animal and human studies ${ }^{4,12,47,48}$, but the pathophysiological basis of this association is incompletely understood. Impaired insulin-mediated microvascular dilatation might link salt-sensitivity and insulin resistance, as it affects both peripheral vascular resistance and whole-body insulin-induced glucose disposal. This is illustrated by findings of diminished skeletal muscle insulin-stimulated microvascular recruitment and glucose uptake in lean rats fed a high salt diet ${ }^{49}$. To our knowledge, however, this has not been investigated in humans. It has long been advocated that hypertension can only develop if renal sodium excretion is deficient ${ }^{50,51}$. Although this paradigm has been questioned, and the exact sequence of events leading to sustained increases in blood pressure is still elusive ${ }^{52}$, there is no doubt that the kidney has an important share in the aetiology of hypertension, and this includes a role for the renal microvasculature. Renal microvascular dysfunction, manifesting itself as renal vasoconstriction and reduced 
renal perfusion, reduces sodium excretion by increasing tubular sodium reabsorption, and can already be observed before the onset of hypertension ${ }^{53,54}$. In addition, due to the ischaemia and resulting fibrosis overall renal functioning may be impaired ${ }^{55}$. The decrease in kidney perfusion that can be observed before or in parallel with increases in blood pressure does not necessarily occur to a similar extent for both kidneys, as we and others have observed left-right differences in renal blood flow in individuals with essential hypertension or in whom imaging of the kidneys was required ${ }^{56-58}$. The mechanisms underlying this asymmetry in kidney perfusion remain to be elucidated.

To conclude, microvascular dysfunction, i.e. rarefaction, impaired vasodilatation and enhanced vasoconstriction, may be involved in the pathogenesis of (salt-sensitive) hypertension by affecting both the regulation of vascular tone and circulating volume. Whether impaired insulin-mediated microvascular dilatation links (salt-sensitivity of) blood pressure and insulin-induced whole-body glucose disposal in humans, and how left-right differences in renal blood flow arise, are questions that require further research.

\section{The renin-angiotensin-aldosterone system as a cause of microvascular and metabolic insulin resistance}

The renin-angiotensin-aldosterone system (RAAS) plays an essential role in blood pressure regulation, and overactivity of this hormonal system, as often observed in obesity, not only induces hypertension, but also affects microvascular functioning and insulin sensitivity ${ }^{10,14,59,60}$.

\section{Angiotensin II}

Angiotensin II (AngII) has been regarded as the major effector peptide of the RAAS, as it is a potent vasoconstrictor, induces salt retention, and stimulates adrenal aldosterone release, via angiotensin II receptor type 1 (AT1R) dependent mechanisms. These actions are opposed by the angiotensin II type 2 receptor ${ }^{60}$.

\section{Microvascular function}

Increased activity of the RAAS generates elevated levels of Ang II, which impairs microvascular function through AT1R stimulation in both animals and humans. Impaired endothelium-dependent relaxation of precapillary arterioles was found to be an early feature of Angll-induced hypertension in mice ${ }^{61}$, while skeletal muscle microvascular density was reduced in spontaneously hypertensive rats (SHR) compared 
to Wistar-Kyoto rats, and this was completely prevented by the angiotensin receptor blocker (ARB) olmesartan and the ACE-inhibitor enalapril ${ }^{62}$. Moreover, Angll administration using the microdialysis technique resulted in decreased skeletal muscle blood flow in both lean and obese individuals ${ }^{63}$. Accordingly, treatment with the ARB irbesartan improved coronary flow reserve as a measure of coronary microvascular function in hypertensive men independent of blood pressure ${ }^{64}$, and both telmisartan and candesartan lowered blood pressure and recovered endothelium-dependent vasodilatation in individuals with the metabolic syndrome ${ }^{65}$. Chronic Angll stimulation promotes microvascular endothelial dysfunction in several ways. Angll itself and Angllinduced oxidative stress reduce NO availability, thus impairing endothelium-dependent vasodilatation. In addition, Angll increases the release and action of endothelin 1 (ET-1) and endothelium-derived vasoconstrictor prostanoids, thereby favouring vasoconstriction ${ }^{14}$. Angll was also found to reduce adiponectin and increase leptin levels and to stimulate the synthesis of pro-inflammatory cytokines, which is accompanied by further impairment of endothelial function ${ }^{66,67}$.

\section{Insulin sensitivity}

Long-term treatment of hypertensive patients with either ACE-inhibitors or ARBs is associated with a substantially reduced risk of developing type 2 diabetes ${ }^{68}$, suggesting that decreasing Angll levels or its interaction with the AT1R has beneficial effects on insulin sensitivity. Data obtained from obese Zucker rats and individuals with impaired glucose metabolism support this concept ${ }^{69-71}$.

Angll is thought to impair metabolic insulin sensitivity by intervening in the IR(S)/PI3-K insulin signalling cascade ${ }^{72-74}$. This can occur directly, but also via exacerbation of adipocyte dysfunction, which is a common phenomenon in obesity, with increased release of free fatty acids (FFA), MCP-1, IL-6, TNF $\alpha$, and ROS, and reduced adiponectin production, all individually contributing to the development of insulin resistance ${ }^{72,75,76}$. Angll also interferes with insulin-mediated NO synthesis via comparable molecular mechanisms ${ }^{14,73}$, as illustrated by our previous findings of impaired insulin-induced skin capillary recruitment following systemic Angll administration in healthy volunteers ${ }^{77}$ and increased functional capillary density during hyperinsulinaemia after acute AT1R blockade in mildly hypertensive individuals ${ }^{78}$. Similarly, skeletal muscle microvascular recruitment improved after short-term candesartan treatment ${ }^{79}$. Surprisingly, in these experiments ${ }^{77-79}$, insulin-mediated whole-body glucose disposal either changed in the opposite direction, or not at all. This may be related to the duration of treatment and/or concomitant AT2R stimulation in skeletal muscle cells, which improves glucose uptake, at least in healthy rats ${ }^{80}$. In obese Zucker rats, however, upregulation of the 
AT1R has been observed ${ }^{81}$, suggesting that Angll signalling via the AT1R predominates in obesity, with detrimental consequences for microvascular and metabolic insulin sensitivity. Indeed, ACE-inhibition with quinapril improved both insulin-induced skeletal muscle capillary recruitment and insulin-mediated glucose disposal in obese, diabetic Zucker rats ${ }^{82}$.

\section{Aldosterone}

Aldosterone is a steroid hormone that is mainly produced in the adrenal zona glomerulosa, and its levels are tightly regulated by Angll, extracellular $\left[\mathrm{K}^{+}\right]$and $\mathrm{ACTH}^{83}$. So-called mineralocorticoid-releasing factors, derived from adipose tissue, have been suggested to increase adrenal aldosterone synthesis as well ${ }^{84-86}$, and adipocytes appeared to be capable of aldosterone production themselves ${ }^{87}$, which may at least partially explain the increase in circulating aldosterone observed in obese individuals ${ }^{88}$. It should be noted, however, that previous studies demonstrating elevated aldosterone levels in obesity, and a decrease following weight loss, have been performed in severely to morbidly ${ }^{88-91}$, and hypertensive overweight and obese individuals ${ }^{92-94}$. Whether moderately obese, otherwise healthy, individuals also display increased aldosterone levels, has not been investigated.

Classically, aldosterone affects blood pressure by inducing sodium retention in the distal tubule of the kidney through interaction with the mineralocorticoid receptor $(\mathrm{MR})^{83}$. During recent years, it has become increasingly clear that aldosterone exerts actions beyond its role in sodium homeostasis that may also affect microvascular and metabolic insulin sensitivity, which is suggested by the presence of mineralocorticoid receptors in non-epithelial cells, including vascular endothelial and smooth muscle cells, and skeletal myocytes ${ }^{95,96}$. Importantly, 11 beta-hydroxysteroid dehydrogenase activity has been encountered in vascular tissue as well, preventing local mineralocorticoid receptor activation by glucocorticoids ${ }^{83}$.

\section{(Micro)vascular function}

Chronically increased aldosterone levels have been associated with (microvascular) endothelial dysfunction: aldosterone administration during 2 weeks impaired endothelium-dependent vasodilatation of the cerebral circulation in mice ${ }^{97}$, while preventing interaction of aldosterone with its receptor via either MR blockade or endothelium-specific MR deletion enhanced acetylcholine-induced relaxation of aortic rings in obese mice ${ }^{98}$. In patients with primary aldosteronism and thus an endogenous continuous exposure to elevated aldosterone levels, endothelial function (assessed by means of flow-mediated dilatation (FMD)) was more impaired than in essential 
hypertensive patients, although blood pressure levels where comparable in both groups $^{99,100}$. Treatment with either mineralocorticoid receptor antagonists or surgery attenuated endothelial dysfunction after 3 months $^{99,100}$. Beneficial effects of mineralocorticoid receptor antagonists on endothelial function have also been observed in patients with heart failure after 1 month $^{101}$, and in patients with resistant hypertension after 6 months ${ }^{102}$. In obese, non-diabetic persons and older adults, however, a 4 to 6 week treatment with mineralocorticoid receptor antagonists did not affect FMD ${ }^{103,104}$, which suggests that endothelial dysfunction is less pronounced in the latter study populations, although in the older adults, individual improvements in FMD in response to the selective MR antagonist eplerenone were associated with higher total body fat ${ }^{104}$. Vasoconstrictor responses to aldosterone have also been specifically observed at the microvascular level, i.e. in hamster cheek pouch arterioles ${ }^{105}$, rat coronary arterioles $^{106}$, and in the rabbit and human renal microcirculation ${ }^{107,108}$, whereas spironolactone, a non-selective mineralocorticoid receptor antagonist, improved endothelium-dependent vasodilatation of coronary arterioles in obese Zucker rats $^{109}$, and, in addition to standard medical therapy, enhanced coronary microvascular function in patients with type 2 diabetes ${ }^{110}$. Aldosterone is thought to impair (microvascular) endothelial function in ways similar to angiotensin II, i.e. by increasing vascular oxidative stress ${ }^{111-113}$ and thus interfering with NO availability ${ }^{114-117}$, by participating in endothelial ET-1 release ${ }^{118}$, and by increasing pre-adipocyte expression of TNF $\alpha$, and reducing expression of adiponectin ${ }^{119}$, which collectively promote a procontractile state. Moreover, adverse microvascular actions of aldosterone may be related to an aldosterone-salt imbalance, as elevated aldosterone levels resulting from salt restriction are not necessarily harmful ${ }^{114}$, while the combination of high circulating aldosterone with increased salt intake has been associated with severe cardiovascular and renal damage, mostly in preclinical experiments ${ }^{120-123}$. This has been ascribed to salt-induced additional oxidative stress, which may activate the mineralocorticoid receptor, also in the absence of increased aldosterone levels ${ }^{114,124,125}$. The interaction between aldosterone and salt can be particularly relevant in obesity, as illustrated by insufficient suppression of aldosterone levels following a salt load in young obese, compared to lean individuals ${ }^{126}$. Thus, currently available evidence suggests that chronically increased aldosterone levels impair microvascular function, although human studies on microvascular effects of aldosterone in obesity are still eagerly awaited.

\section{Insulin sensitivity}

It has been recognized for many years that the risk of developing diabetes is increased in patients with primary hyperaldosteronism, which has initially been ascribed to 
impaired insulin secretion due to aldosterone-induced hypokalaemia ${ }^{127}$. Because correction of hypokalaemia only partially restored glucose tolerance ${ }^{127}$, other mechanisms have been considered as well, including direct effects of aldosterone on insulin sensitivity, as suggested by a number of clinical studies ${ }^{128-131}$. Impairment of insulin sensitivity after aldosterone administration has indeed been demonstrated in animal experiments ${ }^{132,133}$. In humans, aldosterone levels have also been associated with insulin resistance in study populations other than patients with primary hyperaldosteronism, including normotensive lean and overweight individuals ${ }^{89,134}$, patients with essential hypertension and heart failure ${ }^{135}$, and normotensive and hypertensive Caucasians $^{136}$ and African-Americans ${ }^{137,138}$. In addition, plasma aldosterone has been shown to predict the development of insulin resistance in a nondiabetic subset of the general population ${ }^{139}$. Correspondingly, blockade of the mineralocorticoid receptor resulted in improved insulin sensitivity in animal models of RAAS overactivity and diabetes with nonalcoholic fatty liver disease ${ }^{140,141}$, and in patients with primary hyperaldosteronism ${ }^{128}$ and chronic heart failure ${ }^{142}$. Insulin sensitivity was seemingly unaffected in obese normotensive individuals following treatment with spironolactone ${ }^{103}$ and in hypertensive patients and older individuals with metabolic syndrome using eplerenone ${ }^{143}$, but this may be related to the relatively short duration of treatment.

Aldosterone has been proposed to affect insulin sensitivity directly by interfering with insulin signaling pathways ${ }^{132,140,144-146}$, or indirectly by increasing synthesis of reactive oxygen species and pro-inflammatory cytokines and reducing adiponectin expression in adipose tissue ${ }^{147}$. In addition, aldosterone has been demonstrated to suppress insulin signalling in vascular smooth muscle cells ${ }^{148}$, while low-dose spironolactone improved aortic dilatation in response to insulin in female C57BL6 mice fed a Western diet ${ }^{149}$, suggesting that aldosterone might also impair insulin's metabolic actions via effects on microvascular insulin sensitivity. However, this remains to be confirmed in humans. 


\section{Outline of the thesis}

Dysregulation of the renin-angiotensin-aldosterone system (RAAS), including increased circulating angiotensin $\mathrm{II}$ and aldosterone, is being regarded as a major cause of obesity-related hypertension and insulin resistance, which may be partially explained by its effects on microvascular function. While the role of angiotensin in this respect has been studied extensively, less is known about the microvascular actions of aldosterone and its consequences for blood pressure and insulin sensitivity.

Salt-sensitivity of blood pressure is a feature of obesity-related hypertension that is closely related to microvascular functioning and insulin resistance, and has been related to increased aldosterone levels ${ }^{150}$. Whether salt specifically impairs skeletal muscle microvascular insulin signalling in humans, and thereby induces (salt-sensitive) hypertension and insulin resistance has not been studied yet. It is also not clear how the balance between salt and aldosterone affects microvascular and metabolic insulin sensitivity. In this thesis, we focus on aldosterone and salt, and their effects on renal and skeletal muscle microvascular function in hypertension and obesity.

Dysfunctional adipose tissue has been suggested to be a source of Angll and aldosterone in obesity. In addition, it may contribute to decreased metabolism of Angll to angiotensin 1-7 (Ang1-7) ${ }^{151}$, which has also been implicated in the pathogenesis of obesity-associated hypertension ${ }^{152}$, although data in humans are limited. In Chapter $\mathbf{2}$, we discuss experimental and clinical evidence on the role of the adipose tissue in RAAS dysregulation, and the mechanisms linking increased levels of Angll and aldosterone, and decreased levels of Ang1-7, to elevated blood pressure.

Increased circulating aldosterone has been associated with reduced kidney perfusion in normotensive and hypertensive individuals ${ }^{153,154}$. As mentioned earlier, we and others have observed left-right differences in renal blood flow in hypertensive individuals ${ }^{56,57}$, but the aetiology of this asymmetry is unknown. We aimed to investigate in Chapter 3 whether aldosterone differentially affects left and right kidney perfusion, by studying the association of aldosterone and the aldosterone-renin ratio (in an attempt to adjust for the vasoactive effects of angiotensin II) with side-selective renal blood flow in therapy-resistant essential hypertensive individuals.

Predominantly preclinical data suggest interference of aldosterone with microvascular insulin signalling, which may contribute to the development of obesity-associated insulin resistance and hypertension, but this remains to be confirmed in humans. Weight loss is a highly effective interventional strategy to prevent these obesity-related 
complications, given its association with improved (insulin-mediated) microvascular function and whole-body insulin-stimulated glucose disposal, and reduced blood pressure ${ }^{23,155-157}$, and this might be partially explained by reductions in circulating aldosterone. Previous investigations, however, have been performed in severely to morbidly obese, and hypertensive overweight and obese individuals ${ }^{88-91,93,94}$. In Chapter 4, we compared serum aldosterone concentration between lean and moderately abdominally obese, otherwise healthy men, compared to lean men, and studied its association with insulin-mediated muscle microvascular function, insulin-induced glucose disposal and blood pressure. In addition, we studied whether improvements of microvascular and metabolic insulin sensitivity following weight loss are mediated by reductions in circulating aldosterone in the abdominally obese men.

An exaggerated hypertensive response to salt is often accompanied by insulin resistance in obese individuals ${ }^{4,5,47}$. Microvascular dysfunction, and microvascular insulin signalling in particular, may influence the adverse effects of salt on blood pressure and insulin sensitivity ${ }^{12,49}$, but data in humans are scarce. Thus, in Chapter $\mathbf{5}$, we assessed the consequences of a low and high salt diet for blood pressure, insulinstimulated whole-body glucose disposal and insulin-mediated microvascular function in lean and abdominally obese individuals.

Salt intake may be a determinant of aldosterone's effect on blood pressure, but current data are inconsistent ${ }^{158,159}$. Whether potential consequences of aldosterone for metabolic and microvascular insulin sensitivity are affected by salt and body weight is unknown. Therefore, we studied the associations of aldosterone, and its interaction with sodium excretion, with blood pressure, insulin-stimulated whole-body glucose disposal and insulin-mediated microvascular function in lean and abdominally obese individuals with a broad range of salt intake in Chapter 6 . 


\section{References}

1. Chiolero A, Kaufman JS. Metabolic mediators of body-mass index and cardiovascular risk. Lancet. 2014;383:2042

2. Van Gaal LF, Mertens IL, De Block CE. Mechanisms linking obesity with cardiovascular disease. Nature. 2006;444:875-880

3. Despres JP, Lemieux I, Bergeron J, Pibarot P, Mathieu P, Larose E, et al. Abdominal obesity and the metabolic syndrome: Contribution to global cardiometabolic risk. Arterioscler Thromb Vasc Biol. 2008;28:1039-1049

4. Rocchini AP, Key J, Bondie D, Chico R, Moorehead C, Katch V, et al. The effect of weight loss on the sensitivity of blood pressure to sodium in obese adolescents. N Engl J Med. 1989;321:580-585

5. Lastra G, Dhuper S, Johnson MS, Sowers JR. Salt, aldosterone, and insulin resistance: Impact on the cardiovascular system. Nature reviews. Cardiology. 2010;7:577-584

6. Weinberger MH, Fineberg NS, Fineberg SE, Weinberger M. Salt sensitivity, pulse pressure, and death in normal and hypertensive humans. Hypertension. 2001;37:429-432

7. Sorop O, Olver TD, van de Wouw J, Heinonen I, van Duin RW, Duncker DJ, et al. The microcirculation: A key player in obesity-associated cardiovascular disease. Cardiovasc Res. 2017;113:1035-1045

8. De Boer MP, Meijer RI, Wijnstok NJ, Jonk AM, Houben AJ, Stehouwer CD, et al. Microvascular dysfunction: A potential mechanism in the pathogenesis of obesity-associated insulin resistance and hypertension. Microcirculation. 2012;19:5-18

9. de Boer MP, Serne EH, Smulders YM, Eringa EC, Meijer RI. Phenotyping the microcirculation with contrast-enhanced ultrasound. Hypertension. 2012;60:e38; author reply e39

10. Jonk AM, Houben AJ, de Jongh RT, Serne EH, Schaper NC, Stehouwer CD. Microvascular dysfunction in obesity: A potential mechanism in the pathogenesis of obesity-associated insulin resistance and hypertension. Physiology. 2007;22:252-260

11. Kusters $\mathrm{YH}$, Barrett EJ. Muscle microvasculature's structural and functional specializations facilitate muscle metabolism. Am J Physiol Endocrinol Metab. 2016;310:E379-387

12. de Jongh RT, Serne EH, IJzerman R, Stehouwer CD. Microvascular function: A potential link between salt sensitivity, insulin resistance and hypertension. J Hypertens. 2007;25:1887-1893

13. Ko SH, Cao W, Liu Z. Hypertension management and microvascular insulin resistance in diabetes. Curr Hypertens Rep. 2010;12:243-251

14. Muniyappa R, Yavuz S. Metabolic actions of angiotensin ii and insulin: A microvascular endothelial balancing act. Mol Cell Endocrinol. 2013;378:59-69

15. Clerk LH, Vincent MA, Jahn LA, Liu Z, Lindner JR, Barrett EJ. Obesity blunts insulin-mediated microvascular recruitment in human forearm muscle. Diabetes. 2006;55:1436-1442

16. de Jongh RT, Clark AD, RG IJ, Serne EH, de Vries G, Stehouwer CD. Physiological hyperinsulinaemia increases intramuscular microvascular reactive hyperaemia and vasomotion in healthy volunteers. Diabetologia. 2004;47:978-986

17. de Jongh RT, Serne EH, RG IJ, de Vries G, Stehouwer CD. Impaired microvascular function in obesity: Implications for obesity-associated microangiopathy, hypertension, and insulin resistance. Circulation. 2004;109:2529-2535

18. Lillioja S, Young AA, Culter CL, Ivy JL, Abbott WG, Zawadzki JK, et al. Skeletal muscle capillary density and fiber type are possible determinants of in vivo insulin resistance in man. J Clin Invest. 1987;80: 415-424

19. Serne EH, RG IJ, Gans RO, Nijveldt R, De Vries G, Evertz R, et al. Direct evidence for insulin-induced capillary recruitment in skin of healthy subjects during physiological hyperinsulinemia. Diabetes. 2002;51:1515-1522

20. Serne EH, Stehouwer CD, ter Maaten JC, ter Wee PM, Rauwerda JA, Donker AJ, et al. Microvascular function relates to insulin sensitivity and blood pressure in normal subjects. Circulation. 1999;99: 896-902 
21. Serne EH, Gans RO, ter Maaten JC, ter Wee PM, Donker AJ, Stehouwer CD. Capillary recruitment is impaired in essential hypertension and relates to insulin's metabolic and vascular actions. Cardiovasc Res. 2001;49:161-168

22. Wallis MG, Wheatley CM, Rattigan S, Barrett EJ, Clark AD, Clark MG. Insulin-mediated hemodynamic changes are impaired in muscle of zucker obese rats. Diabetes. 2002;51:3492-3498

23. Kusters YH, Schalkwijk CG, Houben AJ, Kooi ME, Lindeboom L, Op 't Roodt J, et al. Independent tissue contributors to obesity-associated insulin resistance. JCI Insight. 2017;2

24. Beevers G, Lip GY, O'Brien E. Abc of hypertension: The pathophysiology of hypertension. BMJ. 2001;322:912-916

25. Rizzoni D, Agabiti-Rosei E. Structural abnormalities of small resistance arteries in essential hypertension. Intern Emerg Med. 2012;7:205-212

26. Levy BI, Schiffrin EL, Mourad JJ, Agostini D, Vicaut E, Safar ME, et al. Impaired tissue perfusion: A pathology common to hypertension, obesity, and diabetes mellitus. Circulation. 2008;118:968-976

27. Levy BI, Ambrosio G, Pries AR, Struijker-Boudier HA. Microcirculation in hypertension: A new target for treatment? Circulation. 2001;104:735-740

28. Potenza MA, Marasciulo FL, Chieppa DM, Brigiani GS, Formoso G, Quon MJ, et al. Insulin resistance in spontaneously hypertensive rats is associated with endothelial dysfunction characterized by imbalance between no and et-1 production. Am J Physiol Heart Circ Physiol. 2005;289:H813-822

29. Schulman IH, Zhou MS. Vascular insulin resistance: A potential link between cardiovascular and metabolic diseases. Curr Hypertens Rep. 2009;11:48-55

30. Prewitt RL, Chen, II, Dowell R. Development of microvascular rarefaction in the spontaneously hypertensive rat. Am J Physiol. 1982;243:H243-251

31. Serne EH, Gans RO, ter Maaten JC, Tangelder GJ, Donker AJ, Stehouwer CD. Impaired skin capillary recruitment in essential hypertension is caused by both functional and structural capillary rarefaction. Hypertension. 2001;38:238-242

32. Greene AS, Tonellato PJ, Lui J, Lombard JH, Cowley AW, Jr. Microvascular rarefaction and tissue vascular resistance in hypertension. Am J Physiol. 1989;256:H126-131

33. Ding J, Wai KL, McGeechan K, Ikram MK, Kawasaki R, Xie J, et al. Retinal vascular caliber and the development of hypertension: A meta-analysis of individual participant data. J Hypertens. 2014;32: 207-215

34. Hedman A, Reneland R, Lithell HO. Alterations in skeletal muscle morphology in glucose-tolerant elderly hypertensive men: Relationship to development of hypertension and heart rate. J Hypertens. 2000;18:559-565

35. Li R, Zhang H, Wang W, Wang $X$, Huang $Y$, Huang $C$, et al. Vascular insulin resistance in prehypertensive rats: Role of pi3-kinase/akt/enos signaling. Eur J Pharmacol. 2010;628:140-147

36. Frisbee JC. Hypertension-independent microvascular rarefaction in the obese zucker rat model of the metabolic syndrome. Microcirculation. 2005;12:383-392

37. Hornstra JM, Serne EH, Eringa EC, Wijnker MC, de Boer MP, Yudkin JS, et al. Insulin's microvascular vasodilatory effects are inversely related to peripheral vascular resistance in overweight, but insulinsensitive subjects. Obesity (Silver Spring). 2013;21:2557-2561

38. Weinberger MH, Miller JZ, Luft FC, Grim CE, Fineberg NS. Definitions and characteristics of sodium sensitivity and blood pressure resistance. Hypertension. 1986;8:II127-134

39. Feng W, Dell'Italia L, Sanders PW. Novel paradigms of salt and hypertension. J Am Soc Nephrol. 2017;28:1362-1369

40. Guyton AC, Coleman TG, Young DB, Lohmeier TE, DeClue JW. Salt balance and long-term blood pressure control. Annu Rev Med. 1980;31:15-27

41. Toda N, Arakawa K. Salt-induced hemodynamic regulation mediated by nitric oxide. J Hypertens. 2011;29:415-424

42. Boegehold MA, Huffman $\amalg$, Hedge GA. Peripheral vascular resistance and regional blood flows in hypertensive dahl rats. Am J Physiol. 1991;261:R934-938

43. Sullivan JM, Prewitt RL, Ratts TE, Josephs JA, Connor MJ. Hemodynamic characteristics of sodiumsensitive human subjects. Hypertension. 1987;9:398-406 
44. Cavka A, Cosic A, Jukic I, Jelakovic B, Lombard JH, Phillips SA, et al. The role of cyclo-oxygenase-1 in high-salt diet-induced microvascular dysfunction in humans. J Physiol. 2015;593:5313-5324

45. He FJ, Marciniak M, Markandu ND, Antonios TF, MacGregor GA. Effect of modest salt reduction on skin capillary rarefaction in white, black, and asian individuals with mild hypertension. Hypertension. 2010;56:253-259

46. Houben AJ, Willemsen RT, van de Ven H, de Leeuw PW. Microvascular adaptation to changes in dietary sodium is disturbed in patients with essential hypertension. J Hypertens. 2005;23:127-132

47. Chen J, Gu D, Huang J, Rao DC, Jaquish CE, Hixson JE, et al. Metabolic syndrome and salt sensitivity of blood pressure in non-diabetic people in china: A dietary intervention study. Lancet. 2009;373:829-835

48. Ogihara T, Asano T, Ando K, Chiba Y, Sekine N, Sakoda H, et al. Insulin resistance with enhanced insulin signaling in high-salt diet-fed rats. Diabetes. 2001;50:573-583

49. Premilovac D, Richards SM, Rattigan S, Keske MA. A vascular mechanism for high-sodium-induced insulin resistance in rats. Diabetologia. 2014;57:2586-2595

50. Borst JG, Borst-De Geus A. Hypertension explained by starling's theory of circulatory homoeostasis. Lancet. 1963;1:677-682

51. Guyton AC, Coleman TG, Cowley AV, Jr., Scheel KW, Manning RD, Jr., Norman RA, Jr. Arterial pressure regulation. Overriding dominance of the kidneys in long-term regulation and in hypertension. Am $J$ Med. 1972;52:584-594

52. Evans RG, Bie P. Role of the kidney in the pathogenesis of hypertension: Time for a neo-guytonian paradigm or a paradigm shift? Am J Physiol Regul Integr Comp Physiol. 2016;310:R217-229

53. Birkenhäger WH, Reid JL. Assessment of hypertensive organ damage. In: Hansson L, Birkenhäger WH, eds. Handbook of hypertension. Amsterdam: Elsevier; 1997:347-348.

54. Johnson RJ, Herrera-Acosta J, Schreiner GF, Rodriguez-Iturbe B. Subtle acquired renal injury as a mechanism of salt-sensitive hypertension. N Engl J Med. 2002;346:913-923

55. Chade AR. Renal vascular structure and rarefaction. Compr Physiol. 2013;3:817-831

56. Baldwin DS, Hulet WH, Biggs AW, Gombos EA, Chasis H. Renal function in the separate kidneys of man. li. Hemodynamics and excretion of solute and water in essential hypertension. J Clin Invest. 1960;39:395-404

57. van Onna M, Houben AJ, Kroon AA, Wierema TK, Koster D, van Engelshoven JM, et al. Asymmetry of renal blood flow in patients with moderate to severe hypertension. Hypertension. 2003;41:108-113

58. Whitley MA, Jacobson AF. Congenital or early developmental versus later acquired renal function asymmetry. Scintigraphic characteristics. Clin Nucl Med. 1993;18:1020-1023

59. Hall JE, do Carmo JM, da Silva AA, Wang Z, Hall ME. Obesity-induced hypertension: Interaction of neurohumoral and renal mechanisms. Circ Res. 2015;116:991-1006

60. Underwood PC, Adler GK. The renin angiotensin aldosterone system and insulin resistance in humans. Curr Hypertens Rep. 2013;15:59-70

61. Schafer SC, Pellegrin M, Wyss C, Aubert JF, Nussberger J, Hayoz D, et al. Intravital microscopy reveals endothelial dysfunction in resistance arterioles in angiotensin ii-induced hypertension. Hypertens Res. 2012;35:855-861

62. Rizzoni D, Pasini E, Flati V, Rodella LF, Paiardi S, Assanelli D, et al. Angiotensin receptor blockers improve insulin signaling and prevent microvascular rarefaction in the skeletal muscle of spontaneously hypertensive rats. J Hypertens. 2008;26:1595-1601

63. Goossens GH, Blaak EE, Saris WH, van Baak MA. Angiotensin ii-induced effects on adipose and skeletal muscle tissue blood flow and lipolysis in normal-weight and obese subjects. J Clin Endocrinol Metab. 2004;89:2690-2696

64. Lethen $\mathrm{H}$, Tries HP, Kersting $\mathrm{S}$, Bramlage $\mathrm{P}$, Lambertz $\mathrm{H}$. Improvement of coronary microvascular function after angiotensin receptor blocker treatment with irbesartan in patients with systemic hypertension. J Clin Hypertens (Greenwich). 2011;13:155-161

65. Kishi T, Hirooka Y, Konno S, Sunagawa K. Angiotensin ii receptor blockers improve endothelial dysfunction associated with sympathetic hyperactivity in metabolic syndrome. J Hypertens. 2012;30:1646-1655

66. Chen H, Montagnani M, Funahashi T, Shimomura I, Quon MJ. Adiponectin stimulates production of nitric oxide in vascular endothelial cells. J Biol Chem. 2003;278:45021-45026 
67. Boydens C, Maenhaut N, Pauwels B, Decaluwe K, Van de Voorde J. Adipose tissue as regulator of vascular tone. Curr Hypertens Rep. 2012;14:270-278

68. Andraws R, Brown DL. Effect of inhibition of the renin-angiotensin system on development of type 2 diabetes mellitus (meta-analysis of randomized trials). Am J Cardiol. 2007;99:1006-1012

69. Henriksen EJ, Jacob S, Kinnick TR, Teachey MK, Krekler M. Selective angiotensin ii receptor antagonism reduces insulin resistance in obese zucker rats. Hypertension. 2001;38:884-890

70. Munoz MC, Giani JF, Dominici FP, Turyn D, Toblli JE. Long-term treatment with an angiotensin ii receptor blocker decreases adipocyte size and improves insulin signaling in obese zucker rats. $J$ Hypertens. 2009;27:2409-2420

71. van der Zijl NJ, Serne EH, Goossens GH, Moors CC, ljzerman RG, Blaak EE, et al. Valsartan-induced improvement in insulin sensitivity is not paralleled by changes in microvascular function in individuals with impaired glucose metabolism. J Hypertens. 2011;29:1955-1962

72. Frigolet ME, Torres N, Tovar AR. The renin-angiotensin system in adipose tissue and its metabolic consequences during obesity. J Nutr Biochem. 2013;24:2003-2015

73. Velloso LA, Folli F, Sun XJ, White MF, Saad MJ, Kahn CR. Cross-talk between the insulin and angiotensin signaling systems. Proc Natl Acad Sci U S A. 1996;93:12490-12495

74. Goossens GH, Blaak EE, van Baak MA. Possible involvement of the adipose tissue renin-angiotensin system in the pathophysiology of obesity and obesity-related disorders. Obes Rev. 2003;4:43-55

75. Kadowaki T, Yamauchi T, Kubota N, Hara K, Ueki K, Tobe K. Adiponectin and adiponectin receptors in insulin resistance, diabetes, and the metabolic syndrome. J Clin Invest. 2006;116:1784-1792

76. Suzuki H, Eguchi S. Adiponectin versus angiotensin ii: Key pathological role of their misbalance. Kidney Int. 2006;70:1678-1679

77. Jonk AM, Houben AJ, Schaper NC, de Leeuw PW, Serne EH, Smulders YM, et al. Angiotensin ii enhances insulin-stimulated whole-body glucose disposal but impairs insulin-induced capillary recruitment in healthy volunteers. J Clin Endocrinol Metab. 2010;95:3901-3908

78. Jonk AM, Houben AJ, Schaper NC, de Leeuw PW, Serne EH, Smulders YM, et al. Acute angiotensin ii receptor blockade improves insulin-induced microvascular function in hypertensive individuals. Microvasc Res. 2011;82:77-83

79. Sauder MA, Liu J, Jahn LA, Fowler DE, Chai W, Liu Z. Candesartan acutely recruits skeletal and cardiac muscle microvasculature in healthy humans. J Clin Endocrinol Metab. 2012;97:E1208-1212

80. Chai W, Wang W, Dong Z, Cao W, Liu Z. Angiotensin ii receptors modulate muscle microvascular and metabolic responses to insulin in vivo. Diabetes. 2011;60:2939-2946

81. Xu ZG, Lanting L, Vaziri ND, Li Z, Sepassi L, Rodriguez-Iturbe B, et al. Upregulation of angiotensin ii type 1 receptor, inflammatory mediators, and enzymes of arachidonate metabolism in obese zucker rat kidney: Reversal by angiotensin ii type 1 receptor blockade. Circulation. 2005;111:1962-1969

82. Clerk LH, Vincent MA, Barrett EJ, Lankford MF, Lindner JR. Skeletal muscle capillary responses to insulin are abnormal in late-stage diabetes and are restored by angiotensin-converting enzyme inhibition. $\mathrm{Am} \mathrm{J}$ Physiol Endocrinol Metab. 2007;293:E1804-1809

83. Connell JM, Davies E. The new biology of aldosterone. J Endocrinol. 2005;186:1-20

84. Dinh Cat AN, Friederich-Persson M, White A, Touyz RM. Adipocytes, aldosterone and obesity-related hypertension. J Mol Endocrinol. 2016;57:F7-F21

85. Huby AC, Antonova G, Groenendyk J, Gomez-Sanchez CE, Bollag WB, Filosa JA, et al. Adipocyte-derived hormone leptin is a direct regulator of aldosterone secretion, which promotes endothelial dysfunction and cardiac fibrosis. Circulation. 2015;132:2134-2145

86. Jeon JH, Kim KY, Kim JH, Baek A, Cho H, Lee YH, et al. A novel adipokine ctrp1 stimulates aldosterone production. Faseb J. 2008;22:1502-1511

87. Briones AM, Nguyen Dinh Cat A, Callera GE, Yogi A, Burger D, He Y, et al. Adipocytes produce aldosterone through calcineurin-dependent signaling pathways: Implications in diabetes mellitusassociated obesity and vascular dysfunction. Hypertension. 2012;59:1069-1078

88. Engeli S, Bohnke J, Gorzelniak K, Janke J, Schling P, Bader M, et al. Weight loss and the reninangiotensin-aldosterone system. Hypertension. 2005;45:356-362

89. Goodfriend TL, Kelley DE, Goodpaster BH, Winters SJ. Visceral obesity and insulin resistance are associated with plasma aldosterone levels in women. Obes Res. 1999;7:355-362 
90. Rocchini AP, Katch VL, Grekin R, Moorehead C, Anderson J. Role for aldosterone in blood pressure regulation of obese adolescents. Am J Cardiol. 1986;57:613-618

91. Tuck ML, Sowers J, Dornfeld L, Kledzik G, Maxwell M. The effect of weight reduction on blood pressure, plasma renin activity, and plasma aldosterone levels in obese patients. N Engl J Med. 1981;304:930-933

92. Feldstein AE, Werneburg NW, Canbay A, Guicciardi ME, Bronk SF, Rydzewski R, et al. Free fatty acids promote hepatic lipotoxicity by stimulating tnf-alpha expression via a lysosomal pathway. Hepatology. 2004;40:185-194

93. Fogari R, Zoppi A, Corradi L, Preti P, Mugellini A, Lazzari P, et al. Effect of body weight loss and normalization on blood pressure in overweight non-obese patients with stage 1 hypertension. Hypertens Res. 2010;33:236-242

94. Ikeda T, Gomi T, Hirawa N, Sakurai J, Yoshikawa N. Improvement of insulin sensitivity contributes to blood pressure reduction after weight loss in hypertensive subjects with obesity. Hypertension. 1996;27:1180-1186

95. Chadwick JA, Hauck JS, Lowe J, Shaw JJ, Guttridge DC, Gomez-Sanchez CE, et al. Mineralocorticoid receptors are present in skeletal muscle and represent a potential therapeutic target. Faseb J. 2015;29:4544-4554

96. McCurley A, Jaffe IZ. Mineralocorticoid receptors in vascular function and disease. Mol Cell Endocrinol. 2012;350:256-265

97. Chrissobolis S, Drummond GR, Faraci FM, Sobey CG. Chronic aldosterone administration causes nox2mediated increases in reactive oxygen species production and endothelial dysfunction in the cerebral circulation. J Hypertens. 2014;32:1815-1821

98. Schafer N, Lohmann C, Winnik S, van Tits L, Miranda MX, Vergopoulos A, et al. Endothelial mineralocorticoid receptor activation mediates endothelial dysfunction in diet-induced obesity. Eur Heart J. 2013;34(45):3515-3524

99. Nishizaka MK, Zaman MA, Green SA, Renfroe KY, Calhoun DA. Impaired endothelium-dependent flowmediated vasodilation in hypertensive subjects with hyperaldosteronism. Circulation. 2004;109: 2857-2861

100. Tsuchiya K, Yoshimoto T, Hirata Y. Endothelial dysfunction is related to aldosterone excess and raised blood pressure. Endocr J. 2009;56:553-559

101. Farquharson CA, Struthers AD. Spironolactone increases nitric oxide bioactivity, improves endothelial vasodilator dysfunction, and suppresses vascular angiotensin i/angiotensin ii conversion in patients with chronic heart failure. Circulation. 2000;101:594-597

102. Ando K, Fujita M. Reactive oxygen species and the central nervous system in salt-sensitive hypertension: Possible relationship with obesity-induced hypertension. Clin Exp Pharmacol Physiol. 2012;39:111-116

103. Garg R, Kneen L, Williams GH, Adler GK. Effect of mineralocorticoid receptor antagonist on insulin resistance and endothelial function in obese subjects. Diabetes Obes Metab. 2014;16(3):268-272

104. Hwang MH, Yoo JK, Luttrell M, Kim HK, Meade TH, English M, et al. Mineralocorticoid receptors modulate vascular endothelial function in human obesity. Clin Sci (Lond). 2013;125(11):513-520

105. Lapi D, Emdin M, Mastantuono T, Sapio D, Santillo M, Colantuoni A. Microvascular responses to aldosterone in hamster cheek pouch microcirculation. Clin Hemorheol Microcirc. 2013;53:303-315

106. Kushibiki M, Yamada M, Oikawa K, Tomita H, Osanai T, Okumura K. Aldosterone causes vasoconstriction in coronary arterioles of rats via angiotensin ii type-1 receptor: Influence of hypertension. Eur J Pharmacol. 2007;572:182-188

107. Arima S. Aldosterone and the kidney: Rapid regulation of renal microcirculation. Steroids. 2006;71: 281-285

108. Schmidt BM, Sammer U, Fleischmann I, Schlaich M, Delles C, Schmieder RE. Rapid nongenomic effects of aldosterone on the renal vasculature in humans. Hypertension. 2006;47:650-655

109. Bender SB, DeMarco VG, Padilla J, Jenkins NT, Habibi J, Garro M, et al. Mineralocorticoid receptor antagonism treats obesity-associated cardiac diastolic dysfunction. Hypertension. 2015;65:1082-1088

110. Garg R, Rao AD, Baimas-George M, Hurwitz S, Foster C, Shah RV, et al. Mineralocorticoid receptor blockade improves coronary microvascular function in individuals with type 2 diabetes. Diabetes. 2015;64:236-242 
111. Bayorh MA, Rollins-Hairston A, Adiyiah J, Lyn D, Eatman D. Eplerenone suppresses aldosterone/ saltinduced expression of nox-4. J Renin Angiotensin Aldosterone Syst. 2011;12:195-201

112. Iwashima F, Yoshimoto T, Minami I, Sakurada M, Hirono Y, Hirata Y. Aldosterone induces superoxide generation via rac1 activation in endothelial cells. Endocrinology. 2008;149:1009-1014

113. Leopold JA, Dam A, Maron BA, Scribner AW, Liao R, Handy DE, et al. Aldosterone impairs vascular reactivity by decreasing glucose-6-phosphate dehydrogenase activity. Nat Med. 2007;13:189-197

114. Skott O, Uhrenholt TR, Schjerning J, Hansen PB, Rasmussen LE, Jensen BL. Rapid actions of aldosterone in vascular health and disease--friend or foe? Pharmacol Ther. 2006;111:495-507

115. Toda N, Nakanishi S, Tanabe S. Aldosterone affects blood flow and vascular tone regulated by endothelium-derived no: Therapeutic implications. Br J Pharmacol. 2013;168:519-533

116. Maron BA, Zhang YY, Handy DE, Beuve A, Tang SS, Loscalzo J, et al. Aldosterone increases oxidant stress to impair guanylyl cyclase activity by cysteinyl thiol oxidation in vascular smooth muscle cells. J Biol Chem. 2009;284:7665-7672

117. Maron BA, Zhang YY, White K, Chan SY, Handy DE, Mahoney CE, et al. Aldosterone inactivates the endothelin-b receptor via a cysteinyl thiol redox switch to decrease pulmonary endothelial nitric oxide levels and modulate pulmonary arterial hypertension. Circulation. 2012;126:963-974

118. Pu Q, Neves MF, Virdis A, Touyz RM, Schiffrin EL. Endothelin antagonism on aldosterone-induced oxidative stress and vascular remodeling. Hypertension. 2003;42:49-55

119. Guo C, Ricchiuti V, Lian BQ, Yao TM, Coutinho P, Romero JR, et al. Mineralocorticoid receptor blockade reverses obesity-related changes in expression of adiponectin, peroxisome proliferator-activated receptor-gamma, and proinflammatory adipokines. Circulation. 2008;117:2253-2261

120. Rocha R, Rudolph AE, Frierdich GE, Nachowiak DA, Kekec BK, Blomme EA, et al. Aldosterone induces a vascular inflammatory phenotype in the rat heart. Am J Physiol Heart Circ Physiol. 2002;283: H1802-1810

121. Blasi ER, Rocha R, Rudolph AE, Blomme EA, Polly ML, McMahon EG. Aldosterone/salt induces renal inflammation and fibrosis in hypertensive rats. Kidney Int. 2003;63:1791-1800

122. Galmiche G, Pizard A, Gueret A, El Moghrabi S, Ouvrard-Pascaud A, Berger S, et al. Smooth muscle cell mineralocorticoid receptors are mandatory for aldosterone-salt to induce vascular stiffness. Hypertension. 2014;63:520-526

123. Oberleithner H, Riethmuller C, Schillers H, MacGregor GA, de Wardener HE, Hausberg M. Plasma sodium stiffens vascular endothelium and reduces nitric oxide release. Proc Natl Acad Sci U S A. 2007;104:16281-16286

124. Catena C, Colussi G, Sechi LA. Aldosterone, organ damage and dietary salt. Clin Exp Pharmacol Physiol. 2013;40:922-928

125. Nagase M, Matsui H, Shibata S, Gotoda T, Fujita T. Salt-induced nephropathy in obese spontaneously hypertensive rats via paradoxical activation of the mineralocorticoid receptor: Role of oxidative stress. Hypertension. 2007;50:877-883

126. Licata G, Volpe M, Scaglione R, Rubattu S. Salt-regulating hormones in young normotensive obese subjects. Effects of saline load. Hypertension. 1994;23:120-24

127. Conn JW. Hypertension, the potassium ion and impaired carbohydrate tolerance. $N$ Engl J Med. 1965;273:1135-1143

128. Catena C, Lapenna R, Baroselli S, Nadalini E, Colussi G, Novello M, et al. Insulin sensitivity in patients with primary aldosteronism: A follow-up study. J Clin Endocrinol Metab. 2006;91:3457-3463

129. Giacchetti G, Ronconi V, Turchi F, Agostinelli L, Mantero F, Rilli S, et al. Aldosterone as a key mediator of the cardiometabolic syndrome in primary aldosteronism: An observational study. J Hypertens. 2007; $25: 177-186$

130. Sindelka G, Widimsky J, Haas T, Prazny M, Hilgertova J, Skrha J. Insulin action in primary hyperaldosteronism before and after surgical or pharmacological treatment. Exp Clin Endocrinol Diabetes. 2000;108:21-25

131. Widimsky J, Jr., Sindelka G, Haas T, Prazny M, Hilgertova J, Skrha J. Impaired insulin action in primary hyperaldosteronism. Physiol Res. 2000;49:241-244

132. Selvaraj J, Muthusamy T, Srinivasan C, Balasubramanian K. Impact of excess aldosterone on glucose homeostasis in adult male rat. Clin Chim Acta. 2009;407:51-57 
133. Sherajee SJ, Rafiq K, Nakano D, Mori H, Kobara H, Hitomi H, et al. Aldosterone aggravates glucose intolerance induced by high fructose. Eur J Pharmacol. 2013;720:63-68

134. Bentley-Lewis R, Adler GK, Perlstein T, Seely EW, Hopkins PN, Williams GH, et al. Body mass index predicts aldosterone production in normotensive adults on a high-salt diet. J Clin Endocrinol Metab. 2007;92:4472-4475

135. Freel EM, Tsorlalis IK, Lewsey JD, Latini R, Maggioni AP, Solomon S, et al. Aldosterone status associated with insulin resistance in patients with heart failure--data from the aloft study. Heart. 2009;95: 1920-1924

136. Colussi G, Catena C, Lapenna R, Nadalini E, Chiuch A, Sechi LA. Insulin resistance and hyperinsulinemia are related to plasma aldosterone levels in hypertensive patients. Diabetes Care. 2007;30:2349-2354

137. Huan Y, Deloach S, Keith SW, Goodfriend TL, Falkner B. Aldosterone and aldosterone: Renin ratio associations with insulin resistance and blood pressure in african americans. J Am Soc Hypertens. 2012;6:56-65

138. Kidambi S, Kotchen JM, Grim CE, Raff H, Mao J, Singh RJ, et al. Association of adrenal steroids with hypertension and the metabolic syndrome in blacks. Hypertension. 2007;49:704-711

139. Kumagai $E$, Adachi $H$, Jacobs DR, Jr., Hirai $Y$, Enomoto $M$, Fukami A, et al. Plasma aldosterone levels and development of insulin resistance: Prospective study in a general population. Hypertension. 2011;58:1043-1048

140. Lastra G, Whaley-Connell A, Manrique C, Habibi J, Gutweiler AA, Appesh L, et al. Low-dose spironolactone reduces reactive oxygen species generation and improves insulin-stimulated glucose transport in skeletal muscle in the tg(mren2)27 rat. Am J Physiol Endocrinol Metab. 2008;295:E110-116

141. Wada T, Kenmochi H, Miyashita Y, Sasaki M, Ojima M, Sasahara M, et al. Spironolactone improves glucose and lipid metabolism by ameliorating hepatic steatosis and inflammation and suppressing enhanced gluconeogenesis induced by high-fat and high-fructose diet. Endocrinology. 2010;151: 2040-2049

142. Ogino K, Kinugasa Y, Kato M, Yamamoto K, Hisatome I, Anker SD, et al. Spironolactone, not furosemide, improved insulin resistance in patients with chronic heart failure. Int J Cardiol. 2014;171:398-403

143. McMurray EM, Wallace IR, Ennis C, Hunter SJ, Atkinson AB, Bell PM. Effect of eplerenone on insulin action in essential hypertension: A randomised, controlled, crossover study. J Hum Hypertens. 2014;28:575-578

144. Campion J, Maestro B, Mata F, Davila N, Carranza MC, Calle C. Inhibition by aldosterone of insulin receptor mrna levels and insulin binding in u-937 human promonocytic cells. J Steroid Biochem Mol Biol. 1999;70:211-218

145. Campion J, Maestro B, Molero S, Davila N, Carranza MC, Calle C. Aldosterone impairs insulin responsiveness in $\mathrm{u}-937$ human promonocytic cells via the downregulation of its own receptor. Cell Biochem Funct. 2002;20:237-245

146. Wada T, Ohshima S, Fujisawa E, Koya D, Tsuneki H, Sasaoka T. Aldosterone inhibits insulin-induced glucose uptake by degradation of insulin receptor substrate (irs) 1 and irs2 via a reactive oxygen species-mediated pathway in 3t3-I1 adipocytes. Endocrinology. 2009;150:1662-1669

147. Marcus Y, Shefer G, Stern N. Adipose tissue renin-angiotensin-aldosterone system (raas) and progression of insulin resistance. Mol Cell Endocrinol. 2013;378:1-14

148. Hitomi H, Kiyomoto H, Nishiyama A, Hara T, Moriwaki K, Kaifu K, et al. Aldosterone suppresses insulin signaling via the downregulation of insulin receptor substrate-1 in vascular smooth muscle cells. Hypertension. 2007;50:750-755

149. DeMarco VG, Habibi J, Jia G, Aroor AR, Ramirez-Perez FI, Martinez-Lemus LA, et al. Low-dose mineralocorticoid receptor blockade prevents western diet-induced arterial stiffening in female mice. Hypertension. 2015;66:99-107

150. Ando K, Fujita T. Pathophysiology of salt sensitivity hypertension. Ann Med. 2012;44 Suppl 1:S119-126

151. Gupte M, Boustany-Kari CM, Bharadwaj K, Police S, Thatcher S, Gong MC, et al. Ace2 is expressed in mouse adipocytes and regulated by a high-fat diet. Am J Physiol Regul Integr Comp Physiol. 2008;295:R781-788 
152. Gupte M, Thatcher SE, Boustany-Kari CM, Shoemaker R, Yiannikouris F, Zhang X, et al. Angiotensin converting enzyme 2 contributes to sex differences in the development of obesity hypertension in c57bl/6 mice. Arterioscler Thromb Vasc Biol. 2012;32:1392-1399

153. Brown JM, Underwood PC, Ferri C, Hopkins PN, Williams GH, Adler GK, et al. Aldosterone dysregulation with aging predicts renal vascular function and cardiovascular risk. Hypertension. 2014;63:1205-1211

154. Kotchen TA, Kotchen JM, Grim CE, Krishnaswami S, Kidambi S. Aldosterone and alterations of hypertension-related vascular function in african americans. Am J Hypertens. 2009;22:319-324

155. Joris PJ, Plat J, Kusters YH, Houben AJ, Stehouwer CD, Schalkwijk CG, et al. Diet-induced weight loss improves not only cardiometabolic risk markers but also markers of vascular function: A randomized controlled trial in abdominally obese men. Am J Clin Nutr. 2017;105:23-31

156. Prior SJ, Blumenthal JB, Katzel LI, Goldberg AP, Ryan AS. Increased skeletal muscle capillarization after aerobic exercise training and weight loss improves insulin sensitivity in adults with igt. Diabetes Care. 2014;37:1469-1475

157. Vinet A, Obert P, Dutheil F, Diagne L, Chapier R, Lesourd B, et al. Impact of a lifestyle program on vascular insulin resistance in metabolic syndrome subjects: The resolve study. $J$ Clin Endocrinol Metab. 2014:jc20142704

158. Meneton P, Galan P, Bertrais S, Heudes D, Hercberg S, Menard J. High plasma aldosterone and low renin predict blood pressure increase and hypertension in middle-aged caucasian populations. $J$ Hum Hypertens. 2008;22:550-558

159. Vasan RS, Evans JC, Larson MG, Wilson PW, Meigs JB, Rifai N, et al. Serum aldosterone and the incidence of hypertension in nonhypertensive persons. N Engl J Med. 2004;351:33-41 


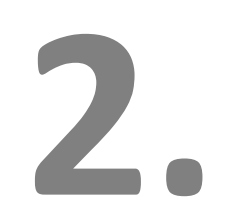

THE LINK BETWEEN ADIPOSE TISSUE RENINANGIOTENSIN-ALDOSTERONE-SYSTEM (RAAS)

SIGNALING AND OBESITY-ASSOCIATED

HYPERTENSION

M.T.J. Schütten, A.J.H.M. Houben, P.W. de Leeuw, C.D.A. Stehouwer

Physiology 2017; 32: 197-209 


\section{Abstract}

Obese individuals frequently develop hypertension, which is for an important part attributable to renin-angiotensin-aldosterone system (RAAS) overactivity. This review summarizes preclinical and clinical evidence on the involvement of dysfunctional adipose tissue in RAAS activation, and on the renal, central and vascular mechanisms linking RAAS components to obesity-associated hypertension. 


\section{Introduction}

Up to $80 \%$ of essential hypertension can be ascribed to excess weight, via several mechanisms ${ }^{1,2}$. The aim of this paper is to discuss recent insights in how dysfunctional adipose tissue contributes to increased activity of the renin-angiotensin-aldosterone system (RAAS), which is thought to play a crucial role in the pathogenesis of obesityinduced hypertension ${ }^{3}$, and whether these insights suggest new antihypertensive strategies.

\section{Adipose tissue renin-angiotensin-aldosterone-system and blood pressure regulation}

Activation of the renin-angiotensin-aldosterone system is an important mediator of elevated blood pressure under circumstances of obesity. This is not only attributable to sympathetic nervous system overactivity and renal compression ${ }^{2}$, but also to dysfunctional adipose tissue.

First, significant angiotensin II (AngII) secretion from abdominal subcutaneous adipose tissue has clearly been demonstrated in obese individuals ${ }^{4}$. The fact that the machinery necessary to generate Angll, i.e. angiotensinogen (AGT) mRNA and protein, renin mRNA and activity, and angiotensin converting enzyme (ACE) mRNA and protein, has been encountered in both animal and human adipose tissue (components) ${ }^{5-15}$ indicates that the reported substantial arteriovenous difference in Angll levels is not a consequence of Angll release after reuptake by adipose tissue, but of de novo synthesis. This is underlined by observations of Angll production by cultured human adipocytes ${ }^{16}$.

Second, white adipose tissue is the most abundant source of angiotensinogen (AGT) after the liver ${ }^{17}$, which is particularly relevant in obesity, given the increase in adipose tissue mass and AGT expression in rats with diet-induced obesity, while liver AGT expression remains unchanged ${ }^{18}$. Subcutaneous adipose tissue AGT expression in obese, compared to lean humans is enhanced as well, while body weight correlates positively and independently with adipose tissue AGT expression ${ }^{19}$. How adipose tissue AGT expression relates to AGT secretion is not entirely clear yet, given the fact that unchanged or even decreased adipose tissue AGT expression has been reported as well in both obese animals ${ }^{20,21}$ and humans ${ }^{22,23}$. This could however serve as a compensating mechanism for the expanded fat mass, nevertheless resulting in a net increase in AGT release, as observed in obese mice and humans ${ }^{15}$. In obese rats, adipose tissue AGT expression corresponds with plasma AGT and angiotensin II levels and blood pressure ${ }^{18}$, whereas both adipose tissue AGT secretion and plasma AGT levels are increased in mice 
with diet-induced obesity, and adipose-tissue derived AGT correlates with circulating AGT in these mice before and after weight loss ${ }^{15}$. Moreover, mice deficient in adipocyte angiotensinogen fed a high fat diet remain normotensive, while wild-type mice fed the same diet display elevations in plasma Angll and blood pressure ${ }^{24}$. Correspondingly, in obese, compared to lean women, plasma AGT, renin, ACE - activity and aldosterone are higher, and decrease after weight loss. Adipose tissue AGT expression is reduced as well following weight loss and this is correlated with changes in circulating AGT and systolic blood pressure ${ }^{22}$.

Third, human adipocytes are also capable of aldosterone production, which is partially Angll-dependent ${ }^{25}$, and accordingly, BMI predicts plasma aldosterone concentration in overweight and obese hypertensive patients ${ }^{26}$. In addition, adipose-tissue derived mineralocorticoid-releasing factors, including leptin and complement-C1q TNF-related protein 1 (CTRP1), but also angiotensin II, stimulate aldosterone release in human adrenocortical cells ${ }^{27-29}$. Thus, both the adipose tissue and adrenal glands are sources of aldosterone in obesity.

In addition to local production of Angll and aldosterone or mineralocorticoid-releasing factors, conversion of adipocyte-derived AGT by systemic renin and ACE-activity represents another way in which adipose tissue can contribute to increased circulating levels of Angll and aldosterone (Figure 2.1). It is not clear whether it is truly adipocytederived renin, or renin-like activity, that is responsible for the generation of angiotensin I and II, because renin mRNA levels in human adipocytes are threefold lower compared to human adipocyte angiotensinogen levels ${ }^{30}$. Due to the presence of cathepsins and chymase in human adipose tissue ${ }^{5,9}$, however, Angl and II can be formed via alternative routes. In addition, (pro)renin receptors, which have been encountered in human adipocytes colocalized with renin, and seem to be functional ${ }^{31}$, may enhance renin enzymatic activity ${ }^{32}$, although some investigators report normal Angll levels in rats overexpressing the human (pro)renin receptor ${ }^{33}$.

Thus, it is likely that adipose tissue-derived RAAS components are involved in regulation of blood pressure. The role of ACE2, angiotensin1-7 (Ang1-7) and the Mas and AT2 receptors, which are thought to constitute a potentially antihypertensive axis of the RAAS $^{34}$, in obesity-associated hypertension is as yet unclear but seems an important area of investigation. For example, ACE2 deficiency increased systolic blood pressure in mice fed a high-fat diet, probably resulting from decreased metabolism of Angll to Ang $1-7^{35}$, although there are few data in humans. 


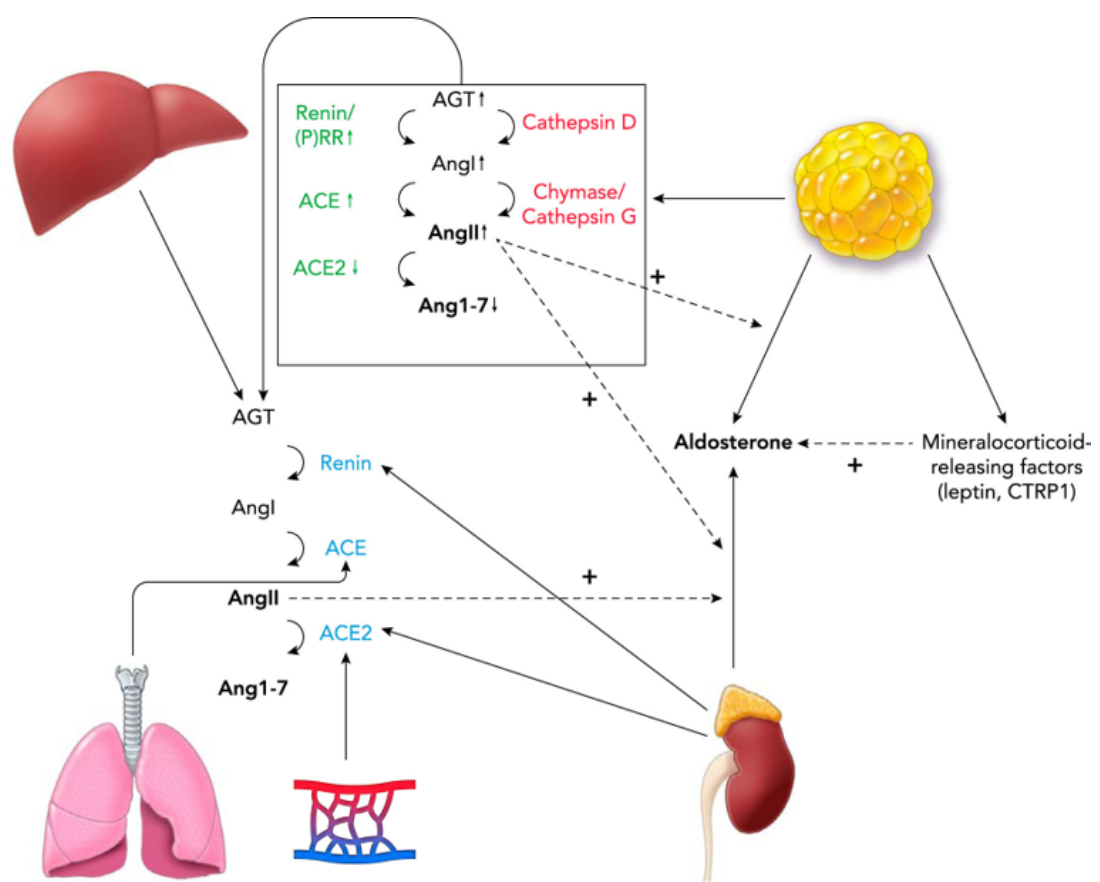

Figure 2.1: Overview of the adipose tissue RAAS and its interactions with the systemic RAAS. Adipocytederived extracellular RAAS enzymes are indicated in green; intracellular enzymes involved in angiotensin (Ang) I and II generation are indicated in red, and systemic extracellular RAAS enzymes are indicated in blue. $A G T=$ angiotensinogen; Ang1-7 = angiotensin1-7; $(P) R R=($ pro $)$ renin receptor ACE = angiotensin converting enzyme; ACE2 = angiotensin converting enzyme 2, CTRP1 = complement-C1q TNF-related protein.

\section{The renin-angiotensin-aldosterone system and obesity- associated hypertension: pathophysiological mechanisms}

Alterations in RAAS activity, in part resulting from dysfunctional adipose tissue as observed in obesity, can interfere with blood pressure regulation at multiple levels.

\section{The renin-angiotensin-aldosterone system and sodium homeostasis}

Increased renal sodium reabsorption and impaired pressure natriuresis are major contributors to the rise in blood pressure associated with excess weight ${ }^{2}$. This is at least partially attributable to increased Angll levels stimulating sodium transport in multiple nephron segments, altering tubuloglomerular feedback, and constricting efferent arterioles $^{36-42}$ (Figure 2.2), which may be reinforced by upregulation of the renal AT1R, as has been demonstrated in obese Zucker rats ${ }^{43}$. Accordingly, both enalapril and 
candesartan produced greater increases in urinary sodium excretion in obese compared to lean Zucker rats ${ }^{44}$, whereas losartan reduced renovascular resistance in essential hypertensive patients with a relatively high $\mathrm{BMI}^{45}$. Interestingly, renal $\mathrm{AT} 2 \mathrm{R}$ upregulation has been reported as well in obese rats ${ }^{46}$, and chronic AT2R activation has been shown to both promote urinary sodium excretion, probably via effects on proximal tubule $\mathrm{Na}^{+}$-pump activity ${ }^{47}$, and lower blood pressure in these rats. Although it remains to be established whether renal $A T 2 R$ upregulation also occurs in human obesity, these findings may be of therapeutic relevance when AT2R agonists become available for administration in humans.

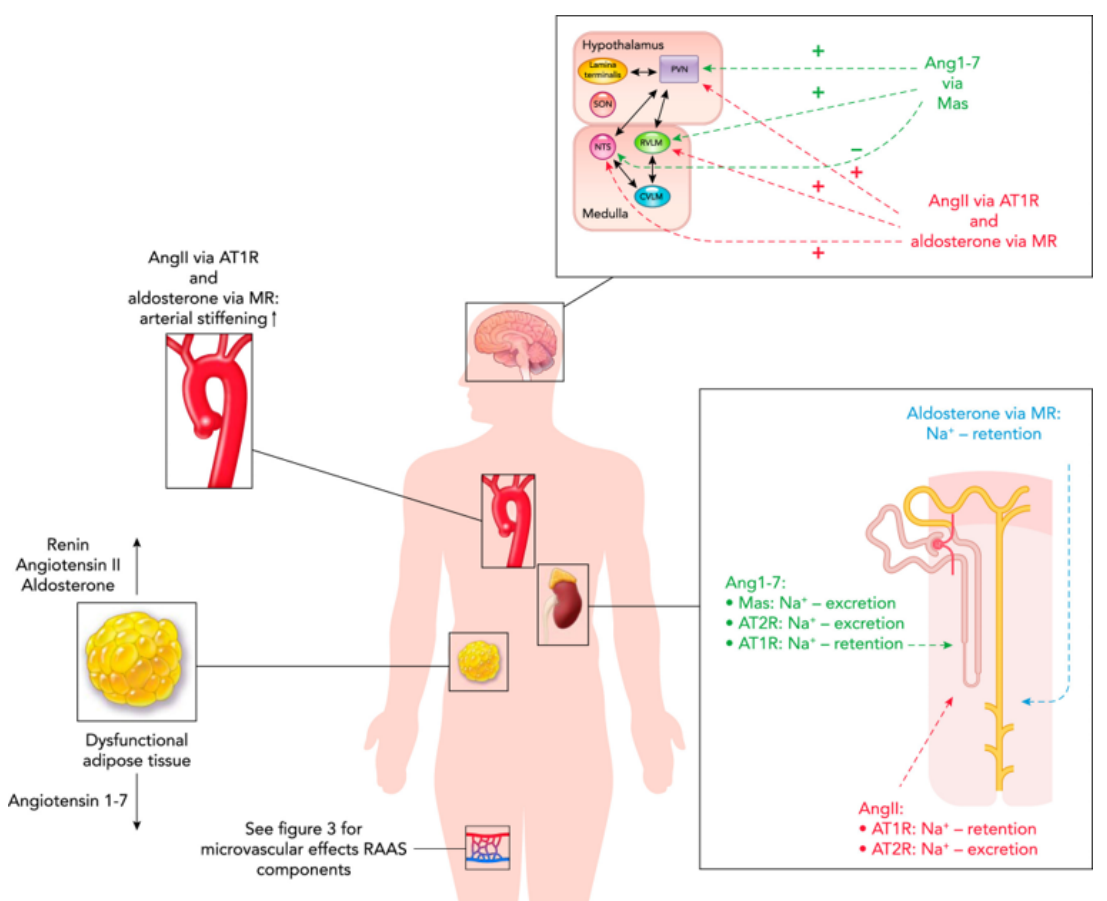

Figure 2.2: Effects of RAAS-components on sodium balance, central blood pressure regulation and arterial stiffening. AngII = angiotensin II; AT1R = angiotensin II type 1 receptor; AT2R = angiotensin II type 2 receptor; $\mathrm{MR}=$ mineralocorticoid receptor; Ang1-7 = angiotensin1-7; SON = supraoptic nucleus; PVN = paraventricular nucleus; NTS = nucleus tractus solitarius; RVLM = rostroventrolateral medulla; CVLM = caudal ventrolateral medulla. 
Increased aldosterone levels combined with a reduced 'aldosterone escape' capability constitute another factor partly responsible for the salt surplus in obesity, through its actions in the distal nephron promoting sodium reabsorption ${ }^{48,49}$ (Figure 2.2), which are to a lesser extent suppressed by usual regulatory mechanisms in obese rats $^{50}$, and potentially by increasing sodium appetite $e^{49}$ and renal vascular resistance ${ }^{51,52}$. Indeed, mineralocorticoid receptor (MR) blockade with eplerenone reduced sodium retention in parallel with blood pressure in obese, hypertensive dogs ${ }^{53}$. Moreover, intracerebral administration of both aldosterone and Angll increased salt appetite in animals, while aldosterone enhanced the effect of Angll on sodium intake and vice versa ${ }^{49,54}$. The relevance of these observations for the sodium retention often accompanying human obesity remains to be established. This also applies to the renal vasoconstrictor effects of aldosterone, which may be more pronounced in the left kidney as a result of selectively altered reactivity of the renal vasculature ${ }^{55}$.

Intricate interactions exist between Ang1-7 signaling through renal AT1R, AT2R and Mas receptors, and the net effect of Ang1-7 on sodium balance is ambiguous. Ang1-7 has been demonstrated to reverse the stimulatory effects of Angll on $\mathrm{Na}^{+}$-ATPase activity in pig kidney proximal tubules by interaction with the Mas receptor ${ }^{56}$, and is in addition capable of suppressing proximal tubule $\mathrm{Na}^{+}$-ATPase through the AT2 receptor $^{57}$, and through increasing phosholipase $A 2$ activation $^{58}$. On the other hand, Ang1-7 was found to increase $\mathrm{Na}^{+}$-ATPase activity by binding to the AT1 receptor ${ }^{59}$ (Figure 2.2). Inconsistent findings on the renovascular actions of Ang1-7, with potential consequences for sodium balance, have been reported as well in animal models, with Ang1-7 administration exerting either no effect ${ }^{60}$, vasodilatation which was prevented by the Mas receptor antagonist A-779 ${ }^{61,62}$, or vasoconstriction ${ }^{62,63}$. These discrepancies are probably due to differences in dose and in degree of RAAS activation ${ }^{64}$. Few data are available on the contribution of the renal actions of Ang1-7 to the regulation of blood pressure in healthy, obese and hypertensive individuals. Nevertheless, findings of decreased urinary Ang1-7 excretion in untreated essential hypertensive individuals ${ }^{65}$, and of chronic ACE inhibition being correlated with increases in urinary Ang1-7 levels ${ }^{66}$, point to an association of decreased renal Ang1-7 signaling with elevated blood pressure.

The renin-angiotensin-aldosterone system and the sympathetic nervous system

Activation of the sympathetic nervous system (SNS) is an important mechanism linking obesity to hypertension, as illustrated by studies in obese dogs showing that renal 
denervation induces considerable reductions in blood pressure ${ }^{67,68}$. Alterations in RAAS signaling can partially account for obesity-associated SNS overactivity ${ }^{2,3}$.

Sympathoexcitatory actions of angiotensin II are twofold. Under normal circumstances, Angll does not cross the blood-brain barrier, but circulating Angll is sensed by the subfornical organ (SFO) and area postrema (AP) residing outside the blood-brain barrier, which convey information to key autonomic/neurosecretory centers in the hypothalamus and brain stem, including the paraventricular nucleus of the hypothalamus (PVN), the rostral ventrolateral medulla (RVLM), and the nucleus tractus solitarii (NTS) ${ }^{69-71}$. Elevated circulating angiotensin II levels have been suggested to increase blood-brain barrier permeability ${ }^{72,73}$, thereby allowing for its direct access to these major cardiovascular control centers, which results in increased (renal) sympathetic nerve activity (and thus renin secretion and sodium retention), reduced baroreflex sensitivity, vasopressin release, and elevated mean arterial pressure ${ }^{74-80}$ (Figure 2.2). In addition, Angll facilitates neurotransmission at sympathetic nerve terminals ${ }^{81}$. Inhibitory effects of AngIl on SNS activity have also been reported ${ }^{82}$, potentially resulting from Angll signaling via AT2 receptors in the RVLM ${ }^{83}$. The relevance of the latter findings is however doubtful, given the fact that increasing peripheral Angll levels generally results in sympathoexcitation, as has been demonstrated in rabbits ${ }^{84}$ and normotensive individuals ${ }^{85}$. Correspondingly, angiotensin receptor blocker (ARB) treatment was found to reduce sympathetic nerve activity, improve baroreceptor function and decrease blood pressure in both obese animals and humans ${ }^{86-89}$.

Aldosterone is capable as well of elevating blood pressure by acting directly within the CNS. Brain regions involved in mineralocorticoid modulation of blood pressure are the circumventricular organs, paraventricular and supraoptic nuclei, NTS and RVLM, and excess aldosterone signaling in these areas is associated with increased sodium appetite, (renal) sympathetic nerve activity and vasopressin release, impaired baroreflex sensitivity, and elevated blood pressure ${ }^{90-93}$, potentially in part by interaction with Angl| ${ }^{93}$ (Figure 2.2). Although the (patho)physiological importance of aldosterone's central effects has been questioned due to its limited blood-brain barrier penetration, a number of findings challenge this concern. In rats, the hypertensive effect of aldosterone or DOCA plus sodium administered subcutaneously was attenuated following intracerebroventricular (ICV) infusion of MR antagonists by reducing sympathetic tone and normalizing baroreflex acitivity ${ }^{94,95}$. Similarly, aldosterone infusion increased muscle sympathetic nerve activity (MSNA) and impaired baroreflex responses in healthy human volunteers ${ }^{96}$, while spironolactone prevented chlorthalidone-induced sympathetic activation in individuals with untreated stage 1 hypertension ${ }^{97}$. The relative contribution of aldosterone to obesity-associated 
sympathoexcitation remains to be determined, but the correlation of aldosterone levels with heart rate variability in obese, diabetic patients with resistant hypertension suggests its involvement ${ }^{98}$.

While central effects of ACE2 generally result in blood pressure reduction ${ }^{99-102}$, the consequences of Ang1-7 signaling for SNS activity and blood pressure depend on the brain region involved (Figure 2.2). Microinjection of Ang1-7 into the RVLM of normotensive and spontaneously hypertensive rats induced stimulation of renal SNA and pressor responses ${ }^{103}$, which was blocked by $A-779^{104-106}$. Similar effects on renal SNA have been observed following A-779 microinjection into the PVN ${ }^{107}$, but whether Ang1-7 increases vasopressin release via PVN signaling is as yet unclear ${ }^{108,109}$. On the other hand, when administered ICV or applied directly to the NTS, Ang1-7 increased baroreflex sensitivity and reduced mean arterial pressure and heart rate in both normotensive and hypertensive rats ${ }^{110,111}$, and centrally administered A-779 exerted the opposite effect in different rat models of hypertension ${ }^{112-114}$. The net effect of CNS Ang1-7 signaling on blood pressure under physiological and pathophysiological circumstances, including hypertension and obesity, remains to be elucidated and confirmed in humans. Findings of increased baroreflex sensitivity and decreased blood pressure following chronic i.v. administration of Ang1-7 in spontaneously hypertensive rats $(\mathrm{SHRs})^{115}$, however, suggest that its antihypertensive actions predominate.

\section{The renin-angiotensin-aldosterone system and microvascular function}

Microcirculatory (arteriolar and capillary) structure and function determine peripheral vascular resistance and thus blood pressure. Impairment of normal microcirculatory function (i.e. rarefaction, impaired dilatation and enhanced constriction ${ }^{116-119}$ ) is thought to be both cause and consequence of hypertension ${ }^{118,120-123}$, and is considered an important pathway linking obesity to hypertension ${ }^{124-128}$. An impaired ability of insulin to dilate precapillary terminal arterioles and induce capillary recruitment by increasing endothelial NO-synthesis, i.e. microvascular insulin resistance ${ }^{118,120,129,130}$ (Figure 2.3), is a feature of obesity-associated microvascular dysfunction that has not only been suggested to increase blood pressure ${ }^{131,132}$, but also to hamper insulinstimulated glucose uptake in skeletal muscle cells ${ }^{126,133-138}$. Therefore, microvascular insulin resistance may be a shared pathophysiological mechanism between hemodynamic and metabolic consequences of obesity.

Increased angiotensin II levels due to adipose tissue dysfunction can enhance microvascular vasoconstriction through multiple mechanisms via the $\operatorname{AT}^{1} \mathrm{R}^{118,130}$, notably by decreasing the synthesis and availability of endothelium-derived nitric oxide; stimulating the secretion and action of endothelium-derived vasoconstrictors such as 
endothelin 1 (ET-1) and prostanoids ${ }^{118,130,139,140}$; promoting vascular smooth muscle cell (VSMC) contraction ${ }^{141}$; and increasing sympathetic nervous system activity ${ }^{142}$ (Figure 2.3). In addition, angiotensin II interferes with vascular insulin signaling, thereby further hampering NO release ${ }^{143-145}$, and consequently, insulin-mediated capillary recruitment ${ }^{146}$ (Figure 2.3). Thus, beneficial effects of ACE-inhibitors and AT1R blockers on insulin-induced microvascular recruitment, as observed in lean and obese rats ${ }^{147,148}$, and healthy and mildly hypertensive individuals ${ }^{149,150}$, might underlie part of their antihypertensive actions, and could explain to a certain extent the reduced risk of developing type 2 diabetes in hypertensive patients following long-term treatment with these agents ${ }^{151}$. The vasoactive properties of Angll may comprise more than just vasoconstriction, as it is capable of promoting vasodilatation by increasing NO release and enhancing insulin-mediated muscle microvascular recruitment through the AT2 receptor $^{130,152}$. Increased AT2R protein expression, mediating decreased contractile responses to AngII, has been demonstrated in arteries of obese rats ${ }^{153}$, but how these findings fit in the current view of vasoconstriction predominating in obesity ${ }^{154}$, or whether this also applies to obese humans is not yet known.

Aldosterone excess in obesity may contribute to a pro-contractile state of the microvasculature ${ }^{155-160}$ by increasing oxidative stress ${ }^{161-163}$, ET-1 release ${ }^{164}$, and TNF $\alpha$ expression, reducing expression of adiponectin ${ }^{165}$, and interacting with salt and angiotensin $\|{ }^{159,166,167}$ (Figure 2.3), which could add to its hypertensive effect, as suggested by animal data ${ }^{168,169}$. This might be enhanced by suppression of vascular insulin signaling ${ }^{170}$. Accordingly, both MR blockade and endothelium-specific MRdeletion improved endothelial function in obese rats and mice ${ }^{171,172}$, while low-dose spironolactone increased aortic dilatation in response to insulin in female mice fed a Western diet ${ }^{173}$. There are currently no data on microvascular consequences of MR blockade in human obesity. In patients with type 2 diabetes, however, add-on therapy with spironolactone enhanced coronary microvascular function ${ }^{174}$, and in older adults, individual improvements in flow-mediated dilatation (FMD) following eplerenone treatment were associated with higher total body fat ${ }^{175}$. Although effects of MRblockade on FMD and (insulin-mediated) microvascular function are not necessarily comparable ${ }^{176,177}$, these findings indicate a favorable response. 


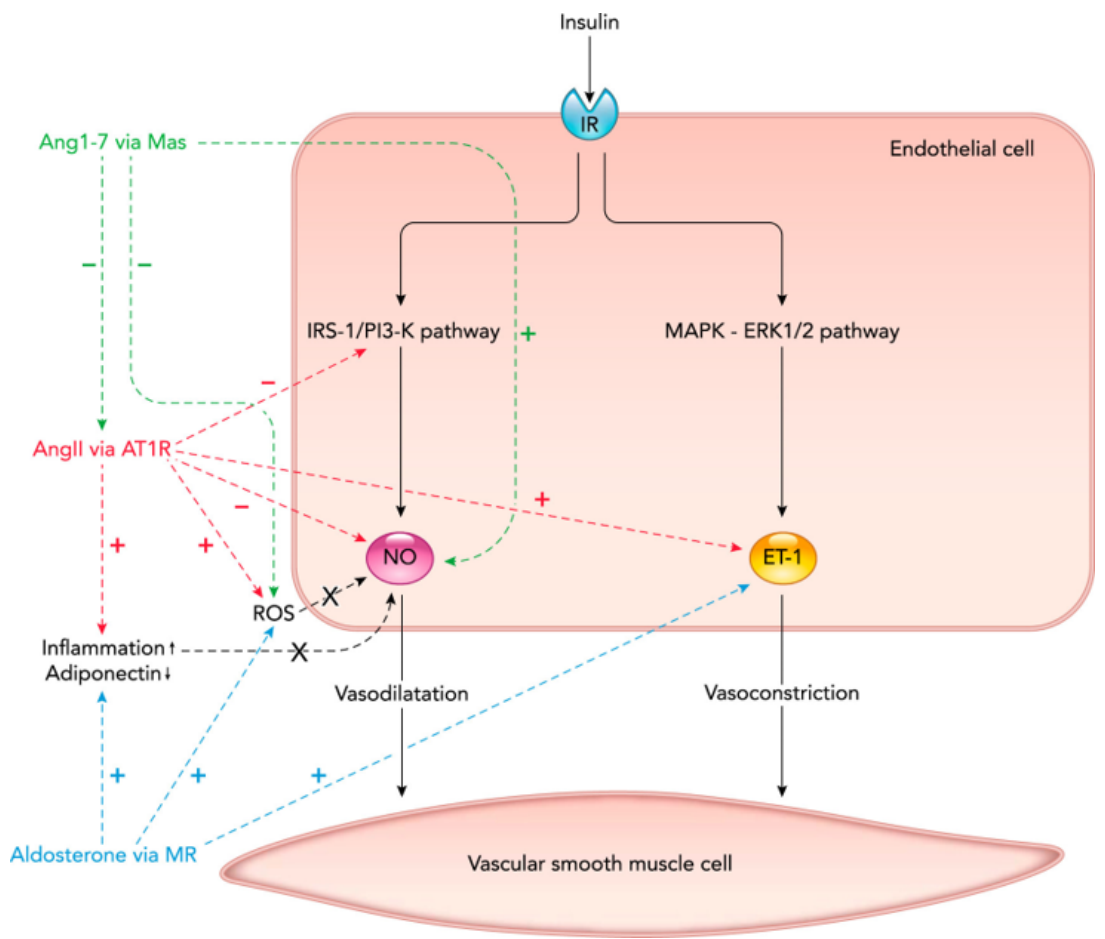

Figure 2.3: Interference of RAAS-components with (insulin-mediated) nitric oxide and endothelin-1 production. AngII = angiotensin II; MR = mineralocorticoid receptor; ROS = reactive oxygen species; $I R=$ insulin receptor; NO = nitric oxide; ET-1 = endothelin 1; Ang1-7 = angiotensin1-7

Angiotensin1-7 antagonizes microvascular actions of AngII ${ }^{178}$, and promotes NO-release by activating the Mas, and possibly AT2, receptor ${ }^{179,180}$ (Figure 2.3). This ultimately results in vasorelaxation, as demonstrated in normotensive and obese mice ${ }^{62,181}$, and in normotensive and hypertensive individuals ${ }^{182,183}$. Administration of higher doses of Ang1-7 induced peripheral vasoconstriction in both animals ${ }^{62,184,185}$ and humans ${ }^{186}$, potentially due to concomitant AT1R stimulation and/or Mas receptor saturation and desensitization ${ }^{63,187}$, although the (patho)physiological relevance of these findings is doubtful. Ang1-7 also counteracts the inhibitory effect of Angll on insulin-mediated NO production ${ }^{188}$, thereby stimulating insulin-induced muscle microvascular recruitment in rats $^{189}$. Vascular actions of Ang1-7 may affect blood pressure, as illustrated by amelioration of hypertension in stroke prone SHRs following targeted expression of human ACE2 in VSMCs ${ }^{190}$, but whether reduced microvascular Ang1-7 signaling 
contributes to the development of obesity-associated hypertension, is currently unknown.

Adipocyte-derived RAAS components act in an endocrine manner to modulate (micro)vascular function, as outlined in the foregoing paragraphs. Paracrine effects have been reported as well, due to the presence of a local fat depot around most of the blood vessels in the human body, termed perivascular adipose tissue (PVAT). Under normal circumstances, PVAT exerts anticontractile effects ${ }^{191}$ that may be mediated for an important part by adipocyte-derived Ang1-7 ${ }^{192}$, in addition to adiponectin ${ }^{193}$. Moreover, PVAT from lean mice and women was found to enhance insulin-induced vasodilatation and microvascular recruitment, conceivably in an adiponectindependent manner ${ }^{194,195}$. In obesity, PVAT-induced anticontractility is diminished or even absent ${ }^{196}$, as illustrated by PVAT from obese mice and women revealing insulininduced vasoconstriction ${ }^{194,195}$, and this might be related to an imbalance between Angll and Ang1-7 signaling. Indeed, the PVAT anticontractile response could be inhibited with an Ang1-7 antagonist in normotensive rats ${ }^{197}$, whereas both AT1R antagonism and ACE-inhibition prevented the loss of anticontractile PVAT function in rat small mesenteric arteries subjected to hypoxia ${ }^{198}$ and fructose-fed rats ${ }^{199}$. Adipocyte-derived aldosterone may also contribute to PVAT-induced contraction through activation of mineralocorticoid receptors. Indeed, eplerenone was found to improve acetylcholine-induced relaxation of small mesenteric arteries containing perivascular fat in obese diabetic mice ${ }^{25}$. To our knowledge, studies in humans on the role of RAAS dysregulation in the loss of PVAT anticontractility have not yet been performed.

\section{The renin-angiotensin-aldosterone system and arterial stiffening}

Arterial stiffening, which is both a consequence of greater mean arterial pressure and a cause of increased pulse pressure, is commonly observed in obese individuals ${ }^{200-203}$. Therefore, arterial stiffening may also precede elevations in systolic blood pressure and incident hypertension, as has been observed in a diet-induced model of obesity and in Framingham Offspring Study participants ${ }^{204,205}$.

Angiotensin II promotes arterial stiffening (Figure 2.2), also independent of effects on blood pressure ${ }^{206,207}$, by enhancing low-grade inflammation, VSMC proliferation, collagen deposition, and the development of fibrosis, which is partly mediated through increased oxidative stress ${ }^{201,208-210}$. Correspondingly, ACE-inhibitors and ARBs are more potent in reducing arterial stiffening compared to other classes of antihypertensive drugs $^{211}$. Favorable effects of these agents on arterial distensibility, carotid-femoral (cf) and carotid-radial pulse wave velocity (PWV), augmentation index, and central aortic 
pressure have also been confirmed in obese hypertensive individuals ${ }^{212,213}$, illustrating the significance of angiotensin II-induced vascular remodeling in obesity.

Aldosterone augments arterial stiffening as well ${ }^{214-216}$ (Figure 2.2), through regulation of collagen turnover and fibrous tissue formation, increases in inflammation and oxidative stress $^{208,209,217}$, and potentially endothelial stiffness ${ }^{218}$. These actions may be partly exerted by SMC $\mathrm{MRs}^{219}$ and are not necessarily blood pressure-dependent ${ }^{220}$. In addition, aldosterone was found to potentiate some of the hypertrophic effects of Angll on cultured $\mathrm{SMCs}^{217}$. Thus, several measures of arterial stiffening have been demonstrated to improve as a result of MR blockade in hypertensive and obese animals ${ }^{173,215,221}$, and in essential hypertensive individuals ${ }^{216,222,223}$, also independent of reductions in blood pressure. Similarly, heart-ankle and brachial-ankle PWV decreased following adrenalectomy in patients with aldosterone-producing adenoma ${ }^{224}$. Whether MR blockade affects arterial stiffening in human obesity remains to be established, but the association of aldosterone with heart-femoral PWV in overweight and obese young adults $^{225}$, and a reduction of aldosterone levels in parallel with cfPWV in obese, hypertensive individuals after exercise training ${ }^{226}$ suggest a beneficial response.

Although increased arterial stiffness following Angll administration and with aging has been demonstrated in ACE2 knockout murine mesenteric arteries ${ }^{227}$, the role of the Ang1-7/Mas axis in the modulation of obesity-related arterial stiffening awaits further investigation.

\section{Conclusion and future perspectives}

Dysfunctional adipose tissue contributes to increased circulating levels of angiotensin II and aldosterone as observed in obesity, and potentially, impairs metabolism of Angll to Ang1-7. Whether adipocyte-derived angiotensinogen is predominantly converted to angiotensin peptides within adipose tissue or by systemic RAAS components, and how RAAS dysregulation affects PVAT anticontractility, should be further elucidated. Nevertheless, the involvement of adipose tissue in obesity-associated RAAS overactivity stresses the importance of weight loss as antihypertensive strategy in hypertensive obese individuals.

Increased levels of angiotensin II and aldosterone, in part resulting from adipose tissue dysfunction, not only induce sodium retention and sympathoexcitation, but may also impair (insulin-associated) microvascular function and modulate arterial stiffening, ultimately resulting in elevated blood pressure. By intervening in the regulation of both extracellular volume and vascular tone, ACE-inhibitors, angiotensin receptor blockers, 
and mineralocorticoid receptor antagonists can thus be, at least in theory, of great value in the treatment of obesity-associated hypertension.

In advanced and longstanding hypertension, the complexity of its pathophysiology increases because of the cardiovascular and renal alterations that are secondary to high blood pressure itself. Multiple agents are then often needed for blood pressure control, which makes it difficult to investigate the relative merits of specific agents. Therefore, whether specific agents such as mineralocorticoid receptor antagonists have superior efficacy in obesity-associated hypertension, and can target presumed mechanisms including SNS overactivity, (renal) microvascular dysfunction, and arterial stiffening, can probably best be studied in lean and obese individuals with mild hypertension of relatively short duration, preferably before and after weight loss in the obese individuals. Such studies are very scarce. In addition, unraveling the role of the AT2 receptor in the pathophysiological mechanisms underlying elevated blood pressure in human obesity might be of therapeutic benefit, particularly when AT2R agonists such as Compound 21 become available for clinical applications.

Finally, although the role of angiotensin1-7 in sodium homeostasis, and the net influence of its central actions on blood pressure are ambiguous, favorable effects on (insulin-mediated) microvascular function, and potentially vascular stiffening, have been demonstrated. Future research should be directed towards comparing adipocyte ACE2 expression and activity between lean and obese individuals, and before and after weight loss. Moreover, studying the effect of Ang1-7 administration on sodium balance, sympathetic nerve activity and micro- and macrovascular function in lean versus obese humans would contribute to a better understanding of its relative contribution to the regulation of extracellular volume and vascular tone. For this latter purpose, Mas receptor agonists and antagonists eligible for administration in humans are also eagerly awaited, and in addition, Mas receptor agonists may obviously have therapeutic potential. 


\section{References}

1. Garrison RJ, Kannel WB, Stokes J, 3rd, Castelli WP. Incidence and precursors of hypertension in young adults: The framingham offspring study. Prev Med. 1987;16:235-251

2. Hall JE, do Carmo JM, da Silva AA, Wang Z, Hall ME. Obesity-induced hypertension: Interaction of neurohumoral and renal mechanisms. Circ Res. 2015;116:991-1006

3. Dorresteijn JA, Visseren FL, Spiering W. Mechanisms linking obesity to hypertension. Obes Rev. 2012; 13:17-26

4. Harte A, McTernan P, Chetty R, Coppack S, Katz J, Smith S, et al. Insulin-mediated upregulation of the renin angiotensin system in human subcutaneous adipocytes is reduced by rosiglitazone. Circulation. 2005;111:1954-1961

5. Engeli S, Gorzelniak K, Kreutz R, Runkel N, Distler A, Sharma AM. Co-expression of renin-angiotensin system genes in human adipose tissue. J Hypertens. 1999;17:555-560

6. Fowler JD, Johnson ND, Haroldson TA, Brintnall JA, Herrera JE, Katz SA, et al. Regulated renin release from 3t3-I1 adipocytes. Am J Physiol Endocrinol Metab. 2009;296:E1383-1391

7. Galvez-Prieto B, Bolbrinker J, Stucchi P, de Las Heras Al, Merino B, Arribas S, et al. Comparative expression analysis of the renin-angiotensin system components between white and brown perivascular adipose tissue. J Endocrinol. 2008;197:55-64

8. Giacchetti G, Faloia E, Mariniello B, Sardu C, Gatti C, Camilloni MA, et al. Overexpression of the reninangiotensin system in human visceral adipose tissue in normal and overweight subjects. Am J Hypertens. 2002;15:381-388

9. Karlsson C, Lindell K, Ottosson M, Sjostrom L, Carlsson B, Carlsson LM. Human adipose tissue expresses angiotensinogen and enzymes required for its conversion to angiotensin ii. J Clin Endocrinol Metab. 1998;83:3925-3929

10. Lu C, Su LY, Lee RM, Gao YJ. Mechanisms for perivascular adipose tissue-mediated potentiation of vascular contraction to perivascular neuronal stimulation: The role of adipocyte-derived angiotensin ii. Eur J Pharmacol. 2010;634:107-112

11. Pinterova L, Krizanova O, Zorad S. Rat epididymal fat tissue express all components of the reninangiotensin system. Gen Physiol Biophys. 2000;19:329-334

12. Saye JA, Ragsdale NV, Carey RM, Peach MJ. Localization of angiotensin peptide-forming enzymes of 3t3f442a adipocytes. Am J Physiol. 1993;264:C1570-1576

13. Schling $P$, Mallow $H$, Trindl A, Loffler $G$. Evidence for a local renin angiotensin system in primary cultured human preadipocytes. Int J Obes Relat Metab Disord. 1999;23:336-341

14. Shenoy U, Cassis L. Characterization of renin activity in brown adipose tissue. Am J Physiol. 1997;272:C989-999

15. Yasue S, Masuzaki H, Okada S, Ishii T, Kozuka C, Tanaka T, et al. Adipose tissue-specific regulation of angiotensinogen in obese humans and mice: Impact of nutritional status and adipocyte hypertrophy. Am J Hypertens. 2010;23:425-431

16. Schling P, Schafer T. Human adipose tissue cells keep tight control on the angiotensin ii levels in their vicinity. J Biol Chem. 2002;277:48066-48075

17. Phillips MI, Speakman EA, Kimura B. Levels of angiotensin and molecular biology of the tissue renin angiotensin systems. Regul Pept. 1993;43:1-20

18. Boustany CM, Bharadwaj K, Daugherty A, Brown DR, Randall DC, Cassis LA. Activation of the systemic and adipose renin-angiotensin system in rats with diet-induced obesity and hypertension. Am J Physiol Regul Integr Comp Physiol. 2004;287:R943-949

19. Van Harmelen V, Ariapart P, Hoffstedt J, Lundkvist I, Bringman S, Arner P. Increased adipose angiotensinogen gene expression in human obesity. Obes Res. 2000;8:337-341

20. Giacchetti G, Sechi LA, Griffin CA, Don BR, Mantero F, Schambelan M. The tissue renin-angiotensin system in rats with fructose-induced hypertension: Overexpression of type 1 angiotensin ii receptor in adipose tissue. J Hypertens. 2000;18:695-702 
21. Tamura K, Umemura S, Yamakawa T, Nyui N, Hibi K, Watanabe Y, et al. Modulation of tissue angiotensinogen gene expression in genetically obese hypertensive rats. Am J Physiol. 1997;272: R1704-1711

22. Engeli S, Bohnke J, Gorzelniak K, Janke J, Schling $P$, Bader $M$, et al. Weight loss and the reninangiotensin-aldosterone system. Hypertension. 2005;45:356-362

23. Faloia E, Gatti C, Camilloni MA, Mariniello B, Sardu C, Garrapa GG, et al. Comparison of circulating and local adipose tissue renin-angiotensin system in normotensive and hypertensive obese subjects. $J$ Endocrinol Invest. 2002;25:309-314

24. Yiannikouris F, Gupte M, Putnam K, Thatcher S, Charnigo R, Rateri DL, et al. Adipocyte deficiency of angiotensinogen prevents obesity-induced hypertension in male mice. Hypertension. 2012;60: 1524-1530

25. Briones AM, Nguyen Dinh Cat A, Callera GE, Yogi A, Burger D, He Y, et al. Adipocytes produce aldosterone through calcineurin-dependent signaling pathways: Implications in diabetes mellitusassociated obesity and vascular dysfunction. Hypertension. 2012;59:1069-1078

26. Rossi GP, Belfiore A, Bernini G, Fabris B, Caridi G, Ferri C, et al. Body mass index predicts plasma aldosterone concentrations in overweight-obese primary hypertensive patients. J Clin Endocrinol Metab. 2008;93:2566-2571

27. Dinh Cat AN, Friederich-Persson M, White A, Touyz RM. Adipocytes, aldosterone and obesity-related hypertension. J Mol Endocrinol. 2016;57:F7-F21

28. Huby AC, Antonova G, Groenendyk J, Gomez-Sanchez CE, Bollag WB, Filosa JA, et al. Adipocyte-derived hormone leptin is a direct regulator of aldosterone secretion, which promotes endothelial dysfunction and cardiac fibrosis. Circulation. 2015;132:2134-2145

29. Jeon JH, Kim KY, Kim JH, Baek A, Cho H, Lee YH, et al. A novel adipokine ctrp1 stimulates aldosterone production. Faseb J. 2008;22:1502-1511

30. Engeli S, Schling P, Gorzelniak K, Boschmann M, Janke J, Ailhaud G, et al. The adipose-tissue reninangiotensin-aldosterone system: Role in the metabolic syndrome? Int J Biochem Cell Biol. 2003;35: 807-825

31. Achard V, Boullu-Ciocca S, Desbriere R, Nguyen G, Grino M. Renin receptor expression in human adipose tissue. Am J Physiol Regul Integr Comp Physiol. 2007;292:R274-282

32. Nguyen G, Delarue F, Burckle C, Bouzhir L, Giller T, Sraer JD. Pivotal role of the renin/prorenin receptor in angiotensin ii production and cellular responses to renin. J Clin Invest. 2002;109:1417-1427

33. Kaneshiro $\mathrm{Y}$, Ichihara A, Sakoda M, Takemitsu T, Nabi AH, Uddin MN, et al. Slowly progressive, angiotensin ii-independent glomerulosclerosis in human (pro)renin receptor-transgenic rats. J Am Soc Nephrol. 2007;18:1789-1795

34. Santos RA, Ferreira AJ, Verano-Braga T, Bader M. Angiotensin-converting enzyme 2, angiotensin-(1-7) and mas: New players of the renin-angiotensin system. J Endocrinol. 2013;216:R1-R17

35. Gupte M, Thatcher SE, Boustany-Kari CM, Shoemaker R, Yiannikouris F, Zhang X, et al. Angiotensin converting enzyme 2 contributes to sex differences in the development of obesity hypertension in c57bl/6 mice. Arterioscler Thromb Vasc Biol. 2012;32:1392-1399

36. Bell PD, Peti-Peterdi J. Angiotensin ii stimulates macula densa basolateral sodium/hydrogen exchange via type 1 angiotensin ii receptors. J Am Soc Nephrol. 1999;10 Suppl 11:S225-229

37. Burns KD, Li N. The role of angiotensin ii-stimulated renal tubular transport in hypertension. Curr Hypertens Rep. 2003;5:165-171

38. Cogan MG. Angiotensin ii: A powerful controller of sodium transport in the early proximal tubule. Hypertension. 1990;15:451-458

39. Hall JE. Control of sodium excretion by angiotensin ii: Intrarenal mechanisms and blood pressure regulation. Am J Physiol. 1986;250:R960-972

40. Hall JE, Brands MW, Henegar JR. Angiotensin ii and long-term arterial pressure regulation: The overriding dominance of the kidney. J Am Soc Nephrol. 1999;10 Suppl 12:S258-265

41. Kovacs G, Peti-Peterdi J, Rosivall L, Bell PD. Angiotensin ii directly stimulates macula densa na-2cl-k cotransport via apical at(1) receptors. Am J Physiol Renal Physiol. 2002;282:F301-306

42. Peti-Peterdi J, Warnock DG, Bell PD. Angiotensin ii directly stimulates enac activity in the cortical collecting duct via at(1) receptors. J Am Soc Nephrol. 2002;13:1131-1135 
43. Xu ZG, Lanting L, Vaziri ND, Li Z, Sepassi L, Rodriguez-Iturbe B, et al. Upregulation of angiotensin ii type 1 receptor, inflammatory mediators, and enzymes of arachidonate metabolism in obese zucker rat kidney: Reversal by angiotensin ii type 1 receptor blockade. Circulation. 2005;111:1962-1969

44. Tallam LS, Jandhyala BS. Significance of exaggerated natriuresis after angiotensin at1 receptor blockade or angiotensin- converting enzyme inhibition in obese zucker rats. Clin Exp Pharmacol Physiol. 2001;28:433-440

45. Caruso D, D'Avino M, Acampora C, Romano L, Bevilacqua N, Caruso G, et al. Effects of losartan and chlorthalidone on blood pressure and renal vascular resistance index in non-diabetic patients with essential hypertension and normal renal function. J Cardiovasc Pharmacol. 2004;44:520-524

46. Hakam AC, Hussain T. Renal angiotensin ii type-2 receptors are upregulated and mediate the candesartan-induced natriuresis/diuresis in obese zucker rats. Hypertension. 2005;45:270-275

47. Ali $Q$, Hussain T. At2 receptor non-peptide agonist c21 promotes natriuresis in obese zucker rats. Hypertens Res. 2012;35:654-660

48. Connell JM, Davies E. The new biology of aldosterone. J Endocrinol. 2005;186:1-20

49. Fu Y, Vallon V. Mineralocorticoid-induced sodium appetite and renal salt retention: Evidence for common signaling and effector mechanisms. Nephron Physiol. 2014;128:8-16

50. Riazi S, Khan O, Hu X, Ecelbarger CA. Aldosterone infusion with high-nacl diet increases blood pressure in obese but not lean zucker rats. Am J Physiol Renal Physiol. 2006;291:F597-605

51. Arima S, Kohagura K, Xu HL, Sugawara A, Abe T, Satoh F, et al. Nongenomic vascular action of aldosterone in the glomerular microcirculation. J Am Soc Nephrol. 2003;14:2255-2263

52. Schmidt BM, Sammer U, Fleischmann I, Schlaich M, Delles C, Schmieder RE. Rapid nongenomic effects of aldosterone on the renal vasculature in humans. Hypertension. 2006;47:650-655

53. de Paula RB, da Silva AA, Hall JE. Aldosterone antagonism attenuates obesity-induced hypertension and glomerular hyperfiltration. Hypertension. 2004;43:41-47

54. Formenti S, Bassi M, Nakamura NB, Schoorlemmer GH, Menani JV, Colombari E. Hindbrain mineralocorticoid mechanisms on sodium appetite. Am J Physiol Regul Integr Comp Physiol. 2013;304: R252-259

55. Schutten MT, Houben AJ, Kroon AA, Stehouwer CD, de Leeuw PW. Aldosterone-renin ratio and sideselective renal perfusion in essential hypertension. Am J Hypertens. 2016;29(11):1311-1316

56. Lara LS, Bica RB, Sena SL, Correa JS, Marques-Fernandes MF, Lopes AG, et al. Angiotensin-(1-7) reverts the stimulatory effect of angiotensin ii on the proximal tubule na(+)-atpase activity via a a779-sensitive receptor. Regul Pept. 2002;103:17-22

57. Lara Lda S, Cavalcante F, Axelband F, De Souza AM, Lopes AG, Caruso-Neves C. Involvement of the $\mathrm{gi} / \mathrm{o} / \mathrm{cgmp} / \mathrm{pkg}$ pathway in the at2-mediated inhibition of outer cortex proximal tubule na+-atpase by ang-(1-7). Biochem J. 2006;395:183-190

58. Andreatta-van Leyen S, Romero MF, Khosla MC, Douglas JG. Modulation of phospholipase a2 activity and sodium transport by angiotensin-(1-7). Kidney Int. 1993;44:932-936

59. Lara LS, Correa JS, Lavelle AB, Lopes AG, Caruso-Neves C. The angiotensin receptor type 1-gq proteinphosphatidyl inositol phospholipase cbeta-protein kinase $c$ pathway is involved in activation of proximal tubule na+-atpase activity by angiotensin(1-7) in pig kidneys. Exp Physiol. 2008;93:639-647

60. van der Wouden EA, Ochodnicky P, van Dokkum RP, Roks AJ, Deelman LE, de Zeeuw D, et al. The role of angiotensin(1-7) in renal vasculature of the rat. J Hypertens. 2006;24:1971-1978

61. Ren Y, Garvin JL, Carretero OA. Vasodilator action of angiotensin-(1-7) on isolated rabbit afferent arterioles. Hypertension. 2002;39:799-802

62. Sampaio WO, Nascimento AA, Santos RA. Systemic and regional hemodynamic effects of angiotensin(1-7) in rats. Am J Physiol Heart Circ Physiol. 2003;284:H1985-1994

63. van Rodijnen WF, van Lambalgen TA, van Wijhe MH, Tangelder GJ, Ter Wee PM. Renal microvascular actions of angiotensin ii fragments. Am J Physiol Renal Physiol. 2002;283:F86-92

64. van Twist DJ, Kroon AA, de Leeuw PW. Angiotensin-(1-7) as a strategy in the treatment of hypertension? Curr Opin Nephrol Hypertens. 2014;23:480-486

65. Ferrario CM, Martell N, Yunis C, Flack JM, Chappell MC, Brosnihan KB, et al. Characterization of angiotensin-(1-7) in the urine of normal and essential hypertensive subjects. Am J Hypertens. 1998;11:137-146 
66. Luque M, Martin P, Martell N, Fernandez C, Brosnihan KB, Ferrario CM. Effects of captopril related to increased levels of prostacyclin and angiotensin-(1-7) in essential hypertension. J Hypertens. 1996;14:799-805

67. Henegar JR, Zhang Y, De Rama R, Hata C, Hall ME, Hall JE. Catheter-based radiorefrequency renal denervation lowers blood pressure in obese hypertensive dogs. Am J Hypertens. 2014;27:1285-1292

68. Lohmeier TE, Iliescu R, Liu B, Henegar JR, Maric-Bilkan C, Irwin ED. Systemic and renal-specific sympathoinhibition in obesity hypertension. Hypertension. 2012;59:331-338

69. Anderson JW, Smith PM, Ferguson AV. Subfornical organ neurons projecting to paraventricular nucleus: Whole-cell properties. Brain Res. 2001;921:78-85

70. Ferguson AV, Bains JS. Actions of angiotensin in the subfornical organ and area postrema: Implications for long term control of autonomic output. Clin Exp Pharmacol Physiol. 1997;24:96-101

71. Smith PM, Ferguson AV. Circulating signals as critical regulators of autonomic state--central roles for the subfornical organ. Am J Physiol Regul Integr Comp Physiol. 2010;299:R405-415

72. Biancardi VC, Son SJ, Ahmadi S, Filosa JA, Stern JE. Circulating angiotensin ii gains access to the hypothalamus and brain stem during hypertension via breakdown of the blood-brain barrier. Hypertension. 2014;63:572-579

73. Biancardi VC, Stern JE. Compromised blood-brain barrier permeability: Novel mechanism by which circulating angiotensin ii signals sympathoexcitatory centers during hypertension. J Physiol. 2015; 594(6):1591-1600

74. Averill DB, Tsuchihashi T, Khosla MC, Ferrario CM. Losartan, nonpeptide angiotensin ii-type 1 (at1) receptor antagonist, attenuates pressor and sympathoexcitatory responses evoked by angiotensin ii and I-glutamate in rostral ventrolateral medulla. Brain Res. 1994;665:245-252

75. Boscan P, Allen AM, Paton JF. Baroreflex inhibition of cardiac sympathetic outflow is attenuated by angiotensin ii in the nucleus of the solitary tract. Neuroscience. 2001;103:153-160

76. Li DP, Pan HL. Angiotensin ii attenuates synaptic gaba release and excites paraventricular-rostral ventrolateral medulla output neurons. J Pharmacol Exp Ther. 2005;313:1035-1045

77. Li YF, Wang W, Mayhan WG, Patel KP. Angiotensin-mediated increase in renal sympathetic nerve discharge within the pvn: Role of nitric oxide. Am J Physiol Regul Integr Comp Physiol. 2006;290: R1035-1043

78. Tagawa T, Dampney RA. At(1) receptors mediate excitatory inputs to rostral ventrolateral medulla pressor neurons from hypothalamus. Hypertension. 1999;34:1301-1307

79. Zhu GQ, Patel KP, Zucker IH, Wang W. Microinjection of ang ii into paraventricular nucleus enhances cardiac sympathetic afferent reflex in rats. Am J Physiol Heart Circ Physiol. 2002;282:H2039-2045

80. Veltmar A, Culman J, Qadri F, Rascher W, Unger T. Involvement of adrenergic and angiotensinergic receptors in the paraventricular nucleus in the angiotensin ii-induced vasopressin release. J Pharmacol Exp Ther. 1992;263:1253-1260

81. Reid IA. Interactions between ang ii, sympathetic nervous system, and baroreceptor reflexes in regulation of blood pressure. Am J Physiol. 1992;262:E763-778

82. Dupont AG, Brouwers S. Brain angiotensin peptides regulate sympathetic tone and blood pressure. $J$ Hypertens. 2010;28:1599-1610

83. Matsuura T, Kumagai H, Onimaru H, Kawai A, ligaya K, Onami T, et al. Electrophysiological properties of rostral ventrolateral medulla neurons in angiotensin ii 1a receptor knockout mice. Hypertension. 2005;46:349-354

84. Moretti JL, Burke SL, Davern PJ, Evans RG, Lambert GW, Head GA. Renal sympathetic activation from long-term low-dose angiotensin ii infusion in rabbits. J Hypertens. 2012;30:551-560

85. Matsukawa T, Gotoh E, Minamisawa K, Kihara M, Ueda S, Shionoiri H, et al. Effects of intravenous infusions of angiotensin ii on muscle sympathetic nerve activity in humans. Am J Physiol. 1991;261:R690-696

86. Grassi G, Seravalle G, Dell'Oro R, Trevano FQ, Bombelli M, Scopelliti F, et al. Comparative effects of candesartan and hydrochlorothiazide on blood pressure, insulin sensitivity, and sympathetic drive in obese hypertensive individuals: Results of the cross study. J Hypertens. 2003;21:1761-1769

87. Huber DA, Schreihofer AM. Altered regulation of the rostral ventrolateral medulla in hypertensive obese zucker rats. Am J Physiol Heart Circ Physiol. 2011;301:H230-240 
88. Kishi T, Hirooka Y, Konno S, Sunagawa K. Angiotensin ii receptor blockers improve endothelial dysfunction associated with sympathetic hyperactivity in metabolic syndrome. J Hypertens. 2012;30:1646-1655

89. Konno S, Hirooka Y, Kishi T, Sunagawa K. Sympathoinhibitory effects of telmisartan through the reduction of oxidative stress in the rostral ventrolateral medulla of obesity-induced hypertensive rats. $J$ Hypertens. 2012;30:1992-1999

90. Geerling JC, Loewy AD. Aldosterone in the brain. Am J Physiol Renal Physiol. 2009;297:F559-576

91. Gomez-Sanchez EP, Gomez-Sanchez CE. Central regulation of blood pressure by the mineralocorticoid receptor. Mol Cell Endocrinol. 2012;350:289-298

92. Nakagaki T, Hirooka $Y$, Matsukawa $R$, Nishihara $M$, Nakano $M$, Ito $K$, et al. Activation of mineralocorticoid receptors in the rostral ventrolateral medulla is involved in hypertensive mechanisms in stroke-prone spontaneously hypertensive rats. Hypertens Res. 2012;35:470-476

93. Zhang ZH, Yu Y, Kang YM, Wei SG, Felder RB. Aldosterone acts centrally to increase brain reninangiotensin system activity and oxidative stress in normal rats. Am J Physiol Heart Circ Physiol. 2008;294:H1067-1074

94. Gomez-Sanchez EP, Fort CM, Gomez-Sanchez CE. Intracerebroventricular infusion of ru28318 blocks aldosterone-salt hypertension. Am J Physiol. 1990;258:E482-484

95. Janiak PC, Lewis SJ, Brody MJ. Role of central mineralocorticoid binding sites in development of hypertension. Am J Physiol. 1990;259:R1025-1034

96. Monahan KD, Leuenberger UA, Ray CA. Aldosterone impairs baroreflex sensitivity in healthy adults. Am J Physiol Heart Circ Physiol. 2007;292:H190-197

97. Raheja P, Price A, Wang Z, Arbique D, Adams-Huet B, Auchus RJ, et al. Spironolactone prevents chlorthalidone-induced sympathetic activation and insulin resistance in hypertensive patients. Hypertension. 2012;60:319-325

98. Boer-Martins L, Figueiredo VN, Demacq C, Martins LC, Faria AP, Moraes Cde H, et al. Leptin and aldosterone in sympathetic activity in resistant hypertension with or without type 2 diabetes. Arq Bras Cardiol. 2012;99:642-648

99. Feng $\mathrm{Y}, \mathrm{Xia}$ H, Cai Y, Halabi CM, Becker LK, Santos RA, et al. Brain-selective overexpression of human angiotensin-converting enzyme type 2 attenuates neurogenic hypertension. Circ Res. 2010;106:373-382

100. Feng $\mathrm{Y}$, Yue $\mathrm{X}, \mathrm{Xia} \mathrm{H}$, Bindom SM, Hickman PJ, Filipeanu CM, et al. Angiotensin-converting enzyme 2 overexpression in the subfornical organ prevents the angiotensin ii-mediated pressor and drinking responses and is associated with angiotensin ii type 1 receptor downregulation. Circ Res. 2008;102: 729-736

101. Sriramula S, Cardinale JP, Lazartigues E, Francis J. Ace2 overexpression in the paraventricular nucleus attenuates angiotensin ii-induced hypertension. Cardiovasc Res. 2011;92:401-408

102. Yamazato M, Yamazato Y, Sun C, Diez-Freire C, Raizada MK. Overexpression of angiotensin-converting enzyme 2 in the rostral ventrolateral medulla causes long-term decrease in blood pressure in the spontaneously hypertensive rats. Hypertension. 2007;49:926-931

103. Li P, Zhang F, Zhou YB, Cui BP, Han Y. Superoxide anions modulate the effects of angiotensin-(1-7) in the rostral ventrolateral medulla on cardiac sympathetic afferent reflex and sympathetic activity in rats. Neuroscience. 2012;223:388-398

104. Fontes MA, Silva LC, Campagnole-Santos MJ, Khosla MC, Guertzenstein PG, Santos RA. Evidence that angiotensin-(1-7) plays a role in the central control of blood pressure at the ventro-lateral medulla acting through specific receptors. Brain Res. 1994;665:175-180

105. Santos RA, Campagnole-Santos MJ. Central and peripheral actions of angiotensin-(1-7). Braz J Med Biol Res. 1994;27:1033-1047

106. Nakagaki T, Hirooka Y, Ito K, Kishi T, Hoka S, Sunagawa K. Role of angiotensin-(1-7) in rostral ventrolateral medulla in blood pressure regulation via sympathetic nerve activity in wistar-kyoto and spontaneous hypertensive rats. Clin Exp Hypertens. 2011;33:223-230

107. Silva $A Q$, Santos RA, Fontes MA. Blockade of endogenous angiotensin-(1-7) in the hypothalamic paraventricular nucleus reduces renal sympathetic tone. Hypertension. 2005;46:341-348 
108. Mahon JM, Allen M, Herbert J, Fitzsimons JT. The association of thirst, sodium appetite and vasopressin release with c-fos expression in the forebrain of the rat after intracerebroventricular injection of angiotensin ii, angiotensin-(1-7) or carbachol. Neuroscience. 1995;69:199-208

109. Schiavone MT, Santos RA, Brosnihan KB, Khosla MC, Ferrario CM. Release of vasopressin from the rat hypothalamo-neurohypophysial system by angiotensin-(1-7) heptapeptide. Proc Natl Acad Sci U S A. 1988;85:4095-4098

110. Campagnole-Santos MJ, Heringer SB, Batista EN, Khosla MC, Santos RA. Differential baroreceptor reflex modulation by centrally infused angiotensin peptides. Am J Physiol. 1992;263:R89-94

111. Chaves GZ, Caligiorne SM, Santos RA, Khosla MC, Campagnole-Santos MJ. Modulation of the baroreflex control of heart rate by angiotensin-(1-7) at the nucleus tractus solitarii of normotensive and spontaneously hypertensive rats. J Hypertens. 2000;18:1841-1848

112. Britto RR, Santos RA, Fagundes-Moura CR, Khosla MC, Campagnole-Santos MJ. Role of angiotensin-(1-7) in the modulation of the baroreflex in renovascular hypertensive rats. Hypertension. 1997;30:549-556

113. Xue B, Zhang Z, Johnson RF, Guo F, Hay M, Johnson AK. Central endogenous angiotensin-(1-7) protects against aldosterone/nacl-induced hypertension in female rats. Am J Physiol Heart Circ Physiol. 2013;305:H699-705

114. Oliveira DR, Santos RA, Santos GF, Khosla M, Campagnole-Santos MJ. Changes in the baroreflex control of heart rate produced by central infusion of selective angiotensin antagonists in hypertensive rats. Hypertension. 1996;27:1284-1290

115. Benter IF, Diz DI, Ferrario CM. Pressor and reflex sensitivity is altered in spontaneously hypertensive rats treated with angiotensin-(1-7). Hypertension. 1995;26:1138-1144

116. Levy BI, Ambrosio G, Pries AR, Struijker-Boudier HA. Microcirculation in hypertension: A new target for treatment? Circulation. 2001;104:735-740

117. Karaca U, Schram MT, Houben AJ, Muris DM, Stehouwer CD. Microvascular dysfunction as a link between obesity, insulin resistance and hypertension. Diabetes Res Clin Pract. 2014;103:382-387

118. Jonk AM, Houben AJ, de Jongh RT, Serne EH, Schaper NC, Stehouwer CD. Microvascular dysfunction in obesity: A potential mechanism in the pathogenesis of obesity-associated insulin resistance and hypertension. Physiology. 2007;22:252-260

119. Levy BI, Schiffrin EL, Mourad JJ, Agostini D, Vicaut E, Safar ME, et al. Impaired tissue perfusion: A pathology common to hypertension, obesity, and diabetes mellitus. Circulation. 2008;118:968-976

120. De Boer MP, Meijer RI, Wijnstok NJ, Jonk AM, Houben AJ, Stehouwer CD, et al. Microvascular dysfunction: A potential mechanism in the pathogenesis of obesity-associated insulin resistance and hypertension. Microcirculation. 2012;19:5-18

121. Serne EH, Gans RO, ter Maaten JC, Tangelder GJ, Donker AJ, Stehouwer CD. Impaired skin capillary recruitment in essential hypertension is caused by both functional and structural capillary rarefaction. Hypertension. 2001;38:238-242

122. Ding J, Wai KL, McGeechan K, Ikram MK, Kawasaki R, Xie J, et al. Retinal vascular caliber and the development of hypertension: A meta-analysis of individual participant data. J Hypertens. 2014;32: 207-215

123. Hedman A, Reneland R, Lithell HO. Alterations in skeletal muscle morphology in glucose-tolerant elderly hypertensive men: Relationship to development of hypertension and heart rate. J Hypertens. 2000;18:559-565

124. de Boer MP, Wijnstok NJ, Serne EH, Eringa EC, Stehouwer CD, Flyvbjerg A, et al. Body mass index is related to microvascular vasomotion, this is partly explained by adiponectin. Eur J Clin Invest. 2014;44: 660-667

125. de Jongh RT, Ijzerman RG, Serne EH, Voordouw JJ, Yudkin JS, de Waal HA, et al. Visceral and truncal subcutaneous adipose tissue are associated with impaired capillary recruitment in healthy individuals. $J$ Clin Endocrinol Metab. 2006;91:5100-5106

126. de Jongh RT, Serne EH, RG IJ, de Vries G, Stehouwer CD. Impaired microvascular function in obesity: Implications for obesity-associated microangiopathy, hypertension, and insulin resistance. Circulation. 2004;109:2529-2535

127. Frisbee JC. Hypertension-independent microvascular rarefaction in the obese zucker rat model of the metabolic syndrome. Microcirculation. 2005;12:383-392 
128. Muris DM, Houben AJ, Kroon AA, Henry RM, van der Kallen CJ, Sep SJ, et al. Age, waist circumference, and blood pressure are associated with skin microvascular flow motion: The maastricht study. J Hypertens. 2014;32:2439-2449; discussion 2449

129. Ko SH, Cao W, Liu Z. Hypertension management and microvascular insulin resistance in diabetes. Curr Hypertens Rep. 2010;12:243-251

130. Muniyappa R, Yavuz S. Metabolic actions of angiotensin ii and insulin: A microvascular endothelial balancing act. Mol Cell Endocrinol. 2013;378:59-69

131. Hornstra JM, Serne EH, Eringa EC, Wijnker MC, de Boer MP, Yudkin JS, et al. Insulin's microvascular vasodilatory effects are inversely related to peripheral vascular resistance in overweight, but insulinsensitive subjects. Obesity (Silver Spring). 2013;21:2557-2561

132. Li R, Zhang $\mathrm{H}$, Wang $\mathrm{W}$, Wang $\mathrm{X}$, Huang $\mathrm{Y}$, Huang $\mathrm{C}$, et al. Vascular insulin resistance in prehypertensive rats: Role of pi3-kinase/akt/enos signaling. Eur J Pharmacol. 2010;628:140-147

133. Clerk LH, Vincent MA, Jahn LA, Liu Z, Lindner JR, Barrett EJ. Obesity blunts insulin-mediated microvascular recruitment in human forearm muscle. Diabetes. 2006;55:1436-1442

134. de Jongh RT, Clark AD, RG IJ, Serne EH, de Vries G, Stehouwer CD. Physiological hyperinsulinaemia increases intramuscular microvascular reactive hyperaemia and vasomotion in healthy volunteers. Diabetologia. 2004;47:978-986

135. Lillioja S, Young AA, Culter CL, Ivy JL, Abbott WG, Zawadzki JK, et al. Skeletal muscle capillary density and fiber type are possible determinants of in vivo insulin resistance in man. J Clin Invest. 1987;80: 415-424

136. Serne EH, Gans RO, ter Maaten JC, ter Wee PM, Donker AJ, Stehouwer CD. Capillary recruitment is impaired in essential hypertension and relates to insulin's metabolic and vascular actions. Cardiovasc Res. 2001;49:161-168

137. Serne EH, RG IJ, Gans RO, Nijveldt R, De Vries G, Evertz R, et al. Direct evidence for insulin-induced capillary recruitment in skin of healthy subjects during physiological hyperinsulinemia. Diabetes. 2002; 51:1515-1522

138. Serne EH, Stehouwer CD, ter Maaten JC, ter Wee PM, Rauwerda JA, Donker AJ, et al. Microvascular function relates to insulin sensitivity and blood pressure in normal subjects. Circulation. 1999;99: 896-902

139. Boydens C, Maenhaut N, Pauwels B, Decaluwe K, Van de Voorde J. Adipose tissue as regulator of vascular tone. Curr Hypertens Rep. 2012;14:270-278

140. Chen H, Montagnani M, Funahashi T, Shimomura I, Quon MJ. Adiponectin stimulates production of nitric oxide in vascular endothelial cells. J Biol Chem. 2003;278:45021-45026

141. Mehta PK, Griendling KK. Angiotensin ii cell signaling: Physiological and pathological effects in the cardiovascular system. Am J Physiol Cell Physiol. 2007;292:C82-97

142. Lyons D, Webster J, Benjamin N. Angiotensin ii. Adrenergic sympathetic constrictor action in humans. Circulation. 1995;91:1457-1460

143. Andreozzi F, Laratta E, Sciacqua A, Perticone F, Sesti G. Angiotensin ii impairs the insulin signaling pathway promoting production of nitric oxide by inducing phosphorylation of insulin receptor substrate-1 on ser312 and ser616 in human umbilical vein endothelial cells. Circ Res. 2004;94: 1211-1218

144. Velloso LA, Folli F, Sun XJ, White MF, Saad MJ, Kahn CR. Cross-talk between the insulin and angiotensin signaling systems. Proc Natl Acad Sci U S A. 1996;93:12490-12495

145. Wei Y, Whaley-Connell AT, Chen K, Habibi J, Uptergrove GM, Clark SE, et al. Nadph oxidase contributes to vascular inflammation, insulin resistance, and remodeling in the transgenic (mren2) rat. Hypertension. 2007; 50:384-391

146. Jonk AM, Houben AJ, Schaper NC, de Leeuw PW, Serne EH, Smulders YM, et al. Angiotensin ii enhances insulin-stimulated whole-body glucose disposal but impairs insulin-induced capillary recruitment in healthy volunteers. J Clin Endocrinol Metab. 2010;95:3901-3908

147. Clerk LH, Vincent MA, Barrett EJ, Lankford MF, Lindner JR. Skeletal muscle capillary responses to insulin are abnormal in late-stage diabetes and are restored by angiotensin-converting enzyme inhibition. $\mathrm{Am} J$ Physiol Endocrinol Metab. 2007;293:E1804-1809 
148. Wang N, Chai W, Zhao L, Tao L, Cao W, Liu Z. Losartan increases muscle insulin delivery and rescues insulin's metabolic action during lipid infusion via microvascular recruitment. Am J Physiol Endocrinol Metab. 2013;304:E538-545

149. Jonk AM, Houben AJ, Schaper NC, de Leeuw PW, Serne EH, Smulders YM, et al. Acute angiotensin ii receptor blockade improves insulin-induced microvascular function in hypertensive individuals. Microvasc Res. 2011;82:77-83

150. Sauder MA, Liu J, Jahn LA, Fowler DE, Chai W, Liu Z. Candesartan acutely recruits skeletal and cardiac muscle microvasculature in healthy humans. J Clin Endocrinol Metab. 2012;97:E1208-1212

151. Andraws R, Brown DL. Effect of inhibition of the renin-angiotensin system on development of type 2 diabetes mellitus (meta-analysis of randomized trials). Am J Cardiol. 2007;99:1006-1012

152. Chai W, Wang W, Dong Z, Cao W, Liu Z. Angiotensin ii receptors modulate muscle microvascular and metabolic responses to insulin in vivo. Diabetes. 2011;60:2939-2946

153. Hagihara GN, Lobato NS, Filgueira FP, Akamine EH, Aragao DS, Casarini DE, et al. Upregulation of erk1/2-enos via at2 receptors decreases the contractile response to angiotensin ii in resistance mesenteric arteries from obese rats. PLoS One. 2014;9:e106029

154. Barton M, Baretella O, Meyer MR. Obesity and risk of vascular disease: Importance of endotheliumdependent vasoconstriction. Br J Pharmacol. 2012;165:591-602

155. Kushibiki M, Yamada M, Oikawa K, Tomita H, Osanai T, Okumura K. Aldosterone causes vasoconstriction in coronary arterioles of rats via angiotensin ii type-1 receptor: Influence of hypertension. Eur J Pharmacol. 2007;572:182-188

156. Lapi D, Emdin M, Mastantuono T, Sapio D, Santillo M, Colantuoni A. Microvascular responses to aldosterone in hamster cheek pouch microcirculation. Clin Hemorheol Microcirc. 2013;53:303-315

157. Maron BA, Zhang YY, Handy DE, Beuve A, Tang SS, Loscalzo J, et al. Aldosterone increases oxidant stress to impair guanylyl cyclase activity by cysteinyl thiol oxidation in vascular smooth muscle cells. $J$ Biol Chem. 2009;284:7665-7672

158. Maron BA, Zhang YY, White K, Chan SY, Handy DE, Mahoney CE, et al. Aldosterone inactivates the endothelin-b receptor via a cysteinyl thiol redox switch to decrease pulmonary endothelial nitric oxide levels and modulate pulmonary arterial hypertension. Circulation. 2012;126:963-974

159. Skott O, Uhrenholt TR, Schjerning J, Hansen PB, Rasmussen LE, Jensen BL. Rapid actions of aldosterone in vascular health and disease--friend or foe? Pharmacol Ther. 2006;111:495-507

160. Toda N, Nakanishi S, Tanabe S. Aldosterone affects blood flow and vascular tone regulated by endothelium-derived no: Therapeutic implications. Br J Pharmacol. 2013;168:519-533

161. Bayorh MA, Rollins-Hairston A, Adiyiah J, Lyn D, Eatman D. Eplerenone suppresses aldosterone/ saltinduced expression of nox-4. J Renin Angiotensin Aldosterone Syst. 2011;12:195-201

162. Iwashima F, Yoshimoto T, Minami I, Sakurada M, Hirono Y, Hirata Y. Aldosterone induces superoxide generation via rac1 activation in endothelial cells. Endocrinology. 2008;149:1009-1014

163. Leopold JA, Dam A, Maron BA, Scribner AW, Liao R, Handy DE, et al. Aldosterone impairs vascular reactivity by decreasing glucose-6-phosphate dehydrogenase activity. Nat Med. 2007;13:189-197

164. Pu Q, Neves MF, Virdis A, Touyz RM, Schiffrin EL. Endothelin antagonism on aldosterone-induced oxidative stress and vascular remodeling. Hypertension. 2003;42:49-55

165. Guo C, Ricchiuti V, Lian BQ, Yao TM, Coutinho P, Romero JR, et al. Mineralocorticoid receptor blockade reverses obesity-related changes in expression of adiponectin, peroxisome proliferator-activated receptor-gamma, and proinflammatory adipokines. Circulation. 2008;117:2253-2261

166. Jaffe IZ, Mendelsohn ME. Angiotensin ii and aldosterone regulate gene transcription via functional mineralocortocoid receptors in human coronary artery smooth muscle cells. Circ Res. 2005;96:643-650

167. McCurley A, McGraw A, Pruthi D, Jaffe IZ. Smooth muscle cell mineralocorticoid receptors: Role in vascular function and contribution to cardiovascular disease. Pflugers Arch. 2013;465:1661-1670

168. DeLano FA, Schmid-Schonbein GW. Enhancement of glucocorticoid and mineralocorticoid receptor density in the microcirculation of the spontaneously hypertensive rat. Microcirculation. 2004;11:69-78

169. Nguyen Dinh Cat A, Griol-Charhbili V, Loufrani L, Labat C, Benjamin L, Farman N, et al. The endothelial mineralocorticoid receptor regulates vasoconstrictor tone and blood pressure. Faseb J. 2010;24: 2454-2463 
170. Hitomi H, Kiyomoto H, Nishiyama A, Hara T, Moriwaki K, Kaifu K, et al. Aldosterone suppresses insulin signaling via the downregulation of insulin receptor substrate-1 in vascular smooth muscle cells. Hypertension. 2007;50:750-755

171. Bender SB, DeMarco VG, Padilla J, Jenkins NT, Habibi J, Garro M, et al. Mineralocorticoid receptor antagonism treats obesity-associated cardiac diastolic dysfunction. Hypertension. 2015;65:1082-1088

172. Schafer N, Lohmann C, Winnik S, van Tits LJ, Miranda MX, Vergopoulos A, et al. Endothelial mineralocorticoid receptor activation mediates endothelial dysfunction in diet-induced obesity. Eur Heart J. 2013;34(45):3515-3524

173. DeMarco VG, Habibi J, Jia G, Aroor AR, Ramirez-Perez FI, Martinez-Lemus LA, et al. Low-dose mineralocorticoid receptor blockade prevents western diet-induced arterial stiffening in female mice. Hypertension. 2015;66:99-107

174. Garg R, Rao AD, Baimas-George M, Hurwitz S, Foster C, Shah RV, et al. Mineralocorticoid receptor blockade improves coronary microvascular function in individuals with type 2 diabetes. Diabetes. 2015;64:236-242

175. Hwang MH, Yoo JK, Luttrell M, Kim HK, Meade TH, English M, et al. Mineralocorticoid receptors modulate vascular endothelial function in human obesity. Clin Sci (Lond). 2013;125(11):513-520

176. Garg R, Kneen L, Williams GH, Adler GK. Effect of mineralocorticoid receptor antagonist on insulin resistance and endothelial function in obese subjects. Diabetes Obes Metab. 2014;16(3):268-272

177. Hwang MH, Yoo JK, Luttrell M, Kim HK, Meade TH, English M, et al. Acute effect of mineralocorticoid receptor antagonism on vascular function in healthy older adults. Exp Gerontol. 2015;73:86-94

178. Sampaio WO, Henrique de Castro C, Santos RA, Schiffrin EL, Touyz RM. Angiotensin-(1-7) counterregulates angiotensin ii signaling in human endothelial cells. Hypertension. 2007;50:1093-1098

179. Sampaio WO, Souza dos Santos RA, Faria-Silva R, da Mata Machado LT, Schiffrin EL, Touyz RM. Angiotensin-(1-7) through receptor mas mediates endothelial nitric oxide synthase activation via aktdependent pathways. Hypertension. 2007;49:185-192

180. Walters PE, Gaspari TA, Widdop RE. Angiotensin-(1-7) acts as a vasodepressor agent via angiotensin ii type 2 receptors in conscious rats. Hypertension. 2005;45:960-966

181. Beyer AM, Guo DF, Rahmouni K. Prolonged treatment with angiotensin 1-7 improves endothelial function in diet-induced obesity. J Hypertens. 2013;31:730-738

182. Sasaki S, Higashi Y, Nakagawa K, Matsuura H, Kajiyama G, Oshima T. Effects of angiotensin-(1-7) on forearm circulation in normotensive subjects and patients with essential hypertension. Hypertension. 2001;38:90-94

183. van Twist DJ, Houben AJ, de Haan MW, Mostard GJ, Kroon AA, de Leeuw PW. Angiotensin-(1-7)-induced renal vasodilation in hypertensive humans is attenuated by low sodium intake and angiotensin ii coinfusion. Hypertension. 2013;62:789-793

184. Handa RK, Ferrario CM, Strandhoy JW. Renal actions of angiotensin-(1-7): In vivo and in vitro studies. Am J Physiol. 1996;270:F141-147

185. Heller J, Kramer HJ, Maly J, Cervenka L, Horacek V. Effect of intrarenal infusion of angiotensin-(1-7) in the dog. Kidney Blood Press Res. 2000;23:89-94

186. Ueda S, Masumori-Maemoto S, Ashino K, Nagahara T, Gotoh E, Umemura S, et al. Angiotensin-(1-7) attenuates vasoconstriction evoked by angiotensin ii but not by noradrenaline in man. Hypertension. 2000;35:998-1001

187. Gironacci MM, Adamo HP, Corradi G, Santos RA, Ortiz P, Carretero OA. Angiotensin (1-7) induces mas receptor internalization. Hypertension. 2011;58:176-181

188. Tassone EJ, Sciacqua A, Andreozzi F, Presta I, Perticone M, Carnevale D, et al. Angiotensin (1-7) counteracts the negative effect of angiotensin ii on insulin signalling in huvecs. Cardiovasc Res. 2013;99:129-136

189. Fu Z, Zhao L, Aylor KW, Carey RM, Barrett EJ, Liu Z. Angiotensin-(1-7) recruits muscle microvasculature and enhances insulin's metabolic action via mas receptor. Hypertension. 2014;63:1219-1227

190. Rentzsch B, Todiras M, Iliescu R, Popova E, Campos LA, Oliveira ML, et al. Transgenic angiotensinconverting enzyme 2 overexpression in vessels of shrsp rats reduces blood pressure and improves endothelial function. Hypertension. 2008;52:967-973 
191. Aghamohammadzadeh R, Withers S, Lynch F, Greenstein A, Malik R, Heagerty A. Perivascular adipose tissue from human systemic and coronary vessels: The emergence of a new pharmacotherapeutic target. Br J Pharmacol. 2012;165:670-682

192. Lee RM, Lu C, Su LY, Gao YJ. Endothelium-dependent relaxation factor released by perivascular adipose tissue. J Hypertens. 2009;27:782-790

193. Withers SB, Bussey CE, Saxton SN, Melrose HM, Watkins AE, Heagerty AM. Mechanisms of adiponectinassociated perivascular function in vascular disease. Arterioscler Thromb Vasc Biol. 2014;34:1637-1642

194. Meijer RI, Serne EH, Korkmaz HI, van der Peet DL, de Boer MP, Niessen HW, et al. Insulin-induced changes in skeletal muscle microvascular perfusion are dependent upon perivascular adipose tissue in women. Diabetologia. 2015;58:1907-1915

195. Meijer RI, Bakker W, Alta CL, Sipkema P, Yudkin JS, Viollet B, et al. Perivascular adipose tissue control of insulin-induced vasoreactivity in muscle is impaired in $\mathrm{db} / \mathrm{db}$ mice. Diabetes. 2013;62:590-598

196. Aghamohammadzadeh R, Heagerty AM. Obesity-related hypertension: Epidemiology, pathophysiology, treatments, and the contribution of perivascular adipose tissue. Ann Med. 2012;44 Suppl 1:S74-84

197. Lu C, Su LY, Lee RM, Gao YJ. Alterations in perivascular adipose tissue structure and function in hypertension. Eur J Pharmacol. 2011;656:68-73

198. Rosei CA, Withers SB, Belcaid L, De Ciuceis C, Rizzoni D, Heagerty AM. Blockade of the renin-angiotensin system in small arteries and anticontractile function of perivascular adipose tissue. J Hypertens. 2015;33:1039-1045

199. Huang F, Lezama MA, Ontiveros JA, Bravo G, Villafana S, del-Rio-Navarro BE, et al. Effect of losartan on vascular function in fructose-fed rats: The role of perivascular adipose tissue. Clin Exp Hypertens. 2010;32:98-104

200. DeMarco VG, Aroor AR, Sowers JR. The pathophysiology of hypertension in patients with obesity. Nat Rev Endocrinol. 2014;10:364-376

201. Laurent S, Boutouyrie P. The structural factor of hypertension: Large and small artery alterations. Circ Res. 2015;116:1007-1021

202. Safar ME, Balkau B, Lange C, Protogerou AD, Czernichow S, Blacher J, et al. Hypertension and vascular dynamics in men and women with metabolic syndrome. J Am Coll Cardiol. 2013;61:12-19

203. Stehouwer CD, Henry RM, Ferreira I. Arterial stiffness in diabetes and the metabolic syndrome: A pathway to cardiovascular disease. Diabetologia. 2008;51:527-539

204. Kaess BM, Rong J, Larson MG, Hamburg NM, Vita JA, Levy D, et al. Aortic stiffness, blood pressure progression, and incident hypertension. Jama. 2012;308:875-881

205. Weisbrod RM, Shiang T, Al Sayah L, Fry JL, Bajpai S, Reinhart-King CA, et al. Arterial stiffening precedes systolic hypertension in diet-induced obesity. Hypertension. 2013;62:1105-1110

206. Rehman A, Rahman AR, Rasool AH, Naing NN. The effects of angiotensin ii on pulse wave velocity in healthy humans. Int J Clin Pharmacol Ther. 2001;39:423-430

207. Wilkinson IB, MacCallum H, Hupperetz PC, van Thoor CJ, Cockcroft JR, Webb DJ. Changes in the derived central pressure waveform and pulse pressure in response to angiotensin ii and noradrenaline in man. $J$ Physiol. 2001;530:541-550

208. Jia G, Aroor AR, DeMarco VG, Martinez-Lemus LA, Meininger GA, Sowers JR. Vascular stiffness in insulin resistance and obesity. Front Physiol. 2015;6:231

209. Mahmud A, Feely J. Arterial stiffness and the renin-angiotensin-aldosterone system. J Renin Angiotensin Aldosterone Syst. 2004;5:102-108

210. Safar ME, Levy BI, Struijker-Boudier H. Current perspectives on arterial stiffness and pulse pressure in hypertension and cardiovascular diseases. Circulation. 2003;107:2864-2869

211. Boutouyrie $P$, Lacolley $\mathrm{P}$, Briet $\mathrm{M}$, Regnault $\mathrm{V}$, Stanton $\mathrm{A}$, Laurent $\mathrm{S}$, et al. Pharmacological modulation of arterial stiffness. Drugs. 2011;71:1689-1701

212. Nashar K, Nguyen JP, Jesri A, Morrow JD, Egan BM. Angiotensin receptor blockade improves arterial distensibility and reduces exercise-induced pressor responses in obese hypertensive patients with the metabolic syndrome. Am J Hypertens. 2004;17:477-482

213. Nedogoda SV, Ledyaeva AA, Chumachok EV, Tsoma VV, Mazina G, Salasyuk AS, et al. Randomized trial of perindopril, enalapril, losartan and telmisartan in overweight or obese patients with hypertension. Clin Drug Investig. 2013;33:553-561 
214. Blacher J, Amah G, Girerd X, Kheder A, Ben Mais H, London GM, et al. Association between increased plasma levels of aldosterone and decreased systemic arterial compliance in subjects with essential hypertension. Am J Hypertens. 1997;10:1326-1334

215. Lacolley P, Labat C, Pujol A, Delcayre C, Benetos A, Safar M. Increased carotid wall elastic modulus and fibronectin in aldosterone-salt-treated rats: Effects of eplerenone. Circulation. 2002;106:2848-2853

216. Mahmud A, Feely J. Aldosterone-to-renin ratio, arterial stiffness, and the response to aldosterone antagonism in essential hypertension. Am J Hypertens. 2005;18:50-55

217. Safar ME, Millasseau S, Mahmud A, Blacher J. Relations between large artery structure and function and aldosterone. J Hypertens. 2011;29:1676-1683

218. Kusche-Vihrog K, Jeggle $\mathrm{P}$, Oberleithner $\mathrm{H}$. The role of enac in vascular endothelium. Pflugers Arch. 2014;466:851-859

219. Galmiche G, Pizard A, Gueret A, El Moghrabi S, Ouvrard-Pascaud A, Berger S, et al. Smooth muscle cell mineralocorticoid receptors are mandatory for aldosterone-salt to induce vascular stiffness. Hypertension. 2014;63:520-526

220. Schmidt BM, Schmieder RE. Aldosterone-induced cardiac damage: Focus on blood pressure independent effects. Am J Hypertens. 2003;16:80-86

221. Benetos A, Lacolley $P$, Safar ME. Prevention of aortic fibrosis by spironolactone in spontaneously hypertensive rats. Arterioscler Thromb Vasc Biol. 1997;17:1152-1156

222. Savoia C, Touyz RM, Amiri F, Schiffrin EL. Selective mineralocorticoid receptor blocker eplerenone reduces resistance artery stiffness in hypertensive patients. Hypertension. 2008;51:432-439

223. White WB, Duprez D, St Hillaire R, Krause S, Roniker B, Kuse-Hamilton J, et al. Effects of the selective aldosterone blocker eplerenone versus the calcium antagonist amlodipine in systolic hypertension. Hypertension. 2003;41:1021-1026

224. Lin YH, Lin LY, Chen A, Wu XM, Lee JK, Su TC, et al. Adrenalectomy improves increased carotid intimamedia thickness and arterial stiffness in patients with aldosterone producing adenoma. Atherosclerosis. 2012;221:154-159

225. Cooper JN, Tepper P, Barinas-Mitchell E, Woodard GA, Sutton-Tyrrell K. Serum aldosterone is associated with inflammation and aortic stiffness in normotensive overweight and obese young adults. Clin Exp Hypertens. 2012;34:63-70

226. Collier SR, Sandberg K, Moody AM, Frechette V, Curry CD, Ji H, et al. Reduction of plasma aldosterone and arterial stiffness in obese pre- and stage1 hypertensive subjects after aerobic exercise. $J$ Hum Hypertens. 2015;29:53-57

227. Patel VB, Zhong JC, Fan D, Basu R, Morton JS, Parajuli N, et al. Angiotensin-converting enzyme 2 is a critical determinant of angiotensin ii-induced loss of vascular smooth muscle cells and adverse vascular remodeling. Hypertension. 2014;64:157-164 



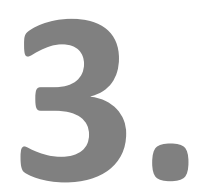

\section{ALDOSTERONE-RENIN RATIO AND SIDE-SELECTIVE} RENAL PERFUSION IN ESSENTIAL HYPERTENSION

M.T.J. Schütten, A.J.H.M. Houben, A.A. Kroon, C.D.A. Stehouwer, P.W. de Leeuw

Am. J. Hypertension 2016; 29: 1311-1316 


\section{Abstract}

\section{Background}

The decrease in kidney perfusion as often observed in hypertensive individuals does not necessarily occur in a symmetrical fashion, thereby potentially introducing left-right differences in the response to vasoactive agents. Increased aldosterone levels have been associated with reduced renal perfusion in normotensive and hypertensive individuals, but it is unknown whether both kidneys are equally affected in this respect and how angiotensin II is involved in this relationship. Therefore, our aim was to investigate the association of both aldosterone and the aldosterone-renin ratio with side-selective renal blood flow in essential hypertension.

\section{Methods}

We studied 146 essential hypertensive patients with patent renal arteries who had undergone renal angiography for exclusion of renal artery stenosis. Prior to contrast administration, blood samples were drawn for determination of renin and aldosterone levels and side-selective renal blood flow was measured using the ${ }^{133}$ Xenon washout technique.

\section{Results}

Left mean renal blood flow (MRBF) was significantly lower than right MRBF $(227 \pm 74$ versus $250 \pm 76 \mathrm{~mL} * \mathrm{~min}^{-1} * 100 \mathrm{~g} \mathrm{kidney}^{-1}, \mathrm{p}=0.01$ ). We could not demonstrate a correlation of $\mathrm{Ln}$ aldosterone or $\mathrm{Ln}$ renin with left or right kidney perfusion. Ln aldosterone-renin ratio, however, was inversely and independently associated with left MRBF ( $\beta=-13.993, p=0.02$; fully adjusted model), but not with right MRBF.

\section{Conclusions}

A higher aldosterone-renin ratio corresponds with reduced perfusion of the left kidney, yet is not associated with right kidney perfusion. Especially under circumstances of diminished right renal blood flow, this may affect blood pressure and kidney function. 


\section{Introduction}

Reduced kidney perfusion and renal vasoconstriction are frequently observed in hypertension and can occur even prior to increases in blood pressure in individuals at risk of developing hypertension ${ }^{1}$. This is at least partly attributable to alterations in renal vascular reactivity to vasoactive substances. Observations of left-right differences in renal blood flow made by us and others in patients with essential hypertension ${ }^{2,3}$, or in individuals in whom imaging of the kidneys was performed ${ }^{4}$ suggest that the decline in renal perfusion does not necessarily occur to a similar extent for both kidneys. The existence of an asymmetry in kidney perfusion implies a differential contractile state of the left versus the right renal vascular bed. This on itself may introduce dissimilarities in the response to vasoactive agents between the left and the right kidney ${ }^{5}$, thereby maintaining or even aggravating the inequality in renal perfusion. Angiotensin II is one of the most important vasoconstrictors known to affect renal vascular tone ${ }^{6}$, and elevations in blood pressure have been found to be accompanied or even preceded by increased renal vascular sensitivity to angiotensin $\mathrm{II}^{7,8}$. A growing body of evidence suggests that aldosterone acts at the renal vasculature as well ${ }^{9}$. Indeed, a direct association of aldosterone levels with renal vascular resistance and an inverse association with renal plasma flow have been demonstrated in both normotensive and essential hypertensive individuals ${ }^{10,11}$. Because these studies used standard clearance techniques to assess renal perfusion, the data obtained do not allow drawing conclusions regarding individual kidney function and renal vascular reactivity. In addition, the effect of angiotensin II on renal vascular resistance, irrespective of that of aldosterone, has not always been taken into account in these investigations. Therefore, we set up the present study to assess whether the relationship of aldosterone with renal perfusion is side-selective. As left renal blood flow is, on average, lower than right renal blood flow, we hypothesized that the association between aldosterone and kidney perfusion would be more prominent on the left side, in this manner contributing to the inequality between left and right renal blood flow. Because the prevailing concentrations of renin and hence, angiotensin II, may confound the relationship between aldosterone levels and renal blood flow, we also explored whether the aldosterone-renin ratio correlated with renal perfusion. We hypothesized that this ratio is a better predictor of renal perfusion than aldosterone alone. 


\section{Methods}

\section{Study protocol and participants}

This study was performed in hypertensive patients who had been referred to our clinic for evaluation of renovascular abnormalities and possible secondary causes of their elevated blood pressure. To this end, we employed a standard diagnostic procedure, including blood sampling from the aorta and both renal veins, side-selective renal blood flow measurements and renal angiography. Antihypertensive treatment was temporarily interrupted for 3 weeks prior to the investigations to avoid interference with the experiments, and sodium intake was standardized during one week. In patients with diabetes mellitus, the use of metformin was discontinued 2 days before renal angiography to prevent contrast-medium induced nephropathy. Other medications, including statins, were allowed. Participants were also instructed to refrain from smoking and drinking caffeine or alcohol containing beverages for at least 48 hours before the investigations.

\section{Experimental procedure}

One day prior to the angiography, $24 \mathrm{~h}$ urine was collected for measurement of sodium and albumin excretion and $24 \mathrm{~h}$ ambulatory blood pressure measurement (ABPM) was performed (devices: TM-2430, A\&D Company, Tokyo, Japan; Mobilograph, I.E.M., Stolberg, Germany, or Spacelabs, Redmond, WA). Blood pressure was measured the non-dominant arm; every 15 minutes during daytime and every 30 minutes during the night. Following a one-night admission and an overnight fast, the aorta and both renal veins were cannulated via the femoral route and blood samples were drawn simultaneously from the aorta and the renal veins for determination of active plasma renin concentration (APRC) and aldosterone levels. Blood samples were spun immediately and stored at a temperature of $-80^{\circ} \mathrm{C}$ until analysis. Subsequently, sideselective mean renal blood flow (MRBF) was measured by means of the ${ }^{133}$ Xenon washout technique, as described previously ${ }^{12,13}$. In short, after administration of a bolus of ${ }^{133}$ Xenon directly into the renal artery, its disappearance was recorded using an extracorporeal scintillation counter. This procedure was performed first for the left kidney and thereafter for the right kidney. The washout curves of both kidneys were analyzed offline using a 2-phase exponential decay model after subtraction of background radiation (Graphpad Software Inc, version 5.1, San Diego, CA). MRBF was calculated as the weighted average of the fast and slow component. Occasionally, a monophasic decline in activity was observed, and the curve was analyzed accordingly. 
In our hands, renal blood flow measured by means of the ${ }^{133}$ Xenon washout technique correlated well with total renal perfusion estimated through assessment of paraaminohippurate clearance $(r=0.76$; unpublished data), whereas the coefficient of variation for repeated measurements was $8 \%{ }^{13}$. Contrast material was administered only after blood sampling and renal blood flow measurements had been completed. Renal angiography was performed using a digital subtraction system. Angiograms were assessed for the presence of renal artery anomalies by two experienced radiologists who were unaware of the flow results. All participants provided written informed consent before execution of the procedure, and the Maastricht University Hospital Ethics Committee approved the study.

\section{Biochemical analyses}

APRC was measured using an immunoradiometric assay method (until 2004: Diagnostics Pasteur, Marnes-La-Coquette, France; intra-assay coefficient of variation (CV) 2.1-9.4\%; inter-assay CV 5.4-6.7\%; from 2004 onwards: Renin III generation, CisBio Bioassays, Codolet, France; intra-assay CV 0.9-3.6\%; inter-assay CV 3.6-5.0\%). After extraction from plasma, aldosterone was determined by means of radio-immunoassay using highly specific antibodies (Coat-A-Count Radioimmunometric Assay, Siemens, Los Angeles, CA; intra-assay CV 2.3-5.4\%; inter-assay CV 3.8-15.7\%). Serum creatinine was measured by means of colorimetry, making use of the alkaline picrate (Jaffé) principle (Beckman Coulter LX20, Brea, CA; within-day CV 2.5\%; between-day CV 4.6\%). Standard analytical methods were used for the assessment of fasting glucose and lipid profile.

\section{Calculations and statistics}

Unless otherwise stated, arterial aldosterone and renin concentrations were used for the statistical analyses, because tissues are exposed to these levels. Estimated glomerular filtration rate (eGFR) was calculated using the CKD Epidemiology Collaboration equation ${ }^{14}$. Normally distributed variables are expressed as mean $\pm S D$; variables with a skewed distribution are displayed as median and interquartile range and were log-transformed before further analyses (aldosterone, renin, aldosteronerenin ratio, urinary sodium excretion, urinary albumin excretion). Left and right mean renal blood flows, and arterial and venous aldosterone and renin levels were compared by means of an independent sample T-test. Relationships among aldosterone, renin, aldosterone-renin ratio, left and right mean renal blood flow, $24 \mathrm{~h}$ systolic and diastolic blood pressure, and eGFR are presented as Pearson correlation coefficients. 
The associations between aldosterone (-renin ratio) on the one hand and left and right mean renal blood flow on the other, if present, were investigated by means of multiple linear regression, initially without and subsequently with adjustment for potential confounders: urinary sodium excretion, age, sex, eGFR, urinary albumin excretion, history of cardiovascular events, diabetes mellitus, smoking, body mass index, total cholesterol, aspirin use, and lipid-modifying therapy. Results of these analyses are expressed as regression coefficients with corresponding $95 \%$ confidence intervals. Twotailed $p$-values of $\leq 0.05$ were considered significant. Analyses were performed using the SPSS statistical software package (IBM SPSS Statistics version 20, Chicago, IL).

\section{Results}

\section{General characteristics and procedural results}

From the participants who had undergone the diagnostic procedure since 2000 ( $n=793), 146$ were judged eligible for the present study by fulfilling the following criteria: a diagnosis of essential hypertension, patent renal arteries, complete blood sampling for assessment of aldosterone and renin levels, at least unilateral renal blood flow measurements performed, available 24h ABPM data, complete data regarding potential confounders, and being Caucasian. Left and right kidney perfusion could be measured successfully in 144 and 140 individuals, respectively. Bilateral renal blood flow measurements were performed in 138 participants. Failure of the procedure was most often due to an inability to catheterize the artery. Table 3.1 shows the characteristics of the total study population of the 146 individuals with essential hypertension. In Table 3.2, the 24h ABPM data, urinary sodium excretion, hormone levels and results of the renal blood flow measurements are displayed. In the 138 participants in whom bilateral renal blood flow measurements were performed, left kidney perfusion was significantly lower than right kidney perfusion (left mean renal blood flow (MRBF): $227 \pm 74 \mathrm{~mL}^{*} \mathrm{~min}^{-1} * 100 \mathrm{~g} \mathrm{kidney}^{-1}$; right MRBF: $250 \pm 76 \mathrm{~mL}$ * $\left.\min ^{-1} * 100 \mathrm{~g} \mathrm{kidney}^{-1}, \mathrm{p}=0.01\right)$. Renin levels in left and right renal venous blood samples were comparable. 
Table 3.1: Clinical characteristics of the 146 patients with essential hypertension.

\begin{tabular}{|c|c|}
\hline Baseline characteristics $(n=146)$ & \\
\hline Age (year) & $1 \pm 12$ \\
\hline Sex (number and \% of men) & $79(54)$ \\
\hline History of cardiovascular events (\%) & $24(16)$ \\
\hline Diabetes mellitus (\%) & $22(15)$ \\
\hline Current smokers (\%) & $42(29)$ \\
\hline BMI $\left(\mathrm{kg} * \mathrm{~m}^{2}{ }^{2}\right)$ & $27 \pm 5$ \\
\hline eGFR $\left(\mathrm{mL}^{*} \mathrm{~min}^{-1} * 1.73 \mathrm{~m}^{-2}\right)$ & $76 \pm 28$ \\
\hline Total cholesterol $\left(\mathrm{mmol} * \mathrm{~L}^{-1}\right)$ & $5.1 \pm 1.2$ \\
\hline Urinary albumin excretion $\left(\mathrm{mg} * 24 \mathrm{~h}^{-1}\right)$ & $10(20-85)$ \\
\hline Lipid-modifying medication (\%) & $49(34)$ \\
\hline Number of antihypertensive drugs before study & $3(2-4)$ \\
\hline$\beta$-blockers (\%) & 82 \\
\hline Calcium antagonists (\%) & 84 \\
\hline Diuretics (\%) & 725 \\
\hline Angiotensin-converting enzyme inhibitors (\%) & 52 \\
\hline Angiotensin type 1 receptor antagonists (\%) & 65 \\
\hline Other: $\alpha$-blockers, centrally acting agents, direct vasodilators (\%) & 23 \\
\hline Aspirin use (\%) & 18 \\
\hline
\end{tabular}

Data are presented as means $\pm \mathrm{SD}$, medians (interquartile ranges) or number (\%); $\mathrm{BMI}$, body mass index; eGFR, estimated glomerular filtration rate.

Table 3.2: Blood pressure data, urinary sodium excretion, hormone levels and results of renal blood flow measurements

\begin{tabular}{lc}
\hline 24h systolic blood pressure $(\mathrm{mm} \mathrm{Hg})$ & $159 \pm 21$ \\
$24 \mathrm{~h}$ diastolic blood pressure $(\mathrm{mm} \mathrm{Hg})$ & $97 \pm 12$ \\
Urinary sodium excretion $\left(\mathrm{mmol}^{*} 24 \mathrm{~h}^{-1}\right)$ & $68(41-129)$ \\
Aldosterone $\left(\mathrm{pmol}^{*} \mathrm{~L}^{-1}\right)$ & \\
$\quad$ Arterial & $365(200-593)$ \\
Left renal vein & $395(210-758)^{1,2}$ \\
Right renal vein & $350(180-585)^{3}$ \\
Renin $\left(\mathrm{mU} * \mathrm{~L}^{-1}\right)$ & \\
Arterial & $15.5(8.5-27.2)$ \\
Left renal vein & $18.4(9.9-33.0)^{4,5}$ \\
Right renal vein & $18.4(10.2-30.7)^{6}$ \\
Left MRBF $\left(\mathrm{mL}^{*} \mathrm{~min}^{-1} * 100 \mathrm{~g} \mathrm{kidney}^{-1}\right)$ & $229 \pm 74$ \\
Right MRBF $\left(\mathrm{mL}^{*} \mathrm{~min}^{-1} * 100 \mathrm{~g} \mathrm{kidney}^{-1}\right)$ & $250 \pm 76$ \\
\hline
\end{tabular}

Data are presented as means \pm SD or medians (interquartile ranges); ARR, aldosterone-renin ratio; MRBF, mean renal blood flow. Left versus right MRBF: $p=0.01 .{ }^{1} p=0.04$ compared to arterial levels; ${ }^{2} p=0.03$ compared to right venous levels; ${ }^{3} p=0.89$ compared to arterial levels; ${ }^{4} p=0.08$ compared to arterial levels; ${ }^{5} \mathrm{p}=0.11$ compared to right venous levels; ${ }^{6} \mathrm{p}=0.87$ compared to arterial levels.

\section{Correlations}

Correlation analysis of the total study population (Table 3.3) revealed that neither the natural logarithm of the aldosterone concentration (Ln aldosterone), nor Ln renin 
displayed an association with left and right mean renal blood flow. The natural logarithm of the aldosterone-renin ratio ( $L n A R R)$, however, was inversely correlated with left mean renal blood flow ( $r=-0.163, p=0.05$; Figure 3.1A). Conversely, Ln ARR and right mean renal blood flow did not correlate ( $r=-0.043, p=0.62$; Figure 3.1B). Ln aldosterone was only directly associated with $24 \mathrm{~h}$ diastolic blood pressure $(r=0.204$, $\mathrm{p}=0.01$ ), whereas $\mathrm{Ln}$ renin was not associated with either $24 \mathrm{~h}$ systolic or diastolic blood pressure. Ln ARR correlated directly with both $24 \mathrm{~h}$ systolic $(r=0.174, p=0.04)$ and diastolic blood pressure $(r=0.186, p=0.02)$. Both left and right MRBF displayed a direct correlation with eGFR (left MRBF: $r=0.365, p<0.001$; right MRBF: $r=0.368, p<0.001$ ) and an inverse correlation with $24 \mathrm{~h}$ systolic blood pressure (left MRBF: $r=-0.193, p=0.02$; right MRBF: $r=-0.231, p=0.01$ ). Systolic blood pressure was inversely associated with eGFR ( $r=-0.229, p=0.01)$, whereas diastolic blood pressure was not associated with eGFR $(r=-0.081, p=0.33)$.

Table 3.3: Pearson correlation coefficients representing associations among hormone levels, MRBF and blood pressure.

\begin{tabular}{lccccc}
\hline & Left MRBF & Right MRBF & 24h SBP & 24h DBP & eGFR \\
\hline Ln aldosterone & -0.076 & -0.063 & 0.043 & $0.204^{*}$ & -0.110 \\
Ln renin & 0.103 & -0.013 & -0.144 & -0.010 & -0.028 \\
Ln ARR & $-0.163^{*}$ & -0.043 & $0.174^{*}$ & $0.186^{*}$ & -0.069 \\
Left MRBF & 1 & $0.657^{+}$ & $-0.193^{*}$ & 0.153 & $0.365^{+}$ \\
Right MRBF & & 1 & $-0.231^{*}$ & 0.121 & $0.368^{+}$ \\
24h SBP & & & 1 & $0.620^{+}$ & $-0.229^{+}$ \\
24h DBP & & & & 1 & -0.081 \\
eGFR & & & & & 1 \\
\hline
\end{tabular}

* $\mathrm{p} \leq 0.05 ;+\mathrm{p}<0.01 ; \mathrm{ARR}$, aldosterone-renin ratio; MRBF, mean renal blood flow; SBP, systolic blood pressure; $\mathrm{DBP}$, diastolic blood pressure; eGFR, estimated glomerular filtration rate.

\section{Association of aldosterone-renin ratio with renal blood flow}

After adjustment for potential confounders, the regression coefficient of the inverse association between Ln ARR and left mean renal blood flow became somewhat more robust (crude association: $\beta=-12.772,95 \% \mathrm{Cl}-25.589$ to $0.045, p=0.05$; fully adjusted model: $\beta=-13.993,95 \% \mathrm{Cl}-25.869$ to $-2.117, p=0.02$ ). The regression coefficient of the fully adjusted model indicates that for every $10 \%$ increase in ARR, left MRBF decreases with $1.3 \mathrm{~mL}^{*} \min ^{-1} * 100 \mathrm{~g} \mathrm{kidney}^{-1}(-13.993 * \ln (1.1))$. Adjustment for the same confounders did not materially change the relationship between Ln ARR and right MRBF (crude association: $\beta=-3.433,95 \% \mathrm{Cl}-16.981$ to $10.115, p=0.62$; fully adjusted model: $\beta=-5.673,95 \% \mathrm{Cl}-18.306$ to $6.961, \mathrm{p}=0.38$ ); see also Table 3.4. 


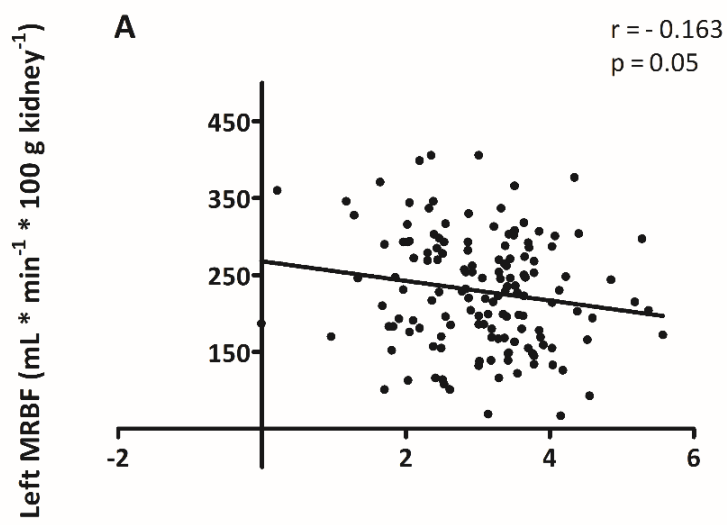

Ln ARR (pmol * $\mathrm{L}^{-1}$ per $\left.\mathrm{mU} * \mathrm{~L}^{-1}\right)$

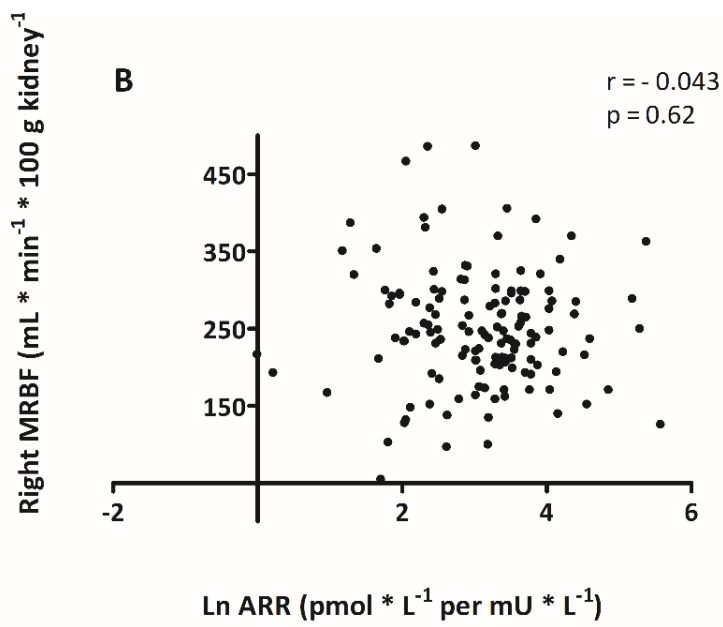

Figure 3.1: Crude linear regression between Ln ARR and left (A) and right (B) MRBF.

\section{Additional analyses}

Both higher aldosterone levels and lower renin levels can individually raise the ARR, by increasing the numerator or lowering the denominator of this ratio. Therefore, we confirmed that the association of a higher ARR with reduced perfusion of the left kidney was not solely present in patients with the highest aldosterone and lowest renin concentration, but could also be demonstrated in individuals with lower aldosterone and higher renin levels (data not shown). In addition, we tested whether the association of Ln ARR with left renal blood flow was different for men and women, but we could not establish an interaction with sex (data not shown). 
Table 3.4: Association between Ln ARR and left (panel A) and right (panel B) MRBF.

\begin{tabular}{lccc}
\hline A & \multicolumn{3}{c}{$\begin{array}{c}\text { Dependent variable: } \\
\text { left mean renal blood flow }\end{array}$} \\
\cline { 2 - 4 } & $\beta$ & $95 \% \mathrm{Cl}^{\prime}$ s & $\mathrm{p}$-value \\
\hline Model 1: crude analysis & -12.772 & $-25.589-0.045$ & 0.05 \\
Model 2: adjusted for Ln urinary sodium excretion & -13.759 & $-26.391--1.127$ & 0.03 \\
Model 3: model 2 with age and sex & -12.404 & $-24.027--0.780$ & 0.04 \\
Model 4: model 3 with eGFR and Ln urinary albumin & -11.365 & $-22.650--0.079$ & 0.05 \\
excretion & & & 0.02 \\
Model 5: model 4 with prior cardiovascular events, & $-13.993^{*}$ & $-25.869--2.117$ & \\
diabetes mellitus, smoking, BMI, total cholesterol, & & & \\
aspirin use and lipid-modifying therapy & & & \\
\hline
\end{tabular}

*The regression coefficient $\beta$ indicates that when ARR increases with $10 \%$, left MRBF decreases (when considering the fully adjusted model) with $1.3 \mathrm{~mL}^{*} \min ^{-1} * 100 \mathrm{~g} \mathrm{kidney}^{-1}(-13.993 * \ln (1.1))$

\begin{tabular}{lccc}
\hline B & \multicolumn{3}{c}{$\begin{array}{c}\text { Dependent variable: } \\
\text { right mean renal blood flow }\end{array}$} \\
\cline { 2 - 4 } & $\beta$ & $95 \% \mathrm{Cl}^{\prime} \mathrm{s}$ & $\mathrm{p}$-value \\
\hline Model 1: crude analysis & -3.433 & $-16.981-10.115$ & 0.62 \\
Model 2: adjusted for Ln urinary sodium excretion & -4.349 & $-17.820-9.122$ & 0.52 \\
Model 3: model 2 with age and sex & -3.073 & $-15.153-9.007$ & 0.62 \\
Model 4: model 3 with eGFR and Ln urinary albumin & -2.138 & $-13.977-9.701$ & 0.72 \\
excretion & & & 0.38 \\
Model 5: model 4 with prior cardiovascular events, & -5.673 & $-18.306-6.961$ & \\
diabetes mellitus, smoking, BMI, total cholesterol, & & & \\
aspirin use and lipid-modifying therapy & & & \\
\hline
\end{tabular}

\section{Discussion}

The present study confirms previous findings of left-right differences in renal blood flow and demonstrates a differential and independent relationship of the aldosteronerenin ratio with perfusion of the left and right kidney in a relatively large and wellcharacterized population of essential hypertensive individuals. More specifically, we observed an inverse association of the natural logarithm of the aldosterone-renin ratio with left mean renal blood flow, independent of confounders, whereas we could not establish such a relationship between Ln ARR and right mean renal blood flow.

Previous studies addressing the association between aldosterone and renal hemodynamics in both normotensive and hypertensive individuals used the inulin clearance method to determine renal plasma flow (RPF), thus only allowing appraisal of the relationship with total blood flow ${ }^{10,11}$. Furthermore, not all investigators have adjusted this relationship for the influence of angiotensin II on aldosterone levels and kidney perfusion. Kotchen et al. ${ }^{11}$ established a direct correlation of aldosterone with renovascular resistance in a group of normotensive and hypertensive African- 
Americans. Similarly, Brown et al. ${ }^{10}$ observed that aldosterone dysfunction, defined as higher levels of the ratio of supine serum aldosterone during a liberal and a restricted sodium diet, was inversely correlated to renal plasma flow and its response to sodium restriction in elderly normotensive or hypertensive participants. In addition, in these individuals they perceived a direct correlation of the ratio of supine serum aldosterone on a liberal sodium diet and following sodium restriction in combination with angiotensin II infusion with the RPF response to angiotensin II administration.

Interestingly, in our study we could not demonstrate an association of absolute aldosterone levels with left and right mean renal blood flow, but we only observed an inverse relationship of the aldosterone-renin ratio with left kidney perfusion. By using the aldosterone-renin ratio, we attempted to adjust for the effects of angiotensin II on aldosterone secretion and renal blood flow. The fact that we did not observe an association of absolute aldosterone levels with kidney perfusion, in contrast to other investigators, might be explained by differences in sodium intake. Because sodium may augment the actions of aldosterone ${ }^{15-17}$, studies conducted under circumstances of higher sodium ingestion might yield stronger associations of aldosterone levels with renal blood flow compared to the current investigation, in which salt intake was relatively low. In addition, we expressed renal blood flow per unit of kidney mass, whereas previous studies have not normalized for kidney mass. This could also account for the different results obtained.

The differential association of the aldosterone-renin ratio with kidney perfusion may very well be the result of an augmented vascular responsiveness of the left kidney to vasoconstrictors as a consequence of the already preconstricted state of this vascular bed $^{5}$. Indeed, asymmetry of kidney perfusion has been most often observed at the expense of the left kidney ${ }^{3,4}$, which might be explained by a denser sympathetic innervation of the left compared to the right renal artery, as has been demonstrated in rats $^{18}$, supposing that this also applies to human anatomy. An exaggerated response of the left renal vasculature to vasoconstrictor substances, among which aldosterone, could sustain or even perpetuate the difference between left and right renal blood flow, either via direct vascular effects ${ }^{19}$, or as a consequence of the sympathoexcitatory ability of aldosterone ${ }^{20-23}$.

Despite the observed inverse correlation of left renal blood flow with systolic blood pressure, it is unlikely that an aldosterone-induced reduction in left kidney perfusion affects blood pressure substantially, because this is most probably compensated for by the right kidney. Our findings of a higher right, compared to left mean renal blood flow are in support of a compensating role for the right kidney. Under circumstances of right-sided kidney damage, it is possible that not only blood pressure rises, but also that kidney function becomes endangered. Indeed, higher renal vascular resistance, 
potentially in part due to sympathetic nervous system activation ${ }^{24,25}$, can lead to a reduction in renal blood flow and consequently, renal ischemia and fibrosis, ultimately causing progressive renal injury ${ }^{26}$. This also suggests that an improvement of kidney perfusion may underlie the observed beneficial effects of mineralocorticoid receptor antagonists on renal outcomes in individuals with hypertension ${ }^{27-29}$. In rats with cyclosporin- or ischemia-reperfusion-induced renal vasoconstriction, which may be partly mediated by aldosterone, effects of spironolactone and eplerenone on kidney perfusion are promising ${ }^{30,31}$, although the direct influence of these agents on renal vascular tone in humans remains to be established.

A possible limitation of our study is its cross-sectional design, which does not allow conclusions regarding causality. In theory, reductions in renal blood flow can also be the result of structural abnormalities due to long-standing hypertension, with concomitant changes in renin levels. The differential relationship of the ARR with left and right renal blood flow, and the comparable renin levels in the left and right renal venous blood samples, however, render this explanation unlikely. Unfortunately, the invasive nature of the procedures performed in the present investigation prohibits a longitudinal study design. For this reason, it is also difficult to obtain information on the association of the ARR with renal hemodynamics in a less selected population, either normotensive or hypertensive. Furthermore, it is not known whether the current study population is representative of all individuals participating in this investigation and thus, whether the results obtained can be extrapolated to the hypertensive population at large. Lastly, in this study it was not possible to establish the specific cause of the differential association of the aldosterone-renin ratio with left and right renal blood flow. 


\section{References}

1. Birkenhäger WH, Reid JL. Assessment of hypertensive organ damage. In: Hansson L, Birkenhäger WH, eds. Handbook of hypertension. Amsterdam: Elsevier; 1997:347-348.

2. Baldwin DS, Hulet WH, Biggs AW, Gombos EA, Chasis H. Renal function in the separate kidneys of man. li. Hemodynamics and excretion of solute and water in essential hypertension. J Clin Invest. 1960;39:395-404

3. van Onna M, Houben AJ, Kroon AA, Wierema TK, Koster D, van Engelshoven JM, et al. Asymmetry of renal blood flow in patients with moderate to severe hypertension. Hypertension. 2003;41:108-113

4. Whitley MA, Jacobson AF. Congenital or early developmental versus later acquired renal function asymmetry. Scintigraphic characteristics. Clin Nucl Med. 1993;18:1020-1023

5. Folkow B. Physiological aspects of primary hypertension. Physiol Rev. 1982;62:347-504

6. Hall JE, Brands MW, Henegar JR. Angiotensin ii and long-term arterial pressure regulation: The overriding dominance of the kidney. J Am Soc Nephrol. 1999;10 Suppl 12:S258-265

7. Ljungman S, Aurell M, Hartford M, Wikstrand J, Berglund G. Effects of subpressor doses of angiotensin ii on renal hemodynamics in relation to blood pressure. Hypertension. 1983;5:368-374

8. Palmgren $E$, Widgren $B$, Aurell $M$, Herlitz $H$. Increased renal vascular sensitivity to angiotensin ii in hypertension is due to decreased response to prostaglandins. J Hypertens. 2003;21:969-976

9. Schmidt BM. Rapid non-genomic effects of aldosterone on the renal vasculature. Steroids. 2008;73: 961-965

10. Brown JM, Underwood PC, Ferri C, Hopkins PN, Williams GH, Adler GK, et al. Aldosterone dysregulation with aging predicts renal vascular function and cardiovascular risk. Hypertension. 2014;63:1205-1211

11. Kotchen TA, Kotchen JM, Grim CE, Krishnaswami S, Kidambi S. Aldosterone and alterations of hypertension-related vascular function in african americans. Am J Hypertens. 2009;22:319-324

12. de Leeuw PW, Birkenhager WH. Use of the xenon-133 washout technique in diagnosing renovascular disease in hypertension. Nephron. 1986;44 Suppl 1:5-7

13. Wierema TK, Houben AJ, Kroon AA, Koster D, van der Zander K, van Engelshoven JM, et al. Nitric oxide dependence of renal blood flow in patients with renal artery stenosis. J Am Soc Nephrol. 2001;12: 1836-1843

14. Levey AS, Stevens LA, Schmid CH, Zhang YL, Castro AF, 3rd, Feldman HI, et al. A new equation to estimate glomerular filtration rate. Annals of internal medicine. 2009;150:604-612

15. Kawarazaki H, Ando K, Fujita M, Matsui H, Nagae A, Muraoka K, et al. Mineralocorticoid receptor activation: A major contributor to salt-induced renal injury and hypertension in young rats. Am J Physiol Renal Physiol. 2011;300:F1402-1409

16. Nagase M, Matsui H, Shibata S, Gotoda T, Fujita T. Salt-induced nephropathy in obese spontaneously hypertensive rats via paradoxical activation of the mineralocorticoid receptor: Role of oxidative stress. Hypertension. 2007;50:877-883

17. Te Riet L, van Esch JH, Roks AJ, van den Meiracker AH, Danser AH. Hypertension: Renin-angiotensinaldosterone system alterations. Circ Res. 2015;116:960-975

18. Sanders MW, Fazzi GE, Janssen GM, de Leeuw PW, Blanco CE, De Mey JG. Reduced uteroplacental blood flow alters renal arterial reactivity and glomerular properties in the rat offspring. Hypertension. 2004;43:1283-1289

19. McCurley A, Jaffe IZ. Mineralocorticoid receptors in vascular function and disease. Mol Cell Endocrinol. 2012;350:256-265

20. Connell JM, Davies E. The new biology of aldosterone. J Endocrinol. 2005;186:1-20

21. Gomez-Sanchez EP. Intracerebroventricular infusion of aldosterone induces hypertension in rats. Endocrinology. 1986;118:819-823

22. Lincevicius GS, Shimoura CG, Nishi EE, Perry JC, Casarini DE, Gomes GN, et al. Aldosterone contributes to sympathoexcitation in renovascular hypertension. Am J Hypertens. 2015;28:1083-1090

23. Raheja P, Price A, Wang Z, Arbique D, Adams-Huet B, Auchus RJ, et al. Spironolactone prevents chlorthalidone-induced sympathetic activation and insulin resistance in hypertensive patients. Hypertension. 2012;60:319-325 
24. Esler M, Jennings G, Lambert G, Meredith I, Horne M, Eisenhofer G. Overflow of catecholamine neurotransmitters to the circulation: Source, fate, and functions. Physiol Rev. 1990;70:963-985

25. Hollenberg NK, Adams DF, Solomon H, Chenitz WR, Burger BM, Abrams HL, et al. Renal vascular tone in essential and secondary hypertension: Hemodynamic and angiographic responses to vasodilators. Medicine (Baltimore). 1975;54:29-44

26. Chade AR. Renal vascular structure and rarefaction. Compr Physiol. 2013;3:817-831

27. Flack JM, Oparil S, Pratt JH, Roniker B, Garthwaite S, Kleiman JH, et al. Efficacy and tolerability of eplerenone and losartan in hypertensive black and white patients. J Am Coll Cardiol. 2003;41: 1148-1155

28. White WB, Duprez D, St Hillaire R, Krause S, Roniker B, Kuse-Hamilton J, et al. Effects of the selective aldosterone blocker eplerenone versus the calcium antagonist amlodipine in systolic hypertension. Hypertension. 2003;41:1021-1026

29. Williams GH, Burgess E, Kolloch RE, Ruilope LM, Niegowska J, Kipnes MS, et al. Efficacy of eplerenone versus enalapril as monotherapy in systemic hypertension. Am J Cardiol. 2004;93:990-996

30. Mejia-Vilet JM, Ramirez V, Cruz C, Uribe N, Gamba G, Bobadilla NA. Renal ischemia-reperfusion injury is prevented by the mineralocorticoid receptor blocker spironolactone. Am J Physiol Renal Physiol. 2007;293:F78-86

31. Nielsen FT, Jensen BL, Marcussen N, Skott O, Bie P. Inhibition of mineralocorticoid receptors with eplerenone alleviates short-term cyclosporin a nephrotoxicity in conscious rats. Nephrol Dial Transplant. 2008;23:2777-2783 


\title{
4.
}

\section{ALDOSTERONE IS NOT ASSOCIATED WITH}

\author{
METABOLIC AND MICROVASCULAR INSULIN
}

SENSITIVITY IN LEAN AND ABDOMINALLY OBESE MEN

M.T.J. Schütten, Y.H.A.M. Kusters, A.J.H.M. Houben, J.L.J.M. Scheijen, M.P.H. van de Waarenburg, C.G. Schalkwijk, P.J. Joris, J. Plat, R.P. Mensink, P.W. de Leeuw, C.D.A. Stehouwer

J. Clin. Endocrinol. Metab. 2018;103:759-767 


\section{Abstract}

Context

Impaired insulin-mediated muscle microvascular recruitment (IMMR) may add to the development of insulin resistance and hypertension. Higher aldosterone levels have been linked to these obesity-related complications in severely to morbidly obese individuals, and to impaired microvascular function in experimental studies.

\section{Objectives}

To investigate whether aldosterone levels are associated with IMMR, insulin sensitivity and blood pressure in lean and moderately abdominally obese men, and to study the effect of weight loss.

\section{Methods}

In 25 lean and 53 abdominally obese men, 24-hour blood pressure measurement was performed, and aldosterone levels were measured using ultra-performance liquid chromatography tandem mass spectrometry. Insulin sensitivity was assessed by determining whole-body glucose disposal during a hyperinsulinaemic clamp. IMMR in forearm skeletal muscle was measured with contrast-enhanced ultrasonography. These assessments were repeated in the abdominally obese men following an 8-week weight loss or weight stable period.

Results

Sodium excretion and aldosterone levels were similar in lean and abdominally obese participants, but sodium excretion was inversely associated with aldosterone concentration only in the lean individuals (lean: $\beta / 100 \mathrm{mmol}$ sodium excretion (adjusted for age and urinary potassium excretion) $=-0.481 \quad(-0.949$ to -0.013$)$; abdominally obese: $\beta / 100 \mathrm{mmol}$ sodium excretion $=-0.081(-0.433$ to 0.271$) ; p$ for interaction=0.02). Aldosterone was not associated with IMMR, M/I-value, or blood pressure, and was unaffected by weight loss.

\section{Conclusion}

In moderately abdominally obese men, the inverse relationship between sodium excretion and aldosterone concentration is less than in lean men, but this does not translate in higher aldosterone levels. The absolute aldosterone level does not explain differences in microvascular and metabolic insulin sensitivity and blood pressure between lean and moderately abdominally obese men. 


\section{Introduction}

Obesity is accompanied by impaired insulin-mediated microvascular dilatation ${ }^{1,2}$. A reduced ability of insulin to dilate microvessels can add to the development of obesity-associated hypertension by increasing peripheral vascular resistance ${ }^{3}$, and of metabolic insulin resistance by impeding insulin-stimulated glucose disposal ${ }^{4-7}$. On the other hand, weight loss is associated with amelioration of microvascular dysfunction, including the microvascular response to insulin ${ }^{5,8-10}$, and the improvement of skeletal muscle microvascular function was an independent determinant of the increase in insulin-induced glucose uptake ${ }^{5,9}$. The molecular basis of these phenomena has not been fully elucidated. Over the years, evidence has accumulated suggesting involvement of aldosterone in the pathogenesis of obesity-related hypertension and insulin resistance. Higher aldosterone levels have been observed in severely to morbidly obese individuals, in parallel with higher blood pressure ${ }^{11-13}$, which may be a consequence of aldosterone synthesis in (visceral) adipose tissue ${ }^{12,14}$. In addition, aldosterone has been reported to correlate with insulin resistance in normotensive, overweight individuals $^{15}$, and to predict the development of insulin resistance in a general population ${ }^{16}$. Conversely, aldosterone concentration has been found to decrease following weight loss in severely to morbidly obese ${ }^{11-13,17}$, and hypertensive obese individuals ${ }^{18,19}$, and this was accompanied not only by reductions in blood pressure ${ }^{11-13,17-19}$, but also by improvement of insulin sensitivity ${ }^{12}$. Several experimental studies have shown that aldosterone interferes with microvascular function ${ }^{20-22}$ and more specifically, vascular insulin signaling ${ }^{23}$, while mineralocorticoid receptor blockade improved insulin-mediated aortic dilatation in female mice fed a Western diet ${ }^{24}$, and coronary microvascular function in individuals with type 2 diabetes ${ }^{25}$.

However, mediators of the effect of excess weight on (risk factors for) cardiovascular disease are not necessarily similar in severely to morbidly obese and overweight to moderately obese individuals, which may also apply to aldosterone ${ }^{26}$. Whether aldosterone levels are increased in a less advanced stage of obesity, and whether they are associated with impaired insulin-mediated muscle microvascular dilatation, and thus reduced insulin-stimulated glucose uptake and higher blood pressure in humans, has not been studied. Given the previously reported association of visceral obesity with elevated plasma aldosterone concentration ${ }^{12}$, we hypothesized that increased aldosterone levels in abdominally, but not morbidly, obese men contribute to the development of microvascular, and therefore, metabolic insulin resistance, and higher blood pressure. In addition, we expect these abnormalities to be reversible by weight loss. 
Therefore, the aims of the present study were to assess the association of aldosterone levels with insulin-mediated muscle microvascular recruitment, whole-body glucose disposal and blood pressure in abdominally obese, compared to lean men, and to determine the effect of weight loss on these variables in the abdominally obese men.

\section{Materials and methods}

\section{Study population}

Apparently healthy men were recruited via advertisements in local newspapers or among participants in previous investigations. Ultimately, 53 abdominally obese and 25 lean Caucasian men were enrolled in this randomized controlled trial with blinded analyses. Participants were 18-65 years of age, non-smoking, nondiabetic and free of cardiovascular disease, and had a waist circumference below $94 \mathrm{~cm}$ (lean) or between 102 and $110 \mathrm{~cm}$ (abdominally obese), and a stable body weight for at least 3 months. Exclusion criteria were fasting plasma glucose $>7.0 \mathrm{mmol} / \mathrm{L}, \mathrm{HbA}_{1 \mathrm{c}}>6.5 \%$, serum total cholesterol $>8.0 \mathrm{mmol} / \mathrm{L}$, serum triglycerides $>4.5 \mathrm{mmol} / \mathrm{L}$, systolic blood pressure $>160 \mathrm{~mm} \mathrm{Hg}$, and use of medication affecting blood pressure, lipid profile, or glucose metabolism. All participants gave written informed consent. The study was approved by the local ethics committee, performed in accordance with the Declaration of Helsinki, and registered at clinicaltrials.gov (NCT01675401).

\section{Study design}

Abdominally obese men were randomly assigned in a 1:1 ratio to either an 8-week weight loss program or maintenance of their habitual diet, and were studied before and after the 8-week period. Lean men were studied at baseline only. Randomization was performed by an independent investigator using block randomization with variable block sizes and stratification for ages below and above 50 years, because (the effect of weight loss on) microvascular and metabolic insulin sensitivity, and blood pressure may differ with age. An independent investigator revealed the allocation to the participant and research team upon completion of all baseline measurements. The weight loss program was designed to induce a $10 \%$ reduction in body weight and consisted of 4-5 weeks of a very low calorie diet providing 2.1 MJ/day (Modifast, Novartis Nutrition, Breda, The Netherlands), 1-2 weeks of an energy-restricted diet providing $4.2 \mathrm{MJ} /$ day, a weight stable phase of 2 weeks, and weekly dietary counseling. During the 8-week period, the control group was monitored as well in order to avoid fluctuations in 
weight. Both groups were instructed not to alter their exercise pattern throughout the study.

At baseline (lean and abdominally obese men) and after the 8-week period (abdominally obese men only), 24h urine was collected for assessment of sodium, potassium and creatinine excretion, and $24 \mathrm{~h}$ ambulatory blood pressure measurements (ABPM) were performed (Mobilograph (New Generation), I.E.M., Stolberg, Germany). Blood pressure was measured at the non-dominant arm; every 15 minutes during daytime and every 30 minutes during the night. Measurements were conducted in a temperature-controlled room $\left(T=24^{\circ} \mathrm{C} \pm 0.5^{\circ} \mathrm{C}\right)$ after a 12-hour overnight fast with participants in the supine position. Individuals were instructed to refrain from alcohol and meals rich in lipids for a period of 24 hours prior to each study day, and strenuous physical exercise for a period of 48 hours prior to each study day. After insertion of two intravenous catheters and a 30-minute acclimatization period with the participants in the supine position, we took blood samples for determination of glucose, HbA1c, overall lipid profile, and aldosterone concentrations, and measured microvascular blood volume of forearm skeletal muscle at baseline.

\section{Assessment of insulin sensitivity}

We determined metabolic insulin sensitivity by means of a modified version of the hyperinsulinaemic, euglycaemic clamp technique as described by DeFronzo et al. ${ }^{27}$. Briefly, insulin (Novorapid, Novo Nordisk, Bagsvaerd, Denmark) was administered in a primed continuous manner at a rate of $1 \mathrm{mU} / \mathrm{kg} / \mathrm{min}$ during 180 minutes. Isoglycaemia was maintained by adjusting the rate of a $20 \%$ D-glucose infusion based on plasma glucose measurements performed at 5 minute intervals. Whole-body glucose disposal (M-value) was estimated from the steady-state glucose infusion rate between 90 and 150 minutes after initiation of insulin administration. $M$ was expressed per kilogram body weight per unit of plasma insulin concentration (M/I-value), thus correcting for variation in steady-state insulin concentrations. For convenience, the $M / I$ ratio was multiplied by 100 .

\section{Evaluation of skeletal muscle microvascular function}

(Insulin-mediated) microvascular recruitment was assessed with contrast enhanced ultrasound as described previously ${ }^{5}$. Briefly, microvascular blood volume (MBV) of forearm skeletal muscle was measured before and during hyperinsulinaemia with a Toshiba Aplio XG ultrasound system (Toshiba, Otawara, Japan) during continuous i.v. administration of sulphur hexafluoride gas-filled microbubbles (SonoVue, Bracco diagnostics, Amsterdam, The Netherlands). After steady state microbubble 
concentration was achieved (3 minutes), five real-time replenishment curves of 30 seconds were acquired. These replenishment curves were stored and analyzed offline in a blinded fashion after completion of the trial using the $\mathrm{CHI}-\mathrm{Q}$ software (Toshiba, Otawara, Japan). The replenishment curves were fitted to the exponential function $y=A\left(1-e^{-b t}\right)$ where $t$ is time since high mechanical index pulse, $y$ is the video intensity at any given $t, A$ is the plateau video intensity (representing MBV), and $\beta$ is the microvascular flow velocity. Insulin-mediated muscle microvascular recruitment (IMMR) was calculated as the relative increase in muscle microvascular blood volume during hyperinsulinaemia.

\section{Measurement of subcutaneous and visceral fat volumes}

Subcutaneous and visceral fat volumes were measured with MRI, as previously described ${ }^{5}$.

\section{Blood and urine measurements}

Plasma glucose was determined with a YSI2300 glucose analyzer (YSI, Yellow Springs, $\mathrm{OH}, \mathrm{USA}$ ). Serum insulin levels during the hyperinsulinaemic clamp were measured with Mercodia Iso-Insulin ELISA (Mercodia AB, Uppsala, Sweden; intra-assay CV=2.8-3.2\%, inter-assay $\mathrm{CV}=3-3.9 \%)$. Serum aldosterone was analyzed with ultra-performance liquid chromatography tandem mass spectrometry (UPLC-MS/MS) as described previously ${ }^{28}$ with minor modifications. Briefly, $30 \mu \mathrm{L}$ of $0.14 \mu \mathrm{mol} / \mathrm{L} \quad \mathrm{D}_{7}$-aldosterone in $50 / 50$ methanol/water ( $v / v, \%)$ was added to $300 \mu \mathrm{L}$ of serum. Samples were mixed and subsequently deproteinized with acetone. After centrifugation $\left(10\right.$ minutes, $25^{\circ} \mathrm{C}$, $14000 \mathrm{rpm}$ ), the supernatant was extracted with two volumes of $800 \mu \mathrm{L}$ tert-butyl methyl ether at room temperature. The phases were separated by centrifugation ( 1 minute, $25^{\circ} \mathrm{C}, 4600 \mathrm{rpm}$ ) and the upper organic phase was transferred to a $4 \mathrm{~mL}$ glass vial and dried under nitrogen at $35^{\circ} \mathrm{C}$. The dried residue was dissolved in $100 \mu \mathrm{L}$ 35/65 methanol/water ( $\mathrm{v} / \mathrm{v}, \%)$. Finally, $10 \mu \mathrm{L}$ was injected into the UPLC-MS/MS for analysis. Intra-assay coefficients of variation (CV) ranged from 4.0-8.7\%; inter-assay CVs from $4.5-10.4 \%$. Urinary sodium and potassium excretion were determined with the ion-selective electrode (ISE) method.

\section{Statistical analyses}

Normally distributed variables are expressed as mean \pm SD; variables with a skewed distribution are displayed as median and interquartile range and natural logarithmic transformation was performed before further analyses (M/I-value and aldosterone). 
Independent sample T-tests were used to compare groups at baseline, and differences in anthropometric, metabolic, haemodynamic, and hormonal variables between the abdominally obese men following either the weight-loss or weight-stable period. Aldosterone concentration in lean and abdominally obese individuals was compared by ANCOVA, and in abdominally obese individuals before and after the weight loss or weight stable period by repeated measures ANCOVA, with adjustment for age, mean arterial pressure (in the comparison between lean and abdominally obese individuals) and urinary sodium and potassium excretion. Relationships of (changes in) aldosterone levels with (alterations in) IMMR, M/I-value, and 24h ambulatory blood pressure were assessed using multiple linear regression with adjustment for age and (differences in) urinary sodium and potassium excretion. Associations of (changes in) aldosterone concentration with (alterations in) other anthropometric, metabolic and haemodynamic variables are presented as Pearson's correlation coefficients. Analyses were performed using the SPSS statistical software package (IBM SPSS Statistics version 20, Chicago, IL). Two-tailed p-values of $<0.05$ were considered statistically significant.

\section{Results}

\section{Cross-sectional analyses}

One of the 53 abdominally obese participants was excluded because of protocol violations. Data on urinary sodium and potassium excretion were available in 21 lean men and 46 abdominally obese men. Baseline characteristics of the lean and abdominally obese men are presented in Table 4.1. Lean men had significantly lower subcutaneous and visceral adipose tissue volumes, fasting plasma glucose levels, and systolic and diastolic blood pressure, as compared to abdominally obese men. Aldosterone levels, on the other hand, were similar in both groups. Urinary sodium excretion was consistent with the average salt intake of Dutch men ${ }^{29}$. Adjustment for age, mean arterial pressure and urinary sodium and potassium excretion yielded similar results with regard to aldosterone concentration in lean and abdominally obese participants $\left(F_{1,61}=0.026 ; p=0.87 ;\right.$ Figure 4.1$)$. Both the $M / I$-value and $I M M R$ were higher, in lean, compared to abdominally obese men (Table 4.2). Aldosterone levels were not associated with IMMR, M/I-value, or 24h systolic blood pressure (SBP) (Ln IMMR: $\beta=-1.713, p=0.82$; Ln $M / I$ value: $\beta=-0.131, p=0.29$; SBP: $\beta=-2.533, p=0.14$ ), which remained unchanged after adjustment for age and urinary sodium and potassium excretion (Ln IMMR: $\beta=-0.715, p=0.93$; Ln $M /$ I value: $\beta=-0.100, p=0.46$; SBP: $\beta=-1.815$, $\mathrm{p}=0.34)$. 
Table 4.1: Baseline characteristics of the lean and abdominally obese men.

\begin{tabular}{lcc}
\hline & Lean & Abdominally obese \\
\hline $\mathrm{n}$ & 25 & 52 \\
Age (years) & $54[25-62]$ & $52[46-61]$ \\
$\mathrm{BMI}\left(\mathrm{kg} / \mathrm{m}^{2}\right)$ & $23.3 \pm 1.8^{\mathrm{a}}$ & $30.1 \pm 2.1$ \\
Waist circumference (cm) & $85 \pm 6^{\mathrm{a}}$ & $107 \pm 4$ \\
Subcutaneous adipose tissue (L) & $1.45 \pm 0.51^{\mathrm{a}}$ & $3.06 \pm 0.77$ \\
Visceral adipose tissue (L) & $0.89 \pm 0.42^{\mathrm{a}}$ & $2.36 \pm 0.72$ \\
Fasting plasma glucose (mmol/L) & $5.35 \pm 0.29^{\mathrm{a}}$ & $5.64 \pm 0.48$ \\
HbA1c (\%) & $5.2 \pm 0.4$ & $5.3 \pm 0.4$ \\
24h SBP/DBP (mm Hg) & $118 \pm 9 / 73 \pm 9^{\mathrm{a}}$ & $123 \pm 9 / 80 \pm 7$ \\
24h MAP (mm Hg) & $93 \pm 8^{\mathrm{a}}$ & $100 \pm 7$ \\
24h pulse pressure (mm Hg) & $45 \pm 8$ & $43 \pm 7$ \\
Aldosterone (pmol/L) & $274[178-512]$ & $278[169-392]$ \\
Urinary sodium excretion (mmol/24h) & $153 \pm 73$ & $172 \pm 64$ \\
Urinary potassium excretion (mmol/24h) & $81 \pm 30$ & $83 \pm 23$ \\
Urinary creatinine excretion (mmol/24h) & $14 \pm 3^{\mathrm{a}}$ & $18 \pm 3$ \\
\hline
\end{tabular}

Data are presented as means \pm SD or medians [interquartile ranges]; BMI: body mass index, SBP: systolic blood pressure, DBP: diastolic blood pressure, MAP: mean arterial pressure. ${ }^{a}$ Lean versus abdominally obese, $\mathrm{p} \leq 0.01$

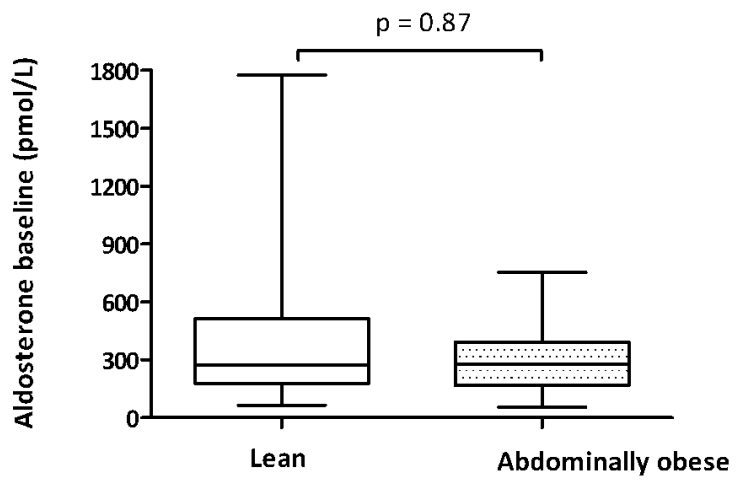

Figure 4.1: Baseline aldosterone levels in lean and abdominally obese individuals (ANCOVA with adjustment for age, mean arterial pressure, and urinary sodium and potassium excretion).

Table 4.2: Microvascular and metabolic insulin sensitivity in lean versus abdominally obese men.

\begin{tabular}{lcc}
\hline & Lean & Abdominally obese \\
\hline $\mathrm{n}$ & 25 & 52 \\
$\mathrm{M}$-value $(\mathrm{mg} / \mathrm{kg} / \mathrm{min})$ & $6.8 \pm 1.8^{\mathrm{a}}$ & $4.1 \pm 1.3$ \\
$\mathrm{M} / \mathrm{l}$-value $(\mathrm{mg} / \mathrm{kg} / \mathrm{min}$ per $\mathrm{mU} / \mathrm{L}) * 100))$ & $9.9[6.7-12.1]^{\mathrm{a}}$ & $4.4[2.9-5.5]$ \\
$\mathrm{IMMR}(\%)$ & $44 \pm 41^{\mathrm{a}}$ & $-3.5 \pm 27$ \\
\hline
\end{tabular}

Data are presented as means \pm SD or medians [interquartile ranges]; IMMR: insulin-mediated microvascular recruitment. ${ }^{a}$ Lean versus abdominally obese, $p \leq 0.01$ 
Supplemental Table S4.1 shows correlations of aldosterone with other anthropometric, metabolic and haemodynamic variables. Aldosterone was not associated with either $\mathrm{BMI}$ or subcutaneous and visceral adipose tissue volumes, but was inversely associated with diastolic blood pressure (DBP) $(r=-0.241, p=0.04)$, which became non-significant after adjustment for confounders, and for $24 \mathrm{~h}$ MAP (data not shown). These associations were similar in lean and abdominally obese individuals ( $p$ for interaction all $>0.14$ ), except for the associations with urinary sodium excretion. Urinary sodium excretion was inversely associated with aldosterone levels only in lean men ( $\beta$ per $100 \mathrm{mmol}$ sodium excretion (adjusted for age and urinary potassium excretion) $=-0.481$ (-0.949 to -0.013$), p<0.05$; i.e. per $100 \mathrm{mmol}$ greater sodium excretion, aldosterone levels were lower by $38 \%$ ( 1 to 61$)$ ), and not in abdominally obese men ( $\beta$ per $100 \mathrm{mmol}$ sodium excretion (adjusted for age and urinary potassium excretion) $=-0.081$ $(-0.433$ to 0.271$), p=0.65$; i.e. per $100 \mathrm{mmol}$ greater sodium excretion, aldosterone levels were lower by $8 \%$ ( -31 to 35 ); $p$ for interaction=0.02; Figure 4.2). Adjustment of associations of aldosterone levels with IMMR, M/I-value and 24h SBP for urinary sodium excretion did not materially change the regression coefficients (Supplemental Table S4.2).

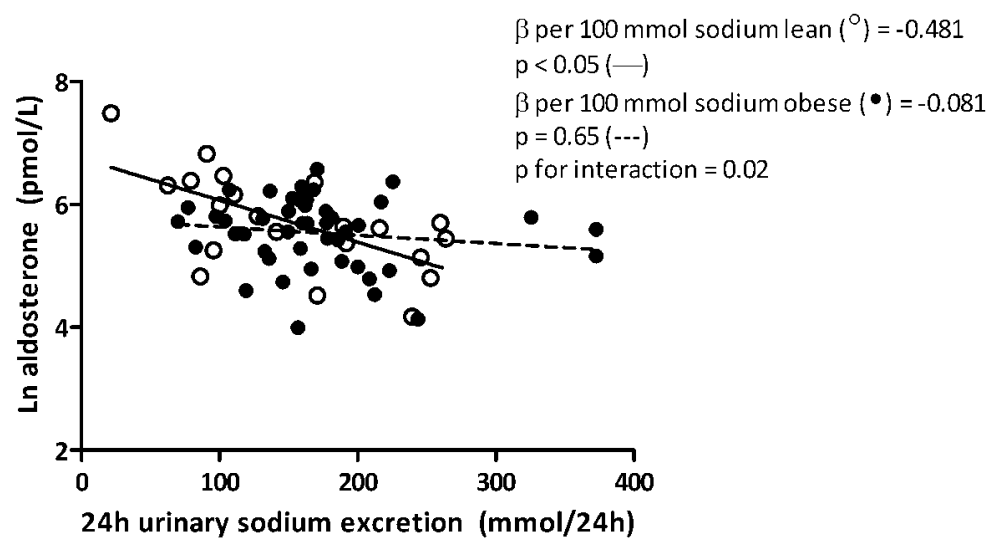

Figure 4.2: Association of $24 \mathrm{~h}$ urinary sodium excretion with aldosterone levels in lean (0) and abdominally obese $(\bullet)$ individuals. Regression coefficients are adjusted for age and urinary potassium excretion. 
Table 4.3: Anthropometric, metabolic, haemodynamic, and hormonal variables in abdominally obese men, and effects of weight loss.

\begin{tabular}{|c|c|c|c|c|}
\hline & \multicolumn{2}{|c|}{ Weight loss $(n=23)$} & \multicolumn{2}{|c|}{ Weight stable $(n=26)$} \\
\hline & Baseline & $\Delta$ & Baseline & $\Delta$ \\
\hline Age (years) & $52[47-62]$ & & $52[45-61]$ & \\
\hline $\mathrm{BMI}\left(\mathrm{kg} / \mathrm{m}^{2}\right)$ & $30.2 \pm 1.5$ & $-3.0 \pm 0.8^{b}$ & $29.9 \pm 2.5$ & $0.1 \pm 0.33$ \\
\hline Waist circumference $(\mathrm{cm})$ & $107 \pm 3$ & $-11 \pm 2^{b}$ & $106 \pm 4$ & $0 \pm 2$ \\
\hline Subcutaneous adipose tissue (L) & $2.81 \pm 0.65^{\mathrm{a}}$ & $-0.34 \pm 0.44$ & $3.26 \pm 0.78$ & $-0.36 \pm 0.53$ \\
\hline Visceral adipose tissue $(\mathrm{L})$ & $2.53 \pm 0.78$ & $-0.33 \pm 0.49$ & $2.19 \pm 0.68$ & $-0.29 \pm 0.55$ \\
\hline Fasting plasma glucose (mmol/L) & $5.49 \pm 0.37$ & $-0.21 \pm 0.33^{c}$ & $5.75 \pm 0.53$ & $0.00 \pm 0.28$ \\
\hline HbA1c (\%) & $5.2 \pm 0.3$ & $-0.2 \pm 0.3^{c}$ & $5.3 \pm 0.4$ & $-0.1 \pm 0.2$ \\
\hline M-value (mg/kg/min) & $4.1 \pm 1.3$ & $1.3 \pm 1.2^{b}$ & $4.0 \pm 1.4$ & $-0.1 \pm 0.9$ \\
\hline $\mathrm{M} / \mathrm{l}$-value $(\mathrm{mg} / \mathrm{kg} / \mathrm{min}$ per $\mathrm{mU} / \mathrm{L}) * 100))$ & $3.4[2.5-5.3]$ & $2.6 \pm 2.7^{b}$ & $4.8[2.7-6.2]$ & $-1.0 \pm 2.4$ \\
\hline IMMR (\%) & $-5.0 \pm 27$ & $40 \pm 49^{b}$ & $0.7 \pm 28$ & $-0.3 \pm 28$ \\
\hline 24h SBP/DBP (mm Hg) & $120 \pm 9^{a} / 78 \pm 8$ & $-5 \pm 6^{b} /-5 \pm 5^{b}$ & $126 \pm 8 / 82 \pm 7$ & $-1 \pm 6 /-1 \pm 5$ \\
\hline 24h MAP (mm Hg) & $98 \pm 8^{a}$ & $-5 \pm 5^{b}$ & $102 \pm 7$ & $-1 \pm 5$ \\
\hline $24 \mathrm{~h}$ pulse pressure $(\mathrm{mm} \mathrm{Hg})$ & $42 \pm 7$ & $0 \pm 3$ & $44 \pm 5$ & $0 \pm 4$ \\
\hline Aldosterone (pmol/L) & 306 [187-394] & $-61 \pm 126$ & $253[156-422]$ & $-30 \pm 141$ \\
\hline Urinary sodium excretion ( $\mathrm{mmol} / 24 \mathrm{~h}$ ) & $163 \pm 62$ & $19 \pm 80$ & $183 \pm 65$ & $0.1 \pm 87$ \\
\hline Urinary potassium excretion ( $\mathrm{mmol} / 24 \mathrm{~h}$ ) & $83 \pm 20$ & $-4.9 \pm 24$ & $85 \pm 25$ & $-5.3 \pm 38$ \\
\hline Urinary creatinine excretion ( $\mathrm{mmol} / 24 \mathrm{~h})$ & $18 \pm 3$ & $0.4 \pm 6.3$ & $18 \pm 4$ & $-1.9 \pm 3.6$ \\
\hline
\end{tabular}

Data are presented as means \pm SD or medians [interquartile ranges]; BMI: body mass index, IMMR: insulinmediated microvascular recruitment, SBP: systolic blood pressure, DBP: diastolic blood pressure, MAP: mean arterial pressure. ${ }^{a}$ Weight loss baseline versus weight stable baseline, $\mathrm{p}<0.05 ;{ }^{\mathrm{b}} \Delta$ weight loss versus $\Delta$ weight stable; $\mathrm{p} \leq 0.01 ;{ }^{\mathrm{c}} \Delta$ weight loss versus $\Delta$ weight stable; $\mathrm{p}<0.05$.

\section{Effects of weight loss}

Twenty-six abdominally obese men were allocated to the weight loss intervention, and 27 men were randomized to the weight-stable (control) group. Two men discontinued the weight loss intervention, one because of non-compliance, and the other for personal reasons, whereas a third man who was allocated to the weight loss program was excluded from the analyses due to protocol violations. One man, in the control group, did not complete the study for a non-study-related reason. Ultimately, analyses were performed on 23 men constituting the weight loss group and 26 men comprising the weight stable group. Data on urinary sodium and potassium excretion at follow-up were available in 19 participants randomized to the weight loss intervention, and 24 participants in the control group. Table 4.3 shows anthropometric, metabolic, haemodynamic, and hormonal variables at baseline, and the effects of weight loss on these variables. Both groups were comparable with regard to baseline characteristics, with the exception of systolic blood pressure, which was lower in the weight loss group ( $120 \pm 9$ vs. $126 \pm 8 \mathrm{~mm} \mathrm{Hg} ; \mathrm{p}=0.03$ ). In the control group, waist circumference, $\mathrm{M} / \mathrm{I}$-value, IMMR and $24 \mathrm{~h}$ ambulatory blood pressure were unchanged over time. In the weight loss group, waist circumference decreased significantly by $11 \pm 2.1 \mathrm{~cm}(\mathrm{p}<0.01)$, while $\mathrm{M} / \mathrm{I}$-value increased with $2.6 \pm 2.7((\mathrm{mg} / \mathrm{kg} / \mathrm{min}$ per $\mathrm{mU} / \mathrm{L}) * 100)(\mathrm{p}<0.01)$ and insulin- 
mediated microvascular recruitment with $40 \pm 49 \%(p<0.01)$. Systolic, diastolic, and mean arterial pressure fell significantly (SBP: $-5 \pm 6 \mathrm{~mm} \mathrm{Hg}, p<0.01 ; \mathrm{DBP}:-5 \pm 5 \mathrm{~mm} \mathrm{Hg}$, p<0.01; MAP: $-5 \pm 5 \mathrm{~mm} \mathrm{Hg}, \mathrm{p}<0.01$ ), but pulse pressure was unaffected. Aldosterone levels remained unchanged as well. The absence of an effect of weight loss on aldosterone concentration was confirmed after adjustment for age, and urinary sodium and potassium excretion at the time of follow up assessments $\left(F_{1,38}=0.824, p=0.37\right)$. Changes in aldosterone concentration following weight loss were not related to alterations in IMMR, M/I-value, or 24h SBP ( $\triangle$ IMMR: $\beta=-0.020, p=0.65 ; \Delta \mathrm{M} / \mathrm{I}$ value: $\beta=-0.001, p=0.72 ; \Delta 24 \mathrm{~h}$ SBP: $\beta=0.002, p=0.73$ ); regression coefficients remained unchanged after adjustment for potential confounders (Figure 4.3). Supplemental Table S4.3 also displays the associations of changes in aldosterone concentration with alterations in other anthropometric, metabolic, and haemodynamic variables due to the weight loss intervention. These associations were similar in the weight loss and weight stable groups ( $p$ for interaction all $>0.11$ ).

A

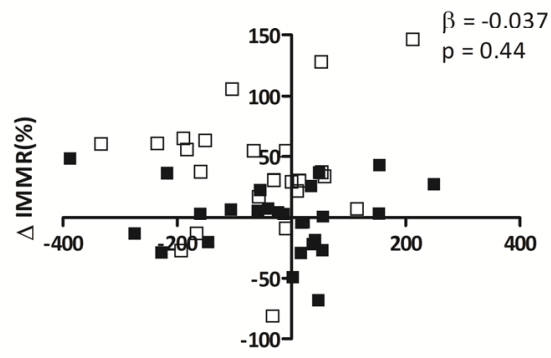

$\Delta$ aldosterone $(\mathrm{pmol} / \mathrm{L})$
B

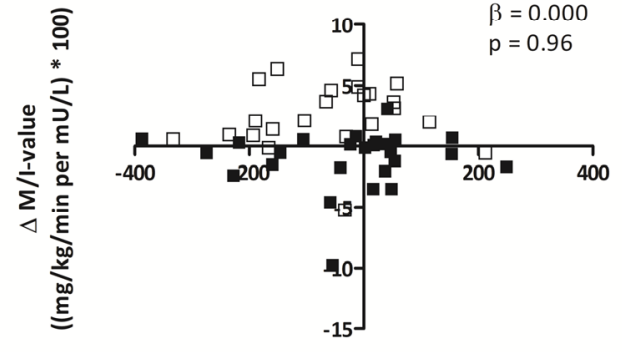

$\Delta$ aldosterone (pmol/L)

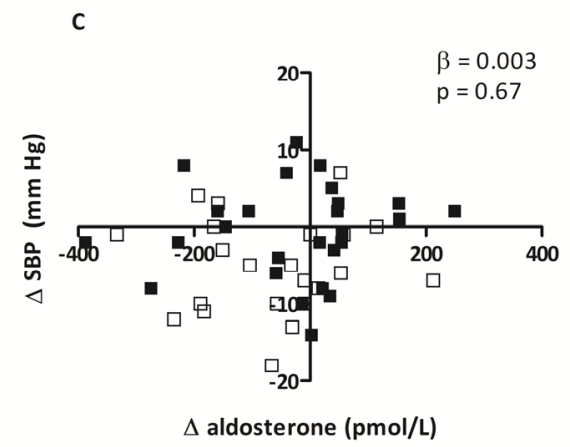

Figure 4.3: Associations of changes in aldosterone levels ( $\Delta$ aldosterone) following the weight loss ( $\square$ ) or weight stable period ( $\mathbf{\square})$ with $(\mathbf{A})$ alterations in insulin-mediated microvascular recruitment $(\Delta \mathrm{IMMR})$, (B) alterations in $\mathrm{M} / \mathrm{I}$-value $(\triangle \mathrm{M} / \mathrm{I})$, and $(\mathrm{C})$ alterations in $24 \mathrm{~h}$ systolic blood pressure $(\triangle 24 \mathrm{~h} \mathrm{SBP})$. Regression coefficients are adjusted for age and differences in urinary sodium and potassium excretion. 


\section{Additional analyses}

When we excluded participants with a BMI between 25 and 30 and thus individuals who would be classified as overweight on the basis of their BMI $(n=29)$, comparison of aldosterone levels between lean and obese individuals yields similar results: $\mathrm{BMI} \leq 25 \mathrm{~kg} / \mathrm{m}^{2}$ ( $\left.\mathrm{n}=21\right): 257$ [178-565] pmol/L, BMI $\geq 30 \mathrm{~kg} / \mathrm{m}^{2}: 288$ [174-394] pmol/L, $\mathrm{p}=0.50$.

In the present study, variation in ad-libitum sodium intake was relatively large. To investigate whether the response of aldosterone levels to controlled variation of sodium ingestion in lean and abdominally obese individuals is comparable to the crosssectional associations between ad libitum sodium intake and corresponding aldosterone concentration in the current population (see above), we determined the relationship between $24 \mathrm{~h}$ urinary sodium excretion and aldosterone levels after a low sodium (50 mmol sodium chloride/24h) and high sodium (250 mmol sodium chloride/24h) diet during 7 days in randomized order in 20 lean and 20 abdominally obese individuals in a separate dataset (characteristics of this study population are presented in Supplemental Table S4.4). Both after the low and high sodium diets, aldosterone levels were not statistically significantly different between lean and abdominally obese individuals. However, multivariate regression analyses adjusted for age, sex and urinary potassium excretion showed that, per $100 \mathrm{mmol}$ increase in urinary sodium excretion, aldosterone levels decreased more in lean than in abdominally obese participants; i.e. by 140 (289 to -10 ) pmol/L, $p=0.07$ in lean individuals and by 52 (237 to -133 ) pmol/L, $p=0.56$ in abdominally obese individuals, $\mathrm{p}$ for interaction $=0.07$ (Supplemental Figure S4.1).

\section{Discussion}

The present study shows that serum aldosterone levels are not higher in abdominally obese, compared to lean men, under circumstances of ad-libitum sodium intake, and are not associated with microvascular and metabolic insulin sensitivity or blood pressure. Moreover, serum aldosterone concentration is unaffected by a weight loss intervention in abdominally obese men, although we observed a significant decline in both insulin resistance and blood pressure.

Several previous investigations report elevated aldosterone levels in parallel with higher blood pressure in severely to morbidly obese participants ${ }^{11-13}$. The excess aldosterone in these individuals could be at least partially derived from (visceral) adipose tissue ${ }^{12,14}$. Therefore, in our study, in moderately abdominally obese men, the 
capacity of adipose tissue to produce aldosterone may have been insufficient to enable detection of elevations in aldosterone levels.

Experimental studies have shown that aldosterone can impair microvascular function and vascular insulin signaling ${ }^{20-23}$, which may predispose to the development of obesityassociated insulin resistance and hypertension ${ }^{1-3,7}$. Nevertheless, we could not establish an association of aldosterone levels with insulin-mediated microvascular recruitment in skeletal muscle, insulin stimulated-glucose disposal, or blood pressure. This again may be explained by the absence of differences in aldosterone concentration between lean and abdominally obese men, and thus the limited dispersion in aldosterone levels. It is also possible that the increase in aldosterone levels reported in severely to morbidly obese individuals reflects either an epiphenomenon that occurs later in the course of obesity and is not causally related to the development of insulin resistance and hypertension, or is a consequence of renal microvascular dysfunction and subsequent RAAS activation. However, observations of impaired insulin sensitivity in parallel with substantially elevated blood pressure in individuals with endogenously high exposure to aldosterone, such as patients with primary aldosteronism, which are both ameliorated following pharmacological or surgical treatment ${ }^{30}$, suggest otherwise. In addition, endothelial function in these individuals is more impaired than in patients with essential hypertension of equal severity ${ }^{31}$. Therefore, our results do not preclude an effect of aldosterone on microvascular and thus metabolic insulin sensitivity and blood pressure, but suggest that such an effect may become more prominent with increasing severity of obesity and thus a greater extent of aldosterone excess. This also indicates that in the current stage of obesity, mechanisms other than aldosterone surplus must be responsible for the increase in blood pressure.

Our data do not imply that regulation of aldosterone levels is completely normal in individuals with moderate abdominal obesity, although this does not immediately seem to affect insulin-mediated muscle microvascular recruitment, whole-body glucose disposal and blood pressure. Indeed, we found that the physiological inverse association of urinary sodium excretion with aldosterone levels was stronger in lean than abdominally obese individuals, pointing to a potential derangement in the abdominally obese group that may eventually add to the already existing increase in blood pressure. This is confirmed by our data of a separate experiment showing that after seven days of low and high salt intake in randomized order, suppression of aldosterone levels by increasing sodium intake is impaired in the abdominally obese participants, consistent with previous findings ${ }^{32}$. These observations are relevant given the fact that aldosterone seems to be particularly detrimental to the endothelium in the presence of high sodium intake ${ }^{33}$. Moreover, aldosterone production was found to correlate with insulin resistance in lean and overweight, normotensive individuals on a 
high-salt diet ${ }^{15}$. In the light of these observations, we cannot exclude that the absence of an association of higher aldosterone levels with microvascular and metabolic insulin resistance and higher blood pressure in the current investigation can be partially explained by a sodium intake in accordance with, and not above, the average ingestion of Dutch men ${ }^{29}$.

In contrast to our findings, other investigators have reported that weight loss in severely to morbidly obese individuals and hypertensive obese individuals is paralleled by reductions in aldosterone concentration ${ }^{11-13,17-19}$, together with a decline in blood pressure ${ }^{11-13,17-19}$ and amelioration of insulin resistance ${ }^{12}$. Although in the current study insulin sensitivity was improved and blood pressure fell significantly in the abdominally obese men randomized to the weight loss intervention, as compared to the control group, aldosterone levels remained unchanged. Again, this may be related to the fact that our abdominally obese participants would be categorized as overweight to moderately obese instead of severely obese on the basis of their BMI, which may entail a limited ability of aldosterone overproduction, as outlined previously.

A limitation of the present investigation is the use of an exclusively male study population, which affects the generalizability of the results. The fact that sodium and potassium intake were not standardized, and were estimated from single $24 \mathrm{~h}$ urine collections, is another limitation. Theoretically, this could have led us to underestimate true aldosterone levels in abdominally obese individuals. This is however unlikely as, in a separate experiment, after seven days of standardized low and high sodium intake, aldosterone levels were also not statistically significantly different between lean and abdominally obese participants. Nevertheless, the inverse association between urinary sodium excretion and serum aldosterone levels was less pronounced in abdominally obese, compared to lean participants both in the observational (Figure 4.2) and the experimental (Supplemental Figure S4.1) part of the current study. This suggests a subtle abnormality in the control of aldosterone concentration by sodium intake which, in this stage of obesity, does not affect absolute aldosterone levels. Yet, it does not detract from our findings that aldosterone levels, whether or not taking into account its regulation by sodium ingestion, were not significantly associated with microvascular or metabolic insulin sensitivity, or blood pressure, in either lean or moderately abdominally obese men.

An important strength of our investigation is its design, which allowed us to study the association between aldosterone and obesity-related complications, including microvascular and metabolic insulin resistance and hypertension, in both a crosssectional and longitudinal manner. In addition, we used the gold standard for assessment of insulin sensitivity, and were able to measure microvascular function in skeletal muscle, which is the main peripheral location of insulin-mediated glucose 
uptake, thus allowing a thorough evaluation of the relationship between microvascular and metabolic insulin sensitivity.

In conclusion, the results of the present study suggest that at an early stage of abdominal obesity, absolute aldosterone levels are not elevated, and do not contribute to the development of microvascular and metabolic insulin resistance and hypertension. However, the inverse relationship between sodium excretion and aldosterone concentration is less than in lean men, although this does not immediately affect insulin-mediated muscle microvascular recruitment, insulin-stimulated glucose disposal and blood pressure. It is possible that the role of aldosterone in this respect becomes more prominent with increasing severity of obesity. Future research should be directed towards investigating the association of aldosterone with microvascular and metabolic insulin sensitivity and blood pressure in a study population with a broader range of abdominal obesity, also including women. Moreover, it would be valuable to study the effect of mineralocorticoid receptor blockade on vascular and metabolic insulin signaling and blood pressure in these individuals as an alternative to weight loss for amelioration of insulin resistance and hypertension, which is often difficult to achieve and sustain. 


\section{References}

1. de Jongh RT, Serne EH, RG IJ, de Vries G, Stehouwer CD. Impaired microvascular function in obesity: Implications for obesity-associated microangiopathy, hypertension, and insulin resistance. Circulation. 2004;109:2529-2535

2. de Jongh RT, Serne EH, RG IJ, Jorstad HT, Stehouwer CD. Impaired local microvascular vasodilatory effects of insulin and reduced skin microvascular vasomotion in obese women. Microvasc Res. 2008;75:256-262

3. Hornstra JM, Serne EH, Eringa EC, Wijnker MC, de Boer MP, Yudkin JS, et al. Insulin's microvascular vasodilatory effects are inversely related to peripheral vascular resistance in overweight, but insulinsensitive subjects. Obesity (Silver Spring). 2013;21:2557-2561

4. Kubota T, Kubota N, Kumagai H, Yamaguchi S, Kozono H, Takahashi T, et al. Impaired insulin signaling in endothelial cells reduces insulin-induced glucose uptake by skeletal muscle. Cell Metab. 2011;13: 294-307

5. Kusters YH, Schalkwijk CG, Houben AJ, Kooi ME, Lindeboom L, Op 't Roodt J, et al. Independent tissue contributors to obesity-associated insulin resistance. JCI Insight. 2017;2

6. Vincent MA, Clerk LH, Lindner JR, Klibanov AL, Clark MG, Rattigan S, et al. Microvascular recruitment is an early insulin effect that regulates skeletal muscle glucose uptake in vivo. Diabetes. 2004;53: 1418-1423

7. Clerk LH, Vincent MA, Jahn LA, Liu Z, Lindner JR, Barrett EJ. Obesity blunts insulin-mediated microvascular recruitment in human forearm muscle. Diabetes. 2006;55:1436-1442

8. Joris PJ, Plat J, Kusters YH, Houben AJ, Stehouwer CD, Schalkwijk CG, et al. Diet-induced weight loss improves not only cardiometabolic risk markers but also markers of vascular function: A randomized controlled trial in abdominally obese men. Am J Clin Nutr. 2017;105:23-31

9. Prior SJ, Blumenthal JB, Katzel LI, Goldberg AP, Ryan AS. Increased skeletal muscle capillarization after aerobic exercise training and weight loss improves insulin sensitivity in adults with igt. Diabetes Care. 2014;37:1469-1475

10. Vinet A, Obert P, Dutheil F, Diagne L, Chapier R, Lesourd B, et al. Impact of a lifestyle program on vascular insulin resistance in metabolic syndrome subjects: The resolve study. $J$ Clin Endocrinol Metab. 2014:jc20142704

11. Engeli S, Bohnke J, Gorzelniak K, Janke J, Schling P, Bader M, et al. Weight loss and the reninangiotensin-aldosterone system. Hypertension. 2005;45:356-362

12. Goodfriend TL, Kelley DE, Goodpaster BH, Winters SJ. Visceral obesity and insulin resistance are associated with plasma aldosterone levels in women. Obes Res. 1999;7:355-362

13. Rocchini AP, Katch VL, Grekin R, Moorehead C, Anderson J. Role for aldosterone in blood pressure regulation of obese adolescents. Am J Cardiol. 1986;57:613-618

14. Briones AM, Nguyen Dinh Cat A, Callera GE, Yogi A, Burger D, He Y, et al. Adipocytes produce aldosterone through calcineurin-dependent signaling pathways: Implications in diabetes mellitusassociated obesity and vascular dysfunction. Hypertension. 2012;59:1069-1078

15. Bentley-Lewis R, Adler GK, Perlstein T, Seely EW, Hopkins PN, Williams GH, et al. Body mass index predicts aldosterone production in normotensive adults on a high-salt diet. $J$ Clin Endocrinol Metab. 2007;92:4472-4475

16. Kumagai E, Adachi H, Jacobs DR, Jr., Hirai Y, Enomoto M, Fukami A, et al. Plasma aldosterone levels and development of insulin resistance: Prospective study in a general population. Hypertension. 2011;58:1043-1048

17. Tuck ML, Sowers J, Dornfeld L, Kledzik G, Maxwell M. The effect of weight reduction on blood pressure, plasma renin activity, and plasma aldosterone levels in obese patients. N Engl J Med. 1981;304:930-933

18. Fogari R, Zoppi A, Corradi L, Preti P, Mugellini A, Lazzari P, et al. Effect of body weight loss and normalization on blood pressure in overweight non-obese patients with stage 1 hypertension. Hypertens Res. 2010;33:236-242 
19. Ikeda T, Gomi T, Hirawa N, Sakurai J, Yoshikawa N. Improvement of insulin sensitivity contributes to blood pressure reduction after weight loss in hypertensive subjects with obesity. Hypertension. 1996;27:1180-1186

20. Arima S, Kohagura K, Xu HL, Sugawara A, Abe T, Satoh F, et al. Nongenomic vascular action of aldosterone in the glomerular microcirculation. J Am Soc Nephrol. 2003;14:2255-2263

21. Kushibiki M, Yamada M, Oikawa K, Tomita H, Osanai T, Okumura K. Aldosterone causes vasoconstriction in coronary arterioles of rats via angiotensin ii type-1 receptor: Influence of hypertension. Eur J Pharmacol. 2007;572:182-188

22. Lapi D, Emdin M, Mastantuono T, Sapio D, Santillo M, Colantuoni A. Microvascular responses to aldosterone in hamster cheek pouch microcirculation. Clin Hemorheol Microcirc. 2013;53:303-315

23. Hitomi H, Kiyomoto H, Nishiyama A, Hara T, Moriwaki K, Kaifu K, et al. Aldosterone suppresses insulin signaling via the downregulation of insulin receptor substrate-1 in vascular smooth muscle cells. Hypertension. 2007;50:750-755

24. DeMarco VG, Habibi J, Jia G, Aroor AR, Ramirez-Perez FI, Martinez-Lemus LA, et al. Low-dose mineralocorticoid receptor blockade prevents western diet-induced arterial stiffening in female mice. Hypertension. 2015;66:99-107

25. Garg R, Rao AD, Baimas-George M, Hurwitz S, Foster C, Shah RV, et al. Mineralocorticoid receptor blockade improves coronary microvascular function in individuals with type 2 diabetes. Diabetes. 2015;64:236-242

26. Lu Y, Hajifathalian K, Ezzati M, Woodward M, Rimm EB, Danaei G. Metabolic mediators of the effects of body-mass index, overweight, and obesity on coronary heart disease and stroke: A pooled analysis of 97 prospective cohorts with 1.8 million participants. Lancet. 2014;383:970-983

27. DeFronzo RA, Tobin JD, Andres R. Glucose clamp technique: A method for quantifying insulin secretion and resistance. Am J Physiol. 1979;237:E214-223

28. Turpeinen $\mathrm{U}$, Hamalainen $\mathrm{E}$, Stenman UH. Determination of aldosterone in serum by liquid chromatography-tandem mass spectrometry. J Chromatogr B Analyt Technol Biomed Life Sci. 2008;862:113-118

29. Hendriksen MA, van Raaij JM, Geleijnse JM, Wilson-van den Hooven C, Ocke MC, van der AD. Monitoring salt and iodine intakes in dutch adults between 2006 and 2010 using $24 \mathrm{~h}$ urinary sodium and iodine excretions. Public health nutrition. 2014;17:1431-1438

30. Catena C, Lapenna R, Baroselli S, Nadalini E, Colussi G, Novello M, et al. Insulin sensitivity in patients with primary aldosteronism: A follow-up study. J Clin Endocrinol Metab. 2006;91:3457-3463

31. Nishizaka MK, Zaman MA, Green SA, Renfroe KY, Calhoun DA. Impaired endothelium-dependent flowmediated vasodilation in hypertensive subjects with hyperaldosteronism. Circulation. 2004;109: 2857-2861

32. Licata G, Volpe M, Scaglione R, Rubattu S. Salt-regulating hormones in young normotensive obese subjects. Effects of saline load. Hypertension. 1994;23:120-24

33. Oberleithner H, Riethmuller C, Schillers H, MacGregor GA, de Wardener HE, Hausberg M. Plasma sodium stiffens vascular endothelium and reduces nitric oxide release. Proc Natl Acad Sci U S A. 2007;104:16281-16286 


\section{Supplemental data}

Supplemental Table S4.1: Correlations* of aldosterone levels with anthropometric, metabolic and haemodynamic variables in lean and abdominally obese men

\begin{tabular}{lcc}
\hline & Ln aldosterone $(\mathrm{pmol} / \mathrm{L})$ & $\mathrm{p}$-value \\
\hline Age & 0.095 & 0.41 \\
$\mathrm{BMI}\left(\mathrm{kg} / \mathrm{m}^{2}\right.$ ) & -0.055 & 0.63 \\
Waist circumference (cm) & -0.082 & 0.48 \\
Subcutaneous adipose tissue (L) & 0.010 & 0.93 \\
Visceral adipose tissue (L) & -0.172 & 0.14 \\
Fasting plasma glucose (mmol/L) & -0.024 & 0.84 \\
HbA1c (\%) & 0.068 & 0.56 \\
M-value (mg/kg/min) & -0.029 & 0.80 \\
Ln M/l-value (mg/kg/min per mU/L) * 100)) & -0.108 & 0.35 \\
IMMR (\%) & -0.038 & 0.74 \\
24h SBP (mm Hg) & -0.168 & 0.14 \\
24h DBP (mm Hg) & -0.241 & 0.04 \\
24h MAP (mm Hg) & -0.219 & 0.06 \\
24h PP (mm Hg) & 0.079 & 0.49 \\
Urinary sodium excretion (mmol/24h) & -0.355 & $<0.01$ \\
Urinary potassium excretion (mmol/24h) & -0.347 & $<0.01$ \\
\hline
\end{tabular}

Data are presented as correlation coefficient with corresponding p-value. BMI: body mass index, IMMR: insulin-mediated muscle microvascular recruitment, SBP: systolic blood pressure, DBP: diastolic blood pressure, MAP: mean arterial pressure, PP: pulse pressure. ${ }^{*}$ Correlations were similar in lean and abdominally obese individuals ( $p$ for interaction all $>0.14$ ), with the exception of the association of urinary sodium ( $p$ for interaction=0.02) and potassium ( $p$ for interaction=0.05) excretion with aldosterone levels.

Supplemental Table S4.2: Associations of aldosterone levels with IMMR, M/I-value and SBP.

\begin{tabular}{|c|c|c|c|c|c|c|}
\hline & \multicolumn{6}{|c|}{ Dependent variable } \\
\hline & \multicolumn{2}{|c|}{$\begin{array}{c}\text { IMMR } \\
(\%)\end{array}$} & \multicolumn{2}{|c|}{$\begin{array}{c}\mathrm{Ln} \mathrm{M} / \mathrm{I} \\
(\mathrm{mg} / \mathrm{kg} / \mathrm{min} \text { per } \\
\mathrm{mU} / \mathrm{L}) * 100))\end{array}$} & \multicolumn{2}{|c|}{$\begin{array}{c}\text { SBP } \\
(\mathrm{mm} \mathrm{Hg})\end{array}$} \\
\hline & $\beta$ & $\mathrm{p}$ & $\beta$ & $\mathrm{p}$ & $\beta$ & $\mathrm{p}$ \\
\hline \multicolumn{7}{|l|}{ Independent variable: Ln aldosterone (pmol/L) } \\
\hline Crude analysis & -1.713 & 0.82 & -0.131 & 0.29 & -2.533 & 0.14 \\
\hline Model 1: adjusted for age & -2.448 & 0.74 & -0.136 & 0.27 & -2.549 & 0.14 \\
\hline Model 2: model 1 with urinary sodium excretion & -3.332 & 0.67 & -0.117 & 0.38 & -1.949 & 0.29 \\
\hline Model 3: model 2 with urinary potassium excretion & -0.715 & 0.93 & -0.100 & 0.46 & -1.815 & 0.34 \\
\hline
\end{tabular}

IMMR: insulin-mediated muscle microvascular recruitment; SBP: systolic blood pressure. 
Supplemental Table S4.3: Correlations ${ }^{*}$ of changes in aldosterone levels following the weight loss or weight stable period with changes in anthropometric, metabolic, and haemodynamic variables.

\begin{tabular}{|c|c|c|}
\hline & $\Delta$ aldosterone (pmol/L) & p-value \\
\hline$\Delta \mathrm{BMI}\left(\mathrm{kg} / \mathrm{m}^{2}\right)$ & 0.083 & 0.57 \\
\hline$\Delta$ waist circumference $(\mathrm{cm})$ & 0.049 & 0.74 \\
\hline$\Delta$ fasting plasma glucose (mmol/L) & 0.004 & 0.98 \\
\hline$\Delta$ subcutaneous adipose tissue $(\mathrm{L})$ & 0.011 & 0.95 \\
\hline$\Delta$ visceral adipose tissue $(\mathrm{L})$ & -0.016 & 0.91 \\
\hline$\Delta \mathrm{HbA} 1 \mathrm{c}(\%)$ & 0.045 & 0.77 \\
\hline$\Delta \mathrm{M}$-value $(\mathrm{mg} / \mathrm{kg} / \mathrm{min})$ & -0.046 & 0.75 \\
\hline$\Delta \mathrm{M} / \mathrm{l}$-value $(\mathrm{mg} / \mathrm{kg} / \mathrm{min}$ per $\mathrm{mU} / \mathrm{L}) * 100))$ & -0.033 & 0.82 \\
\hline$\triangle \mathrm{IMMR}(\%)$ & -0.011 & 0.94 \\
\hline$\triangle 24 \mathrm{~h} \mathrm{SBP}(\mathrm{mm} \mathrm{Hg})$ & 0.087 & 0.55 \\
\hline$\triangle 24 \mathrm{~h} \mathrm{DBP}(\mathrm{mm} \mathrm{Hg})$ & 0.094 & 0.52 \\
\hline$\triangle 24 \mathrm{~h} \mathrm{MAP}(\mathrm{mm} \mathrm{Hg})$ & 0.091 & 0.53 \\
\hline$\Delta 24 \mathrm{~h} \mathrm{PP}(\mathrm{mm} \mathrm{Hg})$ & 0.022 & 0.88 \\
\hline$\Delta$ urinary sodium excretion ( $\mathrm{mmol} / 24 \mathrm{~h})$ & -0.207 & 0.18 \\
\hline$\Delta$ urinary potassium excretion (mmol/24h) & -0.110 & 0.48 \\
\hline
\end{tabular}

Data are presented as correlation coefficient with corresponding p-value. BMI: body mass index, IMMR: insulin-mediated muscle microvascular recruitment, SBP: systolic blood pressure, DBP: diastolic blood pressure, MAP: mean arterial pressure, PP: pulse pressure. ${ }^{*}$ Correlations were similar in the weight loss and weight stable groups ( $p$ for interaction all $>0.11$ ).

Supplemental Table S4.4: Characteristics of the lean and abdominally obese individuals who adhered to a low and high salt diet during 7 days in randomized order.

\begin{tabular}{|c|c|c|c|c|}
\hline & \multicolumn{2}{|c|}{ Lean $(n=20)$} & \multicolumn{2}{|c|}{ Abdominally obese $(n=20)$} \\
\hline & High salt & Low salt & High salt & Low salt \\
\hline Sex ( $\mathrm{n}$ of men/women) & \multicolumn{2}{|c|}{$7 / 13$} & \multicolumn{2}{|c|}{$6 / 14$} \\
\hline Age (years) & \multicolumn{2}{|c|}{$49 \pm 10$} & \multicolumn{2}{|c|}{$50 \pm 11$} \\
\hline $\mathrm{BMI}\left(\mathrm{kg} / \mathrm{m}^{2}\right)$ & \multicolumn{2}{|c|}{$22.5 \pm 2.0$} & \multicolumn{2}{|c|}{$31.3 \pm 3.9$} \\
\hline \multicolumn{5}{|l|}{ Waist circumference $(\mathrm{cm})$} \\
\hline Men & \multicolumn{2}{|c|}{$84 \pm 5$} & \multicolumn{2}{|c|}{$114 \pm 8$} \\
\hline Women & \multicolumn{2}{|c|}{$74 \pm 4$} & \multicolumn{2}{|c|}{$101 \pm 12$} \\
\hline 24h SBP/DBP (mm Hg) & $120^{d} \pm 8 / 77 \pm 7$ & $113^{\mathrm{a}, \mathrm{c}} \pm 8 / 73^{\mathrm{a}} \pm 9$ & $130 \pm 17 / 81 \pm 12$ & $125^{\mathrm{b}} \pm 15 / 79 \pm 11$ \\
\hline Aldosterone (pmol/L) & $61[39-94]$ & $288[134-362]^{a}$ & $109[71-164]$ & $263[201-343]^{b}$ \\
\hline Urinary sodium excretion (mmol/24h) & $241 \pm 61$ & $67 \pm 32^{\mathrm{a}}$ & $239 \pm 76$ & $73 \pm 28^{b}$ \\
\hline Urinary potassium excretion ( $\mathrm{mmol} / 24 \mathrm{~h})$ & $56 \pm 28$ & $54 \pm 22$ & $58 \pm 20$ & $55 \pm 18$ \\
\hline
\end{tabular}

Data are presented as means \pm SD or medians [interquartile ranges]; SBP: systolic blood pressure, DBP: diastolic blood pressure. ${ }^{a}$ Lean: low vs. high salt, $p<0.05 ;{ }^{b}$ Abdominally obese: low vs. high salt, $p<0.05$; ${ }^{c}$ Lean vs. abdominally obese under low salt circumstances, $p<0.05 ;{ }^{d}$ Lean vs. abdominally obese under high salt circumstances, $\mathrm{p}<0.05$. 


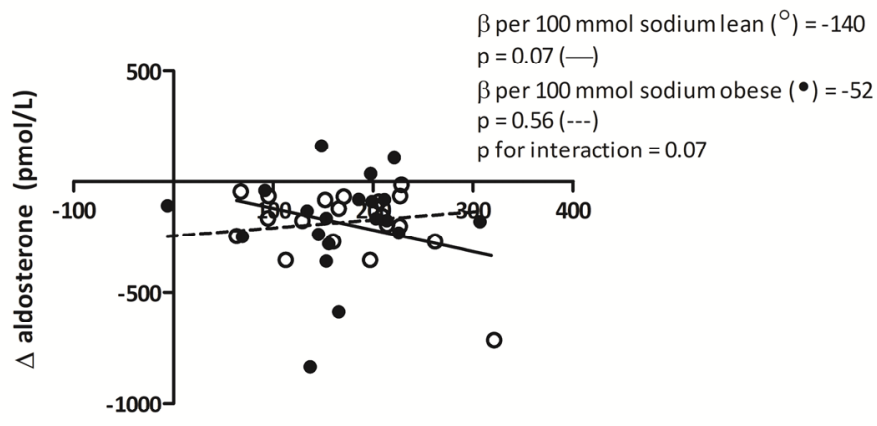

$\Delta 24 \mathrm{~h}$ urinary sodium excretion $(\mathrm{mmol} / 24 \mathrm{~h})$

Supplemental Figure S4.1: Associations of differences $(\Delta)$ in 24 h urinary sodium excretion with differences $(\Delta)$ in aldosterone levels between seven days of low $(50 \mathrm{mmol} / 24 \mathrm{~h})$ and high $(250 \mathrm{mmol} / 24 \mathrm{~h})$ sodium intake in lean $(0)$ and abdominally obese $(\bullet)$ individuals. Regression coefficients are adjusted for age, sex and differences in potassium excretion. 


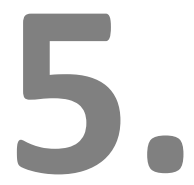

\section{DIFFERENTIAL EFFECTS OF HIGH AND LOW SALT}

INTAKE ON MUSCLE MICROVASCULAR

RECRUITMENT, BLOOD PRESSURE AND INSULIN-

MEDIATED WHOLE-BODY GLUCOSE DISPOSAL IN

LEAN AND ABDOMINALLY OBESE INDIVIDUALS

M.T.J. Schütten, Y.H.A.M. Kusters" ${ }^{*}$ A.J.H.M. Houben ${ }^{*}$, H.E. Niessen,

J. op 't Roodt, J.L.J.M. Scheijen, M.P.H. van de Waarenburg, C.G. Schalkwijk, P.W. de Leeuw, C.D.A. Stehouwer

* Both authors contributed equally

Submitted JCl Insight 


\section{Abstract}

\section{Background}

Salt-sensitive hypertension in obese individuals is often accompanied by insulin resistance, but the underlying mechanisms are obscure. Microvascular function is known to affect both salt-sensitivity of blood pressure and metabolic insulin sensitivity. We hypothesized that excessive salt intake increases blood pressure and decreases insulin-mediated glucose disposal, at least in part by impairing insulin-mediated microvascular recruitment.

\section{Methods}

In 20 lean and 20 abdominally obese individuals, we measured blood pressure (24h ABPM), insulin-mediated whole-body glucose disposal ( $\mathrm{M} / \mathrm{l}$-value; hyperinsulinemic, euglycemic clamp technique) and forearm insulin-mediated muscle microvascular recruitment (IMMR; contrast enhanced ultrasound) after a low $(50 \mathrm{mmol} / 24 \mathrm{~h})$ and high (250 mmol/24h) salt diet during seven days in a randomized double-blind cross-over design.

\section{Results}

On a low, as compared to a high salt intake, mean arterial pressure (MAP) was lower, $\mathrm{M} /$ I-value was lower and IMMR was greater in both lean and abdominally obese individuals (group-, age-, and sex- adjusted; low vs. high salt: MAP: $96 \pm 10$ vs. $100 \pm 11 \mathrm{~mm} \mathrm{Hg}, \mathrm{p}<0.01 ; \mathrm{M} / \mathrm{l}$-value: 8.8 [5.6-12.9] vs. 10.1 [7.0-15.2] ((mg/kg/min per $\mathrm{mU} / \mathrm{L}$ )*100), $\mathrm{p}<0.01$; IMMR: 38 [32-60] vs. 19 [14-41]\%, p=0.03). In addition, Ln IMMR was inversely associated with MAP in lean participants on a low salt diet only (age- and sex-adjusted standardized $\beta=-0.511(-0.778$ to -0.088$)$ ), but not with $\mathrm{M} / \mathrm{I}$-value on either diet.

\section{Conclusion}

A low, compared to a high salt diet, decreases blood pressure, impairs metabolic insulin sensitivity, and improves microvascular insulin sensitivity in both lean and abdominally obese individuals. The enhancement of IMMR on a low salt diet is associated with decreased MAP in lean individuals only, and does not appear to play a role in modulating metabolic insulin sensitivity under these conditions. This implies that mechanisms underlying hemodynamic and metabolic effects of changes in salt intake are not similar, and that the role of IMMR as a determinant of blood pressure differs between lean and abdominally obese individuals. 


\section{Introduction}

In obesity, an increased susceptibility to the hypertensive effects of salt ('salt sensitivity') is often seen in parallel with impaired insulin-mediated glucose disposal (insulin resistance) $)^{1-6}$. The exact underlying mechanisms for the association of saltsensitive hypertension with insulin resistance in obese individuals have not been clarified, although several explanations have been proposed, including inappropriate activation of the renin-angiotensin-aldosterone and sympathetic nervous systems, sodium-induced elevation of circulating free fatty acids, and insulin-mediated sodium retention $^{2,7,8}$.

We and others ${ }^{9-13}$ have proposed that impairment of microvascular function may contribute to the detrimental effects of salt on blood pressure and insulin sensitivity, particularly in obesity. First, if excess salt impairs microvascular dilatation, the resulting increase in peripheral resistance, other things being equal, will increase blood pressure. Indeed, (skin) capillary recruitment capacity during reactive hyperemia has been shown to be inversely associated with salt sensitivity of blood pressure in normotensive and hypertensive individuals ${ }^{10}$. In addition, salt loading was found to impede skin postocclusive reactive hyperemia in healthy women ${ }^{9}$. Conversely, a modest reduction in salt intake increased basal and maximal skin capillary density in mildly hypertensive individuals ${ }^{11}$, while a larger decrease in sodium intake resulted in a higher bulbar conjunctival arteriolar density in essential hypertensive individuals, compared to controls $^{14}$. Second, microvascular dysfunction can impair insulin-stimulated glucose disposal. An important physiological function of insulin in muscle is to dilate arterioles and recruit capillaries, thus enhancing its own access and that of glucose to myocytes, and increasing muscle glucose uptake ${ }^{15}$. In addition, these microvascular actions of insulin may affect blood pressure by reducing peripheral vascular resistance ${ }^{16,17}$. As a consequence, impairment of insulin-mediated microvascular dilatation and capillary recruitment, as often observed in obese individuals, may hinder insulin-stimulated glucose disposal and increase peripheral vascular resistance, thereby contributing to the development of, and linking, insulin resistance and hypertension ${ }^{12,13}$. However, it is not known whether excess salt intake impairs insulin's microvascular effects. We hypothesized that excess salt intake can impair insulin-mediated microvascular recruitment by interfering with NO-availability, and thus contribute to salt-induced increases in blood pressure and decreases in insulin-mediated glucose disposal, especially in obesity. Indeed, in lean rats, a high salt diet impaired both insulinstimulated microvascular recruitment and glucose uptake in muscle ${ }^{18}$, whereas in obese rats, salt restriction prevented the development of hypertension and insulin resistance ${ }^{19}$. 
Data in humans, however, are lacking. In view of these considerations, we studied, in lean and abdominally obese individuals, insulin-mediated muscle microvascular recruitment and its associations with $24 \mathrm{~h}$ ambulatory blood pressure and whole-body insulin-mediated glucose disposal after salt loading and salt restriction.

\section{Materials and methods}

\section{Study population}

Lean and abdominally obese individuals were recruited at the Maastricht University Medical Center, Maastricht, the Netherlands, between September 2014 and August 2016 via advertisements in local newspapers and among participants in previous investigations. A sample size of 20 individuals per group was calculated to be sufficient for detecting a mean difference of $5 \mathrm{~mm} \mathrm{Hg}$ in mean arterial pressure, and of $1((\mathrm{mg} / \mathrm{kg} / \mathrm{min}$ per $\mathrm{mU} / \mathrm{L}) * 100)$ in $\mathrm{M} / \mathrm{l}$-value between the low and high salt diets with a power (1- $\beta$ ) of 0.80 and $\alpha=0.95$, and a mean difference of $7 \mathrm{~mm} \mathrm{Hg}$ in mean arterial pressure and $4((\mathrm{mg} / \mathrm{kg} / \mathrm{min}$ per $\mathrm{mU} / \mathrm{L}) * 100)$ in $\mathrm{M} / \mathrm{l}$-value between lean and abdominally obese individuals with the same power and $\alpha$. Although data on relevant differences in and variation of IMMR were limited, we also expected this sample size to be large enough to demonstrate a difference in IMMR, as previous investigators have observed an average difference in IMMR of $40 \%$ between 10 lean and 11 abdominally obese participants ${ }^{20}$. Thus, we aimed at 20 lean and 20 abdominally obese Caucasian individuals to complete this randomized double-blind cross-over trial with masked analyses. Participants were 18-65 years of age, non-smoking, nondiabetic and free of cardiovascular disease, and had a waist circumference below $80 \mathrm{~cm}$ (lean women)/ $94 \mathrm{~cm}$ (lean men) or above $88 \mathrm{~cm}$ (abdominally obese women)/102 cm (abdominally obese men). Exclusion criteria were fasting plasma glucose $>6.1 \mathrm{mmol} / \mathrm{L}$, office blood pressure $>180 / 110 \mathrm{mmHg}$, unstable or severe pulmonary or thyroid disease, a recent history of malignancy, inflammatory diseases, impairment of renal or hepatic function, pregnancy or lactation, and use of glucose-lowering medication, nonsteroidal antiinflammatory drugs or corticosteroids. Four abdominally obese participants were taking antihypertensive medication at the time of inclusion (calcium channel blocker: $n=1$; angiotensin receptor blocker in combination with a thiazide diuretic: $n=1$; angiotensin converting enzyme (ACE) inhibitor combined with a $\beta$-blocker: $n=1$; ACE-inhibitor combined with a thiazide-like diuretic; $n=1$ ). Antihypertensives were discontinued three weeks before measurements; statin use was not interrupted ( $n=1$ (abdominally obese man)). 
Women on oral contraceptives were instructed to continue using them throughout the study period ( $n=2$ (abdominally obese women)). Measurements were performed in either the follicular or the luteal phase of the menstrual cycle, if applicable, with the exception of two lean women (in one, the first study day took place in the follicular phase and the second in the luteal phase; in the other, vice versa). Data on the menstrual cycle phase were unavailable in 3 lean and 2 abdominally obese women, due to the presence of a hormonal IUD without bleedings $(n=4)$ or a very irregular cycle $(n=1)$.

\section{Study design and general procedures}

Prior to the first and second sets of measurements, participants adhered to a diet aimed at either a high $(250 \mathrm{mmol} \mathrm{NaCl} / 24 \mathrm{~h}$ ) or a low $(50 \mathrm{mmol} \mathrm{NaCl} / 24 \mathrm{~h})$ salt intake for seven days in randomized order in a 1:1 ratio, with a washout period of 14 days. Randomization was performed by an independent investigator using block randomization with variable block sizes. A dietician provided an isocaloric diet containing $50 \mathrm{mmol} \mathrm{NaCl}$ and $70-80 \mathrm{mmol} \mathrm{K+}$ for each individual, which was supplemented with sodium capsules (9 per day, containing $1.3 \mathrm{~g}(22.2 \mathrm{mmol}) \mathrm{NaCl}$ per capsule (BasicPharma, Geleen, The Netherlands)) during the high salt week, and with matched placebo capsules (BasicPharma, Geleen, The Netherlands) in the same amount during the low salt week. To prevent side effects, capsules with delayed release properties were used (DRcaps, Capsugel; Morristown, New Jersey, USA). The containers with capsules were labeled in accordance with the randomization numbers and handed over to the participants by a member of the research team; both were unaware of the treatment allocation. Study data were deblinded only upon completion of all analyses by an independent investigator.

On the seventh day of both the low salt and high salt weeks, $24 \mathrm{~h}$ urine was collected for assessment of sodium, potassium and creatinine excretion, and $24 \mathrm{~h}$ ambulatory blood pressure measurements (ABPM) were performed (Mobilograph (New Generation), I.E.M., Stolberg, Germany) at the non-dominant arm with appropriately sized cuffs at 15-min intervals from 8 a.m. to 11 p.m. and at 30-min intervals from 11 p.m. to 8 a.m. Mean arterial blood pressure values collected with ambulatory blood pressure monitoring during the low and high salt diets were used to compute the salt sensitivity index (SSI). The SSI is the difference in MAP between the low and high salt diet divided by MAP during the low salt diet ${ }^{21}$. Assessments of whole-body insulin-stimulated glucose disposal and insulin-mediated muscle microvascular recruitment were conducted in a temperature-controlled room $\left(T=24^{\circ} \mathrm{C} \pm 0.5^{\circ} \mathrm{C}\right)$ after a 12 -hour overnight fast with participants in the supine position. Individuals were instructed to refrain from 
alcohol and meals rich in lipids for a period of 24 hours prior to each study day, and strenuous physical exercise for a period of 48 hours prior to each study day. After insertion of two intravenous catheters and a 30-minute acclimatization period with the participants in the supine position, we took blood samples for determination of glucose and creatinine levels.

\section{Assessment of whole-body insulin-mediated glucose disposal}

We determined metabolic insulin sensitivity by means of a modified version of the hyperinsulinemic, euglycemic clamp technique as described by DeFronzo et al. ${ }^{22}$. Briefly, insulin (Insuman Rapid, Sanofi, Paris, France) was administered in a primed continuous manner at a rate of $1 \mathrm{mU} / \mathrm{kg} / \mathrm{min}$ during 180 minutes. Isoglycemia was maintained by adjusting the rate of a $20 \%$ D-glucose infusion based on plasma glucose measurements performed at 5-minute intervals. Whole-body glucose disposal (M-value) was estimated from the steady-state glucose infusion rate between 90 and 150 minutes after initiation of insulin administration. $M$ was expressed per kilogram body weight per unit of plasma insulin concentration (M/I-value), thus correcting for variation in steady-state insulin concentrations. For convenience, the $M / I$ ratio was multiplied by 100 .

\section{Assessment of insulin-mediated muscle microvascular recruitment}

Insulin-mediated muscle microvascular recruitment was assessed with contrast enhanced ultrasound as described previously ${ }^{23}$. Briefly, microvascular blood volume (MBV) of forearm skeletal muscle was measured before and during hyperinsulinemia with a Toshiba Aplio XG ultrasound system (Toshiba, Otawara, Japan) during continuous i.v. administration of sulfur hexafluoride gas-filled microbubbles (SonoVue, Bracco diagnostics, Amsterdam, The Netherlands). After steady state microbubble concentration was achieved (3 minutes), five real-time replenishment curves of 30 seconds were acquired. These replenishment curves were stored and analyzed offline in a blinded fashion after completion of the trial using the $\mathrm{CHI}-\mathrm{Q}$ software (Toshiba, Otawara, Japan). The replenishment curves were fitted to the exponential function $y=A\left(1-e^{-b t}\right)$ where $t$ is time since high mechanical index pulse, $y$ is the video intensity at any given $t, A$ is the plateau video intensity (representing MBV), and $\beta$ is the microvascular flow velocity. Insulin-mediated muscle microvascular recruitment (IMMR) was calculated as the relative increase in muscle microvascular blood volume during hyperinsulinemia. 


\section{Blood and urine measurements}

Plasma glucose was determined with a YSI2300 glucose analyzer (YSI, Yellow Springs, $\mathrm{OH}, \mathrm{USA})$. Blood samples were analyzed for total cholesterol, HDL cholesterol and triglycerides (enzymatic colourimetric method; Roche Diagnostics, Mannheim, Germany). LDL cholesterol was calculated with the Friedewald formula ${ }^{24}$. Urinary sodium and potassium were determined with the ion-selective electrode (ISE) method (Roche Diagnostics, Mannheim, Germany); creatinine in serum and urine was measured with an enzymatic assay (Roche Diagnostics, Mannheim, Germany). Estimated glomerular filtration rate (eGFR) was calculated using the CKD Epidemiology Collaboration equation ${ }^{25}$. Expected creatinine excretion was computed as $879.89+$ $12.51^{*}$ weight $(\mathrm{kg})-6.19 *$ age -379.42 if female, as proposed by $\mathrm{Ix}$ et al. ${ }^{26}$, and the creatinine index, i.e. the ratio of observed vs. expected $24 \mathrm{~h}$ urinary creatinine excretion, was used to assess the completeness of the $24 \mathrm{~h}$ urine collection ${ }^{27}$. Serum insulin levels before and during the hyperinsulinemic clamp were measured with a sandwich immunoassay (MSD, Rockville, MD, USA; intra-assay CV $=4.2 \%$, inter-assay $\mathrm{CV}=5.4 \%)$.

\section{Statistics}

Normally distributed variables were expressed as mean \pm SD; variables with a skewed distribution were displayed as median and interquartile range, and natural logarithmic transformation was performed before further analyses (triglycerides, HDL cholesterol, insulin, HOMA, M/I-value, IMMR). Because IMMR results were partially negative, natural logarithmic transformation could only be performed after adding 40 to each value (lowest value, - 38). We used independent samples T-tests to compare general characteristics between lean and abdominally obese individuals and paired samples T-tests to compare $24 \mathrm{~h}$ ambulatory blood pressure, M/I-value and IMMR between the low and high salt diets in the study population as a whole. Next, we used repeated measures ANCOVA to adjust these comparisons for group (lean or abdominally obese), age and sex. We then compared $24 \mathrm{~h}$ ambulatory blood pressure, M/I-value and IMMR on the low and high salt diets between lean and abdominally obese individuals with independent sample T-tests, followed by repeated measures ANCOVA with adjustment for age and sex. We performed interaction analyses (group * low or high salt condition) to investigate whether effects of low and high salt conditions were different between lean and abdominally obese individuals. Where appropriate, stratified analyses are presented. To establish whether IMMR was a potential determinant of MAP and $\mathrm{M} / \mathrm{I}-\mathrm{value}$ under low and/or high salt conditions, we used multiple linear regression analysis with IMMR as independent variable and MAP or M/I-value as dependent 
variables, adjusted for group, age and sex; we performed interaction analyses to study whether these associations differed between lean and abdominally obese individuals. Analyses were performed using the SPSS statistical software package (IBM SPSS Statistics version 20, Chicago, IL). Two-tailed p-values of $<0.05$ and $<0.10$ were considered statistically significant in the main and interaction analyses, respectively.

\section{Study approval}

All participants gave written informed consent. The study was approved by the local ethics committee, performed in accordance with the Declaration of Helsinki, and registered at clinicaltrials.gov (NCT02068781).

\section{Results}

\section{General characteristics (Figure 5.1 and Table 5.1)}

Twenty-one lean and 26 abdominally obese individuals were randomized to start with either the low or the high salt intervention, and ultimately 20 lean and 20 abdominally obese individuals completed the study. Eleven lean and 10 abdominally obese participants used a low salt diet prior to the first set of measurements; the remaining participants started with a high salt diet. Insulin levels during the hyperinsulinemic clamp after a low salt diet were lacking in one lean participant due to hemolysis of blood samples; IMMR data after a high salt diet were unavailable in one abdominally obese individual for technical reasons. Lean, compared to abdominally obese, participants had significantly lower systolic and mean arterial pressure (MAP), expected creatinine excretion, and LDL cholesterol and triglyceride levels, while HDL cholesterol concentration was higher. The numbers of pre- and postmenopausal women were comparable in both groups. Urinary sodium excretion showed adequate compliance to both the low and the high salt diets.

Mean arterial pressure, M/I-value and IMMR on a low, as compared to a high salt diet in the total study population

On a low, as compared to a high salt diet, MAP was lower, M/I-value was lower and IMMR was greater (low vs. high salt: MAP $96 \pm 11$ vs. $100 \pm 11 \mathrm{mmHg}, \mathrm{p}<0.01 ; \mathrm{M} / \mathrm{I}$-value: 8.8 [5.4-12.6] vs. 10.2 [6.1-14.5] ((mg/kg/min per $\mathrm{mU} / \mathrm{L}) * 100), p<0.01 ;$ IMMR: 58 [23-71] vs. 17 [7-54]\%, $p=0.03$; Figure 5.2). Similar conclusions were reached after adjustment for group, age and sex (low vs. high salt: MAP: $96 \pm 10$ vs. $100 \pm 11 \mathrm{~mm} \mathrm{Hg}$, 
$\mathrm{p}<0.01 ; \mathrm{M} / \mathrm{I}$-value: 8.8 [5.6-12.9] vs. 10.1 [7.0-15.2] ((mg/kg/min per $\mathrm{mU} / \mathrm{L}) * 100)$, p<0.01; IMMR: 38 [32-60] vs. 19 [14-41]\%, p=0.03.

Changes in MAP, M/I-value and IMMR during low and high salt intake were not statistically significantly different between lean and abdominally obese individuals ( $p$ for interaction all $>0.26$ ) and were not affected by pre- vs. postmenopausal status.

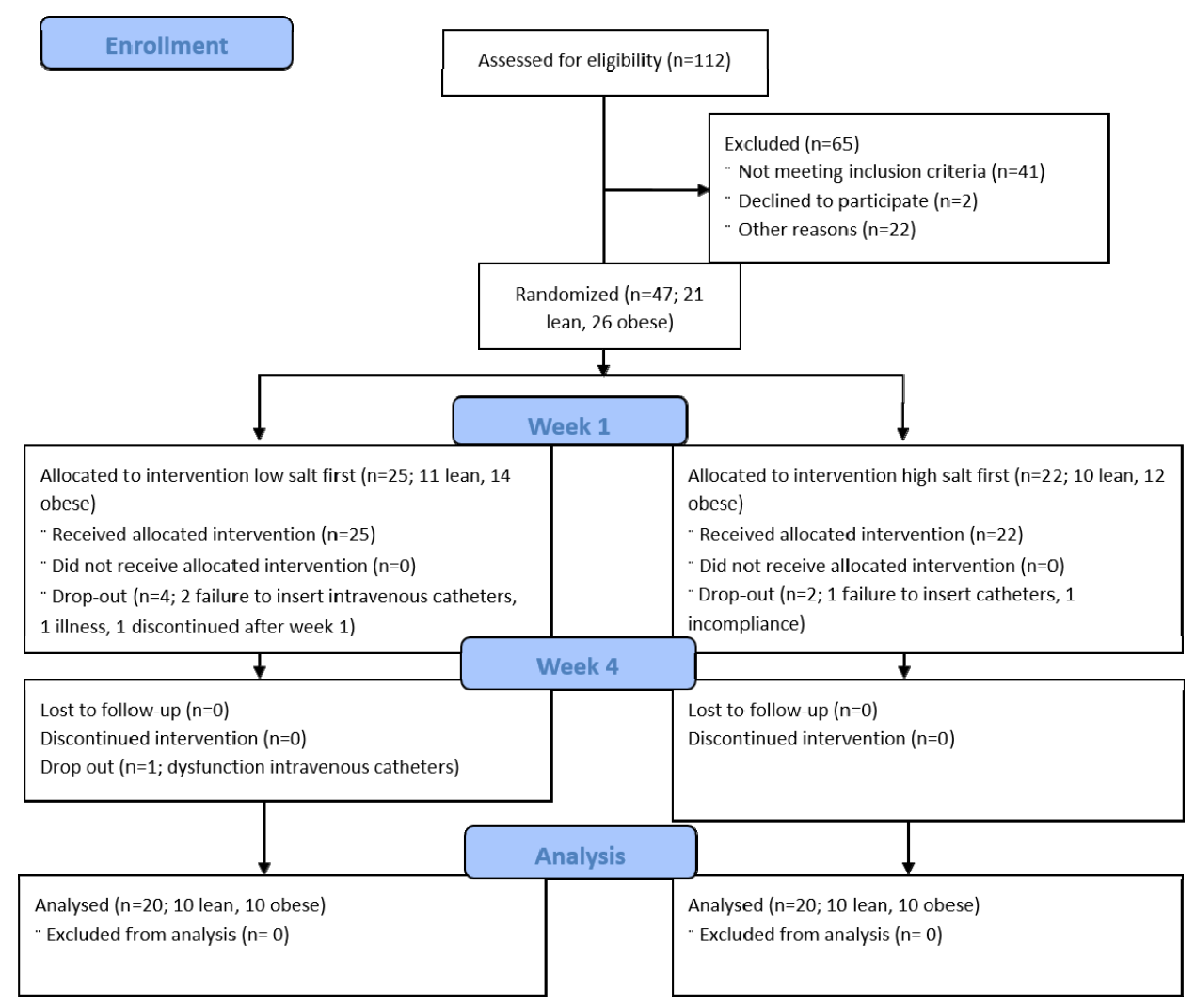

Figure 5.1: Enrollment, randomization and drop-out of participants. 
Table 5.1: General characteristics of the lean and abdominally obese participants.

\begin{tabular}{|c|c|c|}
\hline & Lean & Abdominally obese \\
\hline $\mathrm{n}$ & 20 & 20 \\
\hline Sex ( $n$ of men/women) & $7 / 13$ & $6 / 14$ \\
\hline Age (years) & $49 \pm 10$ & $50 \pm 11$ \\
\hline BMI $\left(\mathrm{kg} / \mathrm{m}^{2}\right)$ & $22.5 \pm 2.0$ & $31.3 \pm 3.9$ \\
\hline \multicolumn{3}{|l|}{ Waist circumference $(\mathrm{cm})$} \\
\hline Men & $84 \pm 5$ & $114 \pm 8$ \\
\hline Women & $74 \pm 4$ & $101 \pm 12$ \\
\hline Fasting plasma glucose (mmol/L) & $5.11^{\mathrm{a}} \pm 0.47$ & $5.31 \pm 0.42$ \\
\hline Office SBP/DBP (mmHg) & $119^{\mathrm{a}} \pm 15 / 74 \pm 12$ & $130 \pm 17 / 81 \pm 9$ \\
\hline Use of antihypertensive medication ( $n$ ) & 0 & 4 \\
\hline Use of statins (n) & 0 & 1 \\
\hline \multicolumn{3}{|l|}{ Hormonal status } \\
\hline Premenopausal (n) & 8 & 8 \\
\hline Postmenopausal (n) & 5 & 6 \\
\hline Use of oral contraceptives (n) & 0 & 2 \\
\hline Hormonal IUD (n) & 3 & 2 \\
\hline eGFR (mL/min/1.73 $\left.\mathrm{m}^{2}\right)$ & $86 \pm 12$ & $82 \pm 13$ \\
\hline Expected creatinine excretion (mmol/24h) & $10.3^{\mathrm{a}} \pm 2.6$ & $13.0 \pm 2.6$ \\
\hline Total cholesterol (mmol/L) & $5.1 \pm 1.0$ & $5.4 \pm 1.0$ \\
\hline Triglycerides (mmol/L) & $0.67^{\mathrm{a}}[0.59-0.94]$ & $1.04[0.93-1.54]$ \\
\hline HDL cholesterol (mmol/L) & $1.92^{\mathrm{a}}[1.75-2.33]$ & $1.55[1.32-1.77]$ \\
\hline LDL cholesterol (mmol/L) & $2.90^{\mathrm{a}} \pm 0.87$ & $3.62 \pm 0.96$ \\
\hline
\end{tabular}

Data are presented as means \pm SD or medians [interquartile ranges]; BMI: body mass index, SBP: systolic blood pressure, DBP: diastolic blood pressure, IUD: intrauterine device. General characteristics between lean and abdominally obese individuals were compared with independent sample T-tests. ${ }^{a}$ Lean vs. abdominally obese, $\mathrm{p}<0.05$
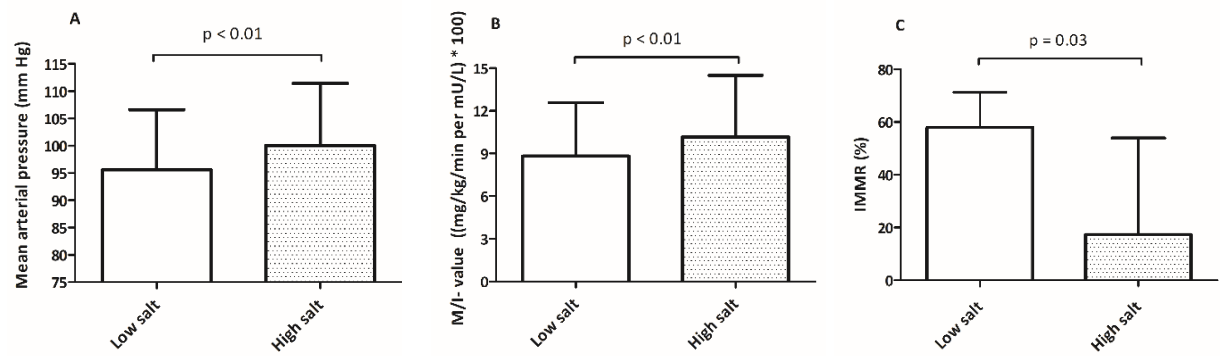

Figure 5.2: Mean arterial pressure, $\mathrm{M} / \mathrm{I}$-value, and insulin-mediated muscle microvascular recruitment (IMMR) on a low, as compared to a high salt diet in the total study population. Mean arterial pressure (A; mean $\pm S D$; low salt: $n=20$ vs. high salt $n=20)$, M/l-value (B; median with interquartile range; low salt: $n=19$ vs. high salt: $n=20$ ), and insulin-mediated muscle microvascular recruitment (IMMR) (C; median with interquartile range; low salt: $n=20$ vs. high salt: $n=19$, compared with paired sample T-tests. 


\section{Mean arterial pressure, $\mathrm{M} / \mathrm{I}$-value and IMMR in lean vs. abdominally obese individuals on a low and high salt diet}

In lean, as compared to abdominally obese individuals, and on both a low and a high salt diet, MAP was lower, M/I-value was higher, and IMMR was not statistically significantly different (Table 5.2). Adjustment for age and sex gave comparable findings with regard to MAP and M/I-value, but IMMR was significantly greater in abdominally obese, compared to lean individuals, on a low salt diet (lean vs. abdominally obese: MAP: low salt $91 \pm 10$ vs. $100 \pm 10 \mathrm{~mm} \mathrm{Hg}, \mathrm{p}=0.01$; high salt $97 \pm 11$ vs. $103 \pm 11 \mathrm{~mm} \mathrm{Hg}$, $\mathrm{p}=0.08 ; \mathrm{M} / \mathrm{l}$-value: low salt 12.9 [11.0-14.4] vs. 5.9 [4.7-6.4] $((\mathrm{mg} / \mathrm{kg} / \mathrm{min}$ per $\mathrm{mU} / \mathrm{L}) * 100), \quad p<0.01$; high salt $15.2[12.6-16.9]$ vs. $7.0[5.6-8.0]((\mathrm{mg} / \mathrm{kg} / \mathrm{min}$ per $\mathrm{mU} / \mathrm{L}) * 100), p<0.01$; and IMMR: low salt: 34 [20-38] vs. 60 [41-69]\%, $\mathrm{p}=0.03$; high salt: 19 [-1-19] vs. 41 [15-43]\%, $p=0.22$; Table 5.3). The salt sensitivity index was comparable between lean and abdominally obese participants (lean: 5.8 [3.0-9.2]\%, abdominally obese: 4.6 [-0.3-7.2]\%, $p=0.124$; difference lean vs. abdominally obese adjusted for age and sex: 2.8 (-0.9 to 6.5$) \%$. Carry-over effects were not detected in any of the above analyses ( $p$-values all $>0.11$ ).

Table 5.2: Blood pressure, insulin-mediated whole-body glucose disposal and insulin-mediated muscle microvascular recruitment on a low and a high salt intake in lean and abdominally obese individuals.

\begin{tabular}{|c|c|c|c|c|}
\hline & \multicolumn{2}{|c|}{ Lean $(n=20)$} & \multicolumn{2}{|c|}{ Abdominally obese $(n=20)$} \\
\hline & Low salt & High salt & Low salt & High salt \\
\hline 24h SBP/DBP (mmHg) & $113 \pm 8^{\mathrm{a}, \mathrm{c}} / 73 \pm 9^{\mathrm{a}}$ & $120 \pm 8^{d} / 77 \pm 7$ & $125 \pm 15^{b} / 79 \pm 11$ & $130 \pm 17 / 81 \pm 12$ \\
\hline 24h MAP (mmHg) & $92 \pm 8^{\mathrm{a}, \mathrm{c}}$ & $97 \pm 7$ & $100 \pm 12^{b}$ & $103 \pm 14$ \\
\hline Salt sensitivity index (\%) & \multicolumn{2}{|c|}{$5.8[3.0-9.2] \%$} & \multicolumn{2}{|c|}{$4.6[-0.3-7.2] \%$} \\
\hline $24 \mathrm{~h}$ heart rate (bpm) & $66 \pm 8$ & $66 \pm 8$ & $69 \pm 7$ & $67 \pm 8$ \\
\hline Fasting plasma glucose (mmol/L) & $4.88 \pm 0.33^{\mathrm{a}}$ & $4.70 \pm 0.31$ & $5.06 \pm 0.44^{b}$ & $4.93 \pm 0.43$ \\
\hline Fasting serum insulin (mU/L) & $2.26[1.67-2.65]^{\mathrm{c}}$ & $1.92[1.29-2.90]^{d}$ & $5.40[3.74-6.55]$ & $4.79[3.32-5.55]$ \\
\hline HOMA-IR & $0.48[0.37-0.60]^{\mathrm{c}}$ & $0.39[0.24-0.60]^{d}$ & $1.23[0.89-1.57]$ & $1.07[0.75-1.24]$ \\
\hline M-value (mg/kg/min) & $7.5 \pm 3.1^{c}$ & $7.8 \pm 3.7^{d}$ & $4.4 \pm 1.5$ & $4.3 \pm 0.96$ \\
\hline $\mathrm{M} / \mathrm{l}$-value $((\mathrm{mg} / \mathrm{kg} / \mathrm{min}$ per $\mathrm{mU} / \mathrm{L}) * 100)$ & $11.4[10.1-17.7]^{a, c}$ & $13.9[10.7-18.2]^{d}$ & $5.5[4.7-7.8]^{\mathrm{b}}$ & $6.3[4.7-9.8]$ \\
\hline IMMR (\%) & $45[13-64]$ & $10[2-54]$ & $68[28-74]^{b}$ & $18[14-71]$ \\
\hline Urinary sodium excretion ( $\mathrm{mmol} / 24 \mathrm{~h})$ & $67 \pm 32^{\mathrm{a}}$ & $241 \pm 61$ & $73 \pm 28^{b}$ & $239 \pm 76$ \\
\hline Urinary potassium excretion ( $\mathrm{mmol} / 24 \mathrm{~h})$ & $54 \pm 22$ & $56 \pm 28$ & $55 \pm 18$ & $58 \pm 20$ \\
\hline Urinary creatinine excretion ( $\mathrm{mmol} / 24 \mathrm{~h}$ ) & $11.2 \pm 4.2$ & $11.8 \pm 4.1$ & $12.7 \pm 3.1$ & $13.2 \pm 3.4$ \\
\hline Creatinine index & $1.08 \pm 0.24$ & $1.14 \pm 0.20$ & $0.99 \pm 0.21$ & $1.03 \pm 0.22$ \\
\hline
\end{tabular}

Data are presented as means \pm SD or medians [interquartile ranges]; SBP: systolic blood pressure, DBP: diastolic blood pressure, MAP: mean arterial pressure, IMMR: insulin-mediated muscle microvascular recruitment. Differences between low and salt diets in lean and abdominally obese individuals separately were compared with paired samples T-tests; differences between lean and abdominally obese individuals on either a low or a high salt diet were compared with independent sample T-tests. ${ }^{a}$ Lean: low vs. high salt, $p<0.05^{b}$ Abdominally obese: low vs. high salt, $p<0.05$; $^{c}$ Lean vs. abdominally obese under low salt circumstances, $p<0.05 ;{ }^{d}$ Lean vs. abdominally obese under high salt circumstances, $p<0.05$. 
Table 5.3: Age- and sex-adjusted blood pressure, insulin-mediated whole-body glucose disposal and insulinmediated muscle microvascular recruitment on a low and a high salt intake in lean versus abdominally obese individuals.

\begin{tabular}{lcccc}
\hline & \multicolumn{2}{c}{ Lean $(\mathrm{n}=20)$} & \multicolumn{2}{c}{ Abdominally obese $(\mathrm{n}=20)$} \\
\cline { 2 - 5 } & Low salt & High salt & Low salt & High salt \\
\hline 24h MAP $(\mathrm{mmHg})$ & $91 \pm 10^{\mathrm{a}}$ & $97 \pm 11$ & $100 \pm 10$ & $103 \pm 11$ \\
M/l-value $\left((\mathrm{mg} / \mathrm{kg} / \mathrm{min}\right.$ per $\left.\mathrm{mU} / \mathrm{L}) *{ }^{*} 100\right)$ & $12.9[11.0-14.4]^{\mathrm{a}}$ & $15.2[12.6-16.9]^{\mathrm{b}}$ & $5.9[4.7-6.4]$ & $7.0[5.6-8.0]$ \\
IMMR (\%) & $34[20-38]^{\mathrm{a}}$ & $19[-1-19]$ & $60[41-69]$ & $41[15-43]$ \\
\hline
\end{tabular}

MAP: mean arterial pressure, IMRR: insulin-mediated muscle microvascular recruitment. Age- and sexadjusted differences between lean and abdominally obese individuals on a low and high salt diet were compared with repeated measures ANCOVA. ${ }^{a}$ Lean vs. abdominally obese under low salt circumstances, $\mathrm{p}<0.05 ;{ }^{\mathrm{b}}$ Lean vs. abdominally obese under high salt circumstances, $\mathrm{p}<0.05$.

\section{Associations of Ln IMMR with MAP and M/I-value on a low and a high salt diet (Table 5.4)}

On a low salt diet, Ln IMMR was not associated with MAP or Ln M/I-value in the total study population, either without or with adjustment for potential confounders (Table 5.4). Interaction analyses, however, showed a significant and independent inverse association of Ln IMMR with MAP in lean participants (crude: standardized $\beta=-0.592(-0.820$ to -0.203$), p=0.006$; age- and sex-adjusted: standardized $\beta=-0.511$ $(-0.778$ to $-0.088, p=0.013))$, while there was no association in abdominally obese participants (crude: standardized $\beta=0.071(-0.384$ to 0.498$), p=0.767$; age- and sexadjusted: standardized $\beta=0.149$ ( -0.314 to 0.555$), p=0.535 ; p$ for interaction 0.084 ) (Figure 5.3 and Table 5.4). On a high salt diet, Ln IMMR was not associated with MAP or Ln M/I-value in the study population as a whole (Table 5.4), or in lean and abdominally obese individuals separately (MAP: $p$ for interaction=0.986; Ln M/I-value: $p$ for interaction=0.831).
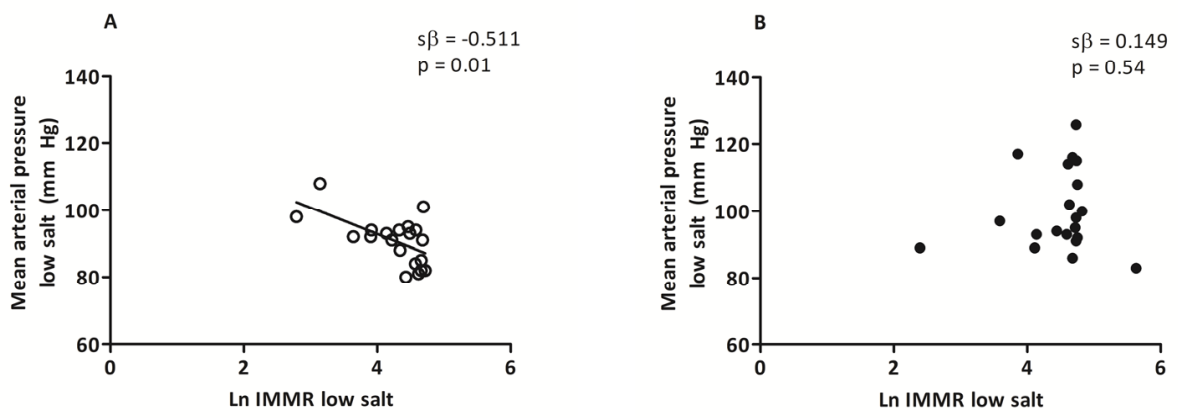

Figure 5.3: Association of Ln IMMR with mean arterial pressure on a low salt diet in lean and abdominally obese individuals. IMMR=insulin-mediated muscle microvascular recruitment. Standardized regression coefficients ( $\beta$; derived from multiple linear regression analyses) are adjusted for age and sex; $p$ for interaction lean vs. abdominally obese $=0.084$. 


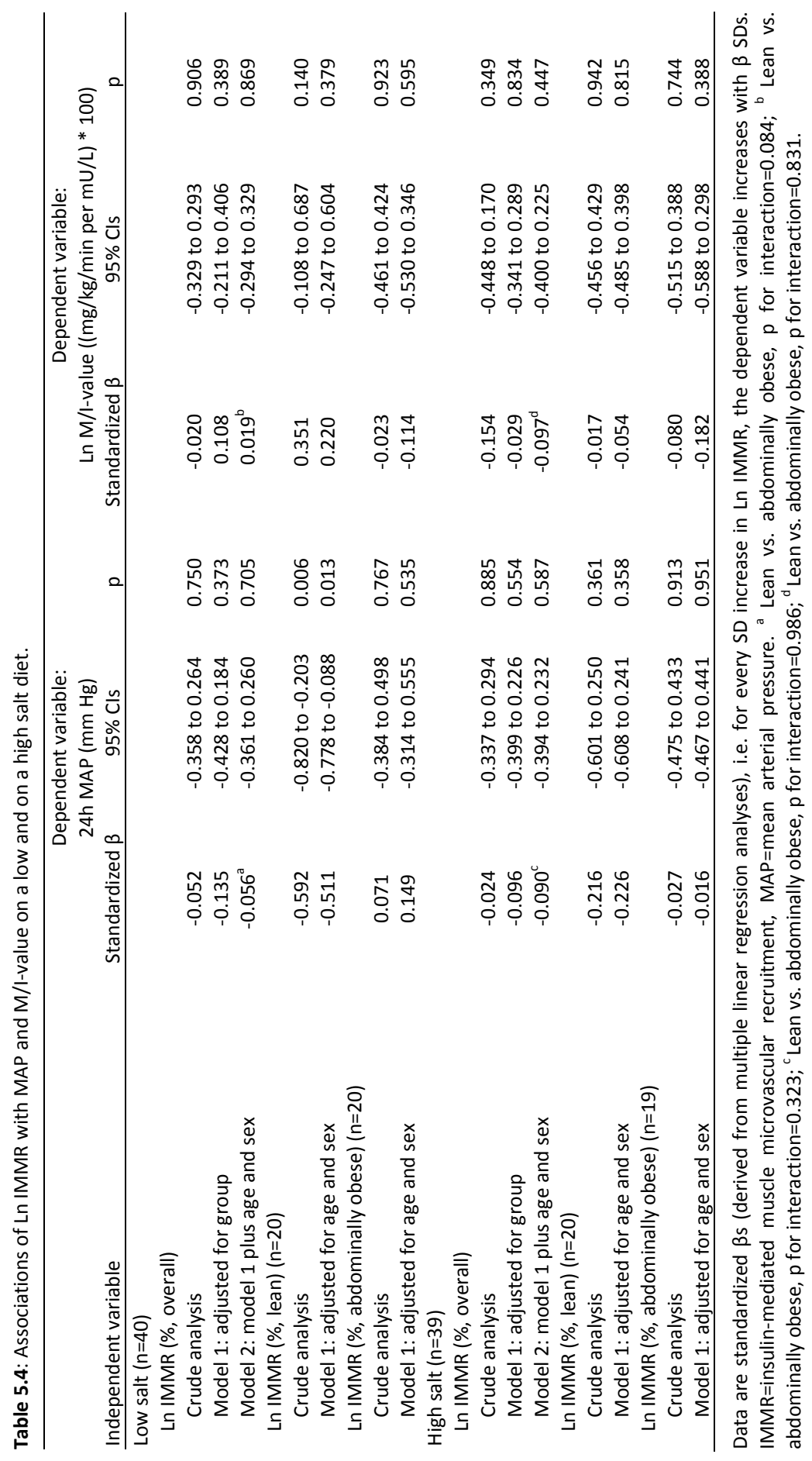




\section{Discussion}

The present study demonstrates that on a low, compared to a high salt diet, blood pressure decreases, whole-body insulin-mediated glucose disposal decreases, and microvascular insulin sensitivity increases in both lean and abdominally obese individuals. In addition, greater insulin-mediated muscle microvascular recruitment is associated with lower mean arterial pressure on a low salt diet in lean, but not in abdominally obese participants, and is not associated with whole-body insulinmediated glucose disposal on either a low or a high salt diet.

A major finding is the improvement of insulin-mediated muscle microvascular recruitment in humans following salt restriction, similar to earlier observations in rats ${ }^{18}$, and in line with previous observations of improved microvascular function and structure in normotensive and hypertensive humans in other vascular beds (skin, conjunctiva) and in response to other stimuli (post-occlusive reactive hyperemia, venous congestion $)^{9,11,28}$. Increased salt intake may interfere with insulin-mediated endothelial NO production and thus insulin-stimulated microvascular dilatation at several levels, notably by reducing eNOS protein expression and activation, by accelerating NO degradation through superoxide generation by NADH oxidase and eNOS when tetrahydrobiopterin availability is reduced, and by inducing superoxide dismutase deficiency, which further increases oxidative stress ${ }^{29}$. It logically follows that reducing salt intake improves microvascular insulin signaling via opposite mechanisms. Whether basal (as opposed to insulin-stimulated) muscle microvascular perfusion is also diminished after a high salt diet cannot be derived from our data, as the ultrasound method we used has a large inter-individual variation under basal circumstances ${ }^{23,30}$. However, it is likely that functional muscle microvascular density under basal circumstances is also diminished after a high salt diet, given the fact that an elevation in blood pressure occurring during high salt intake is eventually the result of increased peripheral resistance ${ }^{31,32}$, which is determined largely at the microvascular level ${ }^{12}$. The rise in (muscle) microvascular resistance can be ascribed to failure of the microvasculature to dilate in response to an initial expansion of the cardiac output induced by increasing salt intake, and/or to direct microvascular actions of salt ${ }^{29,31}$.

After a low salt diet, IMMR was greater in abdominally obese than in lean participants, while after a high salt diet IMMR was more or less equally diminished, and of similar magnitude, in lean and abdominally obese individuals. In a previous study, we have demonstrated impaired IMMR in obese, compared to lean men under ad-libitum salt intake $^{23}$. As the net effect of variation in salt intake on IMMR will be determined by changes in both basal functional muscle microvascular density and microvascular insulin signaling, the discrepancy in responses of IMMR to low, ad-libitum and high salt 
diets between lean and abdominally obese individuals may be related to differences in the relative contributions of both factors. Earlier observations by us and others indicate that under unspecified or ad-libitum salt intake, both functional muscle capillary density under basal circumstances and IMMR are diminished in (abdominally) obese, compared to lean individuals ${ }^{20,23,33}$, due to increased levels of free fatty acids and inflammatory cytokines, and changes in adipokine signaling in obese individuals ${ }^{12,34}$. An explanation for our current findings may be that also under low salt circumstances and through similar mechanisms, basal functional muscle microvascular density is diminished in abdominally obese versus lean individuals, while salt restriction improves microvascular insulin signaling in both lean and abdominally obese participants, thus resulting in greater IMMR in the abdominally obese participants. Vice versa, the intrinsic capacity of the muscle microvasculature to dilate in response to salt loading might be greater in lean than abdominally obese individuals. Therefore, deterioration of microvascular insulin sensitivity, which is already impaired under ad-libitum salt intake in the abdominally obese individuals, will ultimately lead to a comparable IMMR after a high salt diet in both groups (Figure 5.4).

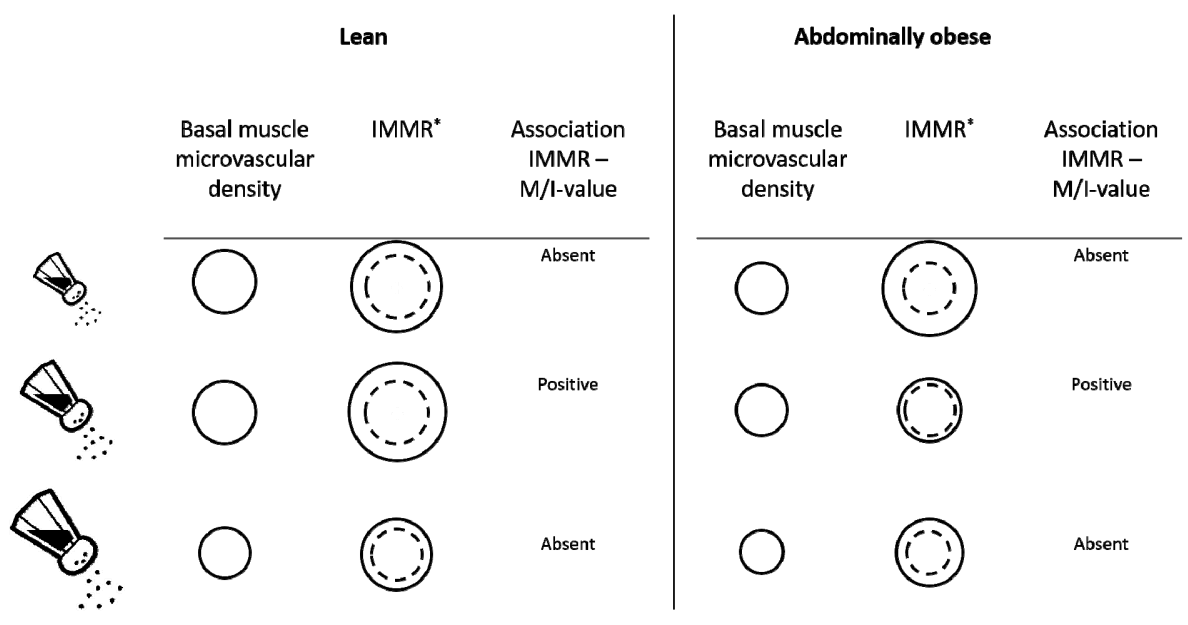

Figure 5.4: Schematic proposal of basal functional muscle microvascular density, insulin-mediated muscle microvascular recruitment (IMMR; i.e. microvascular insulin sensitivity) and the association of IMMR with $\mathrm{M} /$ I-value (i.e. metabolic insulin sensitivity) during low, ad-libitum and high salt intake in lean compared to abdominally obese individuals. * The continuous line represents the insulin-mediated increase of muscle microvascular density, relative to basal density (represented with the interrupted line). 
Contrary to expectation, insulin-mediated whole-body glucose disposal decreased after seven days of low, compared to seven days of high salt intake. Controlled experiments in healthy and Dahl salt-sensitive animals have demonstrated that salt loading impairs insulin-mediated glucose disposal ${ }^{3,35-37}$. Similar findings were obtained using other measures of insulin sensitivity in hypertensive and obese rats ${ }^{38,39}$, while salt restriction has been shown to improve the HOMA index (which reflects both hepatic and muscle insulin sensitivity) in obese rats ${ }^{19}$. However, controlled experiments in humans are limited. Nevertheless, there are several reports of decreased insulin-mediated glucose disposal, as assessed by the hyperinsulinemic, euglycemic clamp technique, in healthy ${ }^{40,41}$, hypertensive ${ }^{42}$, and hypertension-prone ${ }^{43}$ individuals after both moderate and more extreme salt restriction. Comparable results have been acquired with the HOMA index ${ }^{44,45}$. Other investigators did not observe an effect of a low versus high salt diet on peripheral insulin sensitivity in healthy volunteers ${ }^{46}$ or individuals with type 2 diabetes $^{47}$, despite comparable study designs. We found only one investigation, in eight obese and hypertensive individuals, that demonstrated improved insulin sensitivity after salt restriction ${ }^{48}$. Taken together, these studies suggest that, in humans, the response of insulin's metabolic effects to changes in salt intake is heterogeneous. The sources of this heterogeneity are poorly understood, but may involve changes in activity of the sympathetic nervous and renin-angiotensin-aldosterone systems ${ }^{42,43}$. In addition, experiments in Sprague-Dawley and Dahl salt-sensitive rats have demonstrated that during high salt feeding, intracellular insulin signaling leading to PI3-kinase/Akt activation in liver, muscle and adipose tissue is enhanced, despite a reduction in glucose infusion rate $e^{3,18,36}$. If similar changes in PI3-kinase/Akt-signaling occur in humans, this may affect the net effect of variations in salt intake on metabolic insulin signaling. Another possibility is that high salt induces glucocorticoid-driven muscle catabolism to increase urea production and thereby renal water conservation $^{49,50}$. In skeletal muscle of mice fed a high salt diet, this has been demonstrated to result in increased AMPK levels, which on their turn may promote whole-body glucose disposal ${ }^{49}$. Regardless, it is likely that insulin-mediated glucose disposal will decrease in many individuals exposed to a very low salt intake. This finding may inform the current controversy on the merits of a severe versus a more moderate limitation of salt intake, in that blood pressure will decrease in most individuals under both circumstances, while cardiovascular mortality seems to be higher on a low, compared to a moderate salt intake ${ }^{51,52}$. Thus, the effects of high salt intake on blood pressure may explain one end of the J-shaped association between salt ingestion and cardiovascular events, while the impairment of insulin-mediated glucose disposal due to salt restriction could (to some extent) explain the other end. Our findings also support current recommendations for moderate (3-5 g/day) instead of low salt 
intake ${ }^{51,52}$, although large randomized controlled trials providing evidence on optimal salt intake to prevent cardiovascular events are still eagerly awaited.

To the best of our knowledge, this is the first study investigating the association of IMMR with whole-body insulin-mediated glucose disposal on a low versus a high salt diet. At 'usual' or nonspecified salt intake, IMMR has been demonstrated to be a direct determinant of whole-body insulin-mediated glucose disposal ${ }^{20,23,53}$, but this seems not to be the case at a very low or a very high salt intake (Figure 5.4). Dissociated effects of low and high salt diets on vascular and metabolic insulin signaling have been reported previously in rats and healthy humans, although in these studies, insulin-induced vasodilatation was assessed in larger vessels ${ }^{41,46,54}$. One possibility to explain these findings is that, in addition to direct beneficial effects of salt restriction on microvascular insulin signaling, counterregulatory mechanisms that prevent blood pressure from becoming too low during a low salt diet differentially affect microvascular and metabolic insulin sensitivity, with the opposite occurring during a high salt diet. These mechanisms may involve activation of the sympathetic nervous and renin-angiotensin-aldosterone systems. Indeed, epinephrine, acting through a beta-adrenergic receptor, has been demonstrated in both animals and humans to increase muscle blood flow, while impairing insulin-mediated skeletal muscle glucose uptake $^{55-60}$. Correspondingly, salt was found to suppress muscle sympathetic nerve activity in normotensive salt-resistant Japanese young adults ${ }^{61}$, and hypertensive individuals ${ }^{62}$. In addition, angiotensin II (AngII) may not behave as a vasoconstrictor peptide under low salt circumstances due to changes in expression of vascular AT1 and AT2 receptors ${ }^{63-65}$, but can still reduce whole-body insulin-mediated glucose disposal via an AT1R-dependent mechanism ${ }^{66-70}$. In contrast, the vasoconstrictor actions of Angll might be more pronounced under high salt circumstances, which is in line with our observations of reduced insulin-induced skin capillary recruitment following Angll administration in healthy individuals after one week of high salt intake, while insulinmediated whole-body glucose disposal was improved ${ }^{71}$. The latter may be ascribed to an AT2R-dependent mechanism ${ }^{66,67}$.

As expected, and in agreement with previous studies performed in normotensive, hypertensive and obese individuals, salt reduction lowered blood pressure in lean and abdominally obese participants ${ }^{72,73}$, although to a similar extent in both groups, indicating a comparable degree of salt sensitivity. Previous investigations have shown greater salt sensitivity in obese, compared to lean Zucker rats $^{74}$ and human adolescents $^{6}$, and in Chinese non-diabetic individuals with versus without the metabolic syndrome ${ }^{5}$. These seemingly contradictory findings might be explained by differences in degree of obesity and ethnicity (Asian versus Caucasian) between the current and other study populations. 
Although a low salt diet reduced blood pressure and improved insulin-mediated muscle microvascular recruitment in both lean and abdominally obese individuals, a higher IMMR was associated with lower blood pressure under low salt circumstances in the lean individuals only, which may be ascribed to a contribution of insulin's microvascular actions to decreased peripheral vascular resistance ${ }^{17}$. In the abdominally obese participants, mean arterial pressure was higher than in the lean participants after a low salt diet, probably due to interaction of several factors, including overactivity of the renin-angiotensin-aldosterone and sympathetic nervous systems, and physical compression of the kidneys ${ }^{75}$, and these might overrule the contribution of an improvement in IMMR following salt restriction to blood pressure regulation.

A limitation of the present study is the fact that insulin-mediated muscle microvascular recruitment and whole-body insulin-induced glucose disposal were not measured under ad-libitum salt ingestion, which is $\sim 140 \mathrm{mmol}$ per day in the Netherlands ${ }^{76}$. In addition, the underlying mechanisms of the improvement in microvascular insulin signaling and the deterioration of whole-body insulin-mediated glucose disposal following salt restriction were not identified in the current investigation.

An important strength of this study is its randomized, placebo-controlled, blinded design, with a wash-out period between the low and high salt diets. In addition, we assessed insulin-mediated microvascular function directly in skeletal muscle, which is the main site of peripheral glucose uptake, and we used the gold standard for the determination of metabolic insulin sensitivity.

In conclusion, a low, as compared to a high salt diet during seven days reduces blood pressure, impairs insulin-mediated glucose disposal but improves insulin-mediated muscle microvascular recruitment in both lean and abdominally obese participants. In addition, the enhancement of IMMR was associated with decreased mean arterial pressure, but only in lean individuals. An important question is whether a less severe reduction in salt intake also improves microvascular insulin signaling in skeletal muscle, but without impairing metabolic insulin sensitivity, and whether these effects are sustained with longer duration of the salt restriction. In addition, the mechanisms underlying the differential responses of insulin-mediated muscle microvascular recruitment and insulin-stimulated glucose disposal to low salt intake require further elucidation. Nevertheless, our findings indicate that determinants of insulin-mediated glucose disposal are dynamic, i.e. are affected by salt status. Moreover, hemodynamic benefits of reductions in salt intake are not necessarily paralleled by metabolic advantages. 


\section{References}

1. Baudrand R, Campino C, Carvajal CA, Olivieri O, Guidi G, Faccini G, et al. High sodium intake is associated with increased glucocorticoid production, insulin resistance and metabolic syndrome. Clin Endocrinol (Oxf). 2014;80:677-684

2. Lastra G, Dhuper S, Johnson MS, Sowers JR. Salt, aldosterone, and insulin resistance: Impact on the cardiovascular system. Nature reviews. Cardiology. 2010;7:577-584

3. Ogihara T, Asano T, Ando K, Chiba Y, Sekine N, Sakoda H, et al. Insulin resistance with enhanced insulin signaling in high-salt diet-fed rats. Diabetes. 2001;50:573-583

4. Boden G. Obesity, insulin resistance and free fatty acids. Curr Opin Endocrinol Diabetes Obes. 2011;18: 139-143

5. Chen J, Gu D, Huang J, Rao DC, Jaquish CE, Hixson JE, et al. Metabolic syndrome and salt sensitivity of blood pressure in non-diabetic people in china: A dietary intervention study. Lancet. 2009;373:829-835

6. Rocchini AP, Key J, Bondie D, Chico R, Moorehead C, Katch V, et al. The effect of weight loss on the sensitivity of blood pressure to sodium in obese adolescents. N Engl J Med. 1989;321:580-585

7. Artunc F, Schleicher E, Weigert C, Fritsche A, Stefan N, Haring HU. The impact of insulin resistance on the kidney and vasculature. Nat Rev Nephrol. 2016;12:721-737

8. Goodfriend TL, Ball DL, Weinberger MH, Moore TJ, Weder AB, Egan BM. Salt loads raise plasma fatty acids and lower insulin. Hypertension. 1991;17:958-964

9. Cavka A, Cosic A, Jukic I, Jelakovic B, Lombard JH, Phillips SA, et al. The role of cyclo-oxygenase-1 in high-salt diet-induced microvascular dysfunction in humans. J Physiol. 2015;593:5313-5324

10. de Jongh RT, Serne EH, IJzerman R, Stehouwer CD. Microvascular function: A potential link between salt sensitivity, insulin resistance and hypertension. J Hypertens. 2007;25:1887-1893

11. He FJ, Marciniak M, Markandu ND, Antonios TF, MacGregor GA. Effect of modest salt reduction on skin capillary rarefaction in white, black, and asian individuals with mild hypertension. Hypertension. 2010; 56:253-259

12. Jonk AM, Houben AJ, de Jongh RT, Serne EH, Schaper NC, Stehouwer CD. Microvascular dysfunction in obesity: A potential mechanism in the pathogenesis of obesity-associated insulin resistance and hypertension. Physiology. 2007;22:252-260

13. Schutten MT, Houben AJ, de Leeuw PW, Stehouwer CD. The link between adipose tissue reninangiotensin-aldosterone system signaling and obesity-associated hypertension. Physiology (Bethesda). 2017;32:197-209

14. Houben AJ, Willemsen RT, van de Ven H, de Leeuw PW. Microvascular adaptation to changes in dietary sodium is disturbed in patients with essential hypertension. J Hypertens. 2005;23:127-132

15. Kusters $\mathrm{YH}$, Barrett EJ. Muscle microvasculature's structural and functional specializations facilitate muscle metabolism. Am J Physiol Endocrinol Metab. 2016;310:E379-387

16. de Boer MP, Serne EH, Smulders YM, Eringa EC, Meijer RI. Phenotyping the microcirculation with contrast-enhanced ultrasound. Hypertension. 2012;60:e38; author reply e39

17. Hornstra JM, Serne EH, Eringa EC, Wijnker MC, de Boer MP, Yudkin JS, et al. Insulin's microvascular vasodilatory effects are inversely related to peripheral vascular resistance in overweight, but insulinsensitive subjects. Obesity (Silver Spring). 2013;21:2557-2561

18. Premilovac D, Richards SM, Rattigan S, Keske MA. A vascular mechanism for high-sodium-induced insulin resistance in rats. Diabetologia. 2014;57:2586-2595

19. Hattori T, Murase T, Takatsu M, Nagasawa K, Matsuura N, Watanabe S, et al. Dietary salt restriction improves cardiac and adipose tissue pathology independently of obesity in a rat model of metabolic syndrome. J Am Heart Assoc. 2014;3:e001312

20. Clerk LH, Vincent MA, Jahn LA, Liu Z, Lindner JR, Barrett EJ. Obesity blunts insulin-mediated microvascular recruitment in human forearm muscle. Diabetes. 2006;55:1436-1442

21. Yatabe MS, Yatabe J, Yoneda M, Watanabe T, Otsuki M, Felder RA, et al. Salt sensitivity is associated with insulin resistance, sympathetic overactivity, and decreased suppression of circulating renin activity in lean patients with essential hypertension. Am J Clin Nutr. 2010;92:77-82 
22. DeFronzo RA, Tobin JD, Andres R. Glucose clamp technique: A method for quantifying insulin secretion and resistance. Am J Physiol. 1979;237:E214-223

23. Kusters YH, Schalkwijk CG, Houben AJ, Kooi ME, Lindeboom L, Op 't Roodt J, et al. Independent tissue contributors to obesity-associated insulin resistance. JCI Insight. 2017;2(13)

24. Friedewald WT, Levy RI, Fredrickson DS. Estimation of the concentration of low-density lipoprotein cholesterol in plasma, without use of the preparative ultracentrifuge. Clin Chem. 1972;18:499-502

25. Levey AS, Stevens LA, Schmid CH, Zhang YL, Castro AF, 3rd, Feldman HI, et al. A new equation to estimate glomerular filtration rate. Annals of internal medicine. 2009;150:604-612

26. Ix JH, Wassel CL, Stevens LA, Beck GJ, Froissart M, Navis G, et al. Equations to estimate creatinine excretion rate: The ckd epidemiology collaboration. Clin J Am Soc Nephrol. 2011;6:184-191

27. John KA, Cogswell ME, Campbell NR, Nowson CA, Legetic B, Hennis AJ, et al. Accuracy and usefulness of select methods for assessing complete collection of 24-hour urine: A systematic review. J Clin Hypertens (Greenwich). 2016;18:456-467

28. Houben AJ, Willemsen RT, van de Ven H, de Leeuw PW. Microvascular adaptation to changes in dietary sodium is disturbed in patients with essential hypertension. J Hypertens. 2005;23:127-132

29. Toda N, Arakawa K. Salt-induced hemodynamic regulation mediated by nitric oxide. J Hypertens. 2011; 29:415-424

30. Sjoberg KA, Rattigan S, Hiscock N, Richter EA, Kiens B. A new method to study changes in microvascular blood volume in muscle and adipose tissue: Real-time imaging in humans and rat. Am J Physiol Heart Circ Physiol. 2011;301:H450-458

31. Feng W, Dell'Italia LJ, Sanders PW. Novel paradigms of salt and hypertension. J Am Soc Nephrol. 2017;28:1362-1369

32. Guyton AC, Coleman TG, Young DB, Lohmeier TE, DeClue JW. Salt balance and long-term blood pressure control. Annu Rev Med. 1980;31:15-27

33. Gavin TP, Stallings HW, 3rd, Zwetsloot KA, Westerkamp LM, Ryan NA, Moore RA, et al. Lower capillary density but no difference in vegf expression in obese vs. Lean young skeletal muscle in humans. J Appl Physiol. 2005;98:315-321

34. Sorop O, Olver TD, van de Wouw J, Heinonen I, van Duin RW, Duncker DJ, et al. The microcirculation: A key player in obesity-associated cardiovascular disease. Cardiovasc Res. 2017;113:1035-1045

35. Catena C, Cavarape A, Novello M, Giacchetti G, Sechi LA. Insulin receptors and renal sodium handling in hypertensive fructose-fed rats. Kidney Int. 2003;64:2163-2171

36. Ogihara T, Asano T, Ando K, Sakoda H, Anai M, Shojima N, et al. High-salt diet enhances insulin signaling and induces insulin resistance in dahl salt-sensitive rats. Hypertension. 2002;40:83-89

37. Sechi LA, Griffin CA, Giacchetti G, Zingaro L, Catena C, Bartoli E, et al. Abnormalities of insulin receptors in spontaneously hypertensive rats. Hypertension. 1996;27:955-961

38. Cho TM, Peng N, Clark JT, Novak L, Roysommuti S, Prasain J, et al. Genistein attenuates the hypertensive effects of dietary nacl in hypertensive male rats. Endocrinology. 2007;148:5396-5402

39. Hayashida T, Ohno Y, Otsuka K, Suzawa T, Shibagaki K, Suzuki H, et al. Salt-loading elevates blood pressure and aggravates insulin resistance in wistar fatty rats: A possible role for enhanced na+ $-\mathrm{h}+$ exchanger activity. J Hypertens. 2001;19:1643-1650

40. Perry CG, Palmer T, Cleland SJ, Morton IJ, Salt IP, Petrie JR, et al. Decreased insulin sensitivity during dietary sodium restriction is not mediated by effects of angiotensin ii on insulin action. Clin Sci (Lond). 2003;105:187-194

41. Townsend RR, Kapoor S, McFadden CB. Salt intake and insulin sensitivity in healthy human volunteers. Clin Sci (Lond). 2007;113:141-148

42. Gomi T, Shibuya Y, Sakurai J, Hirawa N, Hasegawa K, Ikeda T. Strict dietary sodium reduction worsens insulin sensitivity by increasing sympathetic nervous activity in patients with primary hypertension. $\mathrm{Am}$ J Hypertens. 1998;11:1048-1055

43. Melander O, Groop L, Hulthen UL. Effect of salt on insulin sensitivity differs according to gender and degree of salt sensitivity. Hypertension. 2000;35:827-831

44. Garg R, Sun B, Williams J. Effect of low salt diet on insulin resistance in salt-sensitive versus saltresistant hypertension. Hypertension. 2014;64:1384-1387 
45. Garg R, Williams GH, Hurwitz S, Brown NJ, Hopkins PN, Adler GK. Low-salt diet increases insulin resistance in healthy subjects. Metabolism. 2011;60:965-968

46. Foo M, Denver AE, Coppack SW, Yudkin JS. Effect of salt-loading on blood pressure, insulin sensitivity and limb blood flow in normal subjects. Clin Sci (Lond). 1998;95:157-164

47. Foo M, Coppack SW, Denver AE, Bulmer K, Yudkin JS. Lack of impact of angiotensin-converting enzyme gene polymorphism and salt intake on insulin resistance and limb blood flow. Clin Endocrinol (Oxf). 2015;82:76-83

48. Donovan DS, Solomon CG, Seely EW, Williams GH, Simonson DC. Effect of sodium intake on insulin sensitivity. Am J Physiol. 1993;264:E730-734

49. Kitada K, Daub S, Zhang Y, Klein JD, Nakano D, Pedchenko T, et al. High salt intake reprioritizes osmolyte and energy metabolism for body fluid conservation. J Clin Invest. 2017;127:1944-1959

50. Rakova N, Kitada K, Lerchl K, Dahlmann A, Birukov A, Daub S, et al. Increased salt consumption induces body water conservation and decreases fluid intake. J Clin Invest. 2017;127:1932-1943

51. Graudal N. A radical sodium reduction policy is not supported by randomized controlled trials or observational studies: Grading the evidence. Am J Hypertens. 2016;29:543-548

52. O'Donnell M, Mente A, Yusuf S. Sodium intake and cardiovascular health. Circ Res. 2015;116:1046-1057

53. Meijer RI, De Boer MP, Groen MR, Eringa EC, Rattigan S, Barrett EJ, et al. Insulin-induced microvascular recruitment in skin and muscle are related and both are associated with whole-body glucose uptake. Microcirculation. 2012;19:494-500

54. Vecchione C, Morisco C, Fratta L, Argenziano L, Trimarco B, Lembo G. Dietary sodium restriction impairs endothelial effect of insulin. Hypertension. 1998;31:1261-1265

55. Bessey PQ, Brooks DC, Black PR, Aoki TT, Wilmore DW. Epinephrine acutely mediates skeletal muscle insulin resistance. Surgery. 1983;94:172-179

56. Deibert DC, DeFronzo RA. Epinephrine-induced insulin resistance in man. J Clin Invest. 1980;65:717-721

57. Hunt DG, Ding Z, Ivy JL. Clenbuterol prevents epinephrine from antagonizing insulin-stimulated muscle glucose uptake. J Appl Physiol (1985). 2002;92:1285-1292

58. Laakso M, Edelman SV, Brechtel G, Baron AD. Effects of epinephrine on insulin-mediated glucose uptake in whole body and leg muscle in humans: Role of blood flow. Am J Physiol. 1992;263:E199-204

59. Niklasson M, Holmang A, Lonnroth P. Induction of rat muscle insulin resistance by epinephrine is accompanied by increased interstitial glucose and lactate concentrations. Diabetologia. 1998;41: 1467-1473

60. Rattigan S, Clark MG, Barrett EJ. Hemodynamic actions of insulin in rat skeletal muscle: Evidence for capillary recruitment. Diabetes. 1997;46:1381-1388

61. Miyajima E, Yamada Y. Reduced sympathetic inhibition in salt-sensitive japanese young adults. Am J Hypertens. 1999;12:1195-1200

62. Abrahao SB, Tinucci T, Santello JL, Mion D, Jr. Salt supresses baseline muscle sympathetic nerve activity in salt-sensitive and salt-resistant hypertensives. J Hum Hypertens. 2002;16:843-850

63. Gonzalez M, Lobos L, Castillo F, Galleguillos L, Lopez NC, Michea L. High-salt diet inhibits expression of angiotensin type 2 receptor in resistance arteries. Hypertension. 2005;45:853-859

64. Nickenig G, Strehlow K, Roeling J, Zolk O, Knorr A, Bohm M. Salt induces vascular at1 receptor overexpression in vitro and in vivo. Hypertension. 1998;31:1272-1277

65. Wang $\mathrm{DH}, \mathrm{Du}$ Y. Regulation of vascular type 1 angiotensin ii receptor in hypertension and sodium loading: Role of angiotensin ii. J Hypertens. 1998;16:467-475

66. Chai W, Wang W, Dong Z, Cao W, Liu Z. Angiotensin ii receptors modulate muscle microvascular and metabolic responses to insulin in vivo. Diabetes. 2011;60:2939-2946

67. Chai W, Wang W, Liu J, Barrett EJ, Carey RM, Cao W, et al. Angiotensin ii type 1 and type 2 receptors regulate basal skeletal muscle microvascular volume and glucose use. Hypertension. 2010;55:523-530

68. Henriksen EJ, Jacob S, Kinnick TR, Teachey MK, Krekler M. Selective angiotensin ii receptor antagonism reduces insulin resistance in obese zucker rats. Hypertension. 2001;38:884-890

69. Kobayashi T, Akiyama Y, Akiyama N, Katoh H, Yamamoto S, Funatsuki K, et al. Irbesartan enhances glut4 translocation and glucose transport in skeletal muscle cells. Eur J Pharmacol. 2010;649:23-28

70. Shiuchi T, Iwai M, Li HS, Wu L, Min LJ, Li JM, et al. Angiotensin ii type-1 receptor blocker valsartan enhances insulin sensitivity in skeletal muscles of diabetic mice. Hypertension. 2004;43:1003-1010 
71. Jonk AM, Houben AJ, Schaper NC, de Leeuw PW, Serne EH, Smulders YM, et al. Angiotensin ii enhances insulin-stimulated whole-body glucose disposal but impairs insulin-induced capillary recruitment in healthy volunteers. J Clin Endocrinol Metab. 2010;95:3901-3908

72. Andersson OK, Persson B, Hedner T, Aurell M, Berglund G, Fagerberg B. Central haemodynamics, baroreceptor sensitivity and alpha 1-adrenoceptor-mediated vascular reactivity during weight-stable sodium restriction in obese men with hypertension. J Hypertens. 1986;4:101-107

73. Graudal NA, Hubeck-Graudal T, Jurgens G. Effects of low sodium diet versus high sodium diet on blood pressure, renin, aldosterone, catecholamines, cholesterol, and triglyceride. Cochrane Database Syst Rev. 2017;4:CD004022

74. Pamidimukkala J, Jandhyala BS. Effects of salt rich diet in the obese zucker rats: Studies on renal function during isotonic volume expansion. Clin Exp Hypertens. 2004;26:55-67

75. Hall JE, do Carmo JM, da Silva AA, Wang Z, Hall ME. Obesity-induced hypertension: Interaction of neurohumoral and renal mechanisms. Circ Res. 2015;116:991-1006

76. Hendriksen MA, van Raaij JM, Geleijnse JM, Wilson-van den Hooven C, Ocke MC, van der AD. Monitoring salt and iodine intakes in dutch adults between 2006 and 2010 using $24 \mathrm{~h}$ urinary sodium and iodine excretions. Public health nutrition. 2014;17:1431-1438 


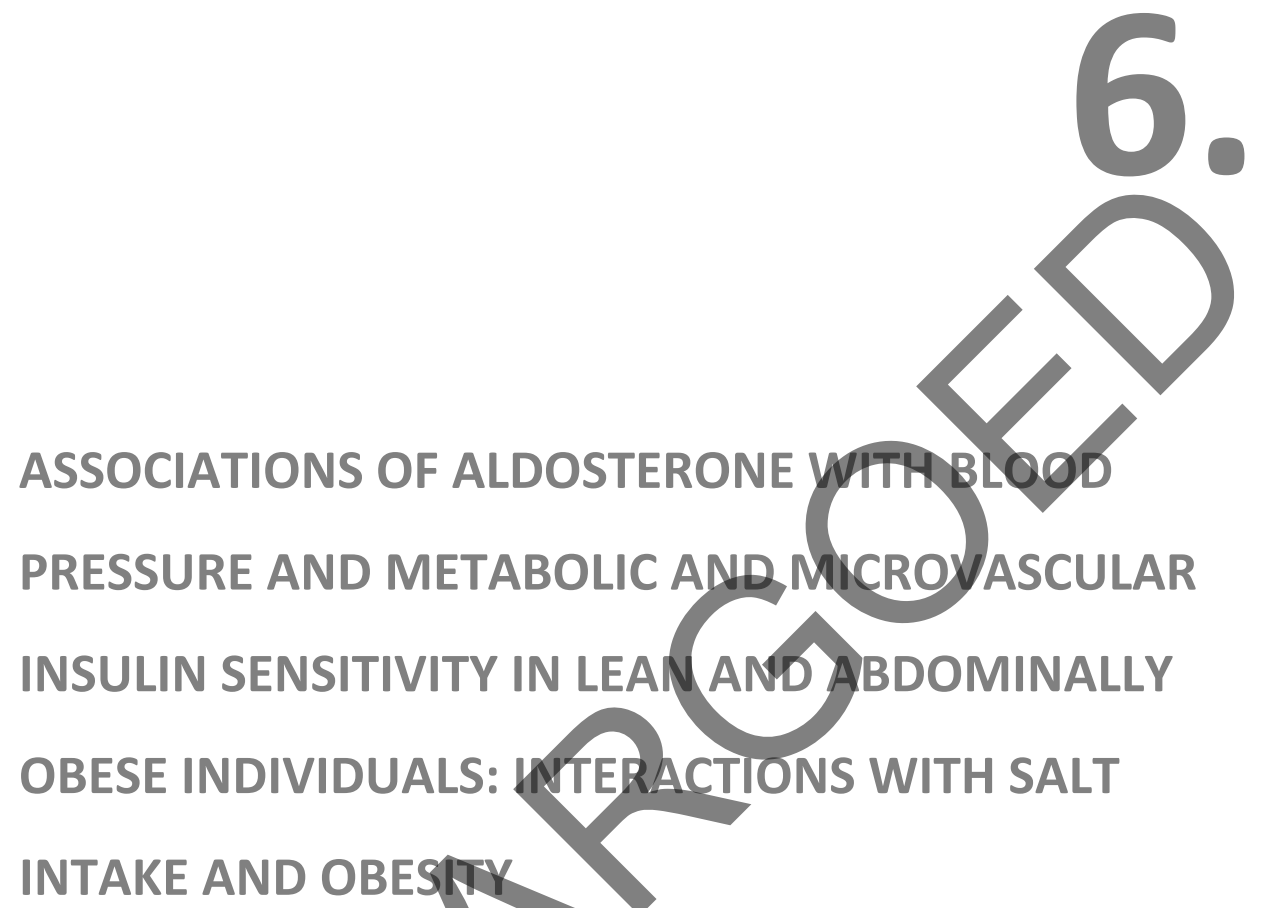

M.T.J. Schütten, A.J.H.M. Houben ${ }^{*}$, Y.H.A.M. Kusters ${ }^{*}$, H.E. Niessen, J. op 't Roodt, J.L.J.M. Scheijen, M.P.H. van de Waarenburg, C.G. Schalkwijk, P.J. Joris, J. Plat, R.P. Mensink, P.W. de Leeuw, C.D.A. Stehouwer * Both authors contributed equally 


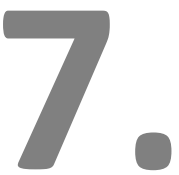

SUMMARY AND GENERAL DISCUSSION 



\section{Summary and general discussion}

The current obesity epidemic has increased the necessity to understand, intervene in, and prevent, the development of hemodynamic and metabolic sequelae of excessive weight. Recent evidence suggests involvement of aldosterone and salt in the pathogenesis of obesity-related hypertension and insulin resistance. Microvascular function is an important determinant of both blood pressure and insulin-mediated glucose disposal, and is known to be impaired in obesity. In an attempt to clarify underlying mechanisms of the increased risk for cardiovascular disease as observed in obesity, we investigated aldosterone and salt as potential causes of microvascular dysfunction. Our main findings are summarized and discussed below.

\section{The adipose tissue renin-angiotensin-aldosterone system and blood pressure regulation}

Dysregulation of the renin-angiotensin-aldosterone system is being regarded as a major cause of hypertension in obesity. Recent observations suggest that this not only involves increased levels of Angll and aldosterone, but perhaps also reduced activity of the ACE2 - Ang1-7 - Mas/AT2 receptor axis. Dysfunctional adipose tissue, as observed in obese individuals, is thought to be partially responsible for this disbalance in RAAScomponents. In Chapter 2, we have summarized existing evidence on the role of the adipose tissue RAAS in blood pressure regulation. Moreover, we have discussed wellknown and newer insights in underlying pathophysiological mechanisms, including effects of RAAS peptides on micro- and macrovascular function, sodium balance and sympathetic nervous system activity.

Although the exact pathways have not yet been entirely elucidated, adipose tissue, in part via adipose tissue-derived factors, seems capable of synthesizing clinically relevant amounts of Angll and aldosterone, which affect blood pressure by intervening in the regulation of both vascular tone and extracellular volume. These findings imply that ACE-inhibitors, AT1 receptor blockers and mineralocorticoid receptor antagonists could be widely applicated in the treatment of obesity-related hypertension. However, there are few studies demonstrating superiority of RAAS-antagonists in achieving blood pressure control in hypertensive obese individuals, when compared with other antihypertensive regimens ${ }^{1-3}$. This may be related to the struggle of constituting a study population eligible to be treated with only one antihypertensive drug, given the fact that obesity-related hypertension is often difficult to control and requires treatment with multiple agents of different classes. Nevertheless, RAAS-inhibition is still a 
preferable antihypertensive strategy in hypertensive obese individuals, because it has also proven to be beneficial in targeting metabolic complications of obesity, particularly insulin resistance.

The role of the ACE2-Ang1-7-AT2R/Mas receptor axis in the pathophysiology of obesityrelated hypertension is an interesting topic with therapeutic potential, but data in humans are still scarce and eagerly awaited.

\section{Aldosterone and microvascular function}

\section{Aldosterone-renin ratio and renal blood flow}

In the light of earlier observed left-right differences in renal blood flow and associations of increased aldosterone levels with reduced renal perfusion in both normotensive and hypertensive individuals, we investigated in Chapter 3 the relationship of absolute aldosterone levels and the aldosterone-renin ratio with side-selective kidney perfusion, as a measure of renal microvascular function, in a therapy-resistant essential hypertensive study population. We found an inverse association of the aldosteronerenin ratio with left, but not with right mean renal blood flow, while there was no association of absolute aldosterone levels with either left or right mean renal blood flow. Kidney perfusion is not the only aspect of human physiology that displays asymmetry. The best-known example is right vs. left handedness, indicating dominance of mostly the left, but sometimes of the right cerebral hemisphere. Moreover, rightsided dominance of the carotid baroreflex has been demonstrated in individuals with therapy-resistant essential hypertension ${ }^{4}$. Thus, our findings of lower left, compared to right mean renal blood flow are not as surprising as they may seem. Whether this asymmetry is also present in healthy individuals or develops in the course of hypertension or kidney diseases, remains to be established. It is, however, difficult to obtain data on side-selective renal blood flow in healthy individuals, due to the invasive character of the ${ }^{133}$ Xenon wash-out technique. A solution could be to perform such measurements in (potential) kidney donors, although this may introduce ethical issues on which kidney to donate, i.e., the one with the higher or lower blood flow.

Left-right differences in kidney perfusion may imply a differential contractile state and response to vasoactive agents of both renal vascular beds. This might be reflected by an association of the aldosterone-renin ratio with left, but not right mean renal blood flow. The question arises why absolute aldosterone levels do not display such a relationship, which may be attributable to the influence of Angll. Angll is an important determinant of aldosterone concentration, and adrenal Angll sensitivity is known to be 
altered in a subgroup of essential hypertensive individuals ${ }^{5}$, introducing a dissociation between renin and aldosterone levels. Therefore, it is plausible that the association between aldosterone and renal blood flow in a hypertensive study population is predicted more reliably by the aldosterone-renin ratio. This seems to contrast with a previous study demonstrating that absolute aldosterone concentration was directly associated with renal vascular resistance, in both normotensive and hypertensive African-Americans ${ }^{6}$. It should be kept in mind, however, that in this study, total, instead of side-selective, renal blood flow was measured, and that measurements were not normalized for kidney mass. Moreover, ethnic differences in RAAS activation might have played a role.

The ${ }^{133}$ Xenon washout technique does not distinguish between functional and structural abnormalities in kidney perfusion. This implies that the observed left-right asymmetry in renal blood flow could also depend on structural inequality between both kidneys, and that the association of aldosterone-renin ratio with left mean renal blood flow reflects subsequent RAAS activation. Nevertheless, the absence of arteriovenous differences in renin levels suggests otherwise.

\section{Aldosterone and skeletal muscle microvascular function}

In Chapters 4 and 6, we studied the association of serum aldosterone concentration with IMMR, whole-body insulin-mediated glucose disposal and blood pressure in lean and abdominally obese individuals, under ad-libitum salt intake (Chapter 4), and within a broader range of salt intake (Chapter 6). Regardless of salt intake, we could not demonstrate an association of aldosterone with IMMR, neither in lean, nor in abdominally obese participants. Although to our knowledge, the association of aldosterone with skeletal muscle microvascular insulin sensitivity has not been investigated before, these findings contrast with previous animal, and a few human experiments, reporting detrimental effects of aldosterone, and beneficial effects of mineralocorticoid receptor blockade, on the functioning of other microvascular beds $^{7-12}$. Moreover, aldosterone has been shown to specifically impair insulin signaling in vascular smooth muscle cells ${ }^{8}$. Our results as presented in Chapters $\mathbf{4}$ and $\mathbf{6}$ also seem inconsistent with the previously reported inverse association of the aldosteronerenin ratio with left mean renal blood flow (Chapter 3 ). However, there are several factors that should be taken into consideration to place these findings in perspective.

First, circulating aldosterone levels differ between study populations. Aldosterone concentration under ad-libitum salt intake was similar in lean and abdominally obese individuals (Chapter 4), but seems to be higher in therapy-resistant essential hypertensive individuals (Chapter $\mathbf{3}$ ) than in both lean and abdominally obese 
individuals, despite comparable salt intake (Chapter 6), and taking into account differences in measurement techniques of aldosterone ${ }^{13}$. Thus, absolute aldosterone concentration in the abdominally obese subpopulation was probably too low to cause microvascular impairment. Indeed, studies demonstrating increased aldosterone levels in obese, compared to lean individuals under ad libitum salt intake have been performed in severely to morbidly obese study populations ${ }^{14-17}$, while our abdominally obese subgroup studied during ad-libitum salt ingestion would be classified as overweight to moderately obese instead of severely obese based on their BMI.

Second, (micro)vascular effects of aldosterone might depend on endothelial 'health'. Aldosterone has been shown to affect vascular tone acutely, i.e. in a non-genomic manner, which involves both vasoconstriction and vasodilatation ${ }^{18}$. The acute vascular response to aldosterone seems to differ between endothelial cells and vascular smooth muscle cells. In the former, aldosterone has been shown to promote NO production in an MR-dependent manner via PI3-kinase dependent eNOS activation ${ }^{19,20}$. In the latter, on the other hand, aldosterone was found to elicit vasoconstriction, involving a presumed MR-independent increase in intracellular $\left[\mathrm{Ca}^{2+}\right]^{21}$, and myosin light chain phosphorylation, which can be induced both by the MR and GPR30, a membranebound oestrogen receptor able to bind multiple steroid ligands ${ }^{22,23}$. The net acute effect of aldosterone on vascular tone may thus be affected by the presence of an intact endothelium. Under normal circumstances, endothelial NO production appears to counteract the aldosterone-induced vasoconstriction in vascular smooth muscle cells ${ }^{24}$. In the absence of a normal functioning endothelium, however, aldosterone has been shown to enhance vasoconstriction ${ }^{19}$. This was nicely illustrated in healthy men, in whom acute aldosterone administration only increased renal vascular resistance in the presence of L-NMMA ${ }^{12}$. Although prolonged exposure to increased aldosterone levels consistently induces a contractile response ${ }^{25}$, the endothelium of individuals with longstanding hypertension (Chapter 3) may be more vulnerable to such a response than the endothelium of otherwise healthy abdominally obese individuals (Chapters 4 and 6). Nevertheless, the abdominally obese men already display a considerable degree of microvascular endothelial dysfunction, as reflected by the reduction in IMMR, compared to the lean men, but this does not seem to be caused by increased aldosterone levels.

Third, it could be considered that differences in measurement techniques, with corresponding limitations, have affected our findings. In Chapter 3, we have measured basal renal blood flow with the ${ }^{133}$ Xenon washout-technique, while we have assessed insulin-stimulated skeletal muscle blood volume with contrast enhanced ultrasound in Chapters $\mathbf{4}$ and $\mathbf{6}$. Although regulation of organ blood flow is an important function of the microcirculation ${ }^{26}$, the ${ }^{133}$ Xenon washout-technique provides a rather indirect 
measure of renal microvascular function, as renal blood flow is for an important part autoregulated by the tubuloglomerular feedback mechanism and thus dependent on salt intake. Moreover, this technique does not distinguish between functional and structural differences in renal blood flow. This may be particularly important in the population studied, who might to a greater or lesser extent already display structural microvascular rarefaction and microvascular remodeling due to insufficiently treated hypertension. Establishing the response to endothelium-dependent vasodilators would provide more insight in the actual function of the renal microcirculation of these individuals, but performing such experiments is difficult given the invasive nature of the ${ }^{133}$ Xenon washout procedure. Nevertheless, it is an elegant method to gain information on individual kidney perfusion. With contrast enhanced ultrasound, we are now able to visualize microvascular responses to insulin directly in skeletal muscle, which is the main site of peripheral glucose uptake. This enables us to relate and compare insulin's microvascular and metabolic actions. However, only changes in microvascular blood volume, i.e. responses to vasoactive stimuli, can be studied within and between persons with this technique. Absolute MBV values cannot be provided due to interindividual differences in the ultrasound signal, which depends on the distribution space and half-life of the contrast agent, the amounts of fascia and subcutaneous adipose tissue, and vascular tone $e^{27,28}$. Therefore, it is not possible to study basal muscle microvascular blood volume with contrast enhanced ultrasound. Furthermore, the obtained ultrasound signal may be partially derived from larger blood vessels, but this can be overcome by careful selection of the region of interest, and adjustment during analysis. Thus, the used measurement techniques assess different vascular beds and aspects of microvascular functioning, which not necessarily respond similarly to aldosterone. There are, however, no data indicating that vascular actions of aldosterone vary between tissues ${ }^{25}$, while aldosterone has been demonstrated previously to affect both basal ${ }^{29}$ and endothelium-dependent changes in forearm blood flow $^{30}$.

Fourth, salt intake has been suggested to influence (micro)vascular effects of aldosterone. Aldosterone has been shown to be particularly detrimental to the vasculature, as well as to the heart and kidneys, in the presence of high salt intake ${ }^{31-34}$. This has been ascribed to increased oxidative stress, which interferes with NO-availability and may activate the mineralocorticoid receptor ${ }^{35,36}$. Conversely, the increase in aldosterone levels resulting from chronic sodium deficiency, as reported in New Guinea hill tribes, does not lead to cardiovascular and renal damage ${ }^{37}$. Therefore, we have investigated in Chapter 6 whether salt intake, varying from low (50 mmol/day) to high $(250 \mathrm{mmol} / \mathrm{day})$, affected the association of aldosterone with microvascular insulin sensitivity in lean and abdominally obese individuals. Consistent with our 
findings in Chapter 4, this association was not demonstrable, and there was no interaction between serum aldosterone concentration and $24 \mathrm{~h}$ urinary sodium excretion. Probably, in this study population, aldosterone levels are still sufficiently suppressed by higher salt intake to prevent microvascular damage. Although in Chapter 3, urinary sodium excretion ( $68 \mathrm{mmol} / \mathrm{day}$ ) reflected a salt intake below the average median salt intake of Dutch adults $(148 \mathrm{mmol} / \mathrm{day})^{38}$, we cannot exclude the presence of an aldosterone-salt imbalance in the therapy-resistant essential hypertensive individuals under study, which may contribute to the observed reduction in left renal blood flow.

Lastly, the absence of an association between aldosterone and muscle microvascular insulin sensitivity may raise the question whether circulating aldosterone levels adequately reflect aldosterone activity at the tissue level. Although we have demonstrated an inverse relationship between the plasma aldosterone-renin ratio and left mean renal blood flow, suggesting that this is indeed the case, it is possible that more subtle changes in aldosterone activity require other measures to be visualized. Provided that aldosterone's effects on microvascular insulin sensitivity are exerted via the mineralocorticoid receptor, mineralocorticoid receptor density could be such a marker, which may change due to variations in salt intake ${ }^{39}$.

\section{Associations of aldosterone with blood pressure and insulin sensitivity}

In therapy-resistant, essential hypertensive individuals, aldosterone was directly associated with $24 \mathrm{~h}$ diastolic blood pressure, and aldosterone-renin ratio with both $24 \mathrm{~h}$ systolic and diastolic blood pressure. In addition, as discussed earlier, aldosterone-renin ratio was inversely associated with left mean renal blood flow only (Chapter $\mathbf{3}$ ). In lean and abdominally obese men on an ad-libitum salt intake, aldosterone was not associated with $24 \mathrm{~h}$ systolic blood pressure (Chapter 4 ). Within a broader range of salt intake, however, aldosterone was inversely associated with $24 \mathrm{~h}$ mean arterial pressure when sodium excretion was below $158 \mathrm{mmol} / 24 \mathrm{~h}$, and directly associated with mean arterial pressure with higher sodium excretion in lean and abdominally obese men and women, although both associations were not statistically significant (Chapter 6). Regardless of salt intake, aldosterone was not associated with IMMR (Chapters $\mathbf{4}$ and 6). These findings suggest that aldosterone may affect blood pressure in hypertensive individuals via effects on left kidney perfusion, particularly when right renal blood flow is diminished, but that effects on muscle microvascular insulin sensitivity do not underlie the association of aldosterone with mean arterial pressure in lean and 
abdominally obese individuals. The inverse association between aldosterone and mean arterial pressure with low salt intake likely reflects activation of the renin-angiotensinaldosterone system in response to the reduction in blood pressure. The degree of activation probably differs between persons, which may explain the non-significant overall association. The direct association of aldosterone with 24h MAP in the higher range of sodium excretion fits well within the assumption that adverse effects of aldosterone are only manifest when levels are inappropriately high for salt intake ${ }^{37}$. It is conceivable that the degree of suppression of aldosterone by salt also differs between persons, perhaps illustrated by previous inconsistent reports on associations between aldosterone, (office) blood pressure and salt intake ${ }^{40,41}$. This could also account for the non-significant association in the current study population.

In lean and abdominally obese men on an ad-libitum salt intake, aldosterone was not associated with insulin sensitivity, assessed with the hyperinsulinemic, euglycemic clamp technique, which is considered the gold standard for measuring insulin sensitivity. However, in a larger population of lean and abdominally obese individuals with a broader range of salt intake, aldosterone displayed a weak, and statistically nonsignificant inverse relationship with insulin-mediated whole-body glucose disposal in the abdominally obese participants, but a direct, also non-significant relationship in lean participants. Associations of aldosterone with glucose disposal were unaffected by sodium excretion. Although the validity of our observations could be questioned, given their non-significance, they are in line with previous studies demonstrating strong inverse associations between aldosterone levels and insulin-mediated whole-body glucose disposal in populations who were either more obese ${ }^{16}$ or more hypertensive ${ }^{42}$, despite comparable absolute aldosterone concentrations. This could indicate that (severe) obesity and/or hypertension are states of increased sensitivity to aldosterone's detrimental effects. Again, it would be interesting to investigate whether this is related to mineralocorticoid receptor density.

As there was no association between aldosterone levels and IMMR, impairment of microvascular insulin sensitivity does not seem to be the mechanism underlying the inverse relationship of aldosterone with whole-body glucose disposal in the abdominally obese individuals. Alternatively, aldosterone might directly interfere with metabolic insulin signalling pathways ${ }^{43-47}$, or indirectly via its effect on levels of reactive oxygen species, cytokines and adipokines ${ }^{48}$. The direct association of aldosterone concentration with metabolic insulin sensitivity in the lean subpopulation probably corresponds with a better reactivity of the renin-angiotensin-aldosterone system in healthy, i.e. normotensive and insulin sensitive, individuals, as a decreased RAAS responsiveness can be demonstrated in essential hypertension ${ }^{49}$, which is often accompanied by insulin resistance ${ }^{50}$. 


\section{Effects of weight loss and changes in salt intake on aldosterone levels}

The implementation of lifestyle changes, aimed at reducing body weight, is essential in the management of obesity ${ }^{51}$. In Chapter 4, we also investigated the effects of weight loss on aldosterone levels, and whether a reduction in circulating aldosterone concentration was associated with improved microvascular and metabolic insulin sensitivity, and reduced blood pressure in the abdominally obese subgroup. Although, consistent with earlier observations, IMMR and whole-body insulin-mediated glucose disposal increased, and blood pressure decreased after an eight-week weight loss intervention ${ }^{52,53}$, aldosterone levels remained unchanged. Thus, changes in aldosterone concentration were also not associated with changes in microvascular and metabolic insulin signaling, and changes in blood pressure. Previous studies reporting beneficial effects of weight loss on aldosterone levels, paralleled by improved insulin sensitivity and reduced blood pressure, have been performed in severely to morbidly obese, and hypertensive obese individuals ${ }^{15-17,54-56}$ with a higher BMI than our abdominally obese population. Because the increase in aldosterone levels in obese individuals as observed by other investigators might be at least partially (visceral) adipose tissue derived ${ }^{16,57}$, this could imply that the abdominally obese men studied in Chapter 4 did not synthesize clinically relevant amounts of aldosterone. These findings may also provide an explanation for earlier observed differences in determinants of cardiovascular disease in overweight versus obese individuals ${ }^{58}$.

We have demonstrated as well that although absolute aldosterone concentration was not different between lean and abdominally obese men, the physiological inverse association of aldosterone with urinary sodium excretion was diminished in the abdominally obese men. Moreover, during seven days of a high versus low salt diet in randomized order, suppression of aldosterone levels with increasing salt intake was impaired in abdominally obese individuals (Chapter 4). This is consistent with previous findings of reduced suppression of plasma aldosterone concentration by a saline load in normotensive obese, compared to lean individuals, while baseline aldosterone concentration was not different between both groups ${ }^{59}$. Thus, regulation of circulating aldosterone concentration by salt intake seems compromised in abdominally obese individuals, which may ultimately lead to overt increases in aldosterone levels. 


\section{Microvascular insulin sensitivity and its association with metabolic insulin sensitivity and blood pressure on a low versus high salt diet}

The human species is genetically adapted to a salt consumption $<1 \mathrm{~g} /$ day. Many years ago, salt intake increased due to the addition of salt to food, which was paralleled by a gradual rise in blood pressure ${ }^{60}$. Increased susceptibility to the hypertensive effects of salt, i.e. salt sensitivity, has been associated with a rise in premature mortality, even independent of blood pressure ${ }^{61}$. In obese individuals, salt sensitivity of blood pressure often co-occurs with metabolic insulin resistance ${ }^{62-65}$, but the underlying mechanisms are still obscure. Salt has been shown to affect skin and conjunctival microvascular function in humans ${ }^{66-68}$, and impair insulin-mediated muscle microvascular recruitment in parallel with insulin-induced glucose uptake in rats ${ }^{69}$. Therefore, we hypothesized that increased salt intake also deteriorates skeletal muscle microvascular insulin sensitivity in humans, particularly in obese individuals, thereby reducing insulinmediated whole-body glucose disposal and increasing blood pressure. In Chapter 5, we have shown that on a low, compared to a high salt diet for seven days, insulin-induced muscle microvascular recruitment increased and blood pressure decreased, and greater insulin-induced muscle microvascular recruitment was associated with lower mean arterial pressure on a low salt diet in lean, but not in abdominally obese participants. Surprisingly, whole-body insulin-stimulated glucose disposal decreased as well, and insulin-mediated muscle microvascular recruitment was not associated with wholebody insulin-stimulated glucose disposal on either a low or a high salt diet.

The observed improvement of microvascular insulin sensitivity after a low salt diet is in agreement with previous studies showing detrimental effects of salt loading ${ }^{66}$, and beneficial effects of salt restriction ${ }^{67,68}$, on the functioning of other microvascular beds in humans, and on insulin-mediated skeletal muscle microvascular recruitment in rats ${ }^{69}$. The presumed mechanism involves increased insulin-mediated NO-synthesis, as salt has been shown to interfere with NO-availability at several levels ${ }^{36}$. Interestingly, IMMR was more improved in the abdominally obese than lean individuals after a low salt diet, but was more or less comparable in both groups after a high salt diet. This could be related to a differential effect of changes in salt intake on both basal functional skeletal muscle microvascular density and microvascular insulin sensitivity in lean and abdominally obese individuals.

Although blood pressure decreased in the study population as a whole due to a reduction in salt intake, the degree of salt sensitivity was not different between lean and abdominally obese individuals. This may seem counterintuitive, but the previously reported associations between obesity and salt sensitivity of blood pressure are largely 
based on observations of a larger percentage of obese individuals among salt-sensitive, compared to salt-resistant study participants, instead of on comparisons between lean and abdominally obese individuals. A small number of studies actually demonstrated greater salt sensitivity in obese, compared to lean Zucker rats ${ }^{70}$ and adolescents ${ }^{65}$, and in Chinese nondiabetic individuals with versus without metabolic syndrome ${ }^{63}$. Differences in degree of obesity and ethnicity (Asian versus Caucasian) between the current and other study populations might explain the comparable degree of salt sensitivity as observed in our lean and abdominally obese participants.

Determinants of blood pressure seem to differ between lean and abdominally obese individuals, and depend on salt intake, as a higher IMMR was associated with lower mean arterial pressure on a low salt diet in the lean individuals only. This was probably due to a contribution of insulin's microvascular effects to reduced peripheral resistance $^{71}$. In abdominally obese individuals, however, several blood pressureincreasing mechanisms may still be active, i.e. the sympathetic nervous and reninangiotensin-aldosterone systems ${ }^{72}$, as reflected by a higher blood pressure, even after a low salt diet. The improvement in IMMR might not be able to compensate for these mechanisms. IMMR was not associated with mean arterial pressure on a high salt diet, either in lean or in abdominally obese individuals. This suggests that although IMMR decreased during a high salt diet, either other aspects of microvascular functioning, or circulating volume are more important determinants of blood pressure under these circumstances.

After seven days of low, compared to seven days of high salt intake, insulin-mediated whole-body glucose disposal decreased, which is in contrast with several animal studies $^{73-79}$. Similar findings, however, have been obtained in a number of controlled experiments performed in healthy ${ }^{80,81}$, hypertensive ${ }^{82}$, and hypertension-prone ${ }^{83}$ individuals, whereas other investigators, using a comparable set-up, did not observe an effect of changes in salt intake on metabolic insulin signalling in healthy individuals ${ }^{84}$ and participants with type 2 diabetes ${ }^{85}$. Only one study has demonstrated improved insulin sensitivity after salt restriction in eight obese and hypertensive individuals ${ }^{86}$. Thus, the response of insulin-mediated whole-body glucose disposal to variations in salt intake is far from straightforward. Changes in activity and responsivity of the sympathetic nervous and renin-angiotensin-aldosterone systems might underlie these differential responses ${ }^{82,83}$ Moreover, recent intriguing reports of salt-induced, glucocorticoid-driven muscle catabolism, which is accompanied by elevated AMPKlevels, could provide an explanation for the increase in whole-body glucose disposal after a high salt diet ${ }^{87,88}$. Another interesting observation in rats is the enhancement of intracellular insulin signaling leading to PI3-kinase/Akt activation in liver, muscle and adipose tissue after high salt feeding, despite a reduction in glucose infusion rate ${ }^{69,74,75}$. 
Performing a comparable experiment in humans is challenging, as it requires invasive procedures, but might provide important new insights on the interplay between salt and insulin signaling.

A somewhat unexpected finding was the absence of an association between insulin's microvascular and metabolic actions on a low and a high salt diet, whereas such an association is clearly demonstrable during ad-libitum salt intake ${ }^{89-91}$. Because insulinmediated muscle microvascular recruitment and insulin-induced glucose disposal changed in the opposite direction, it is plausible that the mechanisms responsible for the improvement of IMMR on a low salt diet, apart from direct effects of salt restriction on microvascular insulin signaling, simultaneously impair metabolic insulin signaling, and vice versa on a high salt diet. Such mechanisms may involve increased epinephrine levels $^{92-96}$ and changes in expression of vascular AT1 and AT2 receptors ${ }^{97-99}$, with preserved skeletal muscle AT1R signaling, during low salt intake. During high salt intake, the vasoconstrictor actions of Angll might be more pronounced due to the predominance of vascular AT1 receptors, while Angll improves insulin-induced glucose uptake via an AT2R-dependent route ${ }^{100-102}$. Indeed, we have previously demonstrated that Angll administration in healthy individuals after one week of high salt intake reduced insulin-induced skin capillary recruitment, but improved insulin-mediated whole-body glucose disposal ${ }^{103}$. Our findings imply that on a low or high salt diet, the delivery of insulin and glucose to skeletal muscle cells is no longer rate-limiting in insulin-induced glucose uptake ${ }^{104}$, and that the mechanisms responsible for the changes in insulin-induced glucose uptake due to variations in salt intake probably affect GLUT4-translocation to the cell surface, as this would be the next rate-limiting step $^{105,106}$. In the light of earlier reported observations in rats of enhanced intracellular insulin signalling leading to PI3-kinase/Akt activation in liver, muscle and adipose tissue after salt loading, which seems to occur early in this cascade, it would be extremely valuable to ascertain at which point salt interferes in humans. This is also helpful to understand the dissociated effects of a low and high salt diet on microvascular and metabolic insulin sensitivity, because insulin induces endothelial NO-production via a similar signaling pathway.

From an evolutionary viewpoint, it is not immediately clear why salt restriction would have beneficial hemodynamic, but unfavorable metabolic effects, as humans are genetically equipped to live under low salt circumstances. It has to be noted, however, that insulin-induced glucose uptake in our lean participants was still more than sufficient on a low salt diet, although evidently lower than on a high salt diet. Possibly, detrimental effects of salt restriction on metabolic insulin sensitivity have developed in the course of evolution, and the human body may be now adapting to living under circumstances of higher salt intake. 


\section{Main conclusions and future perspectives}

In this thesis, we have demonstrated that aldosterone-renin ratio is inversely associated with left mean renal blood flow in therapy-resistant essential hypertensive individuals, but that absolute aldosterone concentration is not associated with insulinmediated muscle microvascular recruitment in lean and moderately abdominally obese men under ad-libitum salt intake, and in lean and abdominally obese men and women with a broad range of salt intake. Moreover, aldosterone displayed an inverse relationship with mean arterial pressure with low salt intake, and a direct relationship with high salt intake. Regardless of salt intake, aldosterone was inversely associated with insulin-mediated whole-body glucose disposal in abdominally obese individuals, but directly associated with glucose disposal in lean individuals. Regulation of aldosterone levels by salt intake in abdominally obese individuals was impaired, although this did not result in increased absolute aldosterone levels. Circulating aldosterone concentration in moderately abdominally obese men was unaffected by weight loss.

On a low, as compared to a high salt diet, microvascular insulin sensitivity improved and blood pressure decreased, but metabolic insulin sensitivity deteriorated. Determinants of blood pressure and metabolic insulin sensitivity seem to be dependent on salt status and differ between lean and abdominally obese individuals, as microvascular insulin sensitivity was associated with mean arterial pressure on a low salt diet only in the lean individuals, but displayed no relationship with insulin-mediated whole-body glucose disposal on either diet.

Although in this thesis a number of questions on the role of aldosterone and salt in the pathogenesis of microvascular dysfunction were answered, our findings have also raised new questions, while others are still unanswered.

With regard to the inverse association of aldosterone-renin ratio with left mean renal blood flow, it would be valuable to study whether such an association exists in healthy individuals as well, and how mineralocorticoid receptor blockade affects left and right kidney perfusion in both normotensive and hypertensive study populations. In practice, however, this will be challenging, due to the invasive nature of the ${ }^{133}$ Xenon procedure. Because we did not observe an association between aldosterone and insulin-mediated muscle microvascular function, irrespective of salt intake, in lean and moderately abdominally obese individuals, while associations with mean arterial pressure and insulin-induced whole-body glucose disposal in the same participants were not statistically significant, it would be a logical next step to study these associations in a population with a broader range of abdominal obesity and with higher blood pressure. 
Moreover, the effect of mineralocorticoid receptor blockade on skeletal muscle microvascular insulin sensitivity in lean and (abdominally) obese humans has to our knowledge never been established. Lastly, investigating the responses of skeletal muscle and vascular mineralocorticoid receptor density to variations in salt intake could contribute considerably to our understanding of the interaction between aldosterone and salt.

The dissociated effects of changes in salt intake on insulin-mediated muscle microvascular recruitment and metabolic insulin sensitivity also provide many directions for future research. We have not studied how a low and high salt diet affected basal muscle capillary density. Although this may require either invasive procedures, i.e. muscle biopsies, or new imaging techniques, it would certainly increase our understanding of the mechanisms underlying our somewhat unexpected findings. It would be interesting as well to establish how our results fit in the recently introduced concept of nonosmotic sodium storage in the endothelial glycocalyx, skin, and skeletal muscle, by making use of side-stream darkfield imaging and ${ }^{23} \mathrm{Na}-\mathrm{MRI}$ techniques ${ }^{107,108}$. In terms of new antihypertensive strategies, the ACE2 - Ang1-7 - Mas/AT2 receptor axis is certainly a promising target. Its role in obesity-related hypertension, however, is insufficiently defined, and requires confirmation in humans. 


\section{References}

1. Reisin E, Weir MR, Falkner B, Hutchinson HG, Anzalone DA, Tuck ML. Lisinopril versus hydrochlorothiazide in obese hypertensive patients: A multicenter placebo-controlled trial. Treatment in obese patients with hypertension (trophy) study group. Hypertension. 1997;30:140-145

2. Dorresteijn JA, Schrover IM, Visseren FL, Scheffer PG, Oey PL, Danser AH, et al. Differential effects of renin-angiotensin-aldosterone system inhibition, sympathoinhibition and diuretic therapy on endothelial function and blood pressure in obesity-related hypertension: A double-blind, placebocontrolled cross-over trial. J Hypertens. 2013;31:393-403

3. Owen JG, Reisin E. Anti-hypertensive drug treatment of patients with and the metabolic syndrome and obesity: A review of evidence, meta-analysis, post hoc and guidelines publications. Curr Hypertens Rep. 2015;17:558

4. Alnima T, Schutten M, de Leeuw PW, Kroon AA. 8b.09: Right-sided dominance of carotid baroreceptor reflexes in patients with resistant hypertension. J Hypertens. 2015;33 Suppl 1:e109

5. Williams GH, Hollenberg NK. Functional derangements in the regulation of aldosterone secretion in hypertension. Hypertension. 1991;18:III143-149

6. Kotchen TA, Kotchen JM, Grim CE, Krishnaswami S, Kidambi S. Aldosterone and alterations of hypertension-related vascular function in african americans. Am J Hypertens. 2009;22:319-324

7. Arima S, Kohagura K, Xu HL, Sugawara A, Abe T, Satoh F, et al. Nongenomic vascular action of aldosterone in the glomerular microcirculation. J Am Soc Nephrol. 2003;14:2255-2263

8. Hitomi H, Kiyomoto H, Nishiyama A, Hara T, Moriwaki K, Kaifu K, et al. Aldosterone suppresses insulin signaling via the downregulation of insulin receptor substrate-1 in vascular smooth muscle cells. Hypertension. 2007;50:750-755

9. Kushibiki M, Yamada M, Oikawa K, Tomita H, Osanai T, Okumura K. Aldosterone causes vasoconstriction in coronary arterioles of rats via angiotensin ii type-1 receptor: Influence of hypertension. Eur J Pharmacol. 2007;572:182-188

10. Lapi D, Emdin M, Mastantuono T, Sapio D, Santillo M, Colantuoni A. Microvascular responses to aldosterone in hamster cheek pouch microcirculation. Clin Hemorheol Microcirc. 2013;53:303-315

11. Garg R, Rao AD, Baimas-George M, Hurwitz S, Foster C, Shah RV, et al. Mineralocorticoid receptor blockade improves coronary microvascular function in individuals with type 2 diabetes. Diabetes. 2015;64:236-242

12. Schmidt BM, Sammer U, Fleischmann I, Schlaich M, Delles C, Schmieder RE. Rapid nongenomic effects of aldosterone on the renal vasculature in humans. Hypertension. 2006;47:650-655

13. Hinchliffe E, Carter S, Owen L, Keevil BG. Quantitation of aldosterone in human plasma by ultra high performance liquid chromatography tandem mass spectrometry. J Chromatogr B Analyt Technol Biomed Life Sci. 2013;913-914:19-23

14. Clinical conference: Hyperparathyroidism: Recent studies. Ann Intern Med. 1973;79:566-581

15. Engeli S, Bohnke J, Gorzelniak K, Janke J, Schling P, Bader M, et al. Weight loss and the reninangiotensin-aldosterone system. Hypertension. 2005; 45:356-362

16. Goodfriend TL, Kelley DE, Goodpaster BH, Winters SJ. Visceral obesity and insulin resistance are associated with plasma aldosterone levels in women. Obes Res. 1999;7:355-362

17. Rocchini AP, Katch VL, Grekin R, Moorehead C, Anderson J. Role for aldosterone in blood pressure regulation of obese adolescents. Am J Cardiol. 1986;57:613-618

18. Skott O, Uhrenholt TR, Schjerning J, Hansen PB, Rasmussen LE, Jensen BL. Rapid actions of aldosterone in vascular health and disease--friend or foe? Pharmacol Ther. 2006;111:495-507

19. Liu SL, Schmuck S, Chorazcyzewski JZ, Gros R, Feldman RD. Aldosterone regulates vascular reactivity: Short-term effects mediated by phosphatidylinositol 3-kinase-dependent nitric oxide synthase activation. Circulation. 2003;108:2400-2406

20. Uhrenholt TR, Schjerning J, Rasmussen LE, Hansen PB, Norregaard R, Jensen BL, et al. Rapid nongenomic effects of aldosterone on rodent vascular function. Acta Physiol Scand. 2004;181:415-419

21. Wehling $M$, Neylon CB, Fullerton M, Bobik A, Funder JW. Nongenomic effects of aldosterone on intracellular ca2+ in vascular smooth muscle cells. Circ Res. 1995;76:973-979 
22. Feldman RD, Gros R. Vascular effects of aldosterone: Sorting out the receptors and the ligands. Clin Exp Pharmacol Physiol. 2013;40:916-921

23. Gros R, Ding Q, Sklar LA, Prossnitz EE, Arterburn JB, Chorazyczewski J, et al. Gpr30 expression is required for the mineralocorticoid receptor-independent rapid vascular effects of aldosterone. Hypertension. 2011;57:442-451

24. Heylen E, Huang A, Sun D, Kaley G. Nitric oxide-mediated dilation of arterioles to intraluminal administration of aldosterone. J Cardiovasc Pharmacol. 2009;54:535-542

25. Lyngso KS, Assersen K, Dalgaard EG, Skott O, Jensen BL, Hansen PB. Does aldosterone play a significant role for regulation of vascular tone? J Cardiovasc Pharmacol. 2016;68:1-10

26. Gutterman DD, Chabowski DS, Kadlec AO, Durand MJ, Freed JK, Ait-Aissa K, et al. The human microcirculation: Regulation of flow and beyond. Circ Res. 2016;118:157-172

27. Sjoberg KA, Rattigan S, Hiscock N, Richter EA, Kiens B. A new method to study changes in microvascular blood volume in muscle and adipose tissue: Real-time imaging in humans and rat. Am J Physiol Heart Circ Physiol. 2011;301:H450-458

28. Wei K, Jayaweera AR, Firoozan S, Linka A, Skyba DM, Kaul S. Quantification of myocardial blood flow with ultrasound-induced destruction of microbubbles administered as a constant venous infusion. Circulation. 1998;97:473-483

29. Romagni P, Rossi F, Guerrini L, Quirini C, Santiemma V. Aldosterone induces contraction of the resistance arteries in man. Atherosclerosis. 2003;166:345-349

30. Farquharson $\mathrm{CA}$, Struthers AD. Aldosterone induces acute endothelial dysfunction in vivo in humans: Evidence for an aldosterone-induced vasculopathy. Clin Sci (Lond). 2002;103:425-431

31. Blasi ER, Rocha R, Rudolph AE, Blomme EA, Polly ML, McMahon EG. Aldosterone/salt induces renal inflammation and fibrosis in hypertensive rats. Kidney Int. 2003;63:1791-1800

32. Galmiche G, Pizard A, Gueret A, El Moghrabi S, Ouvrard-Pascaud A, Berger S, et al. Smooth muscle cell mineralocorticoid receptors are mandatory for aldosterone-salt to induce vascular stiffness. Hypertension. 2014;63:520-526

33. Oberleithner H, Riethmuller C, Schillers H, MacGregor GA, de Wardener HE, Hausberg M. Plasma sodium stiffens vascular endothelium and reduces nitric oxide release. Proc Natl Acad Sci U S A. 2007;104:16281-16286

34. Rocha R, Rudolph AE, Frierdich GE, Nachowiak DA, Kekec BK, Blomme EA, et al. Aldosterone induces a vascular inflammatory phenotype in the rat heart. Am J Physiol Heart Circ Physiol. 2002;283: H1802-1810

35. Nagase M, Matsui H, Shibata S, Gotoda T, Fujita T. Salt-induced nephropathy in obese spontaneously hypertensive rats via paradoxical activation of the mineralocorticoid receptor: Role of oxidative stress. Hypertension. 2007;50:877-883

36. Toda N, Arakawa K. Salt-induced hemodynamic regulation mediated by nitric oxide. J Hypertens. 2011; 29:415-424

37. Funder JW. Primary aldosteronism and salt. Pflugers Arch. 2015;467:587-594

38. Hendriksen MA, van Raaij JM, Geleijnse JM, Wilson-van den Hooven C, Ocke MC, van der AD. Monitoring salt and iodine intakes in dutch adults between 2006 and 2010 using 24 h urinary sodium and iodine excretions. Public health nutrition. 2014;17:1431-1438

39. Lienhard D, Lauterburg M, Escher G, Frey FJ, Frey BM. High salt intake down-regulates colonic mineralocorticoid receptors, epithelial sodium channels and 11beta-hydroxysteroid dehydrogenase type 2. PLoS One. 2012;7:e37898

40. Meneton P, Galan P, Bertrais S, Heudes D, Hercberg S, Menard J. High plasma aldosterone and low renin predict blood pressure increase and hypertension in middle-aged caucasian populations. $J$ Hum Hypertens. 2008;22:550-558

41. Vasan RS, Evans JC, Larson MG, Wilson PW, Meigs JB, Rifai N, et al. Serum aldosterone and the incidence of hypertension in nonhypertensive persons. N Engl J Med. 2004;351:33-41

42. Colussi G, Catena C, Lapenna R, Nadalini E, Chiuch A, Sechi LA. Insulin resistance and hyperinsulinemia are related to plasma aldosterone levels in hypertensive patients. Diabetes Care. 2007;30:2349-2354 
43. Campion J, Maestro B, Mata F, Davila N, Carranza MC, Calle C. Inhibition by aldosterone of insulin receptor mrna levels and insulin binding in u-937 human promonocytic cells. J Steroid Biochem Mol Biol. 1999;70:211-218

44. Campion J, Maestro B, Molero S, Davila N, Carranza MC, Calle C. Aldosterone impairs insulin responsiveness in $\mathrm{u}-937$ human promonocytic cells via the downregulation of its own receptor. Cell Biochem Funct. 2002;20:237-245

45. Lastra G, Whaley-Connell A, Manrique C, Habibi J, Gutweiler AA, Appesh L, et al. Low-dose spironolactone reduces reactive oxygen species generation and improves insulin-stimulated glucose transport in skeletal muscle in the tg(mren2)27 rat. Am J Physiol Endocrinol Metab. 2008;295:E110-116

46. Selvaraj J, Muthusamy T, Srinivasan C, Balasubramanian K. Impact of excess aldosterone on glucose homeostasis in adult male rat. Clin Chim Acta. 2009;407:51-57

47. Wada T, Ohshima S, Fujisawa E, Koya D, Tsuneki H, Sasaoka T. Aldosterone inhibits insulin-induced glucose uptake by degradation of insulin receptor substrate (irs) 1 and irs2 via a reactive oxygen species-mediated pathway in 3t3-I1 adipocytes. Endocrinology. 2009;150:1662-1669

48. Marcus $Y$, Shefer G, Stern N. Adipose tissue renin-angiotensin-aldosterone system (raas) and progression of insulin resistance. Mol Cell Endocrinol. 2013;378:1-14

49. He FJ, Markandu ND, MacGregor GA. Importance of the renin system for determining blood pressure fall with acute salt restriction in hypertensive and normotensive whites. Hypertension. 2001;38:321-325

50. O'Hare JA. The enigma of insulin resistance and hypertension. Insulin resistance, blood pressure, and the circulation. Am J Med. 1988;84:505-510

51. Bray GA, Fruhbeck G, Ryan DH, Wilding JP. Management of obesity. Lancet. 2016;387:1947-1956

52. Prior SJ, Blumenthal JB, Katzel LI, Goldberg AP, Ryan AS. Increased skeletal muscle capillarization after aerobic exercise training and weight loss improves insulin sensitivity in adults with igt. Diabetes Care. 2014;37:1469-1475

53. Vinet A, Obert P, Dutheil F, Diagne L, Chapier R, Lesourd B, et al. Impact of a lifestyle program on vascular insulin resistance in metabolic syndrome subjects: The resolve study. $J$ Clin Endocrinol Metab. 2014:jc20142704

54. Fogari R, Zoppi A, Corradi L, Preti P, Mugellini A, Lazzari P, et al. Effect of body weight loss and normalization on blood pressure in overweight non-obese patients with stage 1 hypertension. Hypertens Res. 2010;33:236-242

55. Ikeda T, Gomi T, Hirawa N, Sakurai J, Yoshikawa N. Improvement of insulin sensitivity contributes to blood pressure reduction after weight loss in hypertensive subjects with obesity. Hypertension. 1996;27:1180-1186

56. Tuck ML, Sowers J, Dornfeld L, Kledzik G, Maxwell M. The effect of weight reduction on blood pressure, plasma renin activity, and plasma aldosterone levels in obese patients. N Engl J Med. 1981;304:930-933

57. Briones AM, Nguyen Dinh Cat A, Callera GE, Yogi A, Burger D, He Y, et al. Adipocytes produce aldosterone through calcineurin-dependent signaling pathways: Implications in diabetes mellitusassociated obesity and vascular dysfunction. Hypertension. 2012;59:1069-1078

58. Lu Y, Hajifathalian K, Ezzati M, Woodward M, Rimm EB, Danaei G. Metabolic mediators of the effects of body-mass index, overweight, and obesity on coronary heart disease and stroke: A pooled analysis of 97 prospective cohorts with 1.8 million participants. Lancet. 2014;383:970-983

59. Licata G, Volpe M, Scaglione R, Rubattu S. Salt-regulating hormones in young normotensive obese subjects. Effects of saline load. Hypertension. 1994;23:120-24

60. Meneton $\mathrm{P}$, Jeunemaitre $\mathrm{X}$, de Wardener HE, MacGregor GA. Links between dietary salt intake, renal salt handling, blood pressure, and cardiovascular diseases. Physiol Rev. 2005;85:679-715

61. Weinberger MH, Fineberg NS, Fineberg SE, Weinberger M. Salt sensitivity, pulse pressure, and death in normal and hypertensive humans. Hypertension. 2001;37:429-432

62. Baudrand R, Campino C, Carvajal CA, Olivieri O, Guidi G, Faccini G, et al. High sodium intake is associated with increased glucocorticoid production, insulin resistance and metabolic syndrome. Clin Endocrinol (Oxf). 2014;80:677-684

63. Chen J, Gu D, Huang J, Rao DC, Jaquish CE, Hixson JE, et al. Metabolic syndrome and salt sensitivity of blood pressure in non-diabetic people in china: A dietary intervention study. Lancet. 2009;373:829-835 
64. Lastra G, Dhuper S, Johnson MS, Sowers JR. Salt, aldosterone, and insulin resistance: Impact on the cardiovascular system. Nature reviews. Cardiology. 2010;7:577-584

65. Rocchini AP, Key J, Bondie D, Chico R, Moorehead C, Katch V, et al. The effect of weight loss on the sensitivity of blood pressure to sodium in obese adolescents. N Engl J Med. 1989;321:580-585

66. Cavka A, Cosic A, Jukic I, Jelakovic B, Lombard JH, Phillips SA, et al. The role of cyclo-oxygenase-1 in high-salt diet-induced microvascular dysfunction in humans. J Physiol. 2015;593:5313-5324

67. He FJ, Marciniak M, Markandu ND, Antonios TF, MacGregor GA. Effect of modest salt reduction on skin capillary rarefaction in white, black, and asian individuals with mild hypertension. Hypertension. 2010;56:253-259

68. Houben AJ, Willemsen RT, van de Ven H, de Leeuw PW. Microvascular adaptation to changes in dietary sodium is disturbed in patients with essential hypertension. J Hypertens. 2005;23:127-132

69. Premilovac D, Richards SM, Rattigan S, Keske MA. A vascular mechanism for high-sodium-induced insulin resistance in rats. Diabetologia. 2014;57:2586-2595

70. Pamidimukkala J, Jandhyala BS. Effects of salt rich diet in the obese zucker rats: Studies on renal function during isotonic volume expansion. Clin Exp Hypertens. 2004;26:55-67

71. Hornstra JM, Serne EH, Eringa EC, Wijnker MC, de Boer MP, Yudkin JS, et al. Insulin's microvascular vasodilatory effects are inversely related to peripheral vascular resistance in overweight, but insulinsensitive subjects. Obesity (Silver Spring). 2013;21:2557-2561

72. Hall JE, do Carmo JM, da Silva AA, Wang Z, Hall ME. Obesity-induced hypertension: Interaction of neurohumoral and renal mechanisms. Circ Res. 2015;116:991-1006

73. Catena C, Giacchetti G, Novello M, Colussi G, Cavarape A, Sechi LA. Cellular mechanisms of insulin resistance in rats with fructose-induced hypertension. Am J Hypertens. 2003;16:973-978

74. Ogihara T, Asano T, Ando K, Chiba Y, Sekine N, Sakoda H, et al. Insulin resistance with enhanced insulin signaling in high-salt diet-fed rats. Diabetes. 2001;50:573-583

75. Ogihara T, Asano T, Ando K, Sakoda H, Anai M, Shojima N, et al. High-salt diet enhances insulin signaling and induces insulin resistance in dahl salt-sensitive rats. Hypertension. 2002;40:83-89

76. Sechi LA, Griffin CA, Giacchetti G, Zingaro L, Catena C, Bartoli E, et al. Abnormalities of insulin receptors in spontaneously hypertensive rats. Hypertension. 1996;27:955-961

77. Cho TM, Peng N, Clark JT, Novak L, Roysommuti S, Prasain J, et al. Genistein attenuates the hypertensive effects of dietary nacl in hypertensive male rats. Endocrinology. 2007;148:5396-5402

78. Hayashida T, Ohno Y, Otsuka K, Suzawa T, Shibagaki K, Suzuki H, et al. Salt-loading elevates blood pressure and aggravates insulin resistance in wistar fatty rats: A possible role for enhanced $n a+-h+$ exchanger activity. J Hypertens. 2001;19:1643-1650

79. Hattori T, Murase T, Takatsu M, Nagasawa K, Matsuura N, Watanabe S, et al. Dietary salt restriction improves cardiac and adipose tissue pathology independently of obesity in a rat model of metabolic syndrome. J Am Heart Assoc. 2014;3:e001312

80. Perry CG, Palmer T, Cleland SJ, Morton IJ, Salt IP, Petrie JR, et al. Decreased insulin sensitivity during dietary sodium restriction is not mediated by effects of angiotensin ii on insulin action. Clin Sci (Lond). 2003;105:187-194

81. Townsend RR, Kapoor S, McFadden CB. Salt intake and insulin sensitivity in healthy human volunteers. Clin Sci (Lond). 2007;113:141-148

82. Gomi T, Shibuya Y, Sakurai J, Hirawa N, Hasegawa K, Ikeda T. Strict dietary sodium reduction worsens insulin sensitivity by increasing sympathetic nervous activity in patients with primary hypertension. $\mathrm{Am}$ J Hypertens. 1998;11:1048-1055

83. Melander O, Groop L, Hulthen UL. Effect of salt on insulin sensitivity differs according to gender and degree of salt sensitivity. Hypertension. 2000;35:827-831

84. Foo M, Denver AE, Coppack SW, Yudkin JS. Effect of salt-loading on blood pressure, insulin sensitivity and limb blood flow in normal subjects. Clin Sci (Lond). 1998;95:157-164

85. Foo M, Coppack SW, Denver AE, Bulmer K, Yudkin JS. Lack of impact of angiotensin-converting enzyme gene polymorphism and salt intake on insulin resistance and limb blood flow. Clin Endocrinol (Oxf). 2015;82:76-83

86. Donovan DS, Solomon CG, Seely EW, Williams GH, Simonson DC. Effect of sodium intake on insulin sensitivity. Am J Physiol. 1993;264:E730-734 
87. Kitada K, Daub S, Zhang Y, Klein JD, Nakano D, Pedchenko T, et al. High salt intake reprioritizes osmolyte and energy metabolism for body fluid conservation. J Clin Invest. 2017;127:1944-1959

88. Rakova N, Kitada K, Lerchl K, Dahlmann A, Birukov A, Daub S, et al. Increased salt consumption induces body water conservation and decreases fluid intake. J Clin Invest. 2017;127:1932-1943

89. Clerk LH, Vincent MA, Jahn LA, Liu Z, Lindner JR, Barrett EJ. Obesity blunts insulin-mediated microvascular recruitment in human forearm muscle. Diabetes. 2006;55:1436-1442

90. Kusters YH, Schalkwijk CG, Houben AJ, Kooi ME, Lindeboom L, Op 't Roodt J, et al. Independent tissue contributors to obesity-associated insulin resistance. JCI Insight. 2017;2

91. Meijer RI, De Boer MP, Groen MR, Eringa EC, Rattigan S, Barrett EJ, et al. Insulin-induced microvascular recruitment in skin and muscle are related and both are associated with whole-body glucose uptake. Microcirculation. 2012;19:494-500

92. Bessey PQ, Brooks DC, Black PR, Aoki TT, Wilmore DW. Epinephrine acutely mediates skeletal muscle insulin resistance. Surgery. 1983;94:172-179

93. Deibert DC, DeFronzo RA. Epinephrine-induced insulin resistance in man. J Clin Invest. 1980;65:717-721

94. Hunt DG, Ding Z, Ivy JL. Clenbuterol prevents epinephrine from antagonizing insulin-stimulated muscle glucose uptake. J Appl Physiol (1985). 2002;92:1285-1292

95. Laakso M, Edelman SV, Brechtel G, Baron AD. Effects of epinephrine on insulin-mediated glucose uptake in whole body and leg muscle in humans: Role of blood flow. Am J Physiol. 1992;263:E199-204

96. Niklasson $\mathrm{M}$, Holmang $\mathrm{A}$, Lonnroth $\mathrm{P}$. Induction of rat muscle insulin resistance by epinephrine is accompanied by increased interstitial glucose and lactate concentrations. Diabetologia. 1998;41: 1467-1473

97. Gonzalez M, Lobos L, Castillo F, Galleguillos L, Lopez NC, Michea L. High-salt diet inhibits expression of angiotensin type 2 receptor in resistance arteries. Hypertension. 2005;45:853-859

98. Nickenig G, Strehlow K, Roeling J, Zolk O, Knorr A, Bohm M. Salt induces vascular at1 receptor overexpression in vitro and in vivo. Hypertension. 1998;31:1272-1277

99. Wang $\mathrm{DH}, \mathrm{Du}$ Y. Regulation of vascular type 1 angiotensin ii receptor in hypertension and sodium loading: Role of angiotensin ii. J Hypertens. 1998;16:467-475

100. Chai W, Wang W, Dong Z, Cao W, Liu Z. Angiotensin ii receptors modulate muscle microvascular and metabolic responses to insulin in vivo. Diabetes. 2011;60:2939-2946

101. Chai W, Wang W, Liu J, Barrett EJ, Carey RM, Cao W, et al. Angiotensin ii type 1 and type 2 receptors regulate basal skeletal muscle microvascular volume and glucose use. Hypertension. 2010;55:523-530

102. Fukushima A, Kinugawa S, Takada S, Matsushima S, Sobirin MA, Ono T, et al. (pro)renin receptor in skeletal muscle is involved in the development of insulin resistance associated with postinfarct heart failure in mice. Am J Physiol Endocrinol Metab. 2014;307:E503-514

103. Jonk AM, Houben AJ, Schaper NC, de Leeuw PW, Serne EH, Smulders YM, et al. Angiotensin ii enhances insulin-stimulated whole-body glucose disposal but impairs insulin-induced capillary recruitment in healthy volunteers. J Clin Endocrinol Metab. 2010;95:3901-3908

104. Kubota T, Kubota N, Kadowaki T. The role of endothelial insulin signaling in the regulation of glucose metabolism. Rev Endocr Metab Disord. 2013;14:207-216

105. Shulman GI. Cellular mechanisms of insulin resistance. J Clin Invest. 2000;106:171-176

106. Muris DM, Houben AJ, Schram MT, Stehouwer CD. Microvascular dysfunction: An emerging pathway in the pathogenesis of obesity-related insulin resistance. Rev Endocr Metab Disord. 2013;14:29-38

107. Oberleithner H, Wilhelmi M. Vascular glycocalyx sodium store - determinant of salt sensitivity? Blood Purif. 2015;39:7-10

108. Titze J, Dahlmann A, Lerchl K, Kopp C, Rakova N, Schroder A, et al. Spooky sodium balance. Kidney Int. 2014;85:759-767 


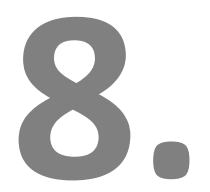

NEDERLANDSE SAMENVATTING 



\section{Introductie}

Obesitas is een risicofactor voor hart- en vaataandoeningen, en is daarmee een belangrijke oorzaak voor ziekte en sterfte wereldwijd. Obesitas verhoogt het risico op hart- en vaatziekten, omdat het kan leiden tot onder andere hoge bloeddruk (hypertensie) en een verminderde gevoeligheid van onder andere spiercellen voor het hormoon insuline (insuline resistentie). Daarnaast is het bloeddukverhogend effect van zout groter bij mensen met obesitas (zoutgevoeligheid). Meer inzicht in de manier waarop obesitas hoge bloeddruk en insuline resistentie kan veroorzaken is cruciaal, omdat dit aanleiding kan zijn voor het ontwikkelen van nieuwe behandelingen, en ook de preventie van hart- en vaatziekten verbeterd kan worden.

Een verminderde functie van de kleinste bloedvaatjes (microvasculaire dysfunctie) blijkt samen te hangen met het ontstaan van hypertensie, zoutgevoeligheid en insuline resistentie, maar het precieze mechanisme hiervan is nog niet geheel opgehelderd. Wat wel duidelijk is, is dat het renine-angiotensine-aldosteron systeem (RAAS) hierin een rol lijkt te spelen. Dit is een hormoonsysteem dat belangrijk is voor bloeddrukregulatie, door het verhogen van de vaatweerstand en het vasthouden van zout. Wanneer het overactief is, bijvoorbeeld bij mensen met obesitas, kan het niet alleen hypertensie veroorzaken, maar ook insuline resistentie en microvasculaire dysfunctie. Dit geldt in ieder geval voor angiotensine II, waarvan lang gedacht is dat dit het belangrijkste hormoon van het RAAS is. Van aldosteron, een ander hormoon dat deel uitmaakt van het RAAS, is de laatste jaren duidelijk geworden dat het ook allerlei negatieve effecten heeft wanneer het in overmate aanwezig is. Dit geldt niet alleen voor bloeddruk, maar ook voor insulinegevoeligheid en de functie van de kleinste bloedvaatjes. Deze negatieve gevolgen van aldosteron zijn niet alleen verklaarbaar door het vasthouden van meer zout, maar zouden ook veroorzaakt kunnen worden door directe effecten van aldosteron op de kleinste bloedvaatjes. Het eten van te veel zout op zich lijkt echter ook in verband te staan met insuline resistentie en microvasculaire dysfunctie, naast de alom bekende bloeddrukverhoging.

Studies hebben aangetoond dat mensen met ernstige obesitas te veel aldosteron lijken aan te maken, en dat dit gepaard gaat met hypertensie en insuline resistentie. Er zijn echter weinig gegevens bij mensen (met obesitas) over de relatie tussen aldosteron en de functie van de kleinste bloedvaatjes, en dan met name het vaatverwijdende effect van insuline op de kleinste bloedvaatjes (insuline-gemedieerde microvasculaire functie). Dit is belangrijk voor de toevoer van insuline en glucose naar de spiercellen, en heeft waarschijnlijk ook een gunstige invloed op de vaatweerstand en daarmee bloeddruk. Ook weten we niet of personen met overgewicht of een mindere mate van obesitas ook te veel aldosteron aanmaken. 
Daarnaast is onbekend of het verband tussen te veel zout, hypertensie en insulineresistentie te verklaren is door een negatief effect van zout op de insulinegemedieerde microvasculaire functie, en of de effecten van aldosteron op insulinegemedieerde microvasculaire functie, bloeddruk en insulinegevoeligheid afhangen van de hoeveelheid zout die een persoon binnenkrijgt (Hoofdstuk 1). Deze vragen hebben we dan ook proberen te beantwoorden in dit proefschrift.

\section{Het RAAS in vetweefsel en obesitas-gerelateerde hypertensie}

De laatste jaren is duidelijk geworden dat het RAAS meer hormonen en enzymen omvat dan angiotensinogeen, renine, angiotensin-converting-enzyme (ACE), angiotensine II, en aldosteron, die mogelijk een gunstig effect hebben op de bloeddruk, namelijk ACE2 en angiotensine 1-7, met de bijbehorende Mas-receptor. In ieder geval een deel van deze hormonen en enzymen kan worden aangemaakt in het vetweefsel, en een dysbalans hierin zou verantwoordelijk kunnen zijn voor het ontstaan van obesitasgerelateerde hypertensie. In Hoofdstuk $\mathbf{2}$ hebben we daarom eerst de belangrijkste gegevens die hierover bekend zijn samengevat, evenals de mechanismen verantwoordelijk voor het ontstaan van hoge bloeddruk in het geval van een dysbalans in het RAAS. We kunnen concluderen dat er belangrijke aanwijzingen zijn dat een overmaat aan angiotensine II en aldosteron in mensen met obesitas in ieder geval gedeeltelijk wordt veroorzaakt door aanmaak van deze hormonen in vetweefsel. Via effecten op de nier, het sympathisch zenuwstelsel, en de kleinere en grotere bloedvaten kan dit leiden tot hoge bloeddruk en tevens bijdragen aan het ontstaan van insuline resistentie. Medicatie die de aanmaak en/of binding aan de receptor van angiotensine II en aldosteron voorkomt lijkt dus cruciaal in de behandeling van obesitas-gerelateerde hypertensie, en kan gunstige effecten hebben op de insulinegevoeligheid. Over de rol van ACE2 en angiotensine 1-7 is weinig bekend in mensen (met obesitas), maar gezien eerdere veelbelovende resultaten uit dierstudies zou dit wel een potentieel aangrijpingspunt kunnen zijn voor nieuwe medicijnen.

\section{Aldosteron}

De kleinste bloedvaatjes in de nier (renale microcirculatie) zijn onder andere belangrijk voor het regelen van de water- en zouthuishouding in het lichaam. Een verminderde functie van de renale microcirculatie, zich onder andere uitend in een afgenomen 
nierdoorbloeding, kan dan ook bijdragen aan de verergering of het ontstaan van hoge bloeddruk, en daarnaast leiden tot achteruitgang van de nierfunctie. Uit eerder onderzoek is gebleken dat bij mensen met hypertensie de nierdoorbloeding vaak niet in gelijke mate verminderd is in de linker- en de rechternier, en dat de linkernier vaak het slechtst doorbloed is. Ook is er een verband tussen hogere aldosteronwaarden en slechtere totale (links + rechts) nierdoorbloeding vastgesteld, maar dit is nooit bekeken per nier afzonderlijk. In Hoofdstuk 3 onderzochten we het verband tussen de aldosteronconcentratie in het bloed en doorbloeding van de linker- en de rechternier, zonder en met correctie voor angiotensine II (omdat angiotensine II ook effecten heeft op de nierdoorbloeding). Dit onderzoek hebben we verricht in mensen met therapieresistente hypertensie (hoge bloeddruk die onvoldoende reageert op 3 of meer verschillende soorten medicijnen). Nierdoorbloeding werd gemeten met behulp van de ${ }^{133}$ Xenon washout techniek, waarbij het radioactieve gas ${ }^{133}$ Xenon rechtstreek in de nierarterie wordt gespoten, en de verandering van radioactiviteit wordt bepaald met een zogenaamde gammacammera. Uit deze verandering van radioactiviteit is af te leiden hoeveel $\mathrm{mL}$ bloed er per minuut door de nier stroomt. We vonden geen verband tussen de ongecorrigeerde aldosteronwaarden en nierdoorbloeding aan beide kanten, maar wel een relatie tussen een hogere gecorrigeerde aldosteronwaarde (ARR) en slechtere doorbloeding van de linkernier. Er was geen verband tussen ARR en doorbloeding van de rechternier. Deze bevindingen zouden kunnen betekenen dat de kleinste bloedvaatjes van de linkernier meer gevoelig zijn voor stoffen die de vaatweerstand kunnen beïnvloeden, waaronder aldosteron. Als ook de doorbloeding van de rechternier verminderd raakt, zou dit dus een negatief effect op de bloeddruk, en op de nierfunctie kunnen hebben.

Zoals eerder beschreven is de veronderstelling dat de aldosteronconcentratie in het bloed verhoogd is bij mensen met obesitas voornamelijk gebaseerd op onderzoeken die proefpersonen met ernstige obesitas vergeleken met slanke proefpersonen. In Hoofdstuk 4 hebben we onderzocht of dit ook geldt voor mensen met overgewicht of een mindere mate van obesitas (met voornamelijk toegenomen buikomtrek; ook wel abdominale obesitas), vergeleken met slanke mensen, en of de aldosteronconcentratie daalt door afvallen. Daarnaast hebben we bekeken of er een verband is tussen aldosteronspiegels enerzijds en insuline-gemedieerde microvasculaire vaatverwijding in de skeletspier, insulinegevoeligheid en bloeddruk in de totale studiepopulatie. Deze insuline-gemedieerde microvasculaire vaatverwijding hebben we bepaald door het meten van de doorbloeding in de spieren van de onderarm door middel van contrastecho, voor en na een infuus met insuline. Hiervoor hebben we gebruik gemaakt van een zogenaamde contrastvloeistof met microbelletjes. Deze microbelletjes gaan kapot door echogeluid, en het signaal dat hierbij vrijkomt is een maat voor het 
bloedvolume in de microcirculatie van de spieren in de onderarm. Door toediening van insuline kan ook de insulinegevoeligheid worden bepaald, aan de hand van de hoeveelheid suiker per kg lichaamsgewicht die gelijktijdig met de insuline moet worden toegediend om de bloedsuikerspiegel constant te houden. Er was geen verschil in aldosteronconcentratie tussen slanke proefpersonen en proefpersonen met abdominale obesitas, maar in de laatste groep was er een minder sterke omgekeerde relatie tussen de zoutconcentratie in het bloed en de aldosteronspiegel. Dit zou kunnen betekenen dat de regulatie van de aldosteronconcentratie door zout gestoord is in abdominaal obese mensen, en dit hebben we inderdaad bevestigd in een andere studiepopulatie met en zonder abdominale obesitas. Deze proefpersonen hebben een week lang een laag zout dieet, en een week lang een hoog zout dieet gevolgd, in willekeurige volgorde, en bij de mensen met abdominale obesitas was de aldosteronspiegel minder goed onderdrukt bij het eten van meer zout. Uiteindelijk zou dit dus wel kunnen leiden tot een verhoogde aldosteronconcentratie bij de abdominaal obese proefpersonen. In de oorspronkelijke studie daalde de aldosteronspiegel ook niet door afvallen, en was er geen verband met insuline-gemedieerde microvasculaire vaatverwijding in de skeletspier, insulinegevoeligheid en bloeddruk. Mogelijk waren de absolute aldosteronwaarden te laag om schadelijke gevolgen te hebben. Er zijn echter ook aanwijzingen dat de bloeddrukverhogende effecten van aldosteron afhankelijk zijn van zoutinname. Of dit ook geldt voor insuline-gemedieerde microvasculaire functie en insuline gevoeligheid, en of dit verschilt in mensen met en zonder (abdominale) obesitas is niet bekend. Daarom hebben we in Hoofdstuk 6 de relatie tussen de aldosteronconcentratie en insuline-gemedieerde microvasculaire vaatverwijding in de skeletspier, insulinegevoeligheid en bloeddruk opnieuw bekeken in slanke en abdominaal obese proefpersonen met een zoutinname variërend van 1.2 tot $23.5 \mathrm{~g}$ per 24 uur, en onderzocht of er een interactie is met zoutinname of al dan niet abdominaal obees zijn. Een deel van de proefpersonen had zowel een laag zout dieet $(2.9 \mathrm{~g}$ per 24 uur) als een hoog zout dieet (14.6 g per 24 uur) gebruikt gedurende een week, in willekeurige volgorde. Binnen het gehele bereik aan zoutinname was er geen verband tussen de aldosteronspiegel en microvasculaire functie, insulinegevoeligheid en bloeddruk. Er bleek echter wel een relatie te bestaan tussen hogere aldosteronwaarden en lagere bloeddruk in geval van lage zoutinname, terwijl er bij hoge zoutinname een relatie was tussen hogere aldosteronwaarden en hogere bloeddruk. Hoewel deze relaties niet statistisch significant waren, zijn ze wel te verklaren. Hogere aldosteronwaarden in combinatie met een hogere zoutinname zullen beide bloeddrukverhogend werken. Als de zoutinname echter laag is en hierdoor de bloeddruk daalt, zal de aldosteronconcentratie stijgen om een te sterke bloeddrukdaling te voorkomen. 
In slanke proefpersonen vonden we een verband tussen hogere aldosteronwaarden en een betere insulinegevoeligheid, terwijl dit verband omgekeerd was in abdominaal obese proefpersonen. Ook deze verbanden waren niet statistisch significant. In de slanke proefpersonen zou dit verband kunnen wijzen op een goede responsiviteit van het RAAS, wat net als een goede insulinegevoeligheid een teken kan zijn van gezond zijn. In de abdominaal obese proefpersonen daarentegen kunnen hogere aldosteronwaarden een ongunstig effect hebben op de insulinegevoeligheid. Hoewel de absolute aldosteronconcentratie niet extreem hoog was, zijn zij wellicht gevoeliger voor dit effect omdat er bij hen al sprake was van enige insuline resistentie, vergeleken met de slanke proefpersonen.

\section{Zout}

Mensen met obesitas lijken gevoeliger te zijn voor de bloeddrukverhogende effecten van zout, en zijn daarnaast vaak minder insulinegevoelig. Te veel zout lijkt ook een ongunstige invloed te hebben op de insuline-gemedieerde microvasculaire vaatverwijding in de skeletspier in dierstudies, en op microvasculaire functie in het algemeen in mensen. In Hoofdstuk 5 hebben we onderzocht wat het effect van een laag zout dieet ( $2.9 \mathrm{~g}$ per 24 uur) en hoog zout dieet (14.6 g per 24) gedurende zeven dagen in willekeurige volgorde is op de insuline-gemedieerde microvasculaire vaatverwijding in de skeletspier in mensen zonder en met abdominale obesitas, en we hebben bekeken hoe dit samenhangt met de gevolgen hiervan voor de bloeddruk en insulinegevoeligheid. Na een laag, vergeleken met een hoog zout dieet daalde de bloeddruk en verbeterde de insuline-gemedieerde microvasculaire vaatverwijding in de skeletspier, maar de insulinegevoeligheid verslechterde in zowel de slanke als abdominaal obese proefpersonen, en alleen in de slanke proefpersonen was er een verband tussen een betere insuline-gemedieerde microvasculaire vaatverwijding in de skeletspier en een lagere bloeddruk na een laag zout dieet. Een laag zout dieet lijkt dus een gunstig effect op de bloeddruk te hebben door verbetering van de insulinegemedieerde microvasculaire functie in de spier, in slanke mensen. Het onderliggende mechanisme hiervoor zal een verbetering van de insuline-gemedieerde stikstofoxide (NO) productie zijn, wat ten grondslag ligt aan het vaatverwijdende effect van insuline. In mensen met abdominale obesitas zijn er waarschijnlijk zelfs na een laag zout dieet nog bloeddruk-verhogende mechanismen actief, die de verbetering van microvasculaire functie tenietdoen. Er was zowel na het laag als na het hoog zout dieet geen verband tussen insuline-gemedieerde microvasculaire functie in de spier en insulinegevoeligheid. Eerdere studies hebben laten zien dat dit verband er wel is bij normale 
zoutinname. Hoe de afwezigheid van deze relatie te verklaren is, is niet geheel duidelijk. Het is mogelijk dat de mechanismen die leiden tot een verbetering van microvasculaire functie, tegelijk de insulinegevoeligheid doen afnemen en andersom, bijvoorbeeld een toename in epinefrine spiegels bij een laag zout dieet, verandering in angiotensine II-spiegels en verdeling van de receptoren, of toegenomen ureumproductie bij een hoog zout dieet.

\section{Algemene discussie}

In Hoofdstuk 7 worden de belangrijkste bevindingen van dit proefschrift besproken en in een breder perspectief geplaatst.

Het feit dat er wel een verband was tussen ARR en nierdoorbloeding links in mensen met therapie-resistente hypertensie, maar niet tussen aldosteron en insulinegemedieerde microvasculaire functie in de skeletspier in proefpersonen zonder en met abdominale obesitas, ongeacht de zoutinname, kan verschillende oorzaken hebben. Zo zullen de absolute aldosteronwaarden in de eerste groep hoger zijn, en zal bij deze mensen het endotheel (de binnenste laag cellen in een bloedvat, die onder andere belangrijke is voor een goede reactiviteit) al meer beschadigd zijn door de hoge bloeddruk. Verder hebben we twee verschillende maten voor microvasculaire functie gebruikt, namelijk basale doorbloeding en reactie op een stimulus, die beide op een andere manier beïnvloed kunnen worden door aldosteron. Tenslotte is het maar de vraag of aldosteronspiegels in het bloed altijd de beste weerspiegeling zijn van wat er op weefselniveau gebeurt. Voor toekomstig onderzoek zou het dan ook interessant zijn om te kijken of er wel een relatie is tussen dichtheid van de mineralocorticoid receptor in nieren en skeletspier, en functie van het betreffende microvasculaire bed, zowel basale doorbloeding als reactie op een stimulus. Ook zou bekeken kunnen worden wat het effect van een laag en hoog zout dieet is op mineralocorticoid receptor dichtheid, aangezien deze in dierstudies leek te veranderen door een aanpassing van zoutinname. Tenslotte zou het nuttig zijn de microvasculaire respons op mineralocorticoid receptor blokkade te onderzoeken. Een kanttekening is echter dat voor het beantwoorden van deze vragen soms invasieve handelingen nodig zijn, wat de praktische uitvoering kan bemoeilijken.

Een andere intrigerende bevinding in dit proefschrift is dat zoutbeperking gunstige effecten heeft op de bloeddruk en microvasculaire functie in de skeletspier, maar juist nadelige effecten op insulinegevoeligheid. Verder lijkt insuline-gemedieerde microvasculaire dilatatie in de skeletspier zowel na een laag als hoog zout dieet geen determinant te zijn van insuline-geïnduceerde glucose opname, wat bij normale 
zoutinname wel het geval is. Om deze onverwachte bevindingen te kunnen verklaren zou het nuttig zijn een indruk te krijgen van wat er op moleculair niveau gebeurt met de insuline-signalering cascade in endotheelcellen en skeletspiercellen. Uit studies in ratten is namelijk gebleken dat na een hoog zout dieet PI3-kinase/Akt activatie (wat deel uitmaakt van de insuline-signalering cascade) optreedt in lever, spier en vetweefsel, ondanks een afname van de insuline-gemedieerde glucose opname. Ook zou het interessant zijn te weten hoe de basale doorbloeding in de skeletspier verandert onder invloed van een laag en hoog zout dieet, omdat dit ook bepaalt hoeveel ruimte er (nog) is voor de vaatverwijdende effecten van insuline. Wederom zijn hier echter weer invasieve handelingen voor nodig. Een nieuw concept is dat van nonosmotische zoutopslag in de endotheliale glycocalyx (een laag proteoglycanen gebonden aan het endotheel), huid en skeletspier, wat wellicht een rol speelt in de tegengestelde effecten van verandering in zoutinname op microvasculaire functie en insulinegevoeligheid. Dit is in beeld te brengen met microscopische en MRI-technieken, die als voordeel hebben dat ze weinig invasief zijn, maar mogelijk wel een ander licht op deze bevindingen kunnen werpen. 



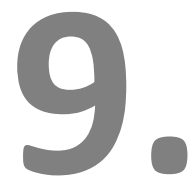

VALORISATION ADDENDUM 



\section{Valorisation addendum}

In this chapter, we outline the relevance of our findings and their implications for daily practice.

\section{The obesity epidemic}

Obesity has become a major threat to public health. In 2015, obesity affected around 600 million adults worldwide. High BMI accounted for 4 million deaths globally, nearly $40 \%$ of which occurred among individuals with a BMI between 25 and 30 . Cardiovascular disease was the leading cause of death, responsible for more than twothirds of mortality attributed to high $\mathrm{BMI}^{1}$. In the Netherlands, overweight has been estimated to be responsible for $20 \%$ of total annual health care costs, and obesity for $9 \%$ of these costs. Of the costs attributable to overweight, i.e. $€ 1,185,688,644,48 \%$ is accounted for by diabetes, $10 \%$ by hypertension, another $10 \%$ by stroke, and $16 \%$ by coronary heart disease ${ }^{2}$. Thus, it is superfluous to say that prevention of obesity-related complications saves lives and money.

\section{Weight loss strategies}

The first step in the management of obesity-related complications should be focused on inducing weight loss. Indeed, weight loss interventions have been proven to be beneficial in terms of lowering blood pressure, reducing incidence of type 2 diabetes and cardiovascular disease, and decreasing cardiovascular and all-cause mortality ${ }^{3-5}$. This may be partially accounted for by improvement of microvascular and metabolic insulin sensitivity ${ }^{6,7}$, which is confirmed by our findings in Chapter 4 . Identifying the molecular mechanisms underlying the amelioration of insulin-mediated muscle microvascular recruitment and insulin-induced whole-body glucose disposal following weight loss provides more insight in the pathophysiology of obesity-related complications. This can be helpful in the development of new pharmacological therapies, as weight loss is often difficult to achieve and sustain. In our study population, serum aldosterone concentration was comparable in lean and moderately abdominally obese individuals, but the regulation of aldosterone levels by salt intake was not entirely normal. Thus, although aldosterone does not seem to have a share in the improvement of microvascular and metabolic insulin resistance after weight loss observed in the abdominally obese male subpopulation, its role may become more 
prominent if these individuals gain weight, and in individuals with advanced stages of obesity in general.

\section{Pharmacological therapies}

Currently, two mineralocorticoid receptor antagonists (MRAs) are available: Spironolactone and Eplerenone. They are widely used in the treatment of heart failure and primary aldosteronism, and as add-on therapy for (resistant) essential hypertension, but are not registered as first-choice antihypertensive regimen in the Netherlands ${ }^{8}$. Although Spironolactone has been demonstrated in the PATHWAY-2 study to be the most effective fourth agent for treatment of uncontrolled resistant hypertension ${ }^{9}$, both Spironolactone and Eplerenone have been proven to effectively lower blood pressure as single antihypertensive drug as well. However, effects on longterm morbidity and mortality are not known ${ }^{10,11}$. During recent years it has become clear that the blood pressure lowering effects of MRAs may not only be attributable to increased sodium excretion, but potentially also to reduced vascular resistance ${ }^{12}$. In the light of our observations in Chapter 3 of an inverse association between ARR and left kidney perfusion, and a direct association with blood pressure in individuals with therapy-resistant essential hypertension, addition of an MRA to the antihypertensive regimen of these patients may partially lower blood pressure by improving renal perfusion, which could also contribute to the preservation of renal function. Indeed, although evidence on the effect of MRAs on hard renal endpoints is limited, they have been shown to reduce urinary protein/albumin excretion ${ }^{13}$. In practice, it will be difficult to prove an effect of MRAs on individual kidney perfusion, unless measurements of differential renal blood flow can be performed in an experimental setting. Nevertheless, our results are an additional argument for clinicians to add an MRA to the existing antihypertensive regimen of individuals with resistant hypertension, naturally with regular monitoring of serum potassium levels.

Obesity is one of the strongest risk factors for uncontrolled hypertension ${ }^{14}$. Although we have demonstrated that aldosterone levels were similar in lean and moderately abdominally obese, predominantly normotensive, men, and not associated with blood pressure in these men (Chapter 4), aldosterone was directly associated with blood pressure under circumstances of higher salt intake in a larger population of both lean and abdominally obese individuals, although statistically non-significant (Chapter 6). Interestingly, body mass index has been recently demonstrated to predict $24 \mathrm{~h}$ urinary aldosterone levels in patients with resistant hypertension ${ }^{15}$. In this study, BMI varied from 15.5 to $73.8 \mathrm{~kg} / \mathrm{m}^{2}$. This once again confirms that increased aldosterone levels 
may become overt and clinically relevant as body weight increases. Thus, clinicians should consider starting an MRA early in the treatment of obesity-related hypertension. In moderately abdominally obese men, aldosterone was also not associated with microvascular and metabolic insulin sensitivity, but in a larger abdominally obese study population, aldosterone displayed an inverse, but statistically non-significant relationship with metabolic insulin sensitivity (Chapter 6). As seems the case with blood pressure, effects of aldosterone on microvascular and metabolic insulin sensitivity may be only demonstrable in individuals with severe (abdominal) obesity. While awaiting these data, potential beneficial effects of MRAs on insulin sensitivity, as demonstrated in patients with primary hyperaldosteronism ${ }^{16}$, can be detected easily by measuring blood glucose levels or HbA1c. Of course, more subtle effects on metabolic insulin signalling, not directly translating in changes in glucose concentration, and on insulin's microvascular actions, cannot be demonstrated in this manner, and should be investigated in controlled experiments.

In terms of cost-effectiveness, the daily costs of Spironolactone are corresponding to those of ACE-inhibitors or AT2-receptor antagonists, but Eplerenone is more expensive $^{8}$. Although Eplerenone has a higher affinity for the mineralocorticoid receptor compared to Spironolactone, resulting in less side effects, it is advisable to prescribe Spironolactone first, and only switch to Eplerenone if these side effects become manifest.

\section{Salt: less or more?}

In Chapter 5, we have demonstrated that on a low, compared to a high salt diet, blood pressure decreases and insulin-mediated muscle microvascular recruitment improves, but insulin-induced whole-body glucose disposal decreases as well. Moreover, aldosterone was directly associated with blood pressure when salt intake was higher than $8.6 \mathrm{~g}$ per day (Chapter 6 ). This immediately raises the question whether we should decrease or increase our salt intake. Over the years, this answer has become less straightforward. It has been demonstrated recently that high intake of sodium is a major dietary risk factor for morbidity and mortality worldwide ${ }^{17}$. Conversely, a salt reduction from 11.7 to $3.9 \mathrm{~g}$ per day has been shown to reduce blood pressure, more in hypertensive than normotensive individuals ${ }^{18}$, with maximum efficacy after one week already ${ }^{19}$. In terms of cardiovascular disease and (all-cause) mortality, however, there does not seem to be a beneficial effect of low, compared to usual salt intake, and mortality even appears to be increased with low salt intake. High, compared to usual salt intake, on the other hand, has been shown to raise both the risk for cardiovascular 
disease and all-cause mortality ${ }^{20}$. Thus, our findings of impaired insulin-mediated glucose uptake on a low salt diet may provide an underlying explanation for the lack of effect of salt restriction on the occurrence of cardiovascular events, and increased mortality, although the consequences of long-term salt restriction for whole-body glucose disposal are not known. Until then, the question remains how to adjust salt intake. Because there is no evidence for beneficial health effects of a salt reduction

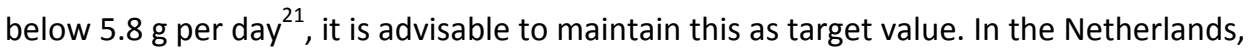
median salt intake is still higher than recommended, i.e. $9.7 \mathrm{~g}$ per day for men and $7.4 \mathrm{~g}$ per day for women ${ }^{22}$. Thus, in practice, it is an ongoing challenge to decrease salt intake to $\sim 6 \mathrm{~g}$ per day, not to speak of larger reductions. This starts with motivating every individual patient, especially those with risk factors for cardiovascular disease, and referral to a dietician may be of great benefit. Compliance to the adjusted diet can be verified by measuring $24 \mathrm{~h}$ urinary sodium excretion, and potential adverse effects on glucose metabolism through determination of blood glucose levels or HbA1c. However, changes in insulin sensitivity in such a way that glucose levels increase are not to be expected, as the absolute decrease in insulin-mediated whole-body glucose disposal induced by $11.7 \mathrm{~g}$ reduction in salt intake was relatively subtle.

The responsibility to reduce salt intake lies not only with the individual, but also with governments. Even if a person is extremely motivated to change his or her diet, it is difficult to reach a salt intake as low as $6 \mathrm{~g}$ per day, due to the high salt content of bread, meat and processed foods. In the Netherlands, several initiatives focus on the reduction of salt levels in these food products. Although reductions as large as $21 \%$ (bread) have been achieved already, a $30-40 \%$ salt reduction in major salt contributing foods is necessary to approach the recommended $6 \mathrm{~g}$ per day ${ }^{22}$. This naturally requires the formulation of sharper regulations concerning the composition of food products by authorities, and cooperation of the food industry, but increasing public awareness of the adverse health effects of high salt ingestion, and which food products to avoid, is still a fundamental part of the challenge to reduce dietary salt intake.

\section{Conclusion}

In this thesis, we investigated microvascular effects of aldosterone and salt in several study populations, i.e. normotensive lean, therapy-resistant essential hypertensive, and abdominally obese individuals. Our data are in support of weight loss as important remedy to ameliorate obesity-related microvascular and metabolic insulin resistance, and hypertension, and of MRAs as (add-on) therapy in therapy-resistant hypertension, preferentially in obese individuals. However, studies demonstrating a role of 
aldosterone in the pathophysiology of microvascular, and thereby metabolic, insulin resistance in severe abdominal obesity are still awaited. It is equally important to gain knowledge on the effects of MRAs on morbidity and mortality, and on insulin's microvascular and metabolic actions. Our findings may also provide an explanation for the increased mortality observed with salt restriction below $6 \mathrm{~g}$ per day, and an additional mechanism for the blood pressure lowering effects of reducing salt intake, at least in healthy individuals. How a decrease in salt ingestion affects the incidence of cardiovascular disease and mortality in this population remains to be established.

Nevertheless, our results contribute to the understanding of pathophysiological mechanisms of obesity-related complications, which may guide clinicians in decisions regarding their treatment. 


\section{References}

1. Afshin A, Reitsma MB, Murray CJL. Health effects of overweight and obesity in 195 countries. $N$ Engl J Med. 2017;377:1496-1497

2. Lette M, Bemelmans WJ, Breda J, Slobbe LC, Dias J, Boshuizen HC. Health care costs attributable to overweight calculated in a standardized way for three european countries. Eur $J$ Health Econ. 2016;17:61-69

3. Force USPST, Curry SJ, Krist AH, Owens DK, Barry MJ, Caughey AB, et al. Behavioral weight loss interventions to prevent obesity-related morbidity and mortality in adults: Us preventive services task force recommendation statement. Jama. 2018;320:1163-1171

4. Poirier P, Giles TD, Bray GA, Hong Y, Stern JS, Pi-Sunyer FX, et al. Obesity and cardiovascular disease: Pathophysiology, evaluation, and effect of weight loss: An update of the 1997 american heart association scientific statement on obesity and heart disease from the obesity committee of the council on nutrition, physical activity, and metabolism. Circulation. 2006;113:898-918

5. Ma C, Avenell A, Bolland M, Hudson J, Stewart F, Robertson C, et al. Effects of weight loss interventions for adults who are obese on mortality, cardiovascular disease, and cancer: Systematic review and metaanalysis. BMJ. 2017;359:j4849

6. Prior SJ, Blumenthal JB, Katzel LI, Goldberg AP, Ryan AS. Increased skeletal muscle capillarization after aerobic exercise training and weight loss improves insulin sensitivity in adults with igt. Diabetes Care. 2014;37:1469-1475

7. Vinet A, Obert P, Dutheil F, Diagne L, Chapier R, Lesourd B, et al. Impact of a lifestyle program on vascular insulin resistance in metabolic syndrome subjects: The resolve study. J Clin Endocrinol Metab. 2014:jc20142704

8. Farmacotherapeutisch kompas; https://www.Farmacotherapeutischkompas.NI.

9. Williams B, MacDonald TM, Morant S, Webb DJ, Sever P, Mclnnes G, et al. Spironolactone versus placebo, bisoprolol, and doxazosin to determine the optimal treatment for drug-resistant hypertension (pathway-2): A randomised, double-blind, crossover trial. Lancet. 2015;386:2059-2068

10. Batterink J, Stabler SN, Tejani AM, Fowkes CT. Spironolactone for hypertension. Cochrane Database Syst Rev. 2010:CD008169

11. Tam TS, Wu MH, Masson SC, Tsang MP, Stabler SN, Kinkade A, et al. Eplerenone for hypertension. Cochrane Database Syst Rev. 2017;2:CD008996

12. McGraw AP, McCurley A, Preston IR, Jaffe IZ. Mineralocorticoid receptors in vascular disease: Connecting molecular pathways to clinical implications. Curr Atheroscler Rep. 2013;15:340

13. Currie G, Taylor AH, Fujita T, Ohtsu H, Lindhardt M, Rossing P, et al. Effect of mineralocorticoid receptor antagonists on proteinuria and progression of chronic kidney disease: A systematic review and metaanalysis. BMC Nephrol. 2016;17:127

14. Calhoun DA, Jones D, Textor S, Goff DC, Murphy TP, Toto RD, et al. Resistant hypertension: Diagnosis, evaluation, and treatment: A scientific statement from the american heart association professional education committee of the council for high blood pressure research. Circulation. 2008;117:e510-526

15. Dudenbostel T, Ghazi L, Liu M, Li P, Oparil S, Calhoun DA. Body mass index predicts 24-hour urinary aldosterone levels in patients with resistant hypertension. Hypertension. 2016;68:995-1003

16. Catena C, Lapenna R, Baroselli S, Nadalini E, Colussi G, Novello M, et al. Insulin sensitivity in patients with primary aldosteronism: A follow-up study. J Clin Endocrinol Metab. 2006;91:3457-3463

17. Collaborators GBDD. Health effects of dietary risks in 195 countries, 1990-2017: A systematic analysis for the global burden of disease study 2017. Lancet. 2019

18. Graudal NA, Hubeck-Graudal T, Jurgens G. Effects of low sodium diet versus high sodium diet on blood pressure, renin, aldosterone, catecholamines, cholesterol, and triglyceride. Cochrane Database Syst Rev. 2017;4:CD004022

19. Graudal NA, Galloe AM, Garred P. Effects of sodium restriction on blood pressure, renin, aldosterone, catecholamines, cholesterols, and triglyceride: A meta-analysis. JAMA. 1998;279:1383-1391 
20. Graudal N, Jurgens G, Baslund B, Alderman MH. Compared with usual sodium intake, low- and excessive-sodium diets are associated with increased mortality: A meta-analysis. Am J Hypertens. 2014;27:1129-1137

21. Graudal N, Jurgens G. Conflicting evidence on health effects associated with salt reduction calls for a redesign of the salt dietary guidelines. Prog Cardiovasc Dis. 2018;61:20-26

22. Temme EHM, Hendriksen MAH, Milder IEJ, Toxopeus IB, Westenbrink S, Brants HAM, et al. Salt reductions in some foods in the netherlands: Monitoring of food composition and salt intake. Nutrients. 2017;9 



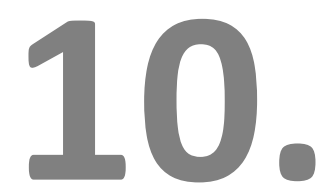

\section{DANKWOORD}





\section{Dankwoord}

In december 2012 zette ik de eerste stappen die tot een proefschrift moesten leiden, en eigenlijk wist ik nog niet zo goed wat me te wachten stond. Inmiddels kijk ik terug op een fantastische tijd, waarin ik ontzettend veel geleerd heb, en lang niet alleen onderzoeks gerelateerd (misschien wel vooral niet), en ik kan oprecht zeggen dat ik er geen moment spijt van heb gehad dat ik de kliniek een aantal jaren verlaten heb. In de loop van die jaren hebben allerlei mensen op de één of andere manier bijgedragen aan de totstandkoming van dit proefschrift. De moeilijkste schrijfopdracht tot nu toe gaat misschien wel zijn de personen in kwestie allemaal te bedanken, maar ik ga een poging wagen:

Om te beginnen ben ik alle proefpersonen heel veel dank verschuldigd voor het volgen van waanzinnige diëten, het nauwkeurig verzamelen van 24-uurs urines en het urenlang op een bedje liggen en ondergaan van allerlei metingen. Heel erg bedankt voor jullie inzet, zonder jullie geen proefschrift!

Mijn promotor, professor dr. C.D.A. Stehouwer: beste Coen, het gaat nog lastig worden om mijn voorgangers niet al te veel te citeren. In de loop der jaren ben ik je op meerdere vlakken ontzettend gaan waarderen: van het doorhakken van knopen in het soms moeizame verloop van mijn projecten, tot het haarscherp formuleren van lastige data, en de interpretatie hiervan. Zelfs toen ik alweer in de kliniek begonnen was konden er toch nog regelmatig meters gemaakt worden door jouw snelle correcties. Als ik het even niet meer zag zitten als er weer een andere draai aan een artikel gegeven moest worden, was ik na een gezamenlijk overleg weer geënthousiasmeerd om de draad weer op te pakken. Bedankt voor alles, ik vond onze discussies ontzettend leerzaam!

Mijn andere promotor, professor dr. P.W. de Leeuw: beste Peter, ons contact was iets minder frequent, maar desondanks heb ik veel van je geleerd. Jij had steeds een net iets andere kijk op mijn data, waardoor de puzzelstukjes vaak beter op hun plaats vielen. Hoewel dit er (soms tot mijn frustratie) niet zelden toe leidde dat het volledige artikel herschreven moest worden, werd het eindresultaat er absoluut beter van. Ook was je altijd in voor op het eerste gezicht onmogelijke projecten, jammer dat ons idee van een studie in patiënten met hyperaldosteronisme uiteindelijk toch niet van de grond is gekomen! 
Mijn copromotor, dr. A.J.H.M. Houben: beste Boy, dankzij de WESP-stage bij jou realiseerde ik me hoe leuk onderzoek eigenlijk was, en ben ik ervan overtuigd geraakt dat ik ook wel vier jaar zonder patiëntenzorg kon. Tijdens ons wekelijks overleg verliet ik vaak met meer vragen jouw kamer dan toen ik binnenkwam, maar je kon me er toch altijd wel van overtuigen dat het uiteindelijk allemaal goed zou komen. Onze gedeelde voorliefde voor de 'vasteloavend' was een garantie voor voldoende gezelligheid, zowel op als buiten de werkvloer. Dankjewel voor alles!

De leden van de beoordelingscommissie, professor dr. N.C. Schaper, professor dr. E.E. Blaak, professor dr. H. ten Cate, dr. J. Deinum en dr. E. Eringa, wil ik graag bedanken voor de beoordeling van mijn proefschrift.

Mijn paranimfen, Janneke en Jean. Lieve Janneke, wij kennen elkaar al heel wat jaren, en hebben aan een half woord genoeg. In die jaren zijn we elkaar qua carrière op de voet blijven volgen, gepaard gaand met frequente broodnodige koffiemomentjes en lunches om kleine en grote succesjes tijdens het onderzoek met elkaar te delen en (niet minder vaak) ook onze frustraties te uiten. Hoe leuk is het dat we inmiddels in hetzelfde ziekenhuis werken! De mooiste momenten hebben we natuurlijk buiten het werk met elkaar beleefd, waaronder onze tripjes naar Scandinavië en de Ardennen (ongelofelijk dat jullie mij aan het wandelen en kamperen hebben gekregen) en niet te vergeten jullie fantastische bruiloft vorig jaar. Dit jaar gaan we er daar weer een aantal aan toevoegen, met als hoogtepunt de geboorte van jullie eerste kindje. Ik ben heel blij dat je vlak daarvoor nog naast me wil staan tijdens mijn verdediging. Dankjewel voor je vriendschap! Lieve Jean, jij hebt werkelijk aan elk onderdeel van dit proefschrift een bijdrage geleverd: de inhoud, niet alleen als proefpersoon, maar ook met de aldosteronbepaling, die nog wel tot enige spanning heeft geleid, want eigenwijs zijn we allebei als geen ander ;); de omslag, die al lang vóór de rest af was; de broodnodige ontspanning gedurende al die jaren met alle koffiepauzes, lunches, borrels en stapavondjes; en op de grote dag zelf sta je naast me. Bedankt voor de eindeloze werken niet-werk-gerelateerde gesprekken (ik weet niet meer welke we het vaakst hebben gevoerd : ) ) en gezelligheid, gelukkig hebben we die erin gehouden, ook nu ik niet meer in Maastricht werk!

Hanneke, wat waren wij een dreamteam, en hoe jammer is het nog steeds dat je ons op de valreep moest verlaten! Niet alleen kon ik met een gerust hart alles wat met monitoring te maken had aan je overlaten; op meetdagen ging alles (meestal : )) van een leien dakje, en dat onder het genot van 'het Foute Uur'. Inmiddels werk je bij 
Medtronic, en ik ben ervan overtuigd dat je daar een gouden toekomst tegemoet gaat. Ontzettend bedankt voor je hulp!

Jos, je was een waardig vervanger van Hanneke. Proefpersonen entertainen kun je als de beste (ik weet nog steeds niet welke van jouw verhalen nu waar zijn en welke volledig uit de duim gezogen), en voor een onmogelijke venapunctie draai jij je hand niet om. Dankjewel voor al je hulp bij de metingen en je vliegensvlugge analyses, en niet te vergeten de peptalk waar nodig : ).

Yvo, ik kan me jouw introductie in de wondere wereld van de CEUS en de clamps nog goed herinneren. Waar ik er in het begin nog van overtuigd was dat ik mijn projecten wel even op poten zou zetten en gemakkelijk binnen 4 jaar kon afronden, zette jij me al snel met beide benen op de grond. Dankzij al het voorwerk dat jij al gedaan had, met het opzetten van de CEUS-techiek en van je eigen studie, kon ik een vliegende start maken. Daarnaast kon ik zowel voor, tijdens als na de metingen altijd bij je terecht met vragen, voor adviezen, en voor hulp met de analyses. Heel erg bedankt voor alles!

Dionne en Katrien, mede-ladies of the first office! Dionne, het is ongelofelijk in welk tempo jij het ene fantastische paper na het andere schreef, wat tot een schitterend proefschrift heeft geleid. Ik vind het een grote eer dat ik je paranimf mocht zijn! Naast al dat harde werk was er altijd tijd voor gezelligheid, waarbij de tranen ons regelmatig over de wangen liepen van het lachen. Ik ben nog steeds benieuwd hoeveel kledingstukken zowel in jouw als in mijn kast hangen! Heel veel succes voor de toekomst bij Medtronic, die ongetwijfeld glansrijk gaat zijn! Katrien, ik ken weinig mensen die zo gedreven en gestructureerd zijn als jij, en je publicatielijst en de prijzen die je de afgelopen jaren gewonnen hebt spreken voor zich. Op werkgebied hebben we weinig met elkaar te maken gehad, maar dit heeft nooit iets afgedaan aan de gespreksstof en ruimte voor droge humor en koffiemomentjes. Onze kamer was absoluut de gezelligste van de hele afdeling, wat de productiviteit zeker niet altijd ten goede kwam. Hopelijk kunnen we de periodieke drankjes en etentjes er nog even inhouden!

Marjo, als er een award bestond voor snel en nauwkeurig bepalingen uitvoeren, zou jij 'm winnen! Ook ik heb meermaals gebruik mogen maken van die kwaliteit, en binnen de kortste keren had ik steeds de resultaten overzichtelijk voor mijn neus liggen. Jouw humor is één van je andere kwaliteiten die ik ontzettend kan waarderen, en je draagt significant bij aan de goede sfeer op de afdeling. Ik hoop dat we de koffiemomentjes blijven voortzetten! 
Mathias, jij bent een waardig opvolger op het Circulatielab. Vliegensvlug had je alle meettechnieken onder de knie, en al waren er wat opstartproblemen, inmiddels draait jouw studie op volle toeren. Veel succes met de laatste loodjes, hopelijk kunnen we jouw laatste meetdag binnenkort ook met een Belgisch biertje in Thembi vieren!

Nynke, het tempo waarin jij papers schrijft en ogenschijnlijk moeiteloos hoog weet te publiceren is ongekend. Daarnaast weet je de mannen in het Circulatielab goed in toom te houden, wat ook zeker een niet te onderschatten taak is : ). Dankjewel voor de fijne samenwerking en de gezellige feestjes, ik hoop dat we de samenwerking kunnen voortzetten in het Zuyderland!

Professor dr. C.G. Schalkwijk, beste Casper: bedankt dat ik deel mocht uitmaken van jouw lab, en zowel gebruik mocht maken van je expertise als delen in alle gezelligheid tijdens de labuitjes en kerstdiners!

Dr. M.M.J. van Greevenbroek, beste Marleen: al werkten we nooit direct samen, toch stond jouw deur altijd open als ik weer eens ingewikkelde statistische vraagstukken had, en altijd ging ik met een oplossing de deur weer uit. Dank hiervoor!

Petra en Vicky, duizendpoten van de afdeling, bedankt voor al jullie hand- en spandiensten de afgelopen jaren, die van onschatbare waarde zijn geweest voor een succesvolle afronding van mijn promotietraject.

Alle andere collega's en oud-collega's: Ad, Annemieke, Barry, Ben, Dennis, Elisabeth, José, Kristiaan, Lian, Marcelle, Margee, Maria, Marja, Marnix, Mitchell, Nordin, Olaf, Pauline, Remy, Suzan, Teba (dankjewel dat ik je paranimf mocht zijn), Thomas en Ying, bedankt voor de fijne samenwerking en gezelligheid!

Dames van het Circulatielab: Claudia, Heidi en Ellen, veel dank voor de nodige logistieke ondersteuning!

Tiny, bedankt voor het zorgvuldig opmaken van mijn proefschrift!

Mede-dokters en onderzoeksbuddies: Stijn, Ellis, Noortje en Ankie. Stijn, ik weet nog goed dat ik semi-arts was toen jij begon in het (destijds) Atrium. Superleuk dat we later ook in Maastricht collega's werden, waar jouw aanwezigheid garantie was voor menig legendarisch congres en stapavondje. Ik vond het een eer om paranimf te zijn bij je verdediging! En voorlopig ben je nog niet van me af: als het een beetje meezit ben je 
binnenkort mijn baas in het MUMC : ). Ellis, wij leerden elkaar ergens in 2012 kennen, en jouw recht-door-zee, niet-lullen-maar-poetsen-mentaliteit vond ik direct heerlijk. Die heeft ongetwijfeld significant bijgedragen aan het hoge tempo waarin jij een prachtig proefschrift hebt weten te schrijven. De vele koffie-dates in UNS30 konden we gelukkig voortzetten in het Zuyderland, zo nu en dan onder het genot van een stuk Limburgse vlaai :). Ik zal de gezamenlijke ski-uitjes en een niet nader te noemen congres niet snel vergeten, ik kijk alweer uit naar het volgende! Noortje, of het nu een volle SEH betreft, het schrijven van een paper, of het opvoeden van drie kinderen, waaronder een tweeling: jij draait er je hand niet voor om, en ik vraag me dan ook regelmatig af: hoe doet ze dat toch? Jouw humeur is en blijft daarbij onverstoorbaar vrolijk, en je vindt altijd wel een momentje om even bij te kletsen (en hoe). Veel succes met het afronden van je proefschrift! Ankie, ook wij kennen elkaar al heel wat jaren, al sinds jouw GEZP-stage in het Atrium, en uiteindelijk kwam je ons ook vergezellen in Maastricht, met al een aantal mooie publicaties als resultaat. Daar vonden we altijd wel een momentje om even de laatste nieuwtjes uit Heerlen door te nemen. De laatste tijd is dat iets lastiger, maar we blijven het proberen : )!

Lieve Zuyderland collega's, mede dankzij jullie had ik niet lang na mijn terugkeer in de kliniek het gevoel dat ik nooit was weggeweest. Bedankt voor de topsfeer op de werkvloer en alle gezellige uitjes!

De internisten in het Zuyderland Medisch Centrum, en, dr. J. Buijs, opleider, in het bijzonder. Ik voel me als een vis in het water bij de Interne Geneeskunde in het Zuyderland, en daar hebben jullie een belangrijk aandeel in. Jacqueline, veel dank voor alle inspanningen om iedereen het opleidingsschema te bieden dat het beste bij hem of haar past.

Mijn lieve vrienden. Janneke en Martijn, Gonny en Patrick. Na al die jaren van lief en soms ook leed voelen jullie bijna als familie. Ik denk met veel plezier terug aan alle tripjes, etentjes en niet te vergeten jullie bruiloften, en ik kijk al uit naar het plannen van een volgende vakantie met Emma en ?

Janou en Richard. Frequente treinritjes van en naar Maastricht bleken een uitstekende basis voor een hechte vriendschap. Jullie deur, of die nu in Kerkrade, Vijlen of Wijlre is, staat altijd open. Ik vind het nog steeds fantastisch peettante te zijn van Julan. Binnenkort zie ik hem en zijn zusjes Jolie en Liene hopelijk wat vaker! Chantal en Sandro. Chantal, al sinds de middelbare school delen we een voorliefde voor sarcastische humor en guilty pleasures. Onze uitjes, eerst zonder en later ook regelmatig met jullie dames Luana en Ella en de gezellige avondjes bij jullie waren een 
heerlijke afleiding van alles wat met promoveren te maken had. Ik vind het heel bijzonder om peettante te mogen zijn van jullie jongste telg!

Nathalie en Silke, ik ben blij dat we er ondanks alle drukte toch in slagen elkaar regelmatig te zien voor een drankje of etentje, en ik heb genoten van onze weekendjes weg de afgelopen jaren. Ik hoop dat we dat nog lang zo kunnen voortzetten!

Eleana, we kwamen elkaar weer tegen bij de BROK-cursus, wat het startpunt was voor regelmatige koffie- en eetdates, citytripjes en saunabezoekjes. Ik kan met jou heerlijk kletsen over alles wat met onderzoek te maken heeft, en alles wat er niet mee te maken heeft. Jouw eindeloze energie werkt aanstekelijk, en heeft ongetwijfeld bijgedragen aan de op het eerste gezicht onmogelijke maar in jouw handen toch succesvolle combinatie van de afronding van een promotietraject, de opleiding tot huisarts en het moederschap. Hopelijk zien we elkaar binnenkort weer wat vaker!

Ramona, hoe leuk is het dat we bevriend waren op de basisschool, en de draad van die vriendschap een paar jaar geleden weer oppakten. Jouw aanwezigheid is altijd een garantie voor gezelligheid, en jouw humor en nuchtere kijk op de wereld kan ik ontzettend waarderen. Binnenkort gaat er een nieuw lid aan jullie gezinnetje toegevoegd worden, waarmee ik jullie alle geluk van de wereld toewens!

Bertie en Wim, bedankt voor de warmte die jullie mij hebben laten voelen vanaf het moment dat ik jullie ken.

Danée en Ramon: nu dit project is afgerond, is er tijd voor het volgende: een hond : ) .

Lieve oma, al had je eigenlijk geen idee wat ik allemaal uitspookte daar in Maastricht, toch was je altijd ontzettend trots op waar ik dan ook mee bezig was. Jammer dat je dit niet meer hebt mogen meemaken, ik had je er nog heel graag bij gehad.

Linda en Cindy, mijn lieve zusjes. Hoe fantastisch is het dat we behalve zussen ook vriendinnen zijn. We begrijpen elkaar (meestal : )) als geen ander, hebben de grootste lol, of het nu tijdens carnaval, festivals of vakanties is, en kunnen altijd bij elkaar terecht. Ik hoop dat we dat zo blijven volhouden, wat het leven ook brengt. Ik ben trots op jullie.

Lieve pappa en mamma, zonder jullie was ik niet gekomen waar ik nu ben in mijn leven. Jullie hebben ons altijd gestimuleerd het beste uit onszelf te halen, en ons geleerd niet te snel tevreden maar wel bescheiden te zijn, en op eigen benen te kunnen staan. Heel erg bedankt voor de stabiele en fijne thuisbasis die jullie ons drieën geboden hebben en waar ik altijd op terug kan vallen. 
Lieve Michèl, jij kwam in mijn leven in een periode dat weekenden achter de laptop of in het ziekenhuis eerder regel dan uitzondering waren, en ik ben heel blij dat je je daardoor niet hebt laten afschrikken. Door je eeuwige optimisme, grenzeloze enthousiasme, humor en vermogen om mij met beide benen op de grond te zetten als dat weer eens nodig was heb je een grote rol gehad in de afronding van dit proefschrift. Dankjewel voor je steun en begrip. Ik kijk uit naar meer tijd samen en alles wat de toekomst nog in petto heeft voor ons. Ik hou van je. 



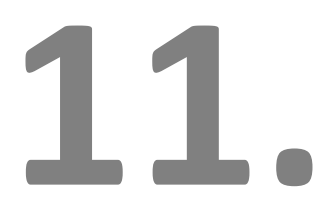

CURRICULUM VITAE 



\section{Curriculum vitae}

Monica Schütten was born on March 4th, 1987 in Kerkrade. She attended secondary school at College Rolduc, Kerkrade and graduated in 2005 (cum laude). Subsequently, she started medical training at the University of Maastricht, and obtained her bachelor's degree in 2008, and her master's degree in 2011. During her scientific internship (WESP), she assisted in the Maastricht Study in measurements of microvascular function, and their analysis and interpretation, under the supervision of dr. A.J.H.M. Houben. Thereafter, she worked at the Atrium Medical Center (currently Zuyderland Medical Center) in Heerlen as resident Internal Medicine and Cardiology, not in training. In December 2012, she started her PhD trajectory entitled 'Aldosterone at the basis of microvascular dysfunction-induced metabolic insulin resistance in obese subjects?' at the University of Maastricht, under the supervision of professor dr. C.D.A. Stehouwer, professor dr. P.W. de Leeuw, and dr. A.J.H.M. Houben. Currently, she works as resident Internal Medicine in training at the Zuyderland Medical Center, under the supervision of dr. J. Buijs and drs. F. Stifft. 



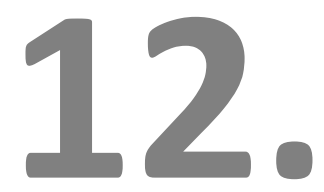

SCIENTIFIC OUTPUT 



\section{List of publications}

Schutten MTJ, Houben A, Kroon AA, Stehouwer CDA, de Leeuw PW. Aldosterone-renin ratio and side-selective renal perfusion in essential hypertension. Am J Hypertens. 2016;29:1311-1316

Schutten MT, Houben AJ, de Leeuw PW, Stehouwer CD. The link between adipose tissue renin-angiotensin-aldosterone system signaling and obesity-associated hypertension. Physiology (Bethesda). 2017;32:197-209

Schutten MTJ, Kusters Y, Houben A, Scheijen J, van de Waarenburg MPH, Schalkwijk $C G$, et al. Aldosterone is not associated with metabolic and microvascular insulin sensitivity in abdominally obese men. J Clin Endocrinol Metab. 2018;103:759-767

Posthuma JJ, Reesink KD, Schutten M, Ghossein C, Spaanderman ME, Ten Cate H, et al. A rare case of intermittent claudication associated with impaired arterial vasodilation. Case Rep Vasc Med. 2017;2017:4868123

\section{Oral presentations}

European Society of Hypertension 2014 (Athens, Greece): Aldosterone and renal hemodynamics in essential hypertension

European Council for Cardiovascular Research 2014 (Lake Garda, Italy): Aldosterone and renal hemodynamics in essential hypertension

Dutch Society for the Investigation of Diabetes (NVDO) 2016 (Oosterbeek, the Netherlands): Aldosterone is not associated with insulin-mediated microvascular recruitment and insulin sensitivity in abdominally obese, but otherwise healthy men

National Hypertension Congress (Nederlands Hypertensie Congres) 2018 (Amersfoort, the Netherlands): Aldosterone is not associated with insulin-mediated microvascular recruitment and insulin sensitivity in abdominally obese, but otherwise healthy men 


\section{Poster presentations}

Joint Meeting Dutch Endothelial Biology Society (DEBS)/Dutch Society for Microcirculation and Vascular Biology (MiVab) 2014 (Biezenmortel, the Netherlands): Aldosterone and renal hemodynamics in essential hypertension

Joint Meeting European Society for Microcirculation (ESM)/European Vascular Biology Organization) 2015 (Pisa, Italy): Aldosterone and renal hemodynamics in essential hypertension

European Society of Hypertension 2016 (Paris, France): Aldosterone is not associated with insulin-mediated microvascular recruitment and insulin sensitivity in abdominally obese, but otherwise healthy men 